INSTITUTO DE PESQUISAS ENERGÉTICAS E NUCLEARES Autarquia associada à Universidade de São Paulo

\title{
SÍNTESE, CARACTERIZAÇÃO MICROESTRUTURAL E ELÉTRICA DE COMPOSTOS CERÂMICOS À BASE DE SOLUÇÕES SÓLIDAS DE TITANATO DE ESTRÔNCIO, TITANATO DE CÁLCIO E ÓXIDO DE FERRO
}

\author{
João Roberto do Carmo
}

Tese apresentada como parte dos requisitos para a obtenção do Grau de Doutor em Ciências na Área de Tecnologia Nuclear - Materiais.

Orientador:

Dr. Reginaldo Muccillo

São Paulo

2011 


\begin{abstract}
A Deus... que, incomparável e inconfundível na sua infinita bondade, compreendeu meus anseios e me deu a coragem necessária para atingir meu propósito, ofereço meu porvir e peço forças para sempre agir com eficiência em meu trabalho e acerto em minhas decisões.
\end{abstract}


A meus pais, João Gualberto e Maria Helena e em especial a minha esposa, Patrícia de Cássia. Pessoas sem as quais este trabalho não teria sequer iniciado. 


\section{AGRADECIMENTOS}

Ao Prof. Dr. Reginaldo Muccillo, pela orientação, paciência e dinamismo na condução deste trabalho.

Ao Dr. Luis Gallego Martinez, pelo refinamento de estruturas cristalinas pelo método de Rietveld.

Ao Dr. Luis Antônio Gênova pelas medidas de dilatometria.

Ao Dr. José Roberto Martinelli pelas medidas de espalhamento laser.

À Dra. Érica Caproni, pelos ensinamentos e discussões ao longo do trabalho.

À Dra Renata Ayres Rocha, por compartilhar técnicas de síntese de materiais.

À Yone França por compartilhar toda a técnica instrumental necessária.

Aos membros da banca, Dr. Luis Gallego Martinez, Dr. José Roberto Martinelli, Dra. Érica Caproni, Dra. Sueli Hatsumi Masunaga, pelas contribuições a este trabalho.

À Dra. Juliana Marchi, pelas conversas, divergências e aconselhamento.

Aos Funcionários, bolsistas e estagiários do IPEN que, cordialmente, se dispuseram a compartilhar sua experiência e conhecimento, colaborando para a realização deste trabalho.

A Fernando Marco Perez Campos, sempre com uma palavra de ânimo.

A todos aqueles que, direta ou indiretamente participaram na elaboração deste trabalho.

Não poderia deixar de agradecer a toda minha família, pelo exemplo, paciência e apoio total.

À Cinyra Ballassini, Ricardo Heitor e Matilde Lúcio, pelas conversas, apoio e incentivo.

A Mauro Cesar e Maria Fernanda, que mesmo distante se fizeram próximos.

Amadeu Heitor (in memoriam) e Neusa Apparecida, exemplos de luta pela vida.

Finalmente, agradeço a Fundação de Amparo à Pesquisa do Estado de São Paulo, pelo financiamento dos reagentes e ao Instituto de Pesquisas Energéticas e Nucleares, fundamentais na execução deste trabalho. 


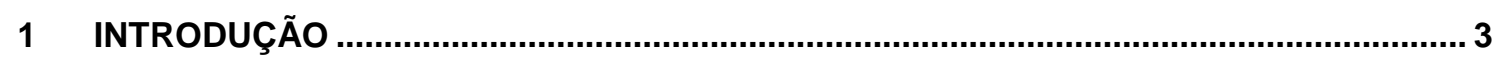

1.1 A IMPORTÂNCIA DOS SENSORES NA VIDA MODERNA ……...............................

1.2 TITANATO DE ESTRÔNCIO.............................................................................

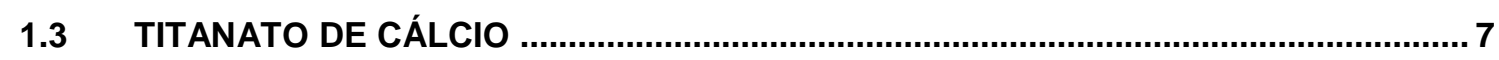

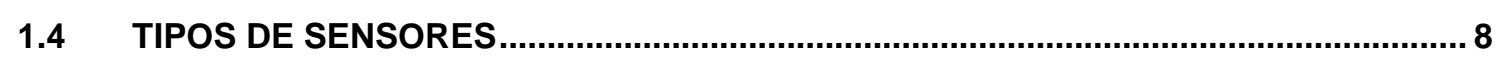

1.5 SENSORES CERÂMICOS ……………………………...............................

1.5.1 SENSORES DE OXIGÊNIO ELETROQUÍMICOS...................................................

1.5.1.1 CARACTERIZAÇÃO DOS SENSORES DE OXIGÊNIO..........................................10

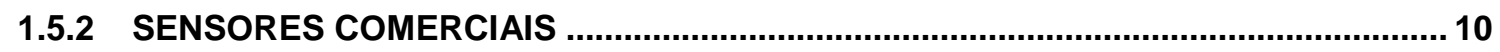

1.5.2.1 SENSORES DE OXIGÊNIO AMPEROMÉTRICOS............................................... 10

1.5.2.2 SENSORES DE OXIGÊNIO POTENCIOMÉTRICOS...............................................11

1.6 SÍNTESE PELA TÉCNICA DE REAÇÃO DE ESTADO SÓLIDO.................................. 12

1.7 SÍNTESE PELA TÉCNICA DOS PRECURSORES POLIMÉRICOS ............................. 12

2 OBJETIVOS .......................................................................................................... 14

2.1 OBJETIVO GERAL............................................................................... 14

2.1.1 OBJETIVOS ESPECÍFICOS.......................................................................... 14

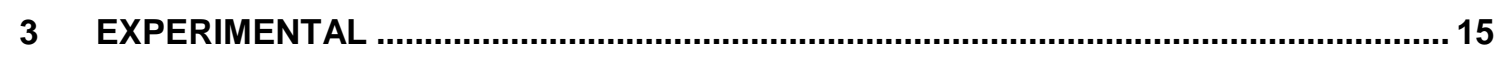

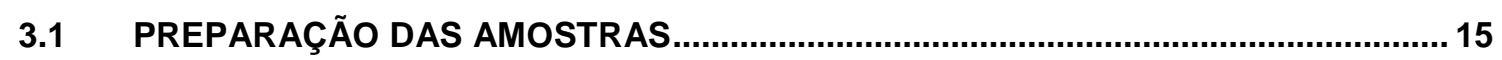

3.1.1 TÉCNICA DE REAÇÃO DE ESTADO SÓLIDO ……………………………….......15

3.1.2 TÉCNICA DOS PRECURSORES POLIMÉRICOS ………......................................... 17

3.2 COMPOSIÇÕES ........................................................................................... 21

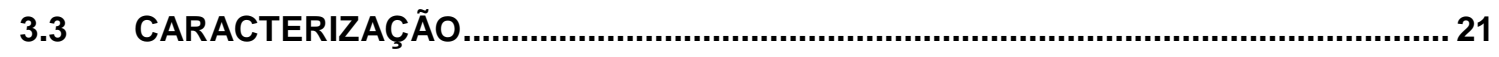

3.4 TAMANHO MÉDIO DE PARTÍCULA/AGLOMERADO …….......................................... 21

3.5 DENSIDADE GEOMÉTRICA APARENTE ......................................................... 22

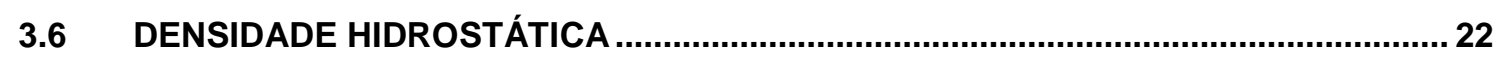

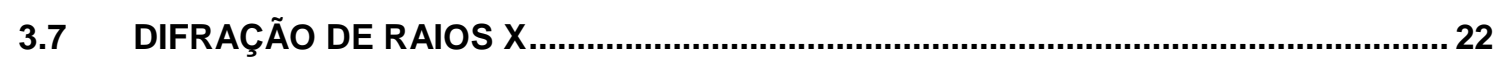

3.7.1 DIFRAÇÃO DE RAIOS X CONVENCIONAL ....................................................... 22

3.7.2 DIFRAÇÃO DE RAIOS $X$ COM FONTE SÍNCROTRON............................................. 23

3.8 REFINAMENTO DA ESTRUTURA E PARÂMETROS DE REDE ................................. 23

3.8.1 MÉTODO DE RIETVELD .................................................................................. 23

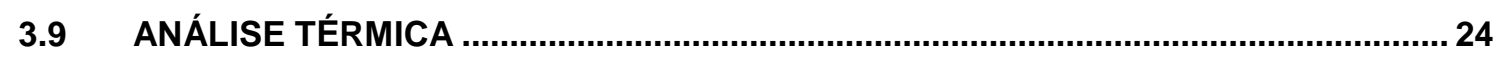

3.9.1 ANÁLISE TERMOGRAVIMÉTRICA E TÉRMICA DIFERENCIAL .............................. 24

3.9.2 DILATOMETRIA ......................................................................................... 24

3.10 MICROSCOPIA ELETRÔNICA ...................................................................... 24

3.10.1 MICROSCOPIA ELETRÔNICA DE TRANSMISSÃO ………………...................... 24 


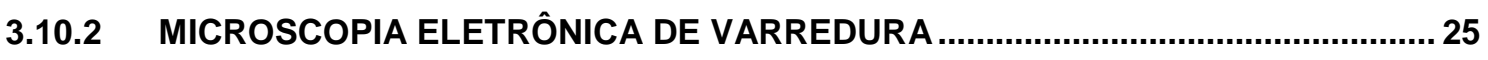

3.10.3 MICROSCOPIA ELETRÔNICA DE VARREDURA POR SONDA ............................. 25

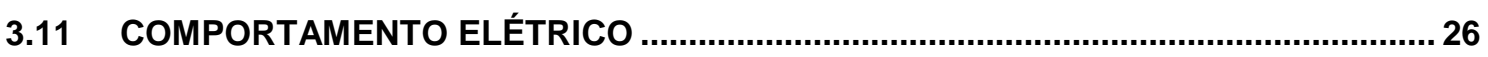

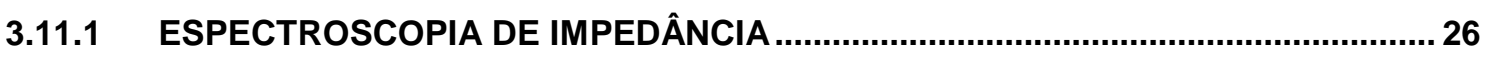

3.11.2 MEDIDAS DE PRESSÃO PARCIAL DE OXIGÊNIO ............................................ 27

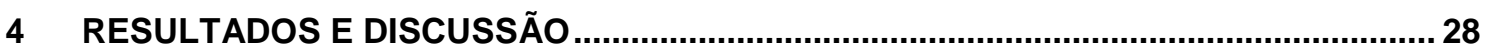

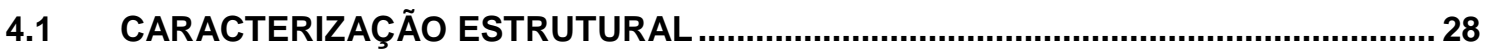

4.1.1 ANÁLISE TERMOGRAVIMÉTRICA E ANÁLISE TÉRMICA DIFERENCIAL................ 28

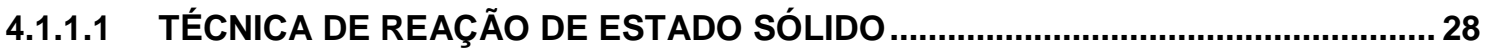

4.1.1.2 TÉCNICA DOS PRECURSORES POLIMÉRICOS ................................................ 37

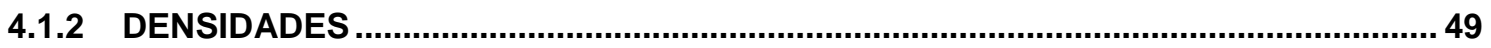

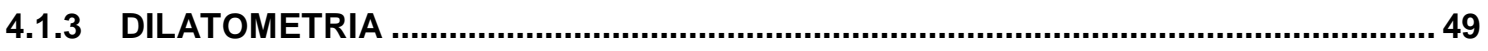

4.1.4 DIFRAÇÃO DE RAIOS X CONVENCIONAL E COM FONTE SÍNCROTRON...............54

4.1.4.1 DIFRAÇÃO DE RAIOS X CONVENCIONAL ........................................................54

4.1.4.2 DIFRAÇÃO COM FONTE SÍNCROTRON..........................................................5 57

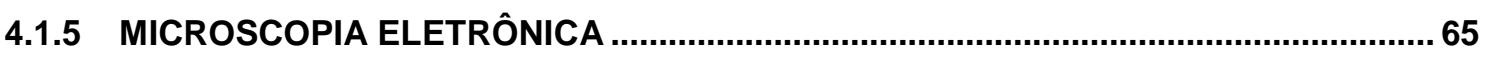

4.1.5.1 MICROSCOPIA ELETRÔNICA DE VARREDURA DOS COMPOSTOS OBTIDOS

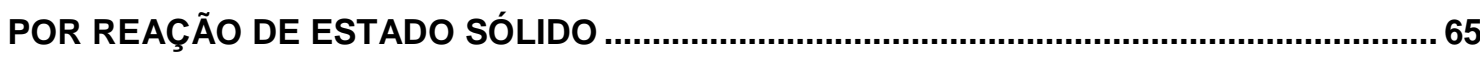

4.1.5.2 MICROSCOPIA ELETRÔNICA DE TRANSMISSÃO DOS PÓS OBTIDOS PELA TÉCNICA DOS PRECURSORES POLIMÉRICOS ….....................................................67

4.1.5.3 MICROSCOPIA ELETRÔNICA DE VARREDURA POR EMISSÃO DE CAMPO DOS PÓS OBTIDOS PELA TÉCNICA DOS PRECURSORES POLIMÉRICOS.................................68

4.1.5.4 MICROSCOPIA ELETRÔNICA DE VARREDURA POR SONDA DOS CORPOS

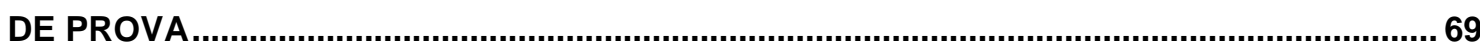

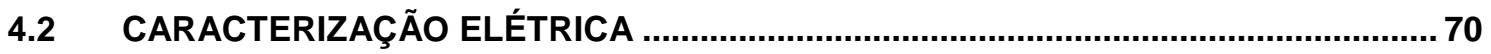

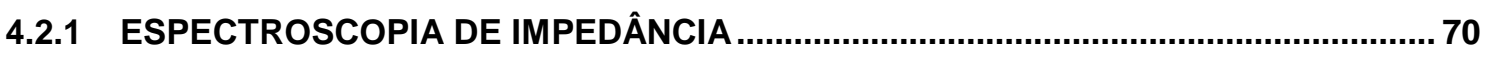

4.2.2 RESISTIVIDADE ELÉTRICA

4.2.3 MEDIDAS DA FORÇA ELETROMOTRIZ X TEOR DE OXIGÊNIO …............................78

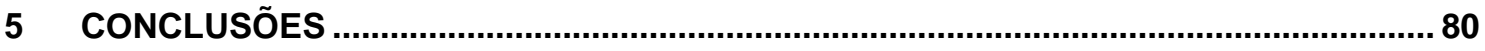

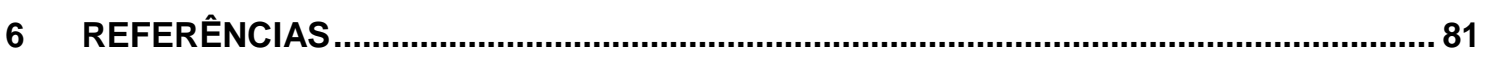

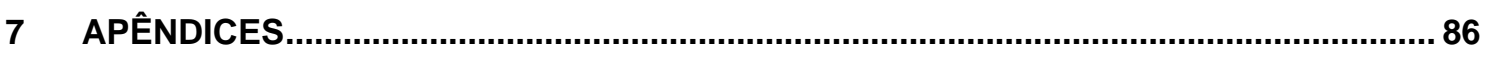

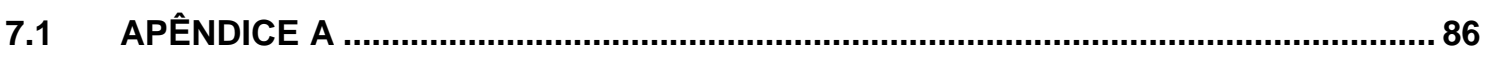

7.1.1 ANÁLISES COM O SOFTWARE PROTEUS .......................................................... 86

7.1.2 CURVAS BASE DE CALIBRAÇÃO DO EQUIPAMENTO DE ANÁLISE TÉRMICA ....92

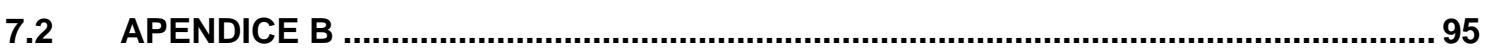

7.2.1 DESCRIÇÃO MATEMÁTICA DA CURVA DE ARCO DE CIRCUNFERÊNCIA DE

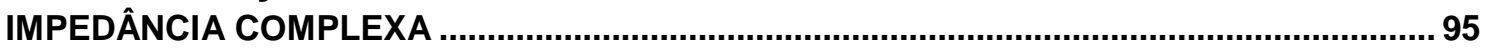




\section{Lista de figuras}

Figura 1 - Sensores automotivos ${ }^{[28]}$ 8

Figura 2 - Foto de um sensor de oxigênio tipo amperométrico 10

Figura 3 - Foto de um sensor potenciométrico de uso automotivo ${ }^{[32]}$ 11

Figura 4 - Esquema elétrico de um sensor potenciométrico comercial. 11

Figura 5 - Fluxograma para obtenção e caracterização dos materiais $\mathrm{CaTi}_{0,65} \mathrm{Fe}_{0,35} \mathrm{O}_{3-\delta}, \mathrm{Ca}_{0,5} \mathrm{Sr}_{0,5} \mathrm{Ti}_{0,65} \mathrm{Fe}_{0,35} \mathrm{O}_{3-\delta}$ e $\mathrm{SrTi}_{0,65} \mathrm{Fe}_{0,35} \mathrm{O}_{3-\delta}$, por reação de estado sólido. ATD: análise térmica diferencial; ATG: Análise termogravimétrica; DRX: difração de raios $\mathrm{X}$; MEV: microscopia eletrônica de varredura; SPM: microscopia de varredura por sonda

Figura 6 - (a), (c) e (e) Materiais $\mathrm{SrTi}_{0,65} \mathrm{Fe}_{0,35} \mathrm{O}_{3-\delta}, \mathrm{Ca}_{0,5} \mathrm{Sr}_{0,5} \mathrm{Ti}_{0,65} \mathrm{Fe}_{0,35} \mathrm{O}_{3-\delta} \mathrm{e}$ $\mathrm{CaTi}_{0,65} \mathrm{Fe}_{0,35} \mathrm{O}_{3-\delta}$, respectivamente na forma de sol-gel e (b), (d) e (f) aspecto dos mesmos materiais após primeira queima.

Figura 7 - (a) Aspecto dos materiais $\mathrm{SrTi}_{0,65} \mathrm{Fe}_{0,35} \mathrm{O}_{3-\delta}$ e $\mathrm{CaTi}_{0,65} \mathrm{Fe}_{0,35} \mathrm{O}_{3-\delta}$ na forma de sol-gel e (b) configuração de laboratório utilizada para produção dos materiais pela técnica dos precursores poliméricos.

Figura 8 - Fluxograma para obtenção e caracterização de $\mathrm{SrTi}_{0,65} \mathrm{Fe}_{0,35} \mathrm{O}_{3-\delta}$, $\mathrm{Ca}_{0,5} \mathrm{Sr}_{0,5} \mathrm{Ti}_{0,65} \mathrm{Fe}_{0,35} \mathrm{O}_{3-\delta}$ e $\mathrm{CaTi}_{0,65} \mathrm{Fe}_{0,35} \mathrm{O}_{3-\delta}$ pela técnica dos precursores poliméricos. ETG: etilenoglicol; ATD: análise térmica diferencial; ATG: análise termogravimétrica; DRX: difração de raios X; MEV: microscopia eletrônica de varredura; MET: microscopia eletrônica de transmissão; SPM: microscopia eletrônica de varredura por sonda.

Figura 9 - Arranjo experimental da montagem para verificação da resposta elétrica dos materiais $\mathrm{Ca}_{x} \mathrm{Sr}_{1-\mathrm{x}} \mathrm{Ti}_{0,65} \mathrm{Fe}_{0,35} \mathrm{O}_{3-\delta}, \quad x=0,0,5$ e 1,0. Detalhe: montagem da amostra.

Figura 10 - Curvas de análise termogravimétrica e térmica diferencial de mistura de $\mathrm{SrCO}_{3}, \mathrm{TiO}_{2}$ e $\mathrm{Fe}_{2} \mathrm{O}_{3}$ na proporção molar 1,0:0,65:0,35; atmosfera: ar sintético. 
Figura 11 - Curvas de análise termogravimétrica e térmica diferencial de mistura de $\mathrm{CaCO}_{3}, \mathrm{SrCO}_{3}, \mathrm{TiO}_{2}$ e $\mathrm{Fe}_{2} \mathrm{O}_{3}$ na proporção molar 0,5:0,5:0,65:0,35; atmosfera: ar sintético.

Figura 12 - Curvas de análise termogravimétrica e térmica diferencial de mistura de $\mathrm{CaCO}_{3}, \mathrm{TiO}_{2}$ e $\mathrm{Fe}_{2} \mathrm{O}_{3}$ na proporção molar 1,0:0,65:0,35; atmosfera: ar sintético. Detalhe pico exotérmico.

Figura 13 - Apresentação conjunta das curvas de análise térmica diferencial das Figuras 10,11 e 12

Figura 14 - Curvas de análise termogravimétrica de mistura de $\mathrm{CaCO}_{3}, \mathrm{SrCO}_{3}$, $\mathrm{TiO}_{2}$ e $\mathrm{Fe}_{2} \mathrm{O}_{3}$ na proporção molar 1,0:0:0,65:0,35, 0:1,0:0,65:0,35 e 0,5:0,5:0,65:0,35; atmosfera: ar sintético. 32

Figura 15 - Curvas de análise termogravimétrica e térmica diferencial de mistura de $\mathrm{SrCO}_{3}$ e TiO 2 na proporção molar 1,0:1,0; atmosfera: ar sintético.

Figura 16 - Curvas de análise termogravimétrica e térmica diferencial de mistura de $\mathrm{CaCO}_{3}, \mathrm{SrCO}_{3}$ e $\mathrm{TiO}_{2}$ na proporção molar 0,5:0,5:1,0, atmosfera: ar sintético.

Figura 17 - Curvas de análise termogravimétrica e térmica diferencial de mistura de $\mathrm{CaCO}_{3}$ e TiO 2 na proporção molar 1,0:1,0; atmosfera: ar sintético.

Figura 18 - Curvas de análise térmica diferencial de misturas de $\mathrm{CaCO}_{3}, \mathrm{SrCO}_{3}$ e $\mathrm{TiO}_{2}$, nas proporções molares 1,0:0:1,0, 0,5:0,5:1,0 e 0:1,0:1,0; atmosfera: ar sintético. 36

Figura 19 - Curvas de análise termogravimétrica de misturas de $\mathrm{CaCO}_{3}, \mathrm{SrCO}_{3}$ e $\mathrm{TiO}_{2}$ nas proporções molares 1,0:0:1,0, 0,5:0,5:1,0 e 0:1,0:1,0; atmosfera: ar sintético.

Figura 20 - Curvas de análise termogravimétrica das resinas precursora de $\mathrm{SrTi}_{0,65} \mathrm{Fe}_{0,35} \mathrm{O}_{3-\delta}, \mathrm{Ca}_{0,5} \mathrm{Sr}_{0,5} \mathrm{Ti}_{0,65} \mathrm{Fe}_{0,35} \mathrm{O}_{3-\delta}$ e $\mathrm{CaTi}_{0,65} \mathrm{Fe}_{0,35} \mathrm{O}_{3-\delta}$, na forma de sol-gel, antes da primeira queima - método dos precursores poliméricos; atmosfera: ar sintético. 
Figura 21 - Curvas de análise térmica diferencial das resinas precursora de $\mathrm{SrTi}_{0,65} \mathrm{Fe}_{0,35} \mathrm{O}_{3-\delta}, \mathrm{Ca}_{0,5} \mathrm{Sr}_{0,5} \mathrm{Ti}_{0,65} \mathrm{Fe}_{0,35} \mathrm{O}_{3-\delta}$ e $\mathrm{CaTi}_{0,65} \mathrm{Fe}_{0,35} \mathrm{O}_{3-\delta}$, na forma de sol-gel, antes da primeira queima - método dos precursores poliméricos; atmosfera: ar sintético.

Figura 22 - Curvas de análise termogravimétrica e térmica diferencial da resina precursora de $\mathrm{SrTi}_{0,65} \mathrm{Fe}_{0,35} \mathrm{O}_{3-\delta}$ - método dos precursores poliméricos; atmosfera: ar sintético.

Figura 23 - Curvas de análise termogravimétrica e térmica diferencial da resina precursora de $\mathrm{Ca}_{0,5} \mathrm{Sr}_{0,5} \mathrm{Ti}_{0,65} \mathrm{Fe}_{0,35} \mathrm{O}_{3-\delta}$ - método dos precursores poliméricos; atmosfera: ar sintético.

Figura 24 - Curvas de análise termogravimétrica e térmica diferencial da resina precursora de $\mathrm{CaTi}_{0,65} \mathrm{Fe}_{0,35} \mathrm{O}_{3-\delta}$ - método dos precursores poliméricos; atmosfera: ar sintético.

Figura 25 - Curvas de análise térmica diferencial das resinas precursoras de $\mathrm{SrTi}_{0,65} \mathrm{Fe}_{0,35} \mathrm{O}_{3-\delta}, \mathrm{Ca}_{0,5} \mathrm{Sr}_{0,5} \mathrm{Ti}_{0,65} \mathrm{Fe}_{0,35} \mathrm{O}_{3-\delta}$ e $\mathrm{CaTi}_{0,65} \mathrm{Fe}_{0,35} \mathrm{O}_{3-\delta}-$ método dos precursores poliméricos; atmosfera: ar sintético

Figura 26 - Curvas de análise termogravimétrica de misturas das resinas poliméricas precursoras de $\mathrm{SrTi}_{0,65} \mathrm{Fe}_{0,35} \mathrm{O}_{3-\delta}$, $\mathrm{Ca}_{0,5} \mathrm{Sr}_{0,5} \mathrm{Ti}_{0,65} \mathrm{Fe}_{0,35} \mathrm{O}_{3-\delta}$ e $\mathrm{CaTi}_{0,65} \mathrm{Fe}_{0,35} \mathrm{O}_{3-\delta} ;$ atmosfera: ar sintético.

Figura 27 - Curvas de análise termogravimétrica e térmica diferencial da resina precursora de $\mathrm{SrTiO}_{3}$ - método dos precursores poliméricos; atmosfera: nitrogênio

Figura 28 - Curvas de análise termogravimétrica e térmica diferencial da resina precursora de $\mathrm{Ca}_{0,5} \mathrm{Sr}_{0,5} \mathrm{TiO}_{3}$ - método dos precursores poliméricos; atmosfera: nitrogênio 44

Figura 29 - Curvas de análise termogravimétrica e térmica diferencial da resina precursora de $\mathrm{CaTiO}_{3}$ - método dos precursores poliméricos; atmosfera: nitrogênio

Figura 30 - Curvas de análise térmica diferencial das resinas precursoras de $\mathrm{SrTiO}_{3}, \mathrm{Ca}_{0,5} \mathrm{Sr}_{0,5} \mathrm{TiO}_{3}$ e $\mathrm{CaTiO}_{3}$ - método dos precursores poliméricos; atmosfera: nitrogênio. 
Figura 31 - Curvas de análise termogravimétrica das resinas precursoras de $\mathrm{SrTiO}_{3}, \mathrm{Ca}_{0,5} \mathrm{Sr}_{0,5} \mathrm{TiO}_{3}$ e $\mathrm{CaTiO}_{3}$ - método dos precursores poliméricos; atmosfera: nitrogênio.

Figura 32 - Curva de retração linear do composto $\mathrm{SrTi}_{0,65} \mathrm{Fe}_{0,35} \mathrm{O}_{3-\delta}$, material obtido pela técnica de reação de estado sólido 50

Figura 33 - Curva de retração linear do composto $\mathrm{Ca}_{0,5} \mathrm{Sr}_{0,5} \mathrm{Ti}_{0,65} \mathrm{Fe}_{0,35} \mathrm{O}_{3-\delta}$, material obtido pela técnica de reação de estado sólido.

Figura 34 - Curva de retração linear do composto $\mathrm{CaTi}_{0,65} \mathrm{Fe}_{0,35} \mathrm{O}_{3-\delta}$, material obtido pela técnica de reação de estado sólido

Figura 35 - Curvas de retração linear dos compostos $\mathrm{Ca}_{x} \mathrm{Sr}_{1-x} \mathrm{Ti}_{0,65} \mathrm{Fe}_{0,35} \mathrm{O}_{3-\delta}$, $x=0,0,5$ e 1 , material obtido pela técnica de reação de estado sólido.

Figura 36 - Difratogramas de raios $X$ de pós de $\mathrm{SrTi}_{0,65} \mathrm{Fe}_{0,35} \mathrm{O}_{3-\delta}$, $\mathrm{Ca}_{0,5} \mathrm{Sr}_{0,5} \mathrm{Ti}_{0,65} \mathrm{Fe}_{0,35} \mathrm{O}_{3-\delta}$ e $\mathrm{CaTi}_{0,65} \mathrm{Fe}_{0,35} \mathrm{O}_{3-\delta}$, normalizados, obtidos pela técnica de reação de estado sólido $-1250^{\circ} \mathrm{C} / 15 \mathrm{~h}$.

Figura 37 - Gráfico do ajuste de Rietveld para a amostra de composição $\mathrm{SrTi}_{0,65} \mathrm{Fe}_{0,35} \mathrm{O}_{3-\delta}$, com base numa simetria cúbica, $\mathrm{P} \mathrm{m} \mathrm{-3} \mathrm{m}$.

Figura 38 - Gráfico do ajuste de Rietveld para a amostra de composição $\mathrm{Ca}_{0,5} \mathrm{Sr}_{0,5} \mathrm{Ti}_{0,65} \mathrm{Fe}_{0,35} \mathrm{O}_{3-\delta}$, com base numa simetria cúbica, $\mathrm{P}$ m $-3 \mathrm{~m}$.

Figura 39 - Gráfico do ajuste de Rietveld para a amostra de composição $\mathrm{CaTi}_{0,65} \mathrm{Fe}_{0,35} \mathrm{O}_{3-\delta}$, com base numa simetria ortorrômbica, $\mathrm{Pcm}$. 56

Figura 40 - Difratogramas de raios $X$ de pós de $\mathrm{SrTi}_{, 65} \mathrm{Fe}_{0,35} \mathrm{O}_{3-\delta}$ $\mathrm{Ca}_{0,5} \mathrm{Sr}_{0,5} \mathrm{Ti}_{0,65} \mathrm{Fe}_{0,35} \mathrm{O}_{3-\delta}$ e $\mathrm{CaTi}_{0,65} \mathrm{Fe}_{0,35} \mathrm{O}_{3-\delta}$, normalizados, preparados pela técnica dos precursores poliméricos.

Figura 41 - Difratograma de raios $X$ com fonte Síncrotron de $\mathrm{SrTi}_{0,65} \mathrm{Fe}_{0,35} \mathrm{O}_{3-\delta}$, $\mathrm{Ca}_{0,5} \mathrm{Sr}_{0,5} \mathrm{Ti}_{0,65} \mathrm{Fe}_{0,35} \mathrm{O}_{3-\delta}$ e $\mathrm{CaTi}_{0,65} \mathrm{Fe}_{0,35} \mathrm{O}_{3-\delta}$, material obtido por reação de estado sólido; dois tratamentos térmicos: $1250{ }^{\circ} \mathrm{C} / 15 \mathrm{~h}$ $+1400^{\circ} \mathrm{C} / 60 \mathrm{~h}$ 
Figura 42 - Difratograma de raios $X$ com fonte Síncrotron de $\mathrm{SrTi}_{0,65} \mathrm{Fe}_{0,35} \mathrm{O}_{3-\delta}$, material obtido por reação de estado sólido; dois tratamentos térmicos: $1250{ }^{\circ} \mathrm{C} / 15 \mathrm{~h}+1400{ }^{\circ} \mathrm{C} / 60 \mathrm{~h}$.

Figura 43 - Identificação da fase cristalina da amostra de $\mathrm{SrTi}_{0,65} \mathrm{Fe}_{0,35} \mathrm{O}_{3-\delta}$, com o programa Search Math ${ }^{[61]}$ e do banco de dados de difração ICDD-PDF ${ }^{[59]}$. Em azul o difratograma medido, em vermelho a simulação do difratograma da fase SrTiO.

Figura 44 - Gráfico do ajuste de Rietveld para a amostra de composição $\mathrm{SrTi}_{0,65} \mathrm{Fe}_{0,35} \mathrm{O}_{3-\delta,}$, com base numa simetria cúbica, $\mathrm{P} \mathrm{m}-3 \mathrm{~m}$. 59

Figura 45 - Difratograma de raios $X$ com fonte Síncrotron de $\mathrm{Ca}_{0,5} \mathrm{Sr}_{0,5} \mathrm{Ti}_{0,65} \mathrm{Fe}_{0,35} \mathrm{O}_{3-\delta}$, material obtido por reação de estado sólido; dois tratamentos térmicos: $1250{ }^{\circ} \mathrm{C} / 15 \mathrm{~h}+$ $1400{ }^{\circ} \mathrm{C} / 60 \mathrm{~h}$.

Figura 46 - Identificação da fase cristalina da amostra de $\mathrm{Ca}_{0,5} \mathrm{Sr}_{0,5} \mathrm{Ti}_{0,65} \mathrm{Fe}_{0,35} \mathrm{O}_{3-\delta}$, pelo programa Search Math ${ }^{[61]}$ e do banco de dados de difração PDF ${ }^{[59]}$. Em azul o difratograma medido, em vermelho a simulação do difratograma da fase CaSrTiO. 60

Figura 47 - Gráfico do ajuste de Rietveld para a amostra de composição $\mathrm{Ca}_{0,5} \mathrm{Sr}_{0,5} \mathrm{Ti}_{0,65} \mathrm{Fe}_{0,35} \mathrm{O}_{3-\delta}$, com base numa simetria ortorrômbica, $\mathrm{B} \mathrm{m} \mathrm{m} \mathrm{b.}$

Figura 48 - Difratograma de raio $\mathrm{X}$ com fonte Síncrotron de $\mathrm{CaTi}_{0,65} \mathrm{Fe}_{0,35} \mathrm{O}_{3-\delta}$, material obtido por reação de estado sólido; dois tratamentos térmicos: $1250{ }^{\circ} \mathrm{C} / 15 \mathrm{~h}+1400^{\circ} \mathrm{C} / 60 \mathrm{~h}$.

Figura 49 - Identificação da fase cristalina da amostra de $\mathrm{CaTi}_{0,65} \mathrm{Fe}_{0,35} \mathrm{O}_{3-\delta}$, pelo programa Search Math ${ }^{[61]}$ e do banco de dados de difração PDF ${ }^{59]}$. Em azul o difratograma medido, em vermelho a simulação do difratograma da fase CaSrTiO.

Figura 50 - Gráfico do ajuste de Rietveld para a amostra de composição $\mathrm{CaTi}_{0,65} \mathrm{Fe}_{0,35} \mathrm{O}_{3-\delta}$, com base numa simetria ortorrômbica, $\mathrm{Pb} \mathrm{n}$. 62

Figura 51 - Cela unitária refinada da amostra de $\mathrm{SrTi}_{0,65} \mathrm{Fe}_{0,35} \mathrm{O}_{3-\delta,}$ estrutura cúbica, simetria P m -3 m, conforme Tabela 7 , dados do Síncrotron. Detalhe: átomos não em escala. 
Figura 52 - Cela unitária refinada da amostra de $\mathrm{Ca}_{0,5} \mathrm{Sr}_{0,5} \mathrm{Ti}_{0,65} \mathrm{Fe}_{0,35} \mathrm{O}_{3-\delta \text {, }}$ estrutura ortorrômbica, simetria $\mathrm{B} \mathrm{m} \mathrm{m} \mathrm{b,} \mathrm{conforme} \mathrm{Tabela} \mathrm{7,} \mathrm{dados}$ do Síncrotron. Detalhe: átomos não em escala

Figura 53 - Cela unitária refinada da amostra de $\mathrm{CaTi}_{0,65} \mathrm{Fe}_{0,35} \mathrm{O}_{3-\delta}$, estrutura ortorrômbica, simetria $\mathrm{P}$ b n m, conforme Tabela 7 , dados do Síncrotron. Detalhe: átomos não em escala.

Figura 54 - Micrografias obtidas por microscopia eletrônica de varredura de pós de $\mathrm{SrTi}_{0,65} \mathrm{Fe}_{0,35} \mathrm{O}_{3-\delta}(\mathrm{a}, \mathrm{b}), \mathrm{Ca}_{0,5} \mathrm{Sr}_{0,5} \mathrm{Ti}_{0,65} \mathrm{Fe}_{0,35} \mathrm{O}_{3-\delta}$ (c,d) e $\mathrm{CaTi}_{0,65} \mathrm{Fe}_{0,35} \mathrm{O}_{3-\delta}(\mathrm{e}, \mathrm{f})$. Esquerda: FEG-MEV; Direita: MEV....

Figura 55 - Micrografias obtidas por microscopia eletrônica de transmissão dos pós de $\mathrm{SrTi}_{0,65} \mathrm{Fe}_{0,35} \mathrm{O}_{3-\delta}(\mathrm{a}, \mathrm{d}), \mathrm{Ca}_{0,5} \mathrm{Sr}_{0,5} \mathrm{Ti}_{0,65} \mathrm{Fe}_{0,35} \mathrm{O}_{3-\delta}$ (b,e) e $\mathrm{CaTi}_{0,65} \mathrm{Fe}_{0,35} \mathrm{O}_{3-\delta}(\mathrm{c}, \mathrm{f})$

Figura 56 - Micrografias obtidas por microscopia eletrônica de varredura (FEG) de pós de $\mathrm{SrTi}_{0,65} \mathrm{Fe}_{0,35} \mathrm{O}_{3-\delta}(\mathrm{a}, \mathrm{b}), \mathrm{Ca}_{0,5} \mathrm{Sr}_{0,5} \mathrm{Ti}_{0,65} \mathrm{Fe}_{0,35} \mathrm{O}_{3-\delta}$ (c,d) e $\mathrm{CaTi}_{0,65} \mathrm{Fe}_{0,35} \mathrm{O}_{3-\delta}(\mathrm{e}, \mathrm{f})$.

Figura 57 - Micrografias obtidas por microscopia eletrônica de varredura por sonda de superfícies polidas e atacadas termicamente de $\mathrm{SrTi}_{0,65} \mathrm{Fe}_{0,35} \mathrm{O}_{3-\delta}$ (a) MO e (d) PP, $\mathrm{Ca}_{0,5} \mathrm{Sr}_{0,5} \mathrm{Ti}_{0,65} \mathrm{Fe}_{0,35} \mathrm{O}_{3-\delta}$ (b) MO e (e) PP, e $\mathrm{CaTi}_{0,65} \mathrm{Fe}_{0,35} \mathrm{O}_{3-\delta}$ (c) $\mathrm{MO}$ e (f) PP.

Figura 58 - Diagramas de impedância na faixa de freqüências $5 \mathrm{~Hz}$ - $13 \mathrm{MHz}$ de $\mathrm{SrTi}_{0,65} \mathrm{Fe}_{0,35} \mathrm{O}_{3-\delta}$ (pós obtidos por síntese de estado sólido $\mathrm{MO})$, a várias temperaturas. Os números são o logaritmo da freqüência $(\mathrm{Hz})$

Figura 59 - Diagramas de impedância na faixa de freqüências $5 \mathrm{~Hz}-13 \mathrm{MHz}$ de $\mathrm{SrTi}_{0,65} \mathrm{Fe}_{0,35} \mathrm{O}_{3-\delta}$ (pós obtidos pela técnica dos precursores poliméricos - PP), a várias temperaturas. Os números são o logaritmo da freqüência $(\mathrm{Hz})$.

Figura 60 - Diagramas de impedância na faixa de freqüências $5 \mathrm{~Hz}$ - $13 \mathrm{MHz}$ de $\mathrm{Ca}_{0,5} \mathrm{Sr}_{0,5} \mathrm{Ti}_{0,65} \mathrm{Fe}_{0,35} \mathrm{O}_{3-\delta}$ (pós obtidos por síntese de estado sólido - MO), a várias temperaturas. Os números são o logaritmo da freqüência $(\mathrm{Hz})$. 
Figura 61 - Diagramas de impedância na faixa de freqüências $5 \mathrm{~Hz}$ - $13 \mathrm{MHz}$ de $\mathrm{Ca}_{0,5} \mathrm{Sr}_{0,5} \mathrm{Ti}_{0,65} \mathrm{Fe}_{0,35} \mathrm{O}_{3-\delta}$ (pós obtidos pela técnica dos precursores poliméricos - $\mathrm{PP}$ ), a várias temperaturas. Os números são o logaritmo da freqüência $(\mathrm{Hz})$.

Figura 62 - Diagramas de impedância na faixa de freqüências $5 \mathrm{~Hz}-13 \mathrm{MHz}$ de $\mathrm{CaTi}_{0,65} \mathrm{Fe}_{0,35} \mathrm{O}_{3-\delta}$ (pós obtidos por síntese de estado sólido $\mathrm{MO}$ ), a várias temperaturas. Os números são o logaritmo da freqüência $(\mathrm{Hz})$

Figura 63 - Diagramas de impedância na faixa de freqüências $5 \mathrm{~Hz}-13 \mathrm{MHz}$ de $\mathrm{CaTi}_{0,65} \mathrm{Fe}_{0,35} \mathrm{O}_{3-\delta}$ (pós obtidos pela técnica dos precursores poliméricos - PP), a várias temperaturas.

Figura 64 - Diagramas de impedância na faixa de freqüências $5 \mathrm{~Hz}-13 \mathrm{MHz}$ de $\mathrm{SrTi}_{0,65} \mathrm{Fe}_{0,35} \mathrm{O}_{3-\delta}, \mathrm{Ca}_{0,5} \mathrm{Sr}_{0,5} \mathrm{Ti}_{0,65} \mathrm{Fe}_{0,35} \mathrm{O}_{3-\delta}$ e $\mathrm{CaTi}_{0,65} \mathrm{Fe}_{0,35} \mathrm{O}_{3-\delta}$ (pós obtidos por síntese de estado sólido - MO), medidos em $65^{\circ} \mathrm{C}$.... 74

Figura 65 - Diagramas de impedância na faixa de freqüências de $5 \mathrm{~Hz}-13 \mathrm{MHz}$ de $\mathrm{SrTi}_{0,65} \mathrm{Fe}_{0,35} \mathrm{O}_{3-\delta}, \mathrm{Ca}_{0,5} \mathrm{Sr}_{0,5} \mathrm{Ti}_{0,65} \mathrm{Fe}_{0,35} \mathrm{O}_{3-\delta}$ e $\mathrm{CaTi}_{0,65} \mathrm{Fe}_{0,35} \mathrm{O}_{3-\delta}$ (pós obtidos pela técnica dos precursores poliméricos - PP) medidos em $100{ }^{\circ} \mathrm{C}$.

Figura 66 - Gráficos de Arrhenius da resistividade elétrica dos grãos e dos contornos de grão de $\mathrm{SrTi}_{0,65} \mathrm{Fe}_{0,35} \mathrm{O}_{3-\delta}$ (pós obtidos por síntese de estado sólido e técnica dos precursores poliméricos).

Figura 67 - Gráficos de Arrhenius da resistividade elétrica dos grãos e dos contornos de grão de $\mathrm{Ca}_{0,5} \mathrm{Sr}_{0,5} \mathrm{Ti}_{0,65} \mathrm{Fe}_{0,35} \mathrm{O}_{3-\delta}$ (pós obtidos por síntese de estado sólido e técnica dos precursores poliméricos).. 76

Figura 68 - Gráficos de Arrhenius da resistividade elétrica dos grãos e dos contornos de grão de $\mathrm{CaTi}_{0,65} \mathrm{Fe}_{0,35} \mathrm{O}_{3-\delta}$ (pós obtidos por síntese de estado sólido e técnica dos precursores poliméricos). 76

Figura 69 - Gráficos de Arrhenius da resistividade elétrica dos grãos (esquerda) e dos contornos de grão (direita) de $\mathrm{SrTi}_{0,65} \mathrm{Fe}_{0,35} \mathrm{O}_{3-\delta \text {, }}$ $\mathrm{Ca}_{0,5} \mathrm{Sr}_{0,5} \mathrm{Ti}_{0,65} \mathrm{Fe}_{0,35} \mathrm{O}_{3-\delta}$ e $\mathrm{CaTi}_{0,65} \mathrm{Fe}_{0,35} \mathrm{O}_{3-\delta}$. MO: pós obtidos por síntese de estado sólido e PP; pela técnica dos precursores poliméricos. 
Figura 70 - Gráfico da força eletromotriz gerada para as composições $\mathrm{SrTi}_{0,65} \mathrm{Fe}_{0,35} \mathrm{O}_{3-\delta}, \mathrm{Ca}_{0,5} \mathrm{Sr}_{0,5} \mathrm{Ti}_{0,65} \mathrm{Fe}_{0,35} \mathrm{O}_{3-\delta}$ e $\mathrm{CaTi}_{0,65} \mathrm{Fe}_{0,35} \mathrm{O}_{3-\delta}$ em função da temperatura para $50 \mathrm{ppm}$ de $\mathrm{O}_{2}$. Detalhe: ampliação da parte selecionada.

Figura 71 - Curva de análise termogravimétrica de mistura de $\mathrm{SrCO}_{3}, \mathrm{TiO}_{2} \mathrm{e}$ $\mathrm{Fe}_{2} \mathrm{O}_{3}$ na proporção molar 1,0:0,65:0,35; análise feita com o software Proteus ${ }^{[53]}$

Figura 72 - Curva de análise termogravimétrica de mistura de $\mathrm{CaCO}_{3}, \mathrm{SrCO}_{3}$, $\mathrm{TiO}_{2}$ e $\mathrm{Fe}_{2} \mathrm{O}_{3}$ na proporção molar 0,5:0,5:0,65:0,35; análise feita com o software Proteus ${ }^{[53]}$

Figura 73 - Curva de análise termogravimétrica de mistura de $\mathrm{CaCO}_{3}, \mathrm{TiO}_{2} \mathrm{e}$ $\mathrm{Fe}_{2} \mathrm{O}_{3}$ na proporção molar 1,0:0,65:0,35; análise feita com o software Proteus ${ }^{[53]}$

Figura 74 - Curva de análise termogravimétrica de mistura de $\mathrm{SrCO}_{3}$ e $\mathrm{TiO}_{2}$ na proporção molar 1,0:1,0; análise feita com o software Proteus ${ }^{[53]}$.

Figura 75 - Curva de análise termogravimétrica de mistura de $\mathrm{CaCO}_{3}, \mathrm{SrCO}_{3} \mathrm{e}$ $\mathrm{TiO}_{2}$ na proporção molar 0,5:0,5:1,0; análise feita o software Proteus ${ }^{[53]}$.

Figura 76 - Curva de análise termogravimétrica de mistura de $\mathrm{CaCO}_{3}$ e $\mathrm{TiO}_{2}$ na proporção molar 1,0:1,0; análise feita com o software Proteus ${ }^{[53]}$. 88

Figura 77 - Curva de análise termogravimétrica da resina precursora de $\mathrm{SrTi}_{0,65} \mathrm{Fe}_{0,35} \mathrm{O}_{3-\delta}$ - método dos precursores poliméricos; análise feita com o software Proteus ${ }^{[53]}$

Figura 78 - Curvas de análise termogravimétrica da resina precursora de $\mathrm{Ca}_{0,5} \mathrm{Sr}_{0,5} \mathrm{TiO}_{, 65} \mathrm{Fe}_{0,35} \mathrm{O}_{3-\delta}$ - método dos precursores poliméricos, análise feita com o software Proteus ${ }^{[53]}$

Figura 79 - Curva de análise termogravimétrica da resina precursora de $\mathrm{CaTi}{ }_{65} \mathrm{Fe}_{0,35} \mathrm{O}_{3-\delta}-$ método dos precursores poliméricos, análise feita com o software Proteus ${ }^{[53]}$ 
Figura 80 - Curvas de análise térmica diferencial da resina precursora de $\mathrm{SrTiO}_{3}$ - método dos precursores poliméricos; atmosfera: nitrogênio, análise feita com o software Proteus ${ }^{[53]}$.

Figura 81 - Curvas de análise térmica diferencial da resina precursora de $\mathrm{Ca}_{0,5} \mathrm{Sr}_{0,5} \mathrm{TiO}_{3-\delta}$ - método dos precursores poliméricos; atmosfera: nitrogênio, análise feita com o software Proteus ${ }^{[53]}$.

Figura 82 - Curvas de análise térmica diferencial da resina precursora de $\mathrm{CaTiO}_{3}$ - método dos precursores poliméricos; atmosfera: nitrogênio, análise feita com o software Proteus ${ }^{[53]}$.

Figura 83 - Curva de calibração usada nas análises termogravimétricas e térmica diferencial.

Figura 84 - Curva termogravimétrica e térmica diferencial de $\mathrm{CaCO}_{3}$ 92

Figura 85 - Curva de análise termogravimétrica de $\mathrm{CaCO}_{3}$, análise feita com 0 software Proteus ${ }^{[53]}$

Figura 86 - Curva termogravimétrica e térmica diferencial de $\mathrm{SrCO}_{3}$ 93

Figura 87 - Curva de análise termogravimétrica de $\mathrm{SrCO}_{3}$, análise feita com o software Proteus ${ }^{[53]}$

Figura 88 - Plano cartesiano complexo

Figura 89 - Circuito RC paralelo no domínio do tempo

Figura 90 - Circuito RC paralelo no domínio da freqüência. 98

Figura 91 - Semicírculo de raio $\frac{R}{2}$, centrado em $\frac{R}{2}$, gerado pelo circuito elétrico da Figura 89 
Tabela 1 - Materiais de partida e algumas de suas características físico-químicas ${ }^{[39]}$

Tabela 2 - Tamanho médio equivalente dos materiais de partida utilizados para a produção de $\mathrm{Ca}_{x} \mathrm{Sr}_{1-x} \mathrm{Ti}_{0,65} \mathrm{Fe}_{0,35} \mathrm{O}_{3-\delta}$, $x=0,0,5$ e 1

Tabela 3 - Valores de perda de massa das composições SrTi0 ${ }_{65} \mathrm{Fe}_{0,35} \mathrm{O}_{3-\delta}, \mathrm{Ca}_{0,5} \mathrm{Sr}_{0,5} \mathrm{TiO}_{6,6} \mathrm{Fe}_{0,35} \mathrm{O}_{3-\delta}$, $\mathrm{CaTi0}, 65 \mathrm{Fe}_{0,35} \mathrm{O}_{3-\delta}, \mathrm{SrTiO}_{3}, \mathrm{Ca}_{0,5} \mathrm{Sr}_{0,5} \mathrm{TiO}_{3}$ e $\mathrm{CaTiO}_{3}$, durante o aquecimento a $10{ }^{\circ} \mathrm{C} / \mathrm{min}$ até a $1550{ }^{\circ} \mathrm{C}$ ao ar.

Tabela 4 - Comparativo das densidades alcançadas em relação à densidade total para as composições $\mathrm{Ca}_{x} \mathrm{Sr}_{1-\mathrm{x}} \mathrm{Ti}_{0,65} \mathrm{Fe}_{0,35} \mathrm{O}_{3-\delta}, \mathrm{x}=0$, 0,5 e 1

Tabela 5 - Valores de expansão e retração máxima para $\mathrm{Ca}_{x} \mathrm{Sr}_{1-\mathrm{x}} \mathrm{Ti}_{0,65} \mathrm{Fe}_{0,35} \mathrm{O}_{3-\delta} \mathrm{x}=0$, 0,5 e 1, material obtido pela técnica de reação de estado sólido.

Tabela 6 - Resultados do ajuste de Rietveld, parâmetros de rede e simetria para as composições $\mathrm{SrTi}_{0,65} \mathrm{Fe}_{0,35} \mathrm{O}_{3-\delta}$, $\mathrm{Ca}_{0,5} \mathrm{Sr}_{0,5} \mathrm{Ti}_{0,65} \mathrm{Fe}_{0,35} \mathrm{O}_{3-\delta}$ e $\mathrm{CaTi}_{0,65} \mathrm{Fe}_{0,35} \mathrm{O}_{3-\delta}$, obtidos pela técnica de reação de estado sólido medidos em equipamento convencional.

Tabela 7 - Principais resultados obtidos pela técnica de refinamento Rietveld para as composições $\mathrm{SrTi}_{0,65} \mathrm{Fe}_{0,35} \mathrm{O}_{3-\delta}$, $\mathrm{Ca}_{0,5} \mathrm{Sr}_{0,5} \mathrm{Ti}_{0,65} \mathrm{Fe}_{0,35} \mathrm{O}_{3-\delta}, \mathrm{CaTi}_{0,65} \mathrm{Fe}_{0,35} \mathrm{O}_{3-\delta} ;$ dois tratamentos térmicos: $1250^{\circ} \mathrm{C} / 15 \mathrm{~h}+1400^{\circ} \mathrm{C} / 60 \mathrm{~h}$ 63

Tabela 8 - Valores de capacitância dos grãos e dos contornos de grão de compostos sinterizados de $\mathrm{SrTi}_{0,65} \mathrm{Fe}_{0,35} \mathrm{O}_{3-\delta}$, $\mathrm{Ca}_{0,5} \mathrm{Sr}_{0,5} \mathrm{Ti}_{0,65} \mathrm{Fe}_{0,35} \mathrm{O}_{3-\delta}$ e $\mathrm{CaTi}_{0,65} \mathrm{Fe}_{0,35} \mathrm{O}_{3-\delta}$, preparados com pós obtidos pelas técnicas dos precursores poliméricos e síntese de estado sólido. 


\title{
Síntese, caracterização microestrutural e elétrica de compostos cerâmicos à base de soluções sólidas de titanato de estrôncio, titanato de cálcio e óxido de ferro
}

\begin{abstract}
Resumo
Composições cerâmicas de $\mathrm{Ca}_{x} \mathrm{Sr}_{1-x} \mathrm{Ti}_{1-y} \mathrm{Fe}_{\mathrm{y}} \mathrm{O}_{3-\delta}, \mathrm{x}=0$, 0,5 e 1,0, y = 0 e 0,35, foram preparadas por meio de síntese reativa de $\mathrm{CaCO}_{3}, \mathrm{SrCO}_{3}, \mathrm{TiO}_{2}$ e $\mathrm{Fe}_{2} \mathrm{O}_{3}$ e pela técnica dos precursores poliméricos. Os pós-cerâmicos foram avaliados por meio de análise térmica (termogravimétrica e térmica diferencial), difração de raios $\mathrm{X}$ e microscopia eletrônica de varredura. Compactos cerâmicos sinterizados foram analisados por difração de raios $X$, microscopia eletrônica de varredura, microscopia de varredura por sonda e espectroscopia de impedância. A força eletromotriz gerada entre duas faces paralelas de amostras cilíndricas foi monitorada na faixa de temperatura $600-1100{ }^{\circ} \mathrm{C}$ para pressão parcial de oxigênio de $\sim 50$ ppm, utilizando-se uma bomba eletroquímica de oxigênio com transdutores de zircônia estabilizada com ítria. Foram refinadas, por meio de análise de Rietveld as estruturas cristalinas determinadas na análise por difração de raios $X$ : perovskita cúbica $(x=0)$ e perovskita ortorrômbica $(x \neq 0)$. A condutividade elétrica foi analisada por medidas de espectroscopia de impedância na faixa de freqüências $5 \mathrm{~Hz}-13$ $\mathrm{MHz}$ da temperatura ambiente até $\sim 200^{\circ} \mathrm{C}$. A deconvolução dos diagramas de impedância $\left[-Z^{\prime \prime}(\omega) \times Z^{\prime}(\omega)\right]$ na faixa de temperaturas $300<T(K)<500$ mostra dois semicírculos atribuídos às contribuições intragranular (grãos) e intergranular (contornos de grão) à resistividade elétrica. Os compactos sinterizado utilizando pós preparados pela síntese de estado sólido apresentam valores de resistividade intergranular e intragranular maiores que os compactos preparados com pós obtidos pela síntese química. O sinal elétrico (força eletromotriz) gerado sob exposição a oxigênio mostra que esses compostos podem ser utilizados em dispositivos sensores de oxigênio entre 600 e $1100^{\circ} \mathrm{C}$. Análises topográficas em microscópio de varredura por sonda em superfícies polidas e atacadas termicamente mostram detalhes morfológicos dos grãos, permitindo concluir que compactos sinterizados preparados com pós obtidos pela rota química são menos porosos que os preparados com pós obtidos pela rota convencional de síntese de estado sólido. Estes resultados estão de acordo com os resultados de medidas de espectroscopia de impedância.
\end{abstract}




\title{
Synthesis, microstructural and electrical characterization of ceramic compounds based on strontium and calcium titanates and iron-oxide
}

\begin{abstract}
$\mathrm{Ca}_{x} \mathrm{Sr}_{1-\mathrm{x}} \mathrm{Ti}_{1-\mathrm{y}} \mathrm{Fe}_{\mathrm{y}} \mathrm{O}_{3-\delta}, \mathrm{x}=0,0.5$ and $1.0, \mathrm{y}=0$ and 0.35 , ceramic compounds were synthesized by reactive solid state synthesis of $\mathrm{CaCO}_{3}, \mathrm{SrCO}_{3}, \mathrm{TiO}_{2}$ and $\mathrm{Fe}_{2} \mathrm{O}_{3}$, and by the polymeric precursor technique. The ceramic powders were evaluated by thermogravimetry and differential thermal analysis, X-ray diffraction and scanning electron microscopy. Sintered ceramic pellets were analyzed by X-ray diffraction, scanning electron microscopy, scanning probe microscopy and impedance spectroscopy. The electromotive force resulting from the exposing the pellets to partial pressure de oxygen in the $\sim 50 \mathrm{ppm}$ in the $600-1100{ }^{\circ} \mathrm{C}$ range was monitored using an experimental setup consisting of an oxygen electrochemical pump with yttria-stabilized zirconia transducer and sensor. Rietveld analysis of the X-ray data allowed for determining the crystalline structures: cubic perovskite $(y=0)$ and orthorhombic perovskite $(y \neq$ $0)$. The electrical conductivity was determined by the two probe impedance spectroscopy measurements in the $5 \mathrm{~Hz}-13 \mathrm{MHz}$ frequency range from room temperature to approximately $200{ }^{\circ} \mathrm{C}$. The deconvolution of the $\left[-Z^{\prime \prime}(\omega) \times Z^{\prime}(\omega)\right]$ impedance diagrams in the $300<\mathrm{T}(\mathrm{K})<500$ range shows two semicircles due to intragranular (bulk) and intergranular (grain boundary) contributions to the electrical resistivity. Sintered pellets using powders prepared by the ceramic route present higher inter- and intragranular resistivity values than pellets prepared with chemically synthesized powders. The emf signal under exposure oxygen shows that these compounds may be used in oxygen sensing devices in the $600-1100{ }^{\circ} \mathrm{C}$ range. Scanning probe microscopy topographic analysis of the polished and thermally etched surfaces of the pellets gave details of grain morphology, showing that pellets prepared with powders synthesized by the chemical route are less porous than the ones obtained by the ceramic route. These results are in agreement with the impedance spectroscopy results.
\end{abstract}




\section{INTRODUÇÃO}

Neste capítulo serão apresentados alguns conceitos sobre materiais cerâmicos, suas aplicações, materiais sensores de oxigênio, funcionamento do sensor lambda, material usado em sensor lambda comercial, as pesquisas de novos materiais para sensores lambda, e as técnicas de obtenção desses materiais usados nesse trabalho.

\subsection{A IMPORTÂNCIA DOS SENSORES NA VIDA MODERNA}

Sensores possuem um lugar de destaque na vida moderna: monitoramento do meio ambiente, processamento de materiais, queima de resíduos industriais, análises químicas, análises patológicas, sistemas automotivos e outras inumeráveis aplicações.

Tem sido crescente a preocupação com os recursos existentes em nosso planeta, principalmente com os não renováveis ou renováveis com um ciclo muito longo.

Num passado recente muitas foram as realizações do Homem no sentido da continuidade de sua espécie na Terra; entre elas, são de grande relevância alterações nas leis de manuseio relativas aos ecossistemas, determinando quantidades máximas permitidas de descarte de sólidos, líquidos e gases no meio ambiente ${ }^{[1]}$.

A emissão de CO pelos carros na atmosfera é o caso mais evidente de poluição por queima incompleta de combustíveis fósseis. Em 1986 foram 6,5 milhões de toneladas lançados na atmosfera somente por veículos automotores, tendo no mesmo ano 2,5 milhões de toneladas de lançadas na atmosfera por termoelétricas e indústrias de maneira geral ${ }^{[1]}$. Diante destes dados, é justificada uma preocupação com a emissão de poluentes em um automóvel.

O transporte veicular é responsável pela maior parcela de emissão de poluentes na atmosfera ${ }^{[2]}$. Entre os poluentes emitidos por veículos automotores destacam-se $\mathrm{CO}_{x}, \mathrm{NO}_{\mathrm{x}}$ e $\mathrm{CH}_{\mathrm{x}}$, que podem ter sua emissão minimizada com o controle da queima do combustível na câmara de combustão de um motor a explosão. 
Atualmente milhões de veículos automotores são equipados com um sensor de oxigênio no sistema de exaustão de gases. Basicamente, todo veículo movido a gasolina possui uma sonda lambda à base de óxido de zircônio $\left(\mathrm{ZrO}_{2}\right)$ em seu sistema de escape de gases, tendo como função regular a taxa oxigênio/combustível admitida para explosão, mantendo um valor próximo do estequiométrico $(\lambda=1)^{[3]}$.

Os sensores de oxigênio comerciais são predominantemente à base de óxido de zircônio, possuindo como característica o funcionamento acima de $600^{\circ} \mathrm{C}$, o que faz com que tenham um aquecedor interno para que atinjam esta temperatura em menor tempo de operação. Muitos trabalhos em busca de novos materiais condutores iônicos tem sido feitos nos últimos anos na tentativa de se obter uma resposta do material independente da temperatura, ou seja, para a faixa de temperatura de operação para a qual foi projetado, sendo dependente apenas do teor de oxigênio. Entre eles podemos destacar os trabalhos de $\mathrm{H}$. L. Tuller e sua equipe no Massachusetts Institute of Technology, Cambridge, Estados Unidos, com o material $\mathrm{SrTi}_{0,65} \mathrm{Fe}_{0,35} \mathrm{O}_{3-\delta}{ }^{[4]}$. As principais conclusões de seus trabalhos são que materiais do tipo $\left(\mathrm{Sr}_{1-\mathrm{x}} \mathrm{D}_{\mathrm{x}}\right)\left[\left(\mathrm{Ti}_{0,7} \mathrm{Fe}_{0,3}\right)_{1-y} \mathrm{~A}_{\mathrm{y}}\right] \mathrm{O}_{3-\delta}$, onde "A" é um elemento do tipo receptor e " $\mathrm{D}$ " um elemento tipo doador, são materiais com excelentes características para serem utilizados como sensores de oxigênio automotivo, devido o seu baixo custo de fabricação e exatidão de medidas da resposta elétrica ${ }^{[5]}$.

Vários eletrólitos sólidos baseados no comportamento elétrico são propostos, como o novo tipo de sensor baseado na dependência da impedância do eletrólito sólido sob diferentes atmosferas. O eletrólito $\left(\mathrm{Gd}_{1-\mathrm{x}} \mathrm{Ca}_{\mathrm{x}}\right)_{2} \mathrm{Ti}_{2} \mathrm{O}_{7}, \mathrm{x}=0,1$ e 0,02 , por exemplo, foi testado com platina porosa como eletrodo, tendo sido obtido um material que apresenta na curva do logaritmo da condutividade elétrica em função do logaritmo da pressão parcial de oxigênio um coeficiente angular $+1 / 2$ para altas temperaturas e altas pressões parciais de oxigênio, embora para temperaturas mais baixas 0 comportamento seja muito mais complexo ${ }^{[6]}$.

Novos conceitos de monitoramento de gases de escapamento de veículos automotivos são tão importantes quanto as técnicas de sensoriamento ${ }^{[1]}$. Sensores medem teores de gases em função da temperatura, possuindo características como boa estabilidade e pequeno 
tempo de resposta ${ }^{[1]}$. Um fator de sucesso para um bom sensor está na escolha de um óxido semicondutor que possa ser facilmente aplicado na forma de filme fino. Isto é de grande importância para a integração de um micro sensor no sistema de controle do veículo automotivo ${ }^{[1]}$.

A seleção do material é um passo importante no processo de desenvolvimento. Testes de laboratório encontraram aplicações para compostos em todo o planeta. Um rápido e novo material sensor lambda com pequeno tempo de resposta já está sendo testado sob condições reais de uso severo, mostrando-se compatível para a substituição dos atuais sensores lambda ${ }^{[1]}$.

Sensores na forma de filmes de titanato de estrôncio após tratamento térmico a $1100{ }^{\circ} \mathrm{C} / 15 \mathrm{~h}$, mostraram reprodutibilidade nas características da condutividade elétrica função da pressão parcial de oxigênio. O tempo de resposta destes filmes a $950{ }^{\circ} \mathrm{C}$ é menor que $5 \mathrm{~ms}{ }^{[7]}$. Variações de pressão parcial de oxigênio e menor dependência da temperatura podem ter suas influencias estudadas em separado ${ }^{[7]}$.

Para a maioria das aplicações dos sensores potenciométricos a maior limitação é a alta temperatura de operação ${ }^{[8]}$. Para sensores de oxigênio, pesquisas são feitas para encontrar um material que possua alta condutividade elétrica em baixas temperaturas. Um problema adicional é o tempo de resposta de um sensor, sendo excessivamente longo a baixas temperaturas. Novos materiais apresentando alta atividade catalítica devem ser usados para superar este problema; a seletividade ao gás também deverá ser melhorada. Não deve ser descartada a vantagem apresentada pelo uso de filmes finos ${ }^{[0]}$ : a redução das temperaturas de operação, a miniaturização, a possibilidade de larga variedade de eletrólitos que usem difusão térmica, a possibilidade de modificar a atividade catalítica do eletrodo, aumentando a seletividade do sensor ${ }^{[9]}$.

O sensor lambda à base de zircônia tem sido a principal solução encontrada para reduzir o aquecimento global provocado por veículos com motores a combustão ${ }^{[10]}$. O sensor lambda usado para detectar a razão estequiométrica ar/combustível tende a ser cada vez menor em tamanho, necessitando um aquecedor interno menor, levando menos tempo para aquecer, evitando que o motor polua em seus primeiros momentos de funcionamento ${ }^{[10]}$. Sensores lambda montados na forma de filmes finos, com 
ou sem oxigênio para referência, são uma promessa para o futuro próximo. A grande faixa de medida ar/combustível dos sensores lambda os tornam potenciais para o controle de emissão de gases poluentes em veículos a combustão, pois as leis ambientais diminuirão cada vez mais o índice de descarte de gases que causam o efeito estufa ${ }^{[10]}$. O sucesso de produção em massa de sensores ar/combustível com baixo tempo de resposta pode levar a substituir o sensor lambda atual, pois a sensibilidade linear ar/combustível é mais conveniente para localizar o ponto estequiométrico ${ }^{[11]}$.

Vários testes para formação de compostos de estrutura perovskita foram feitos por meio de tratamentos térmicos em diferentes temperaturas, mostrando que cada temperatura de calcinação produz uma matriz de cor diferente no composto final; porém, para obtenção de fase única dos compostos $\mathrm{BaTiO}_{3}$, $\mathrm{SrTiO}_{3}$ e $\mathrm{CaTiO}_{3}$ preparados por mistura de óxidos foi necessária uma temperatura de calcinação superior a $1200{ }^{\circ} \mathrm{C}^{[11]}$.

$\mathrm{O}$ sensor de oxigênio baseado em $\mathrm{ZrO}_{2}$ mostrou ser confiável para sistemas de controle automotivo ${ }^{[2]}$. Para motores universais, sensores de $\mathrm{ZrO}_{2}$, são preferíveis na forma de filme fino. O sensor planar resistivo é independente da temperatura, em certa faixa, mostrando ser uma futura alternativa de alto desempenho, substituindo as atuais sondas lambda em aplicações de monitoramento de gases de escapamento de motores automotivos ${ }^{[2]}$.

Em outro trabalho, nanopartículas de $\mathrm{SrTi}_{1-x} \mathrm{Fe}_{x} \mathrm{O}_{3-\delta}, \mathrm{x}=0,0,0,05$ e 0,10 foram sintetizadas pelo método dos precursores poliméricos. Foi monitorada a reação de formação do composto por meio da análise térmica diferencial, apresentando picos entre 400 e $600^{\circ} \mathrm{C}$, indicando a decomposição de material orgânico. $\mathrm{O}$ aumento do teor de ferro na composição causa a diminuição da temperatura dos picos de decomposição ${ }^{[12]}$. Íons de ferro atuam como catalisadores, diminuindo a temperatura de decomposição do material orgânico, quando comparado com o material sem ferro. A adição de ferro, principalmente em $\mathrm{SrTi}_{1-\mathrm{x}} \mathrm{Fe}_{\mathrm{x}} \mathrm{O}_{3-\delta}$, diminui o tamanho médio de cristalito e aumenta o parâmetro de rede, uma vez que o raio iônico do ferro é menor do que o do titânio ${ }^{[12]}$.

Foi mostrado que íons $\mathrm{Y}^{3+}$ no composto $\mathrm{SrTiO}_{3}$ ocupam a posição do estrôncio. Dependendo do tratamento térmico, a carga positiva do doador substituinte pode ser compensada eletronicamente pela redução do titânio $\mathrm{Ti}^{4+}$ 
para $\mathrm{Ti}^{3+}$, ou pela criação de vacâncias de estrôncio ${ }^{[13]}$. O mecanismo de compensação de cargas é função da atmosfera de tratamento térmico. Tratamentos em atmosfera ambiente apresentam compensação iônica, enquanto tratamentos térmicos em atmosfera de hidrogênio (redutora) apresentam compensação eletrônica ${ }^{[15]}$.

Para materiais $\mathrm{SrTiO}_{3}$ dopados com lantânio, dois tipos de condução elétrica foram observadas: eletrônica e iônica ${ }^{[14]}$. Para materiais com alto teor de lantânio, uma região independente da temperatura foi observada a partir de $950{ }^{\circ} \mathrm{C}^{[17]}$.

\subsection{TitANATO DE ESTRÔNCIO}

O titanato de estrôncio é estudado por possuir características ferroelétricas e magnéticas, características raras encontradas em um mesmo material. É uma perovskita tipo $\mathrm{ABO}_{3}$ com máxima condução elétrica em temperaturas médias $\left(\sim 650{ }^{\circ} \mathrm{C}\right){ }^{[15]}$, podendo sua condutividade elétrica ser aumentada substituindo $\mathrm{Ti}^{4+}$ com íons de terras raras ${ }^{[15]}$. Várias perovskitas de titanatos de estrôncio dopados foram estudadas, sendo a mais antiga com lantânio [14,16,17,18,19]. Foi mostrado que amostras de titanato de estrôncio dopado com nióbio têm uma variação expressiva de suas propriedades elétricas [20,21,22,23], dependendo do local da rede onde o nióbio é incorporado ${ }^{[15]}$.

\subsection{TITANATO DE CÁLCIO}

O titanato de cálcio $\mathrm{CaTiO}_{3}$ é um material de estrutura perovsquita do tipo $\mathrm{ABO}_{3}$ com o cátion $\mathrm{B}$ sendo o Ti e o cátion $\mathrm{A} \circ \mathrm{Ca}$. Não apresenta anisotropia e sua estrutura é cúbica acima de $1580 \mathrm{~K}$, tetragonal entre $1380 \mathrm{e}$ $1500 \mathrm{~K}$ e ortorrômbica abaixo de $1380 \mathrm{~K}^{[24,25]}$. A estrutura perovskita cúbica pode ser obtida na temperatura ambiente quando $\mathrm{CaTiO}_{3}$ for dopado com cátions receptores ${ }^{[26]}$. O titanato de cálcio é usado como um elemento resistor com sensibilidade térmica, devido seu coeficiente de temperatura negativo, além de ser um material refratário com alta resistência à corrosão cáustica ${ }^{[27]}$ 


\subsection{TIPOS DE SENSORES}

Sensores geralmente respondem com um sinal elétrico a um estímulo, isto é, convertem a energia recebida em um sinal elétrico. Sensores eletroquímicos têm como principal componente um eletrólito, responsável pela conversão de uma grandeza mecânica, química ou de outra natureza, em sinal elétrico.

Sensores são amplamente usados em medicina, indústria siderúrgica, robótica, aeronaves e veículos; como o sinal é uma forma de energia, os sensores podem ser classificados de acordo com o tipo de energia que detectam. Por exemplo: sensores magnéticos (bússola magnética, magnetômetro, dispositivo de efeito Hall), de partícula subatômica (cintilômetro), de corrente elétrica (galvanômetro, amperímetro), de luz (células solares, fotodiodos, sensor de imagem), de radiação (contador Geiger, dosímetro), de som (microfones, sensores sísmicos) e de espécies químicas (oxigênio, flúor, entre outros).

Um veículo moderno possui mais de doze sensores ${ }^{[28]}$, sendo vários deles cerâmicos, Figura 1.

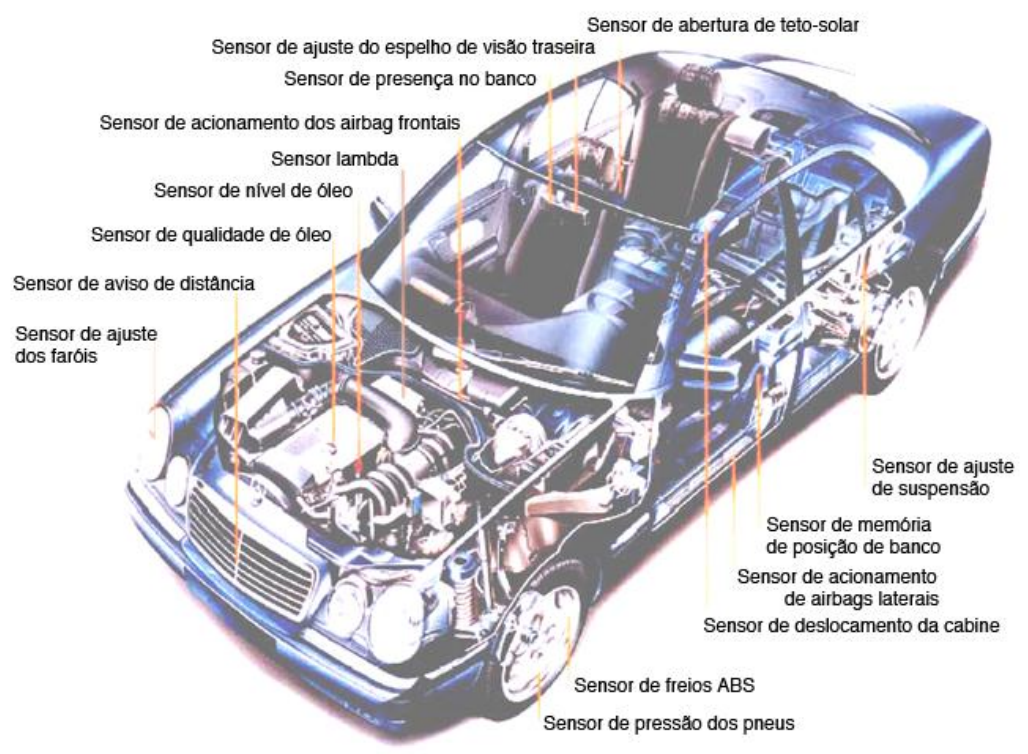

Figura 1 - Sensores automotivos ${ }^{[28]}$.

A utilização de sensores em veículos automotivos é basicamente de quatro tipos ${ }^{[28]}$ : conforto do veículo - acionamento de funções por voz, sistemas sem chave, ar-condicionado, vidros elétricos, cadeiras e espelhos inteligentes; controle operacional - sensores de pressão no motor, nos pneus, 
no freio, sensores para monitoração de qualidade do óleo, controle ativo da suspensão; controle ambiental - sistemas de injeção eletrônica para o controle de queima de combustível e emissão de poluentes, sensores químicos; e segurança - sensores aplicados em sistema ABS, sistemas de assistência ao motorista, sistemas de navegação e sistemas de auto-diagnóstico.

\subsection{SENSORES CERÂMICOS}

\subsubsection{SENSORES DE OXIGÊNIO ELETROQUÍMICOS}

São células galvânicas cujo principal componente é o eletrólito sólido. Em sensores comerciais este eletrólito é constituído por óxido de zircônio estabilizado com óxido de ítrio, de magnésio ou de cálcio.

Os sensores de oxigênio possuem um lugar de destaque nas indústrias de processamento de aço, químicas, automotivas e centros de pesquisa, devido sua ampla aplicação, quer seja no monitoramento de oxigênio em gases de exaustão de automóveis para controlar a razão ar/combustível minimizando a emissão de poluentes ${ }^{[10,29]}$, ou mesmo no monitoramento de oxigênio durante processos metalúrgicos, permitindo um melhor controle da qualidade dos produtos ${ }^{[30,31]}$. Em centros de pesquisa, normalmente são empregados para monitoração e aferição de teores de oxigênio em testes e medidas.

Para que um material seja considerado um eletrólito sólido condutor de íons $\mathrm{O}^{2-}$, deve apresentar algumas características: alta densidade (maior que 92\% da densidade teórica) para evitar a difusão do oxigênio molecular; número de transporte próximo de 1, segundo a Equação (1), para toda a faixa de teor de oxigênio que se deseja aferir, evitando desta forma o transporte de elétrons através da interface, garantindo uma corrente puramente iônica; ser inerte aos gases analisados e aos materiais com que faz contato; e possuir coeficiente de expansão ou retração compatível com os dos outros materiais utilizados em sua construção.

$t_{i}=\sigma_{i} / \sigma_{t}$

na qual $t_{i}$ é o número de transporte iônico, $\sigma_{i}$ a condutividade iônica, $\sigma_{t}$ a condutividade total (iônica + eletrônica) 


\subsubsection{Caracterização dos sensores de oxigênio}

Os sensores de oxigênio são caracterizados por quatro fatores para avaliar seu desempenho: sensibilidade - é a capacidade de gerar um sinal elétrico proporcional à concentração sob análise; seletividade - é a capacidade de aferir apenas a espécie química para qual foi projetado, diferenciando-a das demais; tempo de resposta - é o tempo decorrido para que haja variação no sinal elétrico desde o instante da mudança de valores de concentração; estabilidade - é a capacidade de manter a força eletromotriz constante para a mesma concentração da espécie medida.

\subsubsection{SENSORES COMERCIAIS}

Os sensores de oxigênio comerciais podem ser divididos em dois grandes grupos: amperométricos e potenciométricos.

\subsubsection{Sensores de oxigênio amperométricos}

São caracterizados pela não utilização de um eletrodo de referência, tendo assim sua construção simplificada, Figura 2.

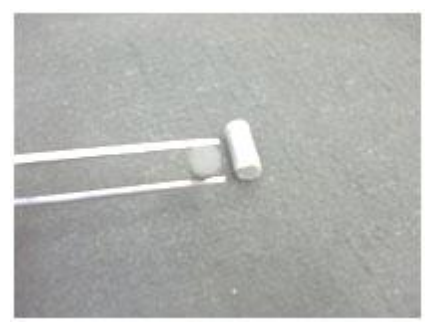

Figura 2 - Foto de um sensor de oxigênio tipo amperométrico.

O oxigênio é bombeado pelo canal de difusão por meio da aplicação de um potencial externo na célula eletroquímica, resultando uma corrente iônica (I) que atravessa o eletrólito sólido e transporta um fluxo de oxigênio (J), segundo a lei de Faraday, Equação (2).

$J=I / z F$

na qual $z$ é a valência do cátion do composto e $F$ a constante de Faraday ( 96485 C/gmol). 


\subsubsection{Sensores de oxigênio potenciométricos}

São caracterizados pela utilização de dois eletrodos, o de trabalho (ou do meio a ser medido) e o de referência. As Figuras 3 e 4 mostram a foto de um sensor do tipo potenciométrico e o seu esquema elétrico de funcionamento, respectivamente.

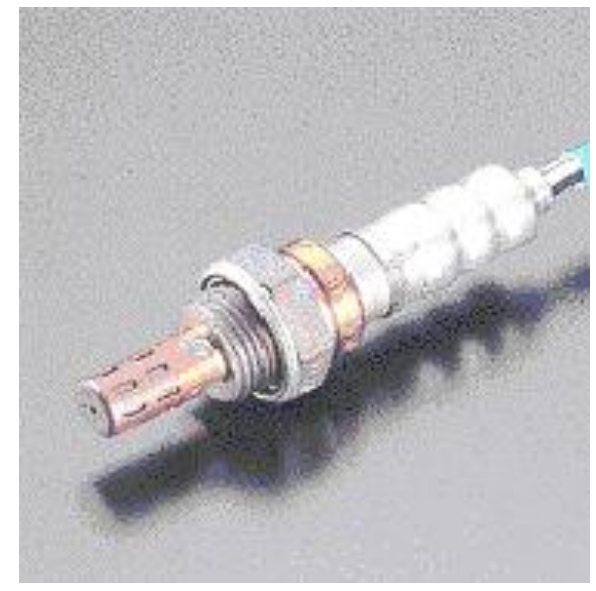

Figura 3 - Foto de um sensor potenciométrico de uso automotivo ${ }^{[32]}$.

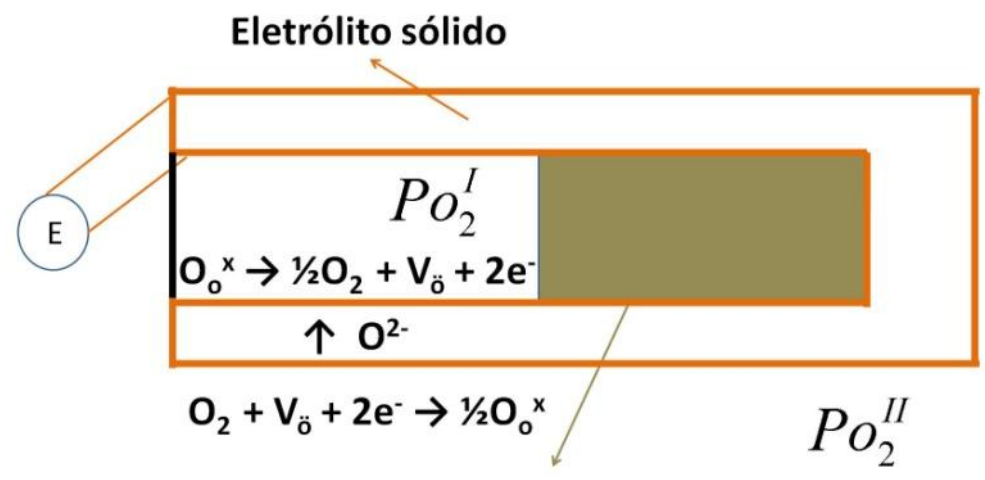

Eletrodo de referência

Figura 4 - Esquema elétrico de um sensor potenciométrico comercial.

Os sensores de oxigênio comerciais são em sua maioria do tipo potenciométrico. Esses sensores estão sujeitos à lei de Nernst, Equação (3). $E=R T / 4 F \ln \left(\mathrm{Po}_{2}^{I} / \mathrm{Po}_{2}^{I I}\right)$

na qual $R$ é a constante universal dos gases $(8,314 \mathrm{~J} / \mathrm{mol} . \mathrm{K}), T$ a temperatura absoluta (K), $\mathrm{F}$ a constante de Faraday ( $96485 \mathrm{C} / \mathrm{gmol}), \mathrm{Po}_{2}^{I}$ a pressão parcial de oxigênio no eletrodo de referência, e $P O_{2}^{I I}$ a pressão parcial de oxigênio no eletrodo a ser medido. 
Neste sensor, as substâncias químicas óxidas em contato com a superfície catalítica perdem 2 elétrons do elemento oxigênio, transformando-se em íons de oxigênio; estes íons atravessam o eletrólito por meio das vacâncias de oxigênio, atingindo a superfície catalítica interna do sensor, onde se recombinam novamente com 2 elétrons, formando novamente o oxigênio molecular. Esta reação pode ser melhor descrita pela notação de Kröger-Vink, Equação (4).

$O_{2}+2 V_{o}^{*}+4 e^{\prime} \leftrightarrow 2 O_{o}^{x}$

\subsection{SínTESE PELA TÉCNICA DE REAÇÃO DE ESTADO SÓLIDO}

A síntese pela técnica de reação de estado sólido para materiais multicomponentes consiste na reação entre óxidos e/ou carbonatos, moagem, mistura e tratamento térmico em temperaturas relativamente altas, próximas dos pontos de fusão dos componentes, podendo decompor o material final ${ }^{[33]}$. Esta técnica de síntese de materiais necessita que as partículas estejam em contato efetivo, e que a distribuição dos reagentes seja homogênea, para um produto final quimicamente homogêneo ${ }^{[34]}$. Entretanto, possui como desvantagens a formação de fases indesejadas, devido ao desvio estequiométrico associado ao uso de altas temperaturas, baixa homogeneidade química e possível presença de contaminantes adquiridos durante o processo de mistura e moagem ${ }^{[33]}$. Como vantagens, a técnica possui baixo custo de materiais de partida, facilidade de preparo e possibilidades de preparo de grandes quantidades, se comparada com as rotas químicas.

\subsection{SÍNTESE PELA TÉCNICA DOS PRECURSORES POLIMÉRICOS}

A técnica dos precursores poliméricos para a formação da estrutura orgânica foi apresentada na patente de M. P. Pechini ${ }^{[35]}$.

O principal objetivo da técnica dos precursores poliméricos é a preparação de uma solução precursora homogênea a partir da qual um gel pode ser obtido com homogeneidade em nível atômico ${ }^{[36]}$. Técnicas químicas de síntese, como a dos precursores poliméricos, apresentam vantagens e desvantagens devido aos princípios químicos envolvidos ${ }^{[37]}$, sendo as 
principais vantagens a homogeneidade química, o controle da composição e a versatilidade para síntese de multicomponentes ${ }^{[33]}$, e como desvantagens a eliminação de grandes quantidades de orgânicos e a pequena quantidade de material resultante quando comparado ao processo de reação de estado sólido, devido à limitação de vidrarias e fornos usados durante o processo ${ }^{[33]}$.

Uma das formas de garantir a homogeneidade da solução dos cátions é o uso de solventes que possam ser removidos, deixando um material amorfo; durante este processo, qualquer tipo de precipitação deve ser evitado, não comprometendo a homogeneidade da solução inicial ${ }^{[36]}$.

O método tradicional para o preparo de compostos baseado em reação de estado sólido está relacionado às altas temperaturas para formação de fase e sinterização, podendo produzir pós cerâmicos não homogêneos e geralmente com tamanho micrométrico de partículas ${ }^{[12]}$. A diminuição no tamanho de partículas de micrométrico para nanométrico pode melhorar as características elétricas de materiais tipo $\mathrm{ABO}_{3}{ }^{[38]}$. $\mathrm{Na}$ tentativa de diminuir o tamanho de partículas para uma escala nanométrica, o material em escala micrométrica pode ser submetido ao processo de moagem, que pode introduzir impurezas. A síntese de materiais em escala nanométrica por rotas químicas tem sido uma boa opção para obtenção de materiais mais homogêneos ${ }^{[12]}$.

Neste trabalho, a preparação dos materiais $\mathrm{Ca}_{x} \mathrm{Sr}_{1-x} \mathrm{Ti}_{0,65} \mathrm{Fe}_{0,35} \mathrm{O}_{3-\delta}$, $x=0,0,5$, e 1 , foi feita por meio de duas técnicas, reação de estado sólido e dos precursores poliméricos, os teores de titânio e ferro utilizados baseiam-se em trabalhos que estudaram $\mathrm{SrTi}_{1-x} \mathrm{Fe}_{x} \mathrm{O}_{3-\delta}$, chegando a conclusão que para $x=0,35$ a composição é altamente dependente do teor de oxigênio e praticamente independente da temperatura, para a faixa de temperatura $750-950^{\circ} \mathrm{C}^{[2]}$. 


\section{OBJETIVOS}

\subsection{OBJETIVO GERAL}

Avaliar a possibilidade de utilização dos compactos sinterizados de compostos à base de soluções sólidas de titanato de estrôncio, titanato de cálcio e óxido de ferro, em dispositivos sensores de oxigênio.

\subsubsection{OBJETIVOS ESPECÍFICOS}

Sintetizar diferentes composições à base de $\mathrm{SrTiO}_{3}$ e $\mathrm{CaTiO}_{3}$ dopados com ferro.

Analisar os pós cerâmicos dessas composições por difração de raios $X$, microscopia eletrônica de varredura, microscopia eletrônica de transmissão e análise térmica.

Preparar compactos cerâmicos sinterizados densos dessas composições. Caracterizar esses compactos por meio de difração de raios $\mathrm{X}$, microscopia de varredura por sonda e espectroscopia de impedância.

Avaliar a resposta elétrica desses compactos sob oxigênio. 


\section{EXPERIMENTAL}

Neste capítulo serão apresentadas as técnicas usadas para o preparo do material $\mathrm{Ca}_{\mathrm{x}} \mathrm{Sr}_{1-\mathrm{x}} \mathrm{Ti}_{0,65} \mathrm{Fe}_{0,35} \mathrm{O}_{3-\delta}, \quad \mathrm{x}=0,0,5$, e 1, algumas características físico-químicas dos materiais de partida ${ }^{[39,40]}$, análises dos materiais resultantes pelas técnicas de reação de estado sólido ${ }^{[41,42,43]}$ e precursores poliméricos ${ }^{[35]}$.

\subsection{Preparação das amostras}

Foram utilizadas as técnicas de reação de estado sólido ${ }^{[41,42,43]}$ e precursores poliméricos ${ }^{[35]}$, descritas a seguir:

\subsubsection{TÉCNICA DE REAÇÃO DE ESTADO SÓLIDO}

Os materiais de partida $\mathrm{CaCO}_{3}, \mathrm{SrCO}_{3}, \mathrm{TiO}_{2}$ e $\mathrm{Fe}_{2} \mathrm{O}_{3}$ foram secos em estufa a $60{ }^{\circ} \mathrm{C} / 30 \mathrm{~min}$, pesados conforme cálculo estequiométrico, misturados em meio alcoólico (álcool isopropílico) em um misturador mecânico tipo túrbula por $120 \mathrm{~min}$. Após, o material foi seco em estufa a $60{ }^{\circ} \mathrm{C} / 4$ dias, sendo desagregado em almofariz de ágata por $\sim 20 \mathrm{~min}$. Foi feito tratamento térmico com patamar de $1250{ }^{\circ} \mathrm{C} / 15 \mathrm{~h}^{[5]}$, sendo as taxas de subida e descida $5^{\circ} \mathrm{C} / \mathrm{min}$; após, o material foi desagregado em almofariz de ágata até a obtenção de um pó visualmente homogêneo e fino, sendo retiradas alíquotas para análise de difração de raios $X$. O restante do material foi compactado uniaxialmente a $100 \mathrm{MPa} / 15 \mathrm{~s}$ e isostaticamente a $207 \mathrm{MPa} / 5 \mathrm{~min}$. Foi determinada a densidade geométrica aparente a verde. Os corpos de prova foram sinterizados a $1300{ }^{\circ} \mathrm{C} / 2 \mathrm{~h}$, com taxas de subida e descida $5^{\circ} \mathrm{C} / \mathrm{min}$.

Foram feitas análises de difração de raios $X$, determinação da densidade hidrostática, microscopia eletrônica de varredura e medidas de espectroscopia de impedância.

A seqüência para obtenção dos corpos de prova por reação de estado sólido é mostrada na Figura 5. 


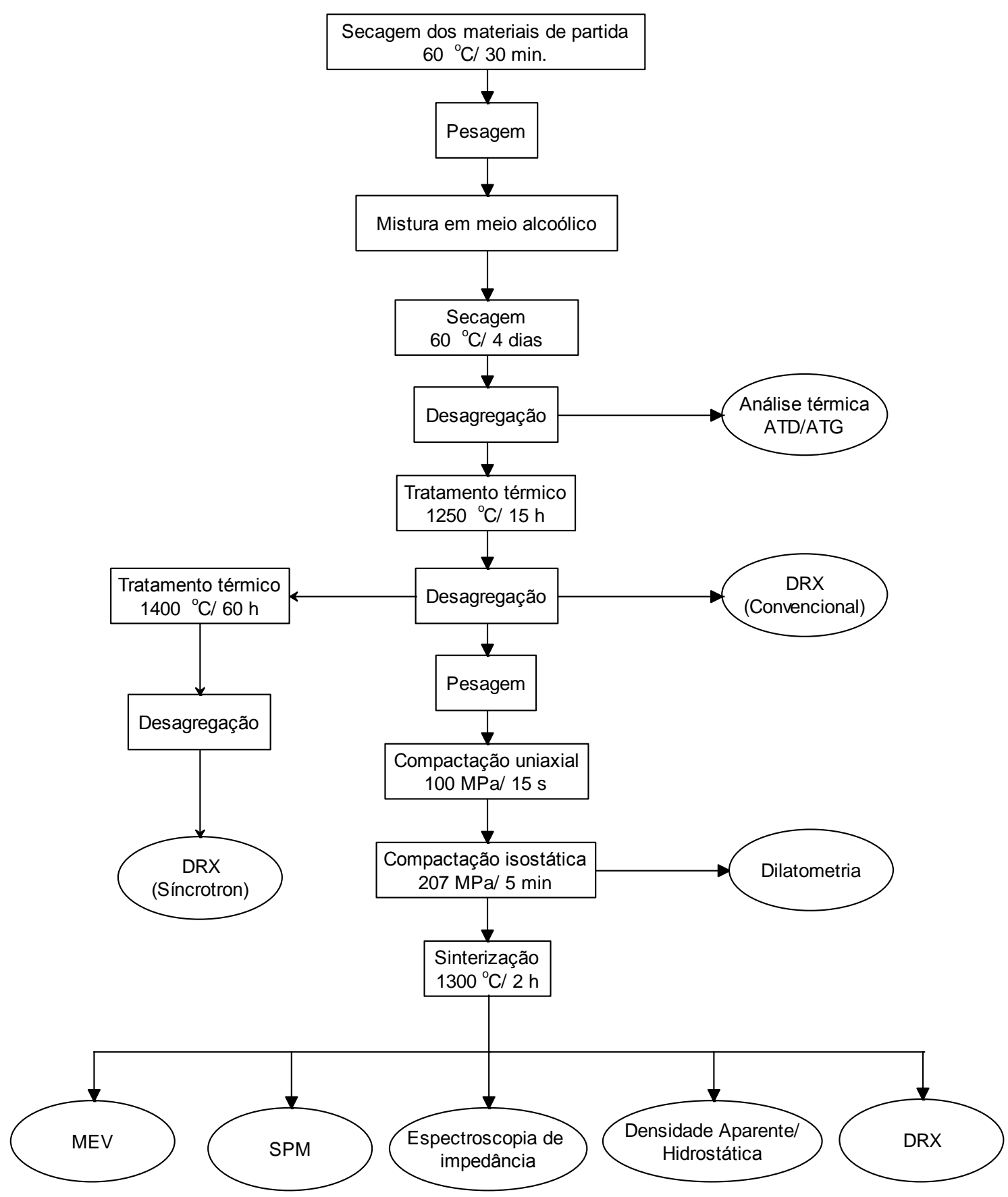

Figura 5 - Fluxograma para obtenção e caracterização dos materiais $\mathrm{CaTi}_{0,65} \mathrm{Fe}_{0,35} \mathrm{O}_{3-\delta}$, $\mathrm{Ca}_{0,5} \mathrm{Sr}_{0,5} \mathrm{Ti}_{0,65} \mathrm{Fe}_{0,35} \mathrm{O}_{3-\delta}$ e $\mathrm{SrTi}_{0,65} \mathrm{Fe}_{0,35} \mathrm{O}_{3-\delta}$, por reação de estado sólido. ATD: análise térmica diferencial; ATG: Análise termogravimétrica; DRX: difração de raios X; MEV: microscopia eletrônica de varredura; SPM: microscopia de varredura por sonda 


\subsubsection{TÉCNICA DOS PRECURSORES POLIMÉRICOS}

Para a produção de $\mathrm{SrTi}_{0,65} \mathrm{Fe}_{0,35} \mathrm{O}_{3-\delta}, \quad \mathrm{Ca}_{0,5} \mathrm{Sr}_{0,5} \mathrm{Ti}_{0,65} \mathrm{Fe}_{0,35} \mathrm{O}_{3-\delta}$ e $\mathrm{CaTi}_{0,65} \mathrm{Fe}_{0,35} \mathrm{O}_{3-\delta}$, pela técnica dos precursores poliméricos, foram utilizados $\mathrm{CaCO}_{3}, \mathrm{SrCO}_{3}, \mathrm{C}_{12} \mathrm{H}_{28} \mathrm{O}_{4} \mathrm{Ti}$ (isopropóxido de titânio) e $\mathrm{Fe}\left(\mathrm{NO}_{3}\right)_{3.9} \mathrm{H}_{2} \mathrm{O}$. Algumas das características podem ser vistas na Tabela 1.

\begin{tabular}{|c|c|c|c|c|c|}
\hline Material & Fórmula & Cor & $\begin{array}{l}\text { Estrutura } \\
\text { cristalina }\end{array}$ & $\begin{array}{l}\text { Densidade } \\
\left(\mathrm{g} / \mathrm{cm}^{3}\right)\end{array}$ & $\begin{array}{l}\text { Temperatura } \\
\text { de fusão } \\
\left({ }^{\circ} \mathrm{C}\right)\end{array}$ \\
\hline $\begin{array}{l}\text { Carbonato de } \\
\text { estrôncio }\end{array}$ & $\mathrm{SrCO}_{3}$ & branca & ortorrômbica & 3,70 & 1100 \\
\hline $\begin{array}{l}\text { Oxido de } \\
\text { titânio IV }\end{array}$ & $\mathrm{TiO}_{2}$ & branca & triclínica & 4,95 & 1830 \\
\hline $\begin{array}{l}\text { Carbonato de } \\
\text { cálcio }\end{array}$ & $\mathrm{CaCO}_{3}$ & branca & romboédrica & 2,93 & 800 \\
\hline $\begin{array}{l}\text { Oxido de } \\
\text { ferro III }\end{array}$ & $\mathrm{Fe}_{2} \mathrm{O}_{3}$ & vermelha & romboédrica & 5,20 & 1538 \\
\hline $\begin{array}{l}\text { Isopropóxido } \\
\text { de titânio IV }\end{array}$ & $\mathrm{C}_{12} \mathrm{H}_{28} \mathrm{O}_{4} \mathrm{Ti}$ & incolor & & 0,96 & - \\
\hline $\begin{array}{l}\text { Nitrato de } \\
\text { ferro III }\end{array}$ & $\mathrm{Fe}\left(\mathrm{NO}_{3}\right)_{3.9} \mathrm{H}_{2} \mathrm{O}$ & vermelha & - & 1,68 & 47,20 \\
\hline
\end{tabular}

Os materiais de partida foram dissolvidos separadamente em solução ácida, sendo a proporção utilizada de 20 partes de água para 1 parte de $\mathrm{HNO}_{3}$ sob forte agitação 20 min.

Após todos os materiais de partida estarem totalmente dissolvidos em solução ácida, com aspecto transparente e suave coloração típica de cada material, foram todos adicionados em um mesmo béquer para homogeneização, permanecendo sob forte agitação por 30 min. Após esta etapa, os materiais de partida foram adicionados lentamente a uma solução de ácido cítrico e etileno glicol, sendo a razão molar desta solução de $1 \mathrm{~mol}$ de metal para 3 moles de ácido cítrico e 6 moles de etileno glicol, permanecendo sob agitação 30 min. Posteriormente a solução foi aquecida em chapa aquecedora com agitador magnético para a formação da solução em forma de gel, Figura 6 (a), (c) e (e) e na Figura 6 (b), (d) e (f), o aspecto dos materiais 
$\mathrm{SrTi}_{0,65} \mathrm{Fe}_{0,35} \mathrm{O}_{3-\delta}, \mathrm{Ca}_{0,5} \mathrm{Sr}_{0,5} \mathrm{Ti}_{0,65} \mathrm{Fe}_{0,35} \mathrm{O}_{3-\delta}$ e $\mathrm{CaTi}_{0,65} \mathrm{Fe}_{0,35} \mathrm{O}_{3-\delta}$, após a primeira queima.

Material na forma de sol-gel

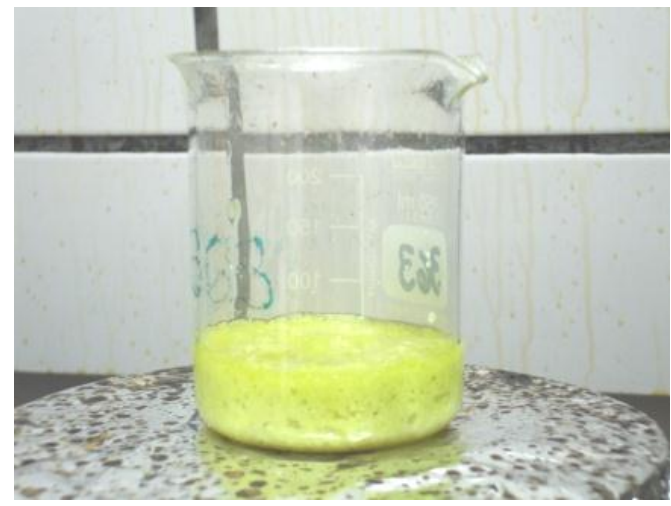

(a) $\mathrm{SrTi}_{0,65} \mathrm{Fe}_{0,35} \mathrm{O}_{3-\delta}$

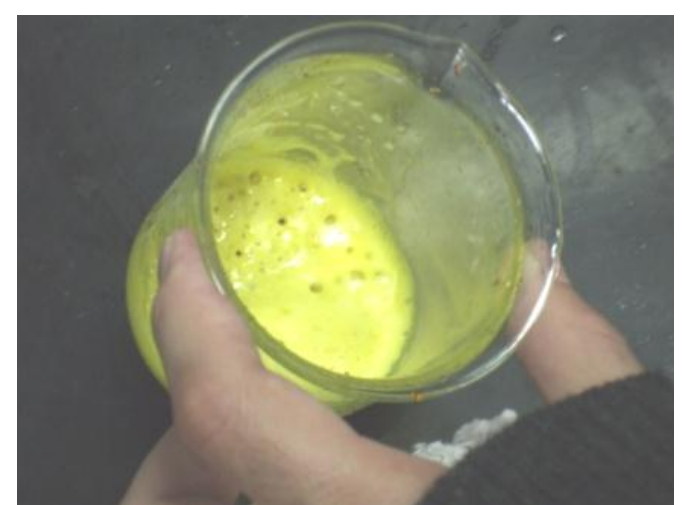

(c) $\mathrm{Ca}_{0,5} \mathrm{Sr}_{0,5} \mathrm{Ti}_{0,65} \mathrm{Fe}_{0,35} \mathrm{O}_{3-\delta}$

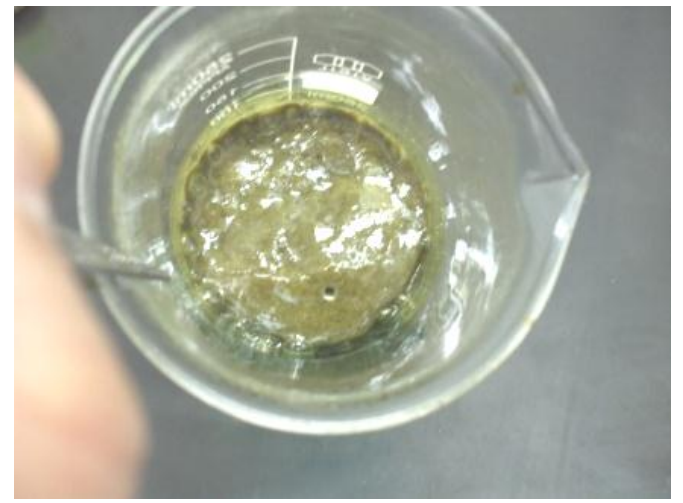

(e) $\mathrm{CaTi}_{0,65} \mathrm{Fe}_{0,35} \mathrm{O}_{3-\delta}$
Após primeira queima

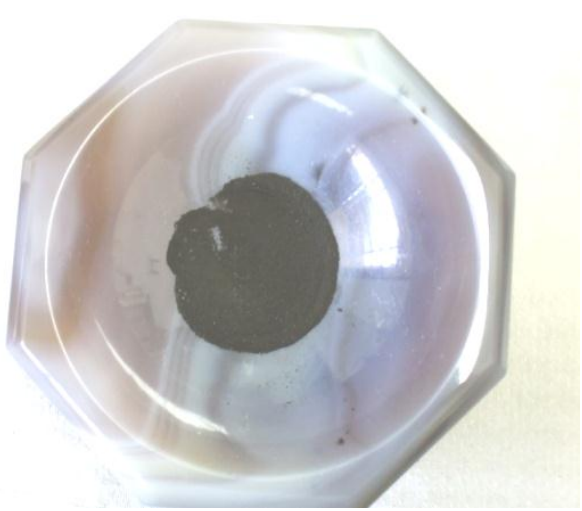

(b) $\mathrm{SrTi}_{0,65} \mathrm{Fe}_{0,35} \mathrm{O}_{3-\delta}$

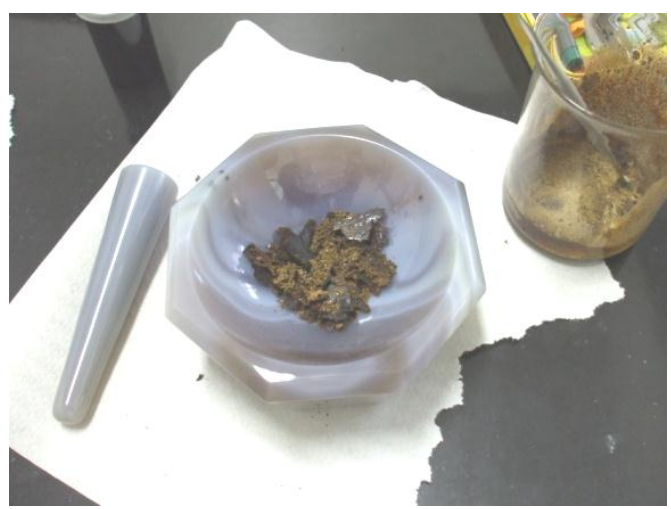

(d) $\mathrm{Ca}_{0,5} \mathrm{Sr}_{0,5} \mathrm{Ti}_{0,65} \mathrm{Fe}_{0,35} \mathrm{O}_{3-\delta}$

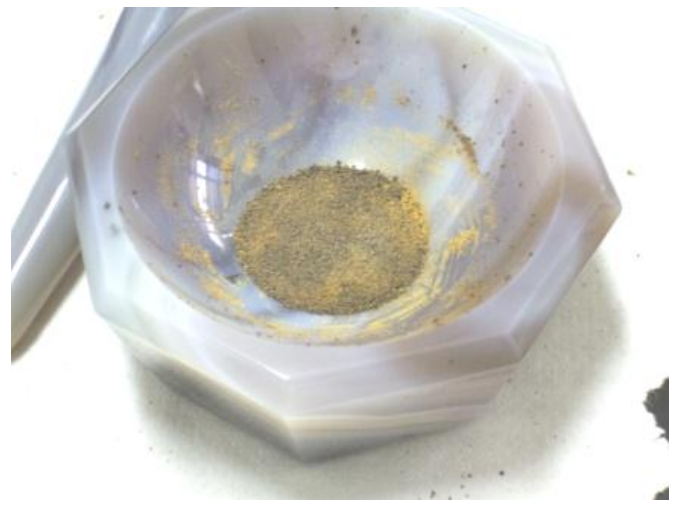

(f) $\mathrm{CaTi}_{0,65} \mathrm{Fe}_{0,35} \mathrm{O}_{3-\delta}$

Figura 6 - (a), (c) e (e) Materiais $\mathrm{SrTi}_{0,65} \mathrm{Fe}_{0,35} \mathrm{O}_{3-\delta}, \mathrm{Ca}_{0,5} \mathrm{Sr}_{0,5} \mathrm{Ti}_{0,65} \mathrm{Fe}_{0,35} \mathrm{O}_{3-\delta}$ e $\mathrm{CaTi}_{0,65} \mathrm{Fe}_{0,35} \mathrm{O}_{3-\delta}$, respectivamente na forma de sol-gel e (b), (d) e (f) aspecto dos mesmos materiais após primeira queima. 
Após a obtenção do gel, um termoplástico altamente viscoso ${ }^{[44]}$, foi feita a primeira queima a $200{ }^{\circ} \mathrm{C} / 2 \mathrm{~h}+250{ }^{\circ} \mathrm{C} / 2 \mathrm{~h}+300{ }^{\circ} \mathrm{C} / 2 \mathrm{~h}$, com taxa de aquecimento $15{ }^{\circ} \mathrm{C} / \mathrm{min}$, sendo o material removido do béquer. A segunda queima foi feita na temperatura de formação de fase de cada composto, determinada pelos resultados de análise térmica diferencial. $O$ tempo de patamar foi $5 \mathrm{~h}$ e taxa de aquecimento de $5^{\circ} \mathrm{C} / \mathrm{min}$.

A Figura 7 (a) mostra fotos de $\mathrm{SrTi}_{0,65} \mathrm{Fe}_{0,35} \mathrm{O}_{3-\delta}$ e $\mathrm{CaTi}_{0,65} \mathrm{Fe}_{0,35} \mathrm{O}_{3-\delta}$, na forma de sol-gel e a Figura 7 (b) mostra a configuração utilizada para obtenção dos materiais $\mathrm{SrTi}_{0,65} \mathrm{Fe}_{0,35} \mathrm{O}_{3-\delta}, \mathrm{Ca}_{0,5} \mathrm{Sr}_{0,5} \mathrm{Ti}_{0,65} \mathrm{Fe}_{0,35} \mathrm{O}_{3-\delta}$ e $\mathrm{CaTi}_{0,65} \mathrm{Fe}_{0,35} \mathrm{O}_{3-\delta}$, pela técnica dos precursores poliméricos.

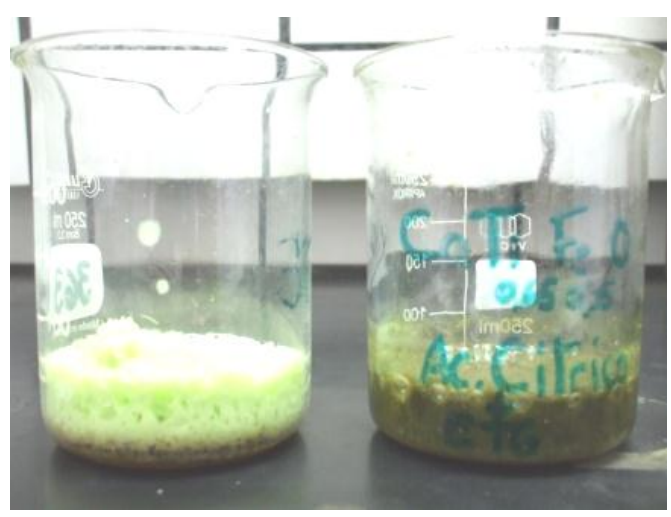

(a) Fotos de $\mathrm{SrTi}_{0,65} \mathrm{Fe}_{0,35} \mathrm{O}_{3-\delta} \mathrm{e}$ $\mathrm{CaTi}_{0,65} \mathrm{Fe}_{0,35} \mathrm{O}_{3-\delta}$

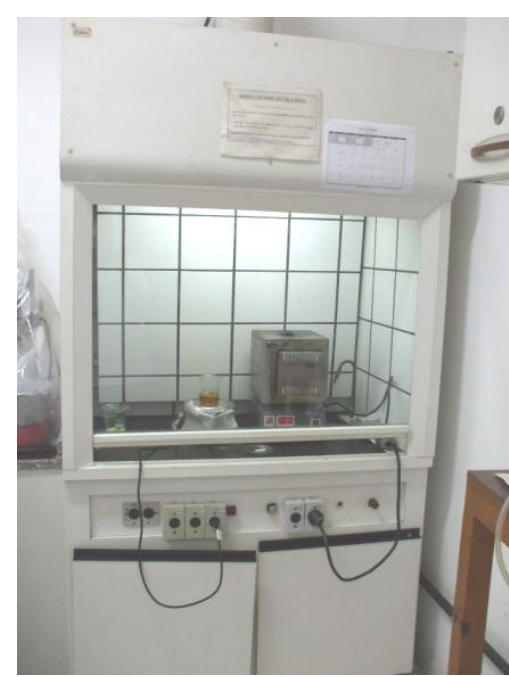

(b) Configuração utilizada para produção de $\mathrm{SrTi}_{0,65} \mathrm{Fe}_{0,35} \mathrm{O}_{3-\delta}$ e $\mathrm{CaTi}_{0,65} \mathrm{Fe}_{0,35} \mathrm{O}_{3-\delta}$ pela técnica dos precursores poliméricos

Figura 7 - (a) Aspecto dos materiais $\mathrm{SrTi}_{0,65} \mathrm{Fe}_{0,35} \mathrm{O}_{3-\delta}$ e $\mathrm{CaTi}_{0,65} \mathrm{Fe}_{0,35} \mathrm{O}_{3-\delta}$ na forma de sol-gel e (b) configuração de laboratório utilizada para produção dos materiais pela técnica dos precursores poliméricos.

O $\mathrm{SrTi}_{0,65} \mathrm{Fe}_{0,35} \mathrm{O}_{3-\delta}$ possui um aspecto aerado, com coloração verde clara; já o $\mathrm{CaTi}_{0,65} \mathrm{Fe}_{0,35} \mathrm{O}_{3-\delta}$ apresenta aspecto denso e coloração verde escuro. A configuração utilizada no laboratório: capela, chapa aquecedora com agitador magnético e forno, onde os materiais foram sintetizados é mostrada na Figura 7 (b).

Foram retiradas alíquotas do material para análise de difração de raios $\mathrm{X}$, e conformados corpos de prova para análise dilatométrica. $\mathrm{O}$ restante 
do material foi compactado uniaxialmente a $100 \mathrm{MPa} / 15 \mathrm{~s}$, seguida de compactação isostática a $207 \mathrm{MPa} / 5 \mathrm{~min}$. Foi determinada a densidade geométrica aparente a verde. Os compactos foram sinterizados a $1300^{\circ} \mathrm{C} / 2 \mathrm{~h}$, com taxas de aquecimento e resfriamento $5^{\circ} \mathrm{C} / \mathrm{min}$.

Após a obtenção dos corpos de prova sinterizados, foram feitas análises de difração de raios $X$, determinação da densidade hidrostática, densidade aparente, microscopia eletrônica de varredura, microscopia eletrônica de transmissão, microscopia de varredura por sonda, espectroscopia de impedância.

A seqüência para obtenção dos corpos de prova pela técnica dos precursores poliméricos é mostrada na Figura 8.

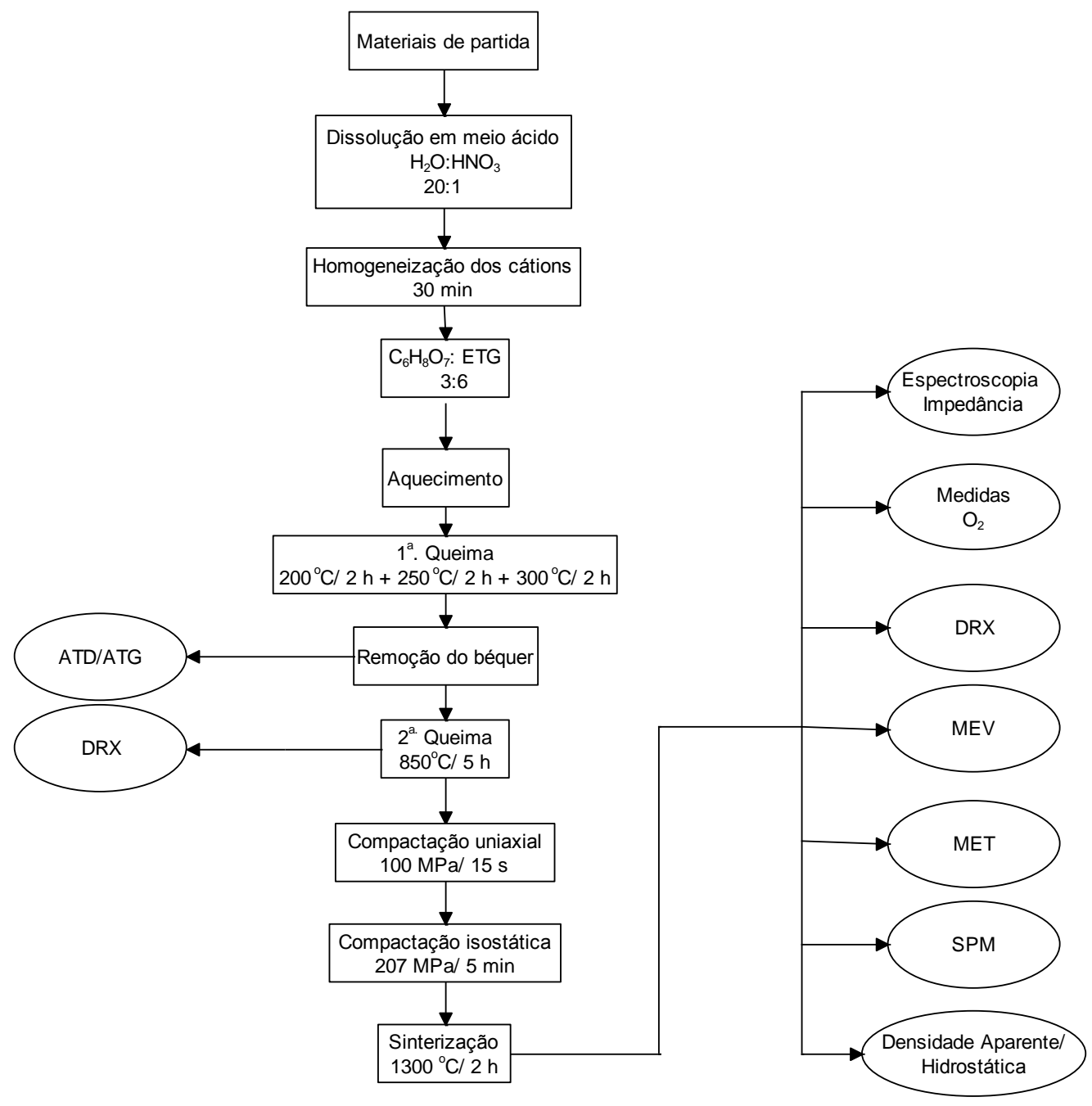

Figura 8 - Fluxograma para obtenção e caracterização de $\operatorname{SrTi}_{0,65} \mathrm{Fe}_{0,35} \mathrm{O}_{3-\delta}$, $\mathrm{Ca}_{0,5} \mathrm{Sr}_{0,5} \mathrm{Ti}_{0,65} \mathrm{Fe}_{0,35} \mathrm{O}_{3-\delta}$ e $\mathrm{CaTi}_{0,65} \mathrm{Fe}_{0,35} \mathrm{O}_{3-\delta}$ pela técnica dos precursores poliméricos. ETG: etilenoglicol; ATD: análise térmica diferencial; ATG: análise termogravimétrica; DRX: difração de raios X; MEV: microscopia eletrônica de varredura; MET: microscopia eletrônica de transmissão; SPM: microscopia eletrônica de varredura por sonda. 


\subsection{COMPOSIÇÕES}

As composições obtidas por reação de estado sólido e pelo método dos precursores poliméricos foram: $\mathrm{SrTi}_{0,65} \mathrm{Fe}_{0,35} \mathrm{O}_{3-\delta}, \quad \mathrm{Ca}_{0,5} \mathrm{Sr}_{0,5} \mathrm{Ti}_{0,65} \mathrm{Fe}_{0,35} \mathrm{O}_{3-\delta}$, $\mathrm{CaTi}_{0,65} \mathrm{Fe}_{0,35} \mathrm{O}_{3-\delta}, \mathrm{SrTiO}_{3}, \mathrm{Ca}_{0,5} \mathrm{Sr}_{0,5} \mathrm{TiO}_{3}$ e $\mathrm{CaTiO}_{3}$,

\subsection{CARACTERIZAÇÃO}

Os materiais $\mathrm{Ca}_{\mathrm{x}} \mathrm{Sr}_{1-\mathrm{x}} \mathrm{Ti}_{0,65} \mathrm{Fe}_{0,35} \mathrm{O}_{3-\delta}, \mathrm{x}=0,0,5$ e 1, foram caracterizados por meio de densidade hidrostática, difração de raios $X$ e determinação de tamanho médio de partícula/aglomerado, análise termogravimétrica e térmica diferencial, dilatometria, microscopia eletrônica de transmissão, microscopia eletrônica de varredura, microscopia de varredura por sonda, espectroscopia de impedância e medidas de pressão parcial de oxigênio.

\subsection{TAMANHO MÉDIO DE PARTÍCULA/AGLOMERADO}

O tamanho médio das partículas dos óxidos e carbonatos de partida pode ser visto na Tabela 2. Foram determinados pelo método de espalhamento laser com o equipamento Cilas 1064, que permite a determinação do tamanho de partículas entre 0,1 e $500 \mu \mathrm{m}$.

Tabela 2 - Tamanho médio equivalente dos materiais de partida utilizados para a produção de $\mathrm{Ca}_{\mathrm{x}} \mathrm{Sr}_{1-\mathrm{x}} \mathrm{Ti}_{0,65} \mathrm{Fe}_{0,35} \mathrm{O}_{3-\delta}, \mathrm{x}=0,0,5$ e 1

\begin{tabular}{lll}
\hline Material & Fórmula & $\begin{array}{l}\text { Diâmetro médio } \\
\text { equivalente }(\mu \mathrm{m})\end{array}$ \\
\hline
\end{tabular}

Carbonato de

estrôncio

$\mathrm{SrCO}_{3}$

4,5

Oxido de

titânio IV

$\mathrm{TiO}_{2}$

0,5

Carbonato de

cálcio

$\mathrm{CaCO}_{3}$

27,0

Oxido de

ferro III

$\mathrm{Fe}_{2} \mathrm{O}_{3}$

16,5 


\subsection{DENSIDADE GEOMÉTRICA APARENTE}

A densidade geométrica foi determinada por meio das medidas das dimensões (micrômetro Tesa) dos corpos de prova e das massas (balança analítica Mettler - Toledo AB204).

\subsection{DENSIDADE HIDROSTÁTICA}

A densidade hidrostática foi determinada pelo princípio de Arquimedes. As amostras foram fervidas em água destilada por $2 \mathrm{~h}$, resfriadas ao ar, verificadas suas massas em balança analítica Mettler - Toledo AG245, secas em estufa a $100{ }^{\circ} \mathrm{C} / 4 \mathrm{~h}$, resfriadas ao ar e pesadas novamente para determinação da massa seca. Esses dados são relacionados com a densidade da água na temperatura medida conforme Equação (5).

$\mathrm{d}_{\mathrm{h}}=\left[\mathrm{m}_{\mathrm{s}} /\left(\mathrm{m}_{\mathrm{u}}-\mathrm{m}_{\mathrm{i}}\right)\right] \cdot \mathrm{d}_{\mathrm{H}_{2} \mathrm{O}}$

na qual $d_{h}$ é a densidade hidrostática $\left(\mathrm{g} / \mathrm{cm}^{3}\right), m_{s}$ a massa seca, $m_{u}$ a massa úmida $(\mathrm{g}), \mathrm{m}_{\mathrm{i}}$ a massa imersa $(\mathrm{g}), \mathrm{d}_{\mathrm{H}_{2} \mathrm{O}}$ a densidade da água na temperatura de medida $\left(\mathrm{g} / \mathrm{cm}^{3}\right)$.

\subsection{DifraÇÃo de RAIOS $X$}

\subsubsection{DiFRAÇÃO DE RAIOS X CONVENCIONAL}

Foram feitas análises de difração de raios $X$ dos compostos $\mathrm{Ca}_{x} \mathrm{Sr}_{1-\mathrm{x}} \mathrm{Ti}_{0,65} \mathrm{Fe}_{0,35} \mathrm{O}_{3-\delta}, \mathrm{x}=0,0,5$ e 1, em amostras na forma de pó e na superfície plana dos corpos de prova cilíndricos. $O$ equipamento usado foi um difratômetro de raios X Bruker-AXS modelo D8 Advance, com radiação Cuka, faixa de $2 \theta 15-90^{\circ}$, passo de $0,05^{\circ}$ e tempo por passo $5 \mathrm{~s}$, sem monocromador, o que justifica o deslocamento da linha base (background) devido à fluorescência de raios $X$ do elemento $F e$, mostrado nas figuras 37,38 e 39, página 55. Para a determinação dos parâmetros de rede foi utilizado o método de Rietveld, implementado no software GSAS/EXPGUI ${ }^{[45,46]}$ 


\subsubsection{DifRAÇÃo DE RAIOS X COM FONTE SínCROTRON}

As medidas de difração de raios $\mathrm{X}$ com fonte Síncrotron foram feitas no LNLS (Laboratório Nacional de Luz Síncrotron), na estação XPD em configuração de alta resolução, com analisador de Ge 111, e comprimento de onda $\lambda=1,2400360 \AA$. Os compostos analisados foram os obtidos por reação de estado sólido para as composições $\mathrm{Ca}_{x} \mathrm{Sr}_{1-\mathrm{x}} \mathrm{Ti}_{0,65} \mathrm{Fe}_{0,35} \mathrm{O}_{3-\delta}, \mathrm{x}=0$, 0,5 e 1 na forma de pó com dois tratamentos térmicos $1250{ }^{\circ} \mathrm{C} / 15 \mathrm{~h}+1400{ }^{\circ} \mathrm{C} / 60 \mathrm{~h}$.

\subsection{ReFINAMENTO DA ESTRUTURA E PARÂMETROS DE REDE}

Foram feitos refinamentos pelo método de Rietveld usando-se o programa GSAS/EXPGUI [45,46]; com isso confirmou-se a simetria cristalina e os parâmetros da rede.

\subsubsection{MÉTOdO DE RIETVELD}

Hugo M. Rietveld ${ }^{[47]}$ no final da década de 1960 desenvolveu um método para refinamento de estruturas cristalinas a partir de dados de difração de nêutrons por policristais, baseado na comparação entre os dados de difratograma calculado e um padrão medido.

Este método consiste em obter-se um padrão de difração representado por funções analíticas e ajustá-los contra um padrão medido, utilizando-se do método dos mínimos quadrados. Pelo fato do processo ser interativo, ou seja, a cada ciclo as funções analíticas serem alteradas, diz-se refinadas. Ao atingir um ajuste aceitável entre os difratogramas medido e calculado, admite-se que a estrutura do material em medida é a estrutura do material que serviu como padrão ${ }^{[48]}$.

Originalmente o método foi desenvolvido para difratogramas de nêutrons; na década de 1970 o método foi adaptado para difratogramas obtidos por raios X, por Young e seu grupo, no School of Physics - Institute of Technology ${ }^{[49,50]}$. A importância da técnica cresce ano após ano, mostrando que pode ser usada na determinação quantitativa de fases, ajuste de parâmetros de cela unitária, estudos estruturais, caracterização física como 
determinação do tamanho de cristalito, microdeformações, formação de vacâncias, posições atômicas e fatores de ocupação atômica ${ }^{[48,51,52]}$.

\subsection{ANÁLISE TÉRMICA}

\subsubsection{ANÁLISE TERMOGRAVIMÉTRICA E TÉRMICA DIFERENCIAL}

Foram feitas análise termogravimétrica para a verificação de variação de massa e análise térmica diferencial para verificação das reações durante o processo de formação de fases em função da temperatura; $\alpha-\mathrm{Al}_{2} \mathrm{O}_{3}$ foi usado como material de referência para as medidas de análise térmica diferencial.

As análises termogravimétrica e térmica diferencial foram feitas com as misturas de óxidos/carbonatos para os compostos $\mathrm{Ca}_{x} \mathrm{Sr}_{1-\mathrm{x}} \mathrm{Ti}_{0,65} \mathrm{Fe}_{0,35} \mathrm{O}_{3-\delta,} \mathrm{x}=0$, 0,5 , e 1. O equipamento utilizado foi Netzsch STA 409E, com taxa de aquecimento $5{ }^{\circ} \mathrm{C} / \mathrm{min}$ até $1500{ }^{\circ} \mathrm{C}$, taxa de resfriamento $20{ }^{\circ} \mathrm{C} / \mathrm{min}$, e atmosfera de ar sintético. As curvas termogravimétrica e térmica diferencial foram analisadas com o software Proteus Analysis ${ }^{[53]}$.

\subsubsection{DILATOMETRIA}

O estudo dilatométrico foi feito em dilatômetro Netzsch modelo 402C.

Para análise dilatométrica foram usados corpos de prova compactados de $\mathrm{Ca}_{x} \mathrm{Sr}_{1-\mathrm{x}} \mathrm{Ti}_{0,65} \mathrm{Fe}_{0,35} \mathrm{O}_{3-\delta}, \mathrm{x}=0,0,5$, e 1, com taxa de aquecimento $5{ }^{\circ} \mathrm{C} / \mathrm{min}$ até $1500{ }^{\circ} \mathrm{C}, 15 \mathrm{~min}$ no patamar e taxa de resfriamento $15{ }^{\circ} \mathrm{C} / \mathrm{min}$, sob atmosfera ambiente.

\subsection{MICROSCOPIA ELETRÔNICA}

\subsubsection{MICROSCOPIA ELETRÔNICA DE TRANSMISSÃO}

Os pós cerâmicos de $\mathrm{Ca}_{\mathrm{x}} \mathrm{Sr}_{1-\mathrm{x}} \mathrm{Ti}_{0,65} \mathrm{Fe}_{0,35} \mathrm{O}_{3-\delta}, \mathrm{x}=0$, 0,5 e 1, obtidos pela técnica dos precursores poliméricos, após a segunda queima $\left(200{ }^{\circ} \mathrm{C} / 2 \mathrm{~h}+\right.$ $250{ }^{\circ} \mathrm{C} / 2 \mathrm{~h}+300{ }^{\circ} \mathrm{C} / 2 \mathrm{~h}$ ), e formação de fase cristalina $850{ }^{\circ} \mathrm{C} / 5 \mathrm{~h}$, foram analisados em microscópio eletrônico de transmissão Jeol modelo 2100, com tensão $200 \mathrm{kV}$. Com equipamento de ultra-som os materiais a serem examinados na forma de pó foram dispersos em água destilada, gotejado-se álcool isopropílico até a obtenção de uma suspensão. A suspensão ficou em 
repouso 15 min para que fossem depositadas partículas de maior densidade; o material na superfície da solução foi utilizado para análise, sendo gotejado em malha de cobre com 400 mesh revestida com grafite, e toda a malha com o material depositado foi recoberta por grafite pela técnica de sputtering. A malha foi retirada da lâmina para montagem no porta-amostras e análise no microscópio eletrônico de transmissão.

\subsubsection{MICROSCOPIA ELETRÔNICA DE VARREDURA}

Os compostos $\mathrm{Ca}_{\mathrm{x}} \mathrm{Sr}_{1-\mathrm{x}} \mathrm{Ti}_{0,65} \mathrm{Fe}_{0,35} \mathrm{O}_{3-\delta}, \mathrm{x}=0$, 0,5 e 1, obtidos por reação de estado sólido, na forma de pó foram observados em microscópio eletrônico de varredura Oxford Leo 4401. As amostras na forma de pó foram depositadas em porta-amostra contendo fita adesiva condutiva dupla face, cuja função é fixar no porta-amostra e permitir que o pó se fixe no lado a ser examinado; a função do grafite é descarregar o excesso de elétrons da amostra. A quantidade de material excedente foi retirada de forma a restar uma camada fina aderida na fita condutiva.

\subsubsection{MICROSCOPIA ELETRÔNICA DE VARREDURA POR SONDA}

Análises topográficas de superfícies polidas e atacadas termicamente foram feitas em microscópio de varredura por sonda (SPM - Scanning Probe Microscope) JEOL modelo 5200, operando em modo contacto, equipado com um transdutor piezoelétrico para varredura até $100 \mu \mathrm{m} \times 100 \mu \mathrm{m}$. As imagens são apresentadas como obtidas, isto é, sem tratamento das imagens. $O$ polimento foi feito sucessivamente com pós de carbeto de silício (granulometria 60) e pastas diamantadas de 30,15, 6, 3 e $1 \mu \mathrm{m}$. O ataque térmico foi feito a uma temperatura $100^{\circ} \mathrm{C}$ menor que a temperatura de sinterização, durante 20 min, com aumento e decréscimo de temperatura a $\sim 500^{\circ} \mathrm{C} / \mathrm{min}$. 


\subsection{COMPORTAMENTO ELÉTRICO}

\subsubsection{ESPECTROSCOPIA DE IMPEDÂNCIA}

Foram depositadas finas camadas de prata nas superfícies paralelas das pastilhas sinterizadas. Este eletrodo contribui de maneira insignificante para as medidas de impedância, não produzindo sobreposição no semicírculo na região de baixas freqüências. A impedância das amostras foi determinada na faixa de freqüências de $5 \mathrm{~Hz}$ até $13 \mathrm{MHz}$, com um sinal de $200 \mathrm{mV}$. Algumas medidas foram feitas aplicando-se 50, 100, 200 e $500 \mathrm{mV}$ para determinação da tensão na região de resposta linear, com melhor relação sinal/ruído. As medidas foram feitas na faixa de temperatura $300<\mathrm{T}(\mathrm{K})<500$ em atmosfera ambiente. Para cada medida de impedância a temperatura foi mantida constante com desvio de $0,5^{\circ} \mathrm{C}$. Os diagramas de impedância $\left[-Z^{\prime \prime}(\omega) \times Z^{\prime}(\omega)\right]$ foram deconvoluídos com um software especial para obtenção da resistência elétrica, capacitância específica, freqüências e ângulos de descentralização ${ }^{[54]}$ para os contornos de grão (cg) e os grãos (g).

Os gráficos de impedância que relacionam a parte imaginária com a parte real são semicírculos ou arcos de circunferência. Esta observação pode ser descrita matematicamente considerando um circuito elétrico característico composto por um circuito RC em paralelo, mostrado no Apendice B, página 95, Equação (6)

$$
\begin{gathered}
\underbrace{\left(\operatorname{Re}(Z)-\frac{R}{2}\right)^{2}}_{\downarrow}+\underbrace{\operatorname{Im}(Z)^{2}}_{\downarrow}=\left(\begin{array}{c}
\left.\frac{R}{2}\right)^{2} \\
\downarrow \\
(x-a)^{2}+(y-b)^{2}
\end{array}=r^{2}\right.
\end{gathered}
$$

sendo $\operatorname{Re}(Z)$ a parte real, $\operatorname{Im}(Z)$ a parte imaginária e $R$ a resistência; $(x-a)^{2}+(y-b)^{2}=r^{2}$ representa a equação da circunferência de raio $r$, centro em $(x, y)$, deslocada $(a, b)$.

As medidas elétricas dos compostos $\mathrm{Ca}_{\mathrm{x}} \mathrm{Sr}_{1-\mathrm{x}} \mathrm{Ti}_{0,65} \mathrm{Fe}_{0,35} \mathrm{O}_{3-\delta}, \quad \mathrm{x}=0,0,5$, e 1, foram feitas em câmara de inconel 600 com um analisador de impedância Hewlett Packard modelo 4192A, sendo as medidas feitas na faixa de freqüências de $5 \mathrm{~Hz}$ a $13 \mathrm{MHz}$, na faixa de temperatura de $20^{\circ} \mathrm{C}$ a $250{ }^{\circ} \mathrm{C}$, com tensão de $200 \mathrm{mV}$. 


\subsubsection{MEDIDAS DE PRESSÃO PARCIAL DE OXIGÊNIO}

Corpos de prova cilíndricos, diâmetro $\sim 10 \mathrm{~mm}$ e espessura $\sim 4 \mathrm{~mm}$ foram conformados com os materiais $\mathrm{Ca}_{x} \mathrm{Sr}_{1-\mathrm{x}} \mathrm{Ti}_{0,65} \mathrm{Fe}_{0,35} \mathrm{O}_{3-\delta}, \quad \mathrm{x}=0,0,5$ e 1 sintetizados pela técnica dos precursores poliméricos, sinterizados a $1300{ }^{\circ} \mathrm{C} / 2 \mathrm{~h}$ em atmosfera ambiente, após foi feito deposição de platina nas superfícies planas dos corpos de prova, e curados a $700{ }^{\circ} \mathrm{C} / 15 \mathrm{~min}$. As medidas elétricas de teor parcial de oxigênio foram feitas segundo o arranjo experimental da Figura 9, o gás utilizado como gás vetor neste trabalho foi argônio 5.0 analítico (White Martins).

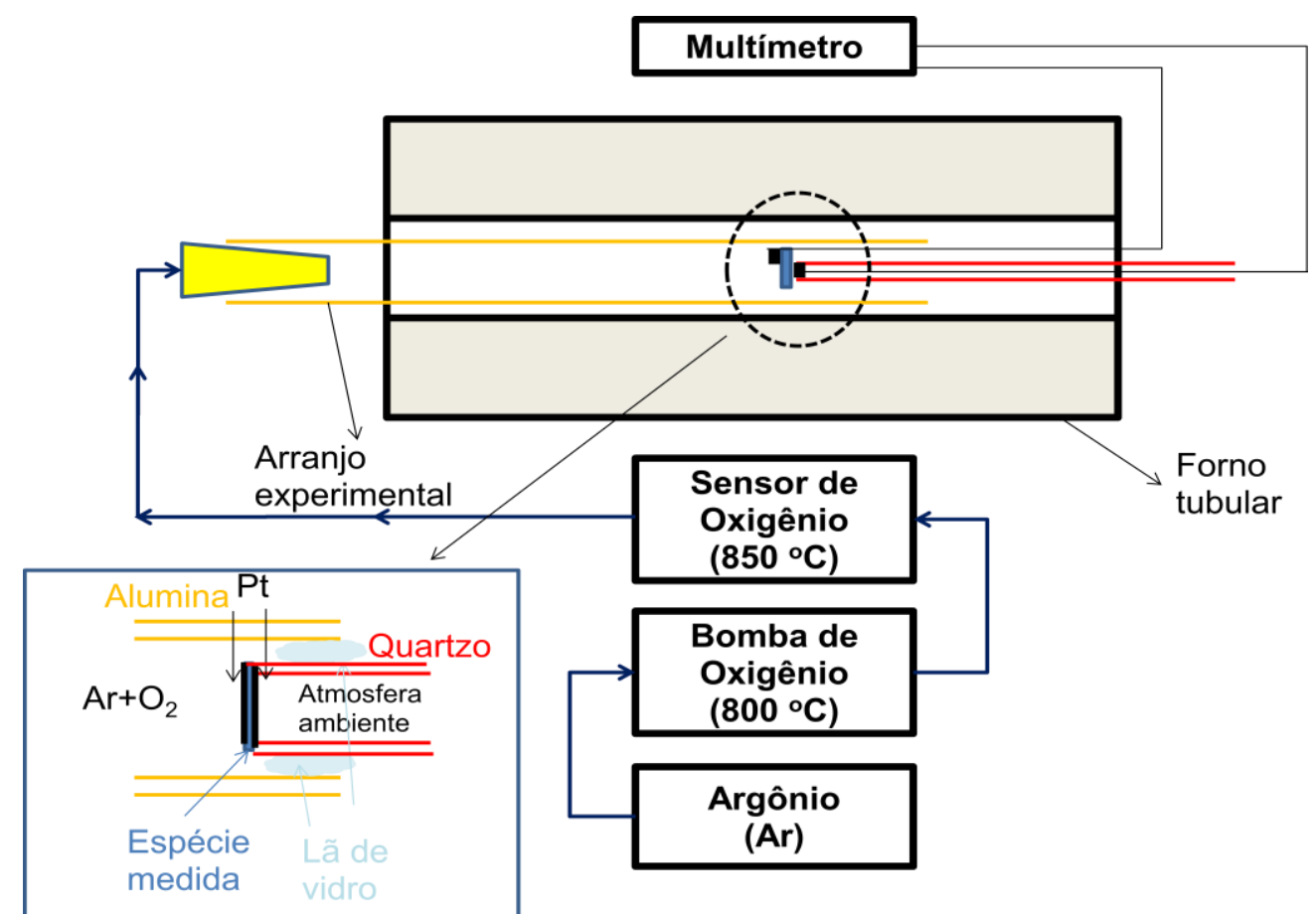

Figura 9 - Arranjo experimental da montagem para verificação da resposta elétrica dos materiais $\mathrm{Ca}_{x} \mathrm{Sr}_{1-x} \mathrm{Ti}_{0,65} \mathrm{Fe}_{0,35} \mathrm{O}_{3-\delta}, x=0,0,5$ e 1,0. Detalhe: montagem da amostra.

O gás vetor passa por uma bomba eletroquímica, construída neste laboratório ${ }^{[55]}$, responsável por enriquecer o argônio com oxigênio, seguindo para um sensor de oxigênio comercial (zircônia-ítria), responsável pela medida do teor de oxigênio no gás vetor. Esta mistura $\mathrm{Ar}+\mathrm{O}_{2}$ percorre toda a montagem. O eletrólito sólido sob estudo está em contato com fios de platina, que transportam o sinal elétrico para o meio externo onde os dados são coletados em um multímetro digital. 


\section{RESULTADOS E DISCUSSÃO}

Neste capítulo serão apresentados os resultados de análise térmica, dilatometria, microscopia eletrônica de varredura, microscopia eletrônica de transmissão, microscopia eletrônica de varredura por sonda, difração de raios $X$ convencional e com fonte Síncrotron e medidas elétricas das amostras cerâmicas de $\mathrm{Ca}_{\mathrm{x}} \mathrm{Sr}_{1-\mathrm{x}} \mathrm{Ti}_{1-\mathrm{y}} \mathrm{Fe}_{\mathrm{y}} \mathrm{O}_{3-\delta}, \mathrm{x}=0$, 0,5, 1, e y = 0 e 0,35, sintetizadas por reação de estado sólido e pela técnica dos precursores poliméricos.

\subsection{CARACTERIZAÇÃo EStRutural}

\subsubsection{ANÁLISE TERMOGRAVIMÉTRICA E ANÁLISE TÉRMICA DIFERENCIAL}

São apresentados primeiramente os resultados de amostras preparadas por mistura de óxidos e/ou carbonatos (síntese de estado sólido). Na seqüência serão apresentados os resultados de análises das resinas poliméricas obtidas na preparação de pós pela técnica dos precursores poliméricos.

\subsubsection{Técnica de reação de estado sólido}

São mostrados nas Figuras 10, 11 e 12 os resultados obtidos nos experimentos de análise termogravimétrica e análise térmica diferencial das misturas de óxido de titânio, óxido de ferro, carbonato de cálcio e carbonato de estrôncio para as composições $\mathrm{Ca}_{x} \mathrm{Sr}_{1-x} \mathrm{Ti}_{0,65} \mathrm{Fe}_{0,35} \mathrm{O}_{3-\delta}, \quad \mathrm{x}=0,0,5$ e 1 , respectivamente. 


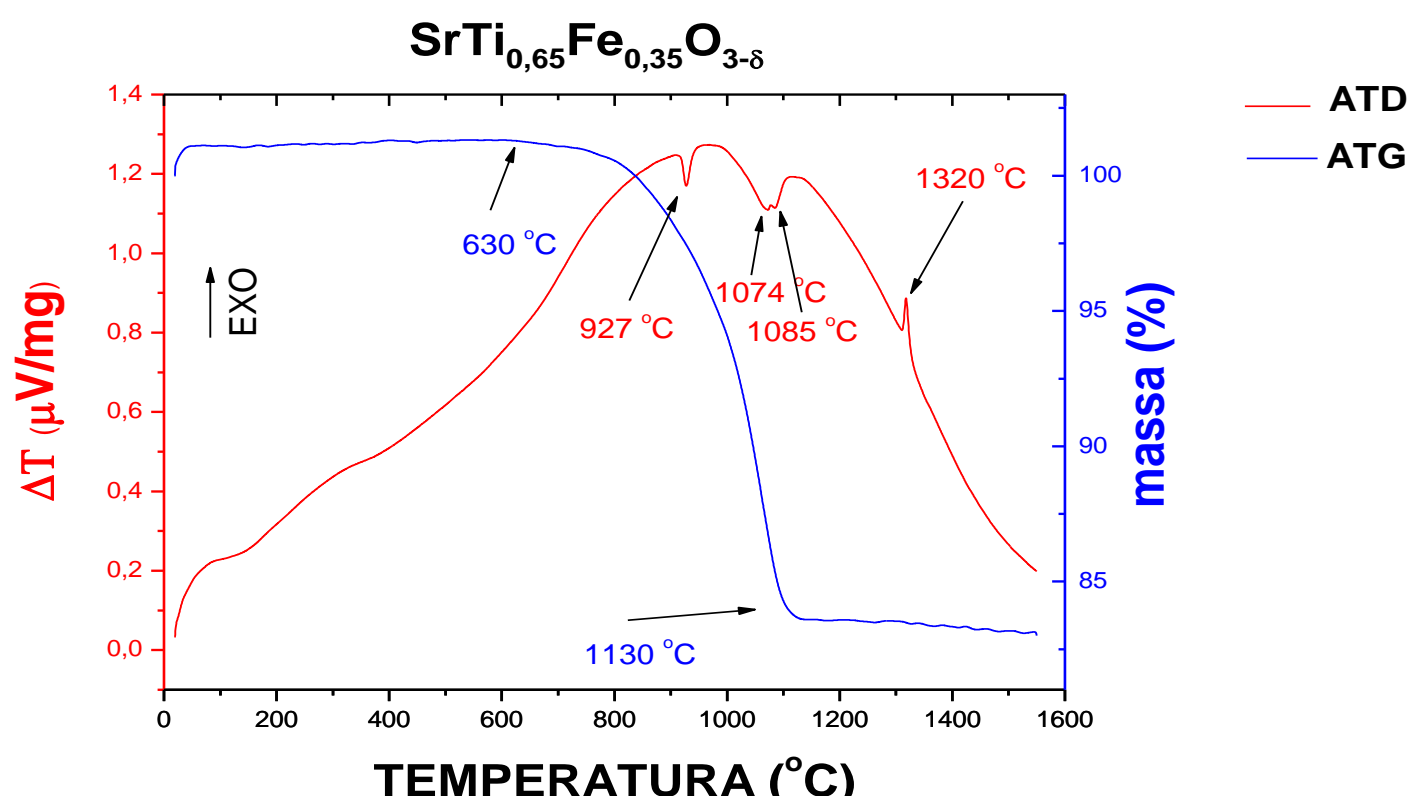

Figura 10 - Curvas de análise termogravimétrica e térmica diferencial de mistura de $\mathrm{SrCO}_{3}$, $\mathrm{TiO}_{2}$ e $\mathrm{Fe}_{2} \mathrm{O}_{3}$ na proporção molar 1,0:0,65:0,35; atmosfera: ar sintético.

A mistura de $\mathrm{SrCO}_{3}, \mathrm{TiO}_{2}$ e $\mathrm{Fe}_{2} \mathrm{O}_{3}$ durante $\mathrm{o}$ aquecimento da temperatura ambiente até $1550^{\circ} \mathrm{C}$ sob atmosfera de ar sintético apresenta uma perda de massa de $\sim 17,5 \%$ com início em $\sim 630{ }^{\circ} \mathrm{C}$ e término em $\sim 1130{ }^{\circ} \mathrm{C}$, Figura 10, causada pela decomposição do carbonato de estrôncio ${ }^{[39]}$. A curva de análise térmica diferencial apresenta 3 picos endotérmicos $\left(927{ }^{\circ} \mathrm{C}\right.$ associado à transformação de fase do $\mathrm{SrCO}_{3}{ }^{[11]}$, de ortorrômbica para hexagonal, 1074 e $1085^{\circ} \mathrm{C}$, associados à decomposição do $\mathrm{SrCO}_{3}$ em duas etapas - liberação de $\mathrm{CO}_{2}$ e dissolução de $\mathrm{SrCO}_{3}$ na rede) e 1 pico exotérmico $\left(1320{ }^{\circ} \mathrm{C}\right)$, devido a cristalização. 


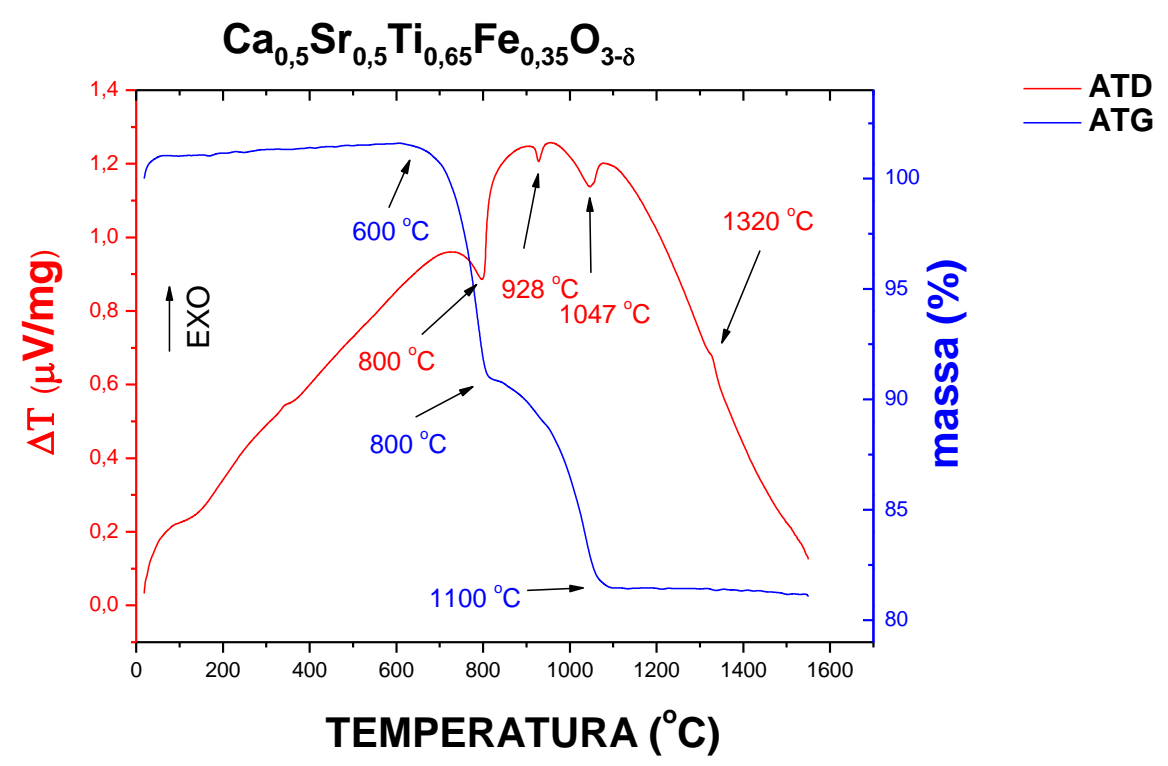

Figura 11 - Curvas de análise termogravimétrica e térmica diferencial de mistura de $\mathrm{CaCO}_{3}$, $\mathrm{SrCO}_{3}, \mathrm{TiO}_{2}$ e $\mathrm{Fe}_{2} \mathrm{O}_{3}$ na proporção molar 0,5:0,5:0,65:0,35; atmosfera: ar sintético.

É mostrada na Figura 11 que a mistura de $\mathrm{CaCO}_{3}, \mathrm{SrCO}_{3}, \mathrm{TiO}_{2}$ e $\mathrm{Fe}_{2} \mathrm{O}_{3}$ na proporção molar 0,5:0,5:0,65:0,35 apresenta duas perdas de massa na faixa de temperaturas entre ambiente e $\sim 1100{ }^{\circ} \mathrm{C}$. A primeira, de $7,9 \%$, de 600 a $800{ }^{\circ} \mathrm{C}$, associada a um pico endotérmico em $800{ }^{\circ} \mathrm{C}$ na curva de análise térmica diferencial. A segunda, de $7 \%$, de 810 a $1130{ }^{\circ} \mathrm{C}$, tendo associados 2 picos endotérmicos, em 928 e $1047^{\circ} \mathrm{C}$. O pico endotérmico em $800{ }^{\circ} \mathrm{C}$ é devido à decomposição do carbonato de cálcio ${ }^{[39]}$, enquanto o pico a $928{ }^{\circ} \mathrm{C}$ é devido à transformação de fase do $\mathrm{SrCO}_{3}$, de ortorrômbica para hexagonal ${ }^{[11]}$, sendo este pico associado também à decomposição do carbonato de estrôncio [39]; o pico em $1047{ }^{\circ} \mathrm{C}$ é associado à decomposição de $\mathrm{CaCO}_{3}$ e $\mathrm{SrCO}_{3}$ remanescentes. $\mathrm{O}$ pico exotérmico em $1320{ }^{\circ} \mathrm{C}$ é associado à cristalização do composto. 


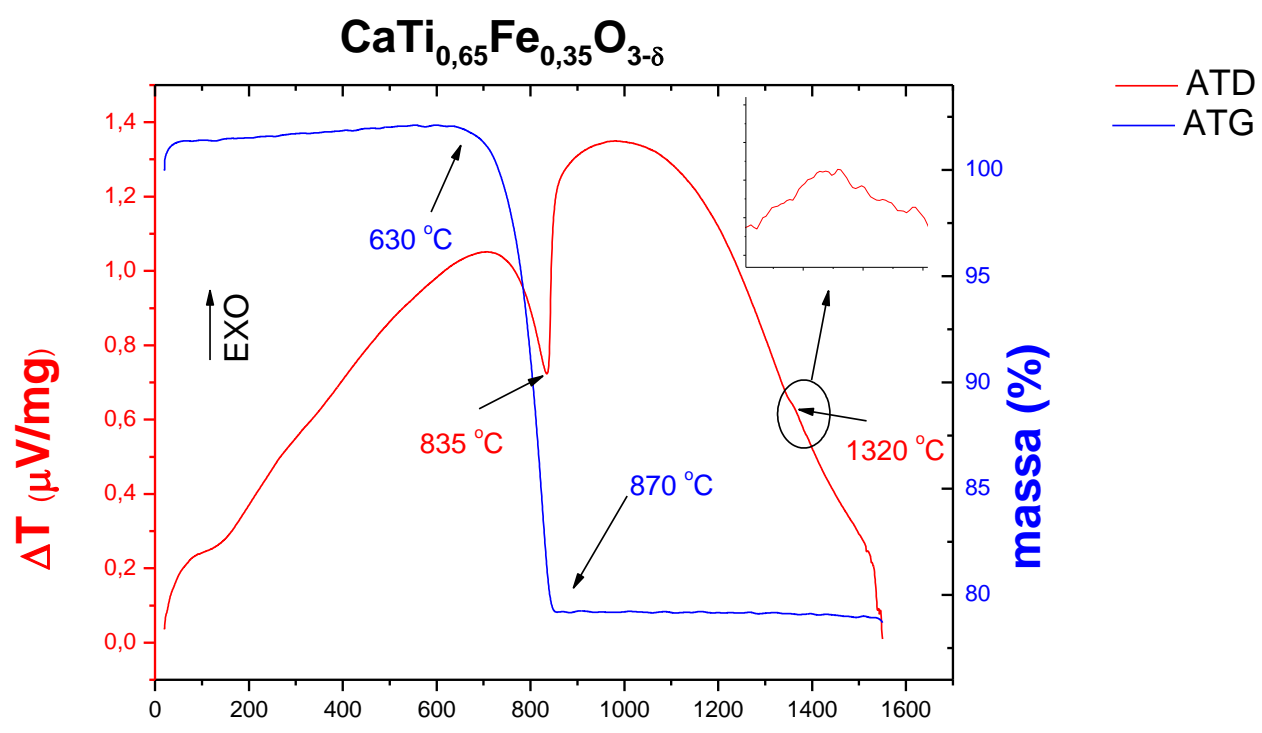

TEMPERATURA $\left({ }^{\circ} \mathrm{C}\right)$

Figura 12 - Curvas de análise termogravimétrica e térmica diferencial de mistura de $\mathrm{CaCO}_{3}$, $\mathrm{TiO}_{2}$ e $\mathrm{Fe}_{2} \mathrm{O}_{3}$ na proporção molar 1,0:0,65:0,35; atmosfera: ar sintético. Detalhe pico exotérmico.

Há uma única perda de massa de $23,3 \%$ mostrada na Figura 12 , ocorrendo entre 630 e $870{ }^{\circ} \mathrm{C}$, com um pico endotérmico, localizado em $835^{\circ} \mathrm{C}$ na curva de análise térmica diferencial, associado à decomposição do carbonato de cálcio ${ }^{[41,56]}$. O pico exotérmico devido à formação da solução sólida $\mathrm{CaTiO}_{3}$ se encontra em $1320{ }^{\circ} \mathrm{C}{ }^{[26]}$.

A Figura 13 mostra, para fins de comparação em uma única figura, os resultados de análise térmica diferencial, mostrados nas Figuras 10, 11 e 12. 


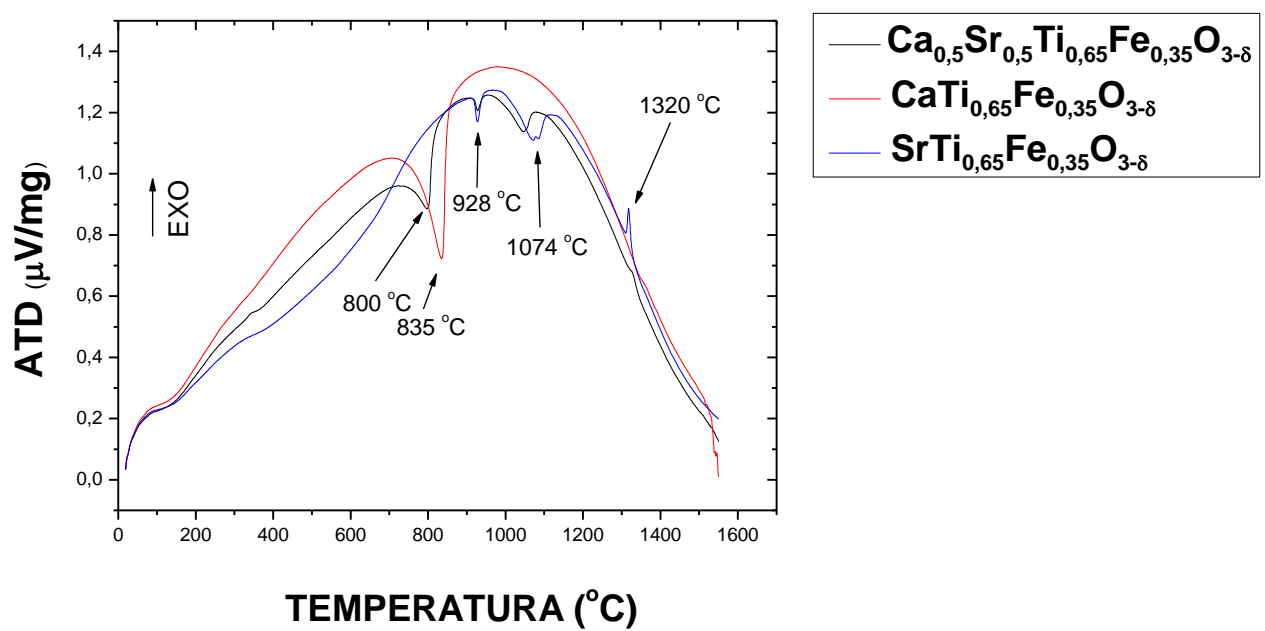

Figura 13 - Apresentação conjunta das curvas de análise térmica diferencial das Figuras 10,11 e 12.

Todas as curvas indicam 4 eventos endotérmicos e 1 evento exotérmico com temperaturas de pico dependentes do cátion $\mathrm{A}$ na estrutura $\mathrm{ABO}_{3}$, conforme Figura 13.

São mostrados na Figura 14, para fins de comparação em uma única figura, os resultados de análise termogravimétrica apresentados nas Figuras 10, 11 e 12 .

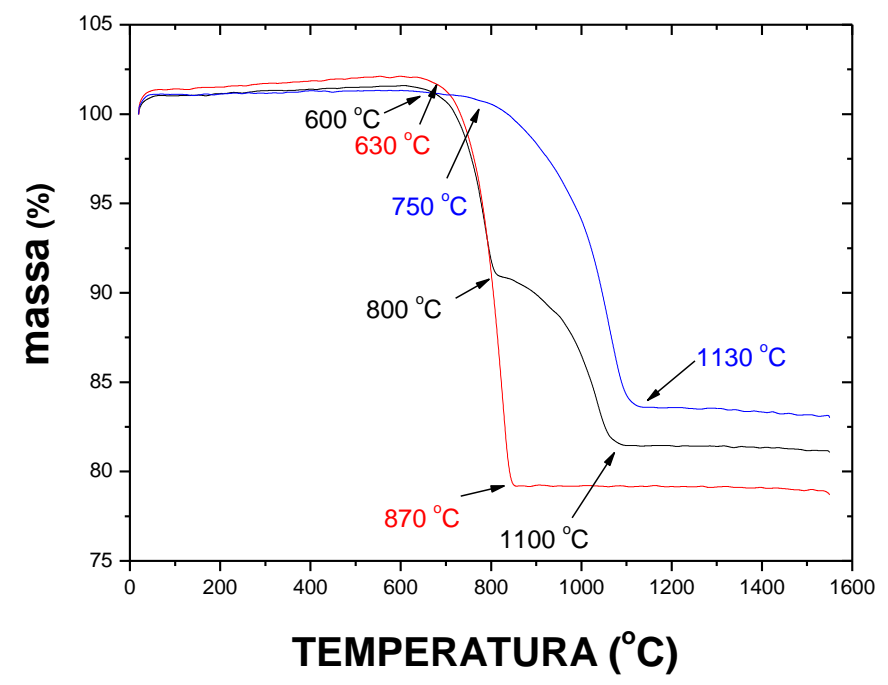$$
-\mathrm{SrTi}_{0,65} \mathrm{Fe}_{0,35} \mathrm{O}_{3-\delta}
$$$$
-\mathrm{Ca}_{0,5} \mathrm{Sr}_{0,5} \mathrm{Ti}_{0,65} \mathrm{Fe}_{0,35} \mathrm{O}_{3-\delta}
$$$$
-\mathrm{CaTi}_{0,65} \mathrm{Fe}_{0,35} \mathrm{O}_{3-\delta}
$$

Figura 14 - Curvas de análise termogravimétrica de mistura de $\mathrm{CaCO}_{3}, \mathrm{SrCO}_{3}, \mathrm{TiO}_{2}$ e $\mathrm{Fe}_{2} \mathrm{O}_{3}$ na proporção molar 1,0:0:0,65:0,35, 0:1,0:0,65:0,35 e 0,5:0,5:0,65:0,35; atmosfera: ar sintético. 
É mostrada na Figura 14 que a decomposição final dos carbonatos de cálcio e de estrôncio se dá a 870 e a $1130{ }^{\circ} \mathrm{C}$, respectivamente. Esses resultados já foram reportados ${ }^{[57]}$. A substituição parcial $(50 \%)$ de $\mathrm{Sr}^{4+}$ por $\mathrm{Ca}^{4+}$ promove as duas decomposições em um mesmo composto, como esperado.

São mostrados nas Figuras 15, 16 e 17 os resultados obtidos nos experimentos de análise termogravimétrica e análise térmica diferencial para as mesmas composições reportadas anteriormente (Figuras 10,11 e 12.), mas agora sem a substituição parcial de Ti por Fe $(0,35 \mathrm{~mol})$ no sítio $B$ da perovskita.

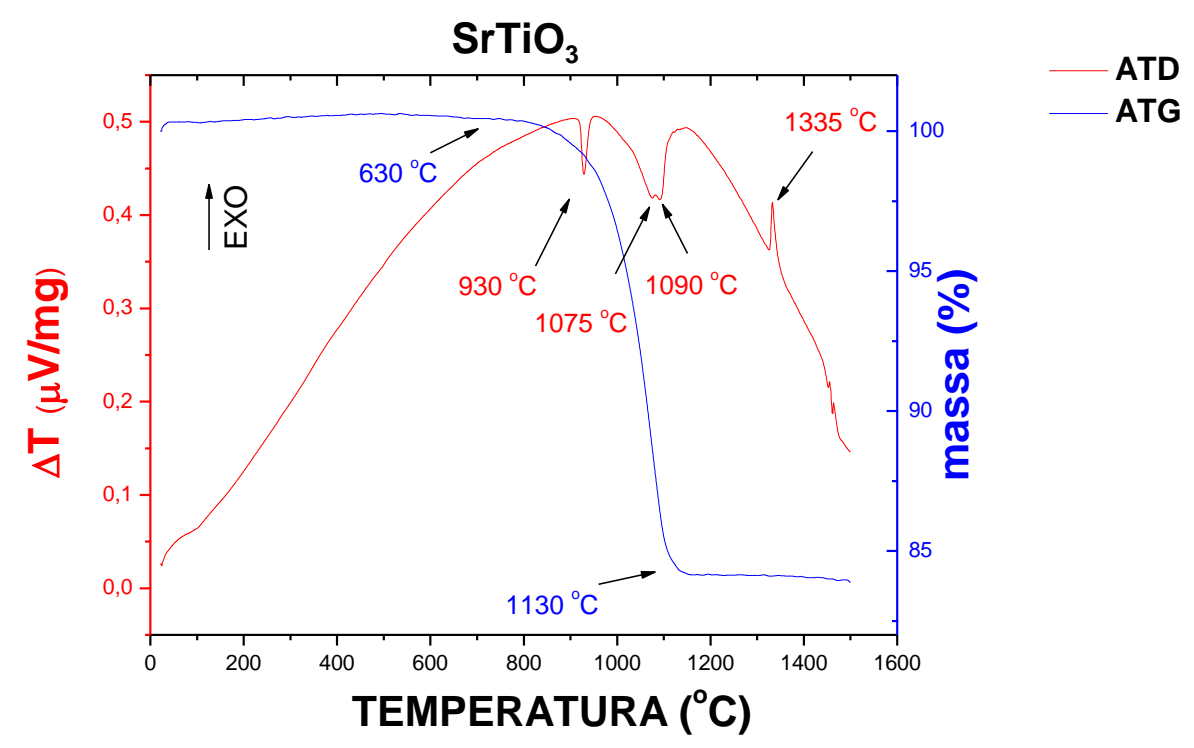

Figura 15 - Curvas de análise termogravimétrica e térmica diferencial de mistura de $\mathrm{SrCO}_{3} \mathrm{e}$ $\mathrm{TiO}_{2}$ na proporção molar 1,0:1,0; atmosfera: ar sintético.

É mostrada na Figura 15 que há uma perda de massa de 16,5\%, entre 630 e $1160{ }^{\circ} \mathrm{C}$, durante o aquecimento até $1550^{\circ} \mathrm{C}$ devida à decomposição do carbonato de estrôncio ${ }^{[39]}$.

$\mathrm{Na}$ curva de análise térmica diferencial, há 3 eventos endotérmicos com picos em 930, 1075 e $1090^{\circ} \mathrm{C}$. O primeiro pico é associado à transformação de fase do $\mathrm{SrCO}_{3}{ }^{[11]}$, de ortorrômbica para hexagonal, e os outros dois à decomposição do $\mathrm{SrCO}_{3}$. Um evento exotérmico com pico em $1335{ }^{\circ} \mathrm{C}$ é associado ao processo de fusão do $\mathrm{SrCO}_{3}$ remanescente ${ }^{[39]}$, evidenciando a cristalização do composto. 


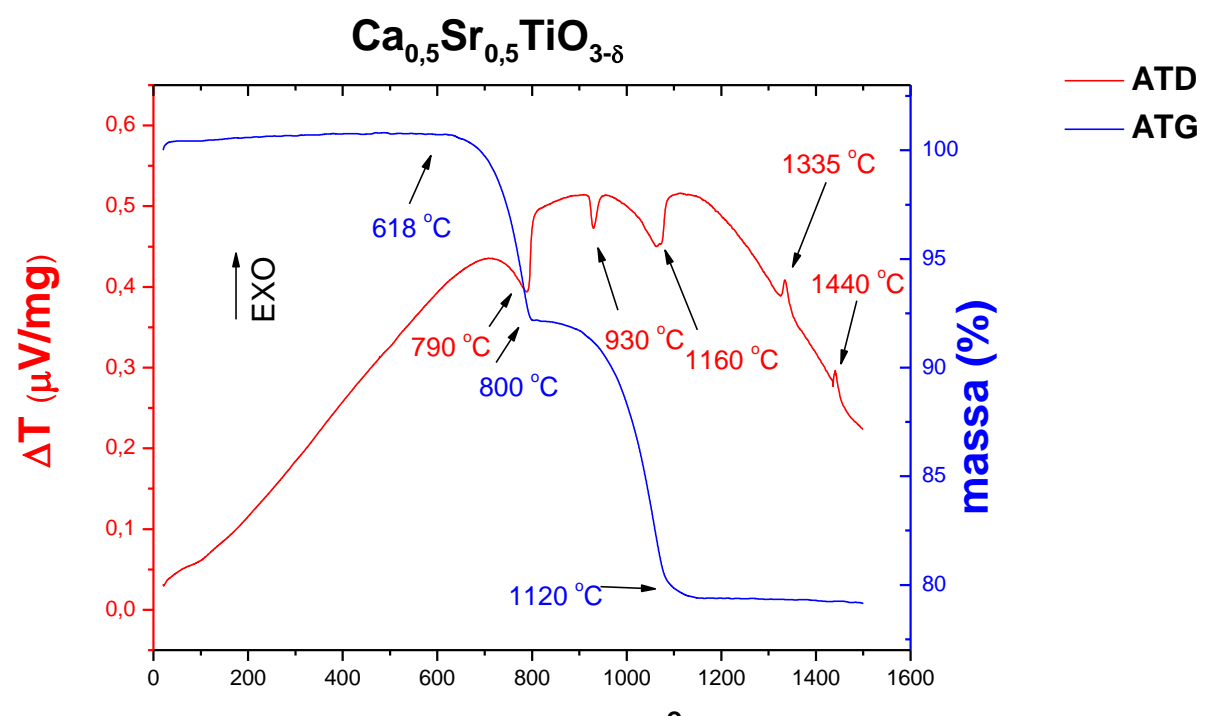

\section{TEMPERATURA $\left({ }^{\circ} \mathrm{C}\right)$}

Figura 16 - Curvas de análise termogravimétrica e térmica diferencial de mistura de $\mathrm{CaCO}_{3}$, $\mathrm{SrCO}_{3}$ e $\mathrm{TiO}_{2}$ na proporção molar 0,5:0,5:1,0, atmosfera: ar sintético.

Na curva de análise termogravimétrica da Figura 16 são mostradas duas perdas de massa associadas à decomposição dos carbonatos, uma ocorrendo de 618 a $800{ }^{\circ} \mathrm{C}(8,6 \%)$ referente a decomposição do carbonato de cálcio, e outra de 800 a $1120{ }^{\circ} \mathrm{C}(11,6 \%)$, associada a decomposição do carbonato de estrôncio. A primeira tem associado um pico endotérmico em $790{ }^{\circ} \mathrm{C}$ na curva de análise térmica diferencial. A segunda, dois picos endotérmicos em 930 e $1160{ }^{\circ} \mathrm{C}$; o primeiro é devido à decomposição do carbonato de cálcio ${ }^{[39]}$, enquanto o segundo à transformação de fase do $\mathrm{SrCO}_{3}$, de ortorrômbica para hexagonal ${ }^{[11]}$, sendo este pico associado também à decomposição do carbonato de estrôncio ${ }^{[39]}$, e os picos em 1335 e $1440{ }^{\circ} \mathrm{C}$ associados a cristalização do composto. 


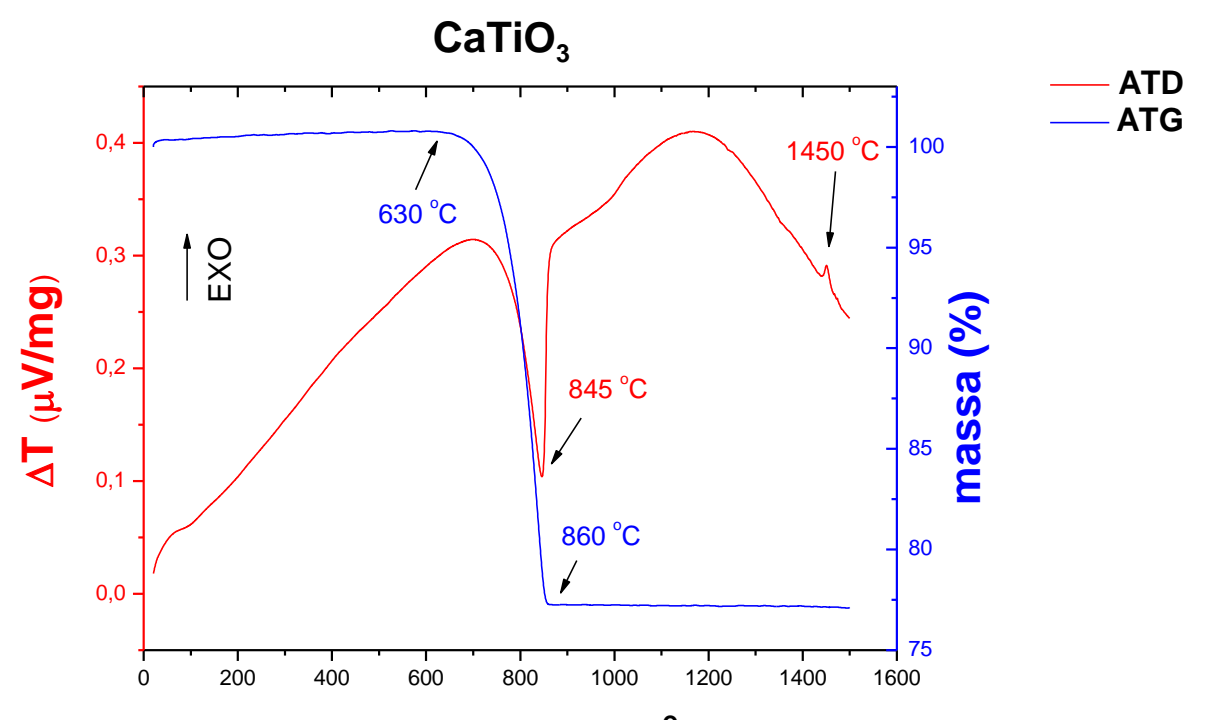

TEMPERATURA $\left({ }^{\circ} \mathrm{C}\right)$

Figura 17 - Curvas de análise termogravimétrica e térmica diferencial de mistura de $\mathrm{CaCO}_{3} \mathrm{e}$ $\mathrm{TiO}_{2}$ na proporção molar 1,0:1,0; atmosfera: ar sintético.

Como também observado no experimento de formação do titanato de estrôncio, na Figura 17 observa-se uma única perda de massa de $23,7 \%$ entre 630 e $860{ }^{\circ} \mathrm{C}$, com um correspondente pico endotérmico, localizado em $845^{\circ} \mathrm{C}$ na curva de análise térmica diferencial, devido à decomposição do carbonato de cálcio ${ }^{[41,56]}$.

Para fins de comparação, são mostrados na Figura 18, os resultados de análise térmica diferencial apresentados nas Figuras 15, 16 e 17. 

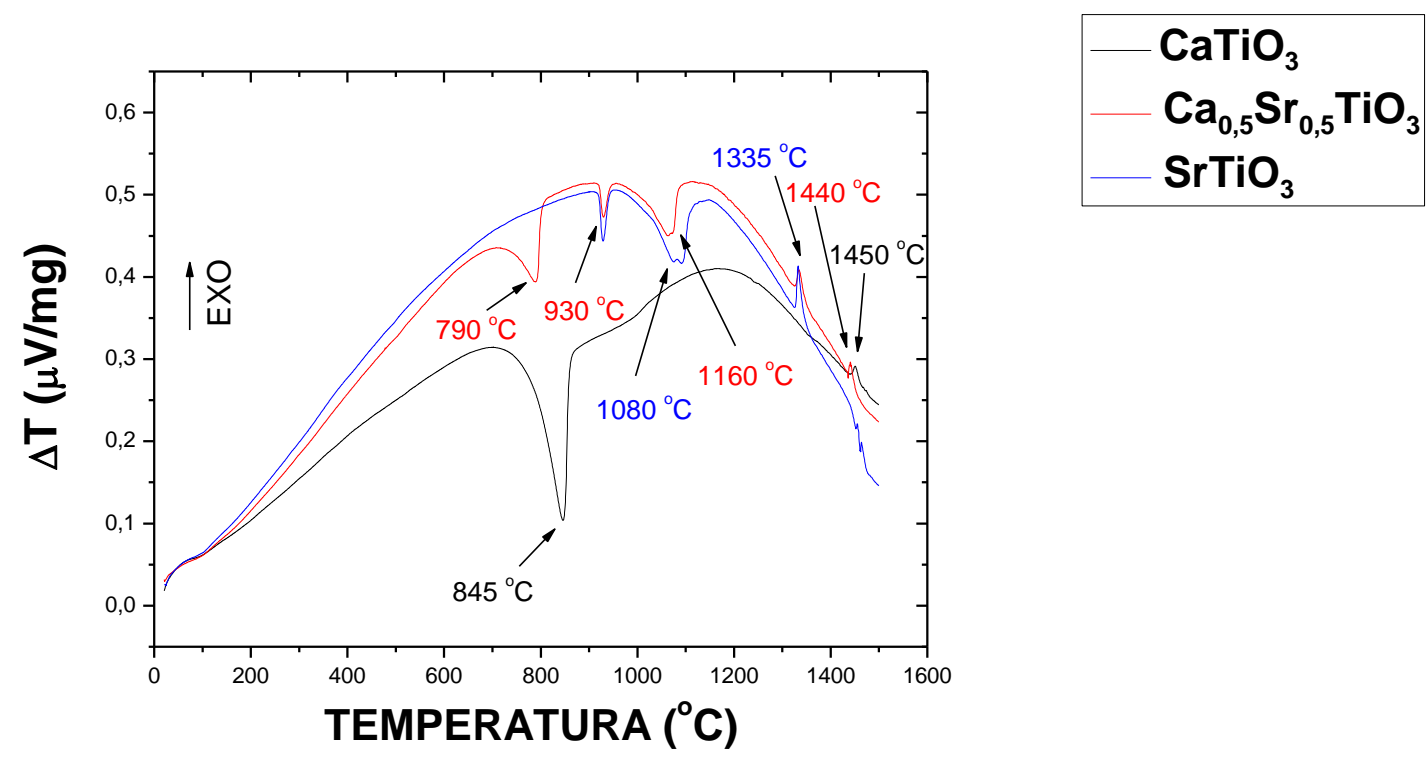

Figura 18 - Curvas de análise térmica diferencial de misturas de $\mathrm{CaCO}_{3}, \mathrm{SrCO}_{3}$ e $\mathrm{TiO}_{2}$, nas proporções molares 1,0:0:1,0, 0,5:0,5:1,0 e 0:1,0:1,0; atmosfera: ar sintético.

As reações químicas de formação de todos os compostos mostram três picos endotérmicos e pelo menos um pico exotérmico, Figura 18. As diferentes temperaturas e as evidentes diferentes áreas sob os picos mostram que as energias envolvidas em cada processo são diferentes, dependendo do cátion que se posiciona no sítio $A$ da estrutura perovskita.

São mostrados na Figura 19, para fins de comparação em uma única figura, os resultados de análise termogravimétrica apresentados nas Figuras 15, 16 e 17. 

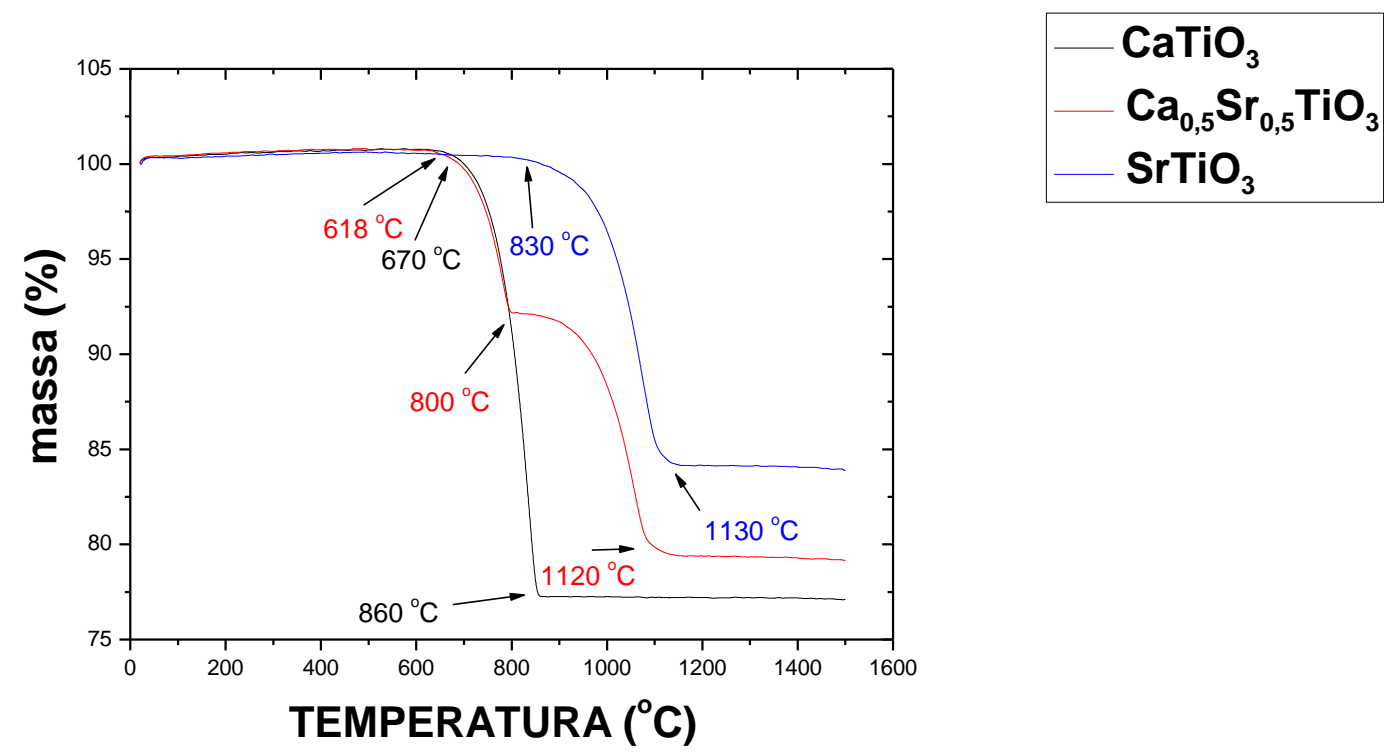

Figura 19 - Curvas de análise termogravimétrica de misturas de $\mathrm{CaCO}_{3}, \mathrm{SrCO}_{3}$ e $\mathrm{TiO}_{2}$ nas proporções molares 1,0:0:1,0, 0,5:0,5:1,0 e 0:1,0:1,0; atmosfera: ar sintético.

As reações de decomposição dos carbonatos são os resultados que sobressaem dessas curvas. As perdas de massa se iniciam em $\sim 618{ }^{\circ} \mathrm{C}$ e terminam em $\sim 1130^{\circ} \mathrm{C}$, conforme Figura 19.

\subsubsection{Técnica dos precursores poliméricos}

São mostrados nas Figuras 20 e 21 as curvas de análise termogravimétrica e análise térmica diferencial das resinas (sol-gel) resultantes da síntese, pela técnica dos precursores poliméricos, dos compostos $\mathrm{SrTi}_{0,65} \mathrm{Fe}_{0,35} \mathrm{O}_{3-\delta}, \mathrm{Ca}_{0,5} \mathrm{Sr}_{0,5} \mathrm{Ti}_{0,65} \mathrm{Fe}_{0,35} \mathrm{O}_{3-\delta}$ e $\mathrm{CaTi}_{0,65} \mathrm{Fe}_{0,35} \mathrm{O}_{3-\delta}$, antes da primeira queima. O principal objetivo destes experimentos é determinar $\mathrm{a}(\mathrm{s})$ temperatura(s) de eliminação dos componentes orgânicos da resina para a produção dos pós cerâmicos dos compostos de estrutura perovskita. 


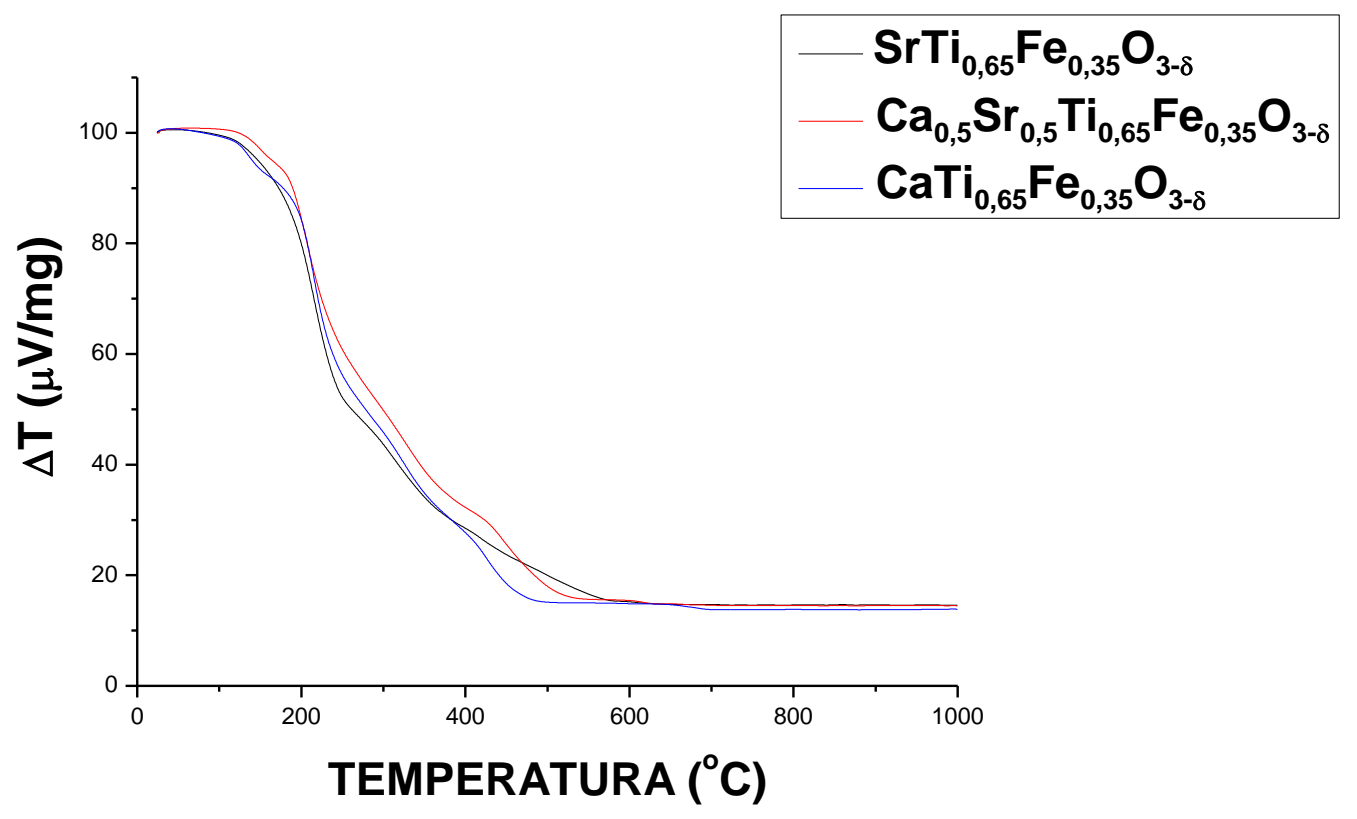

Figura 20 - Curvas de análise termogravimétrica das resinas precursora de $\mathrm{SrTi}_{0,65} \mathrm{Fe}_{0,35} \mathrm{O}_{3-\delta}$, $\mathrm{Ca}_{0,5} \mathrm{Sr}_{0,5} \mathrm{Ti}_{0,65} \mathrm{Fe}_{0,35} \mathrm{O}_{3-\delta}$ e $\mathrm{CaTi}_{0,65} \mathrm{Fe}_{0,35} \mathrm{O}_{3-\delta}$, na forma de sol-gel, antes da primeira queima método dos precursores poliméricos; atmosfera: ar sintético.

A perda de massa, independente do composto, conforme mostrado na Figura 20, se dá por meio de várias etapas. O principal resultado é que essa perda aparentemente se completa em $\sim 600{ }^{\circ} \mathrm{C}$ para todos os compostos. A determinação do porque da ocorrência em várias etapas demandaria a análise dos gases envolvidos em cada etapa, por meio, por exemplo, de medidas em um espectrômetro de massa. 


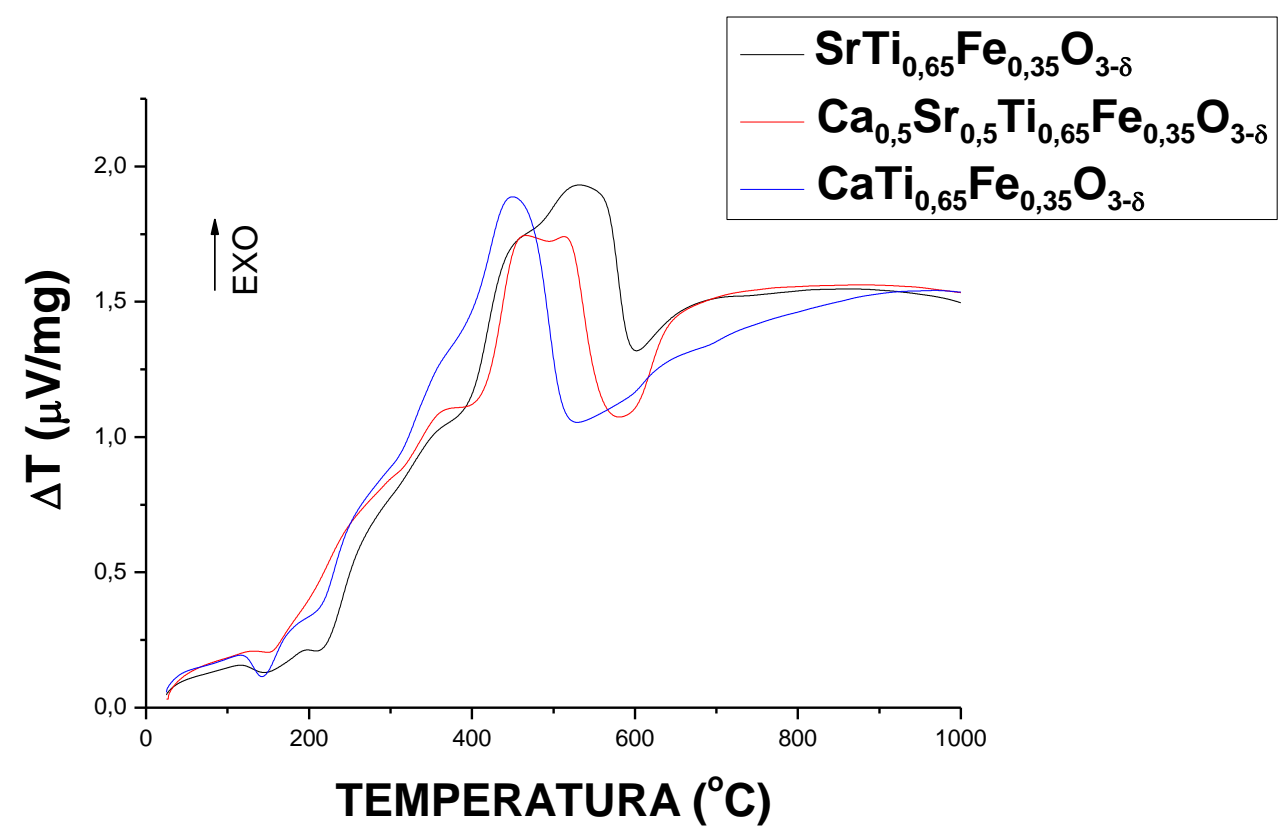

Figura 21 - Curvas de análise térmica diferencial das resinas precursora de $\operatorname{SrTi}{ }_{0,65} \mathrm{Fe}_{0,35} \mathrm{O}_{3-\delta}$, $\mathrm{Ca}_{0,5} \mathrm{Sr}_{0,5} \mathrm{Ti}_{0,65} \mathrm{Fe}_{0,35} \mathrm{O}_{3-\delta}$ e $\mathrm{CaTi}_{0,65} \mathrm{Fe}_{0,35} \mathrm{O}_{3-\delta}$, na forma de sol-gel, antes da primeira queima método dos precursores poliméricos; atmosfera: ar sintético.

Vários eventos ocorrem durante a eliminação dos compostos orgânicos nas resinas poliméricas, conforme mostrado na Figura 21. Esses eventos não foram analisados em detalhe, pois o objetivo principal destes experimentos foi a determinação da temperatura mínima necessária para a produção dos pós cerâmicos isentos de compostos orgânicos.

Novos experimentos de análise térmica foram feitos, agora nos pós cerâmicos resultantes de calcinação das resinas poliméricas. Os resultados estão nas Figuras 22, 23, e 24 para as composições $\mathrm{Ca}_{x} \mathrm{Sr}_{1-x} \mathrm{Ti}_{0,65} \mathrm{Fe}_{0,35} \mathrm{O}_{3-\delta}$, $x=0,0,5$ e 1 , respectivamente. As resinas foram tratadas termicamente seqüencialmente a $200{ }^{\circ} \mathrm{C} / 2 \mathrm{~h}+250{ }^{\circ} \mathrm{C} / 2 \mathrm{~h}+300{ }^{\circ} \mathrm{C} / 2 \mathrm{~h}$, com taxa de aquecimento $5^{\circ} \mathrm{C} / \mathrm{min}$. 


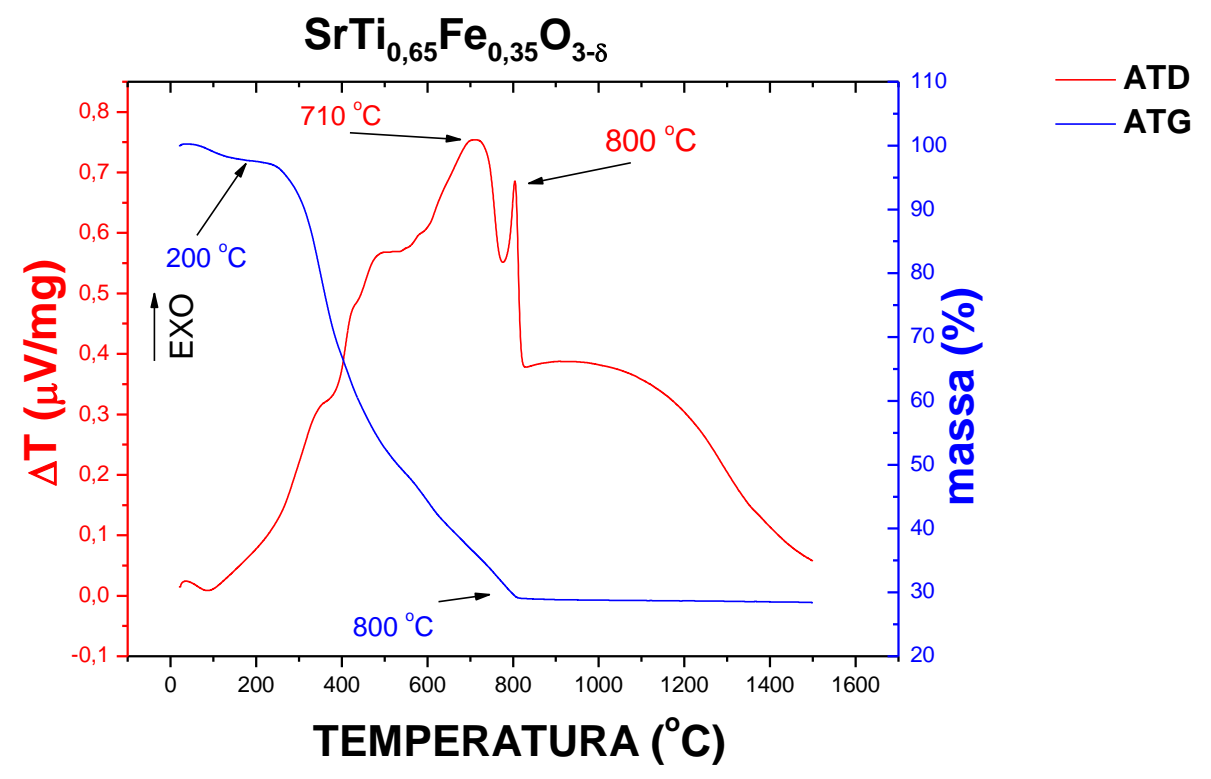

Figura 22 - Curvas de análise termogravimétrica e térmica diferencial da resina precursora de $\mathrm{SrTi}_{0,65} \mathrm{Fe}_{0,35} \mathrm{O}_{3-\delta}$ - método dos precursores poliméricos; atmosfera: ar sintético.

É mostrada na Figura 22 que a perda de massa é de $71,8 \%$ entre 200 e $800{ }^{\circ} \mathrm{C}$. A perda inicial de $\sim 5 \%$ é devida à remoção de água e de dióxido de carbono adsorvidos da atmosfera durante o manuseio da resina. A perda de massa subseqüente até $800{ }^{\circ} \mathrm{C}$ corresponde à eliminação dos compostos orgânicos utilizados na síntese pela técnica dos precursores poliméricos. $O$ pico exotérmico em $800{ }^{\circ} \mathrm{C}$ corresponde à formação de fase cristalina do $\mathrm{SrTi}_{0,65} \mathrm{Fe}_{0,35} \mathrm{O}_{3-\delta}$. Essa temperatura é $450{ }^{\circ} \mathrm{C}$ menor que a que ocorre na síntese de estado sólido deste mesmo composto, evidenciando a grande diferença na quantidade de energia envolvida em ambos os processos de síntese. 


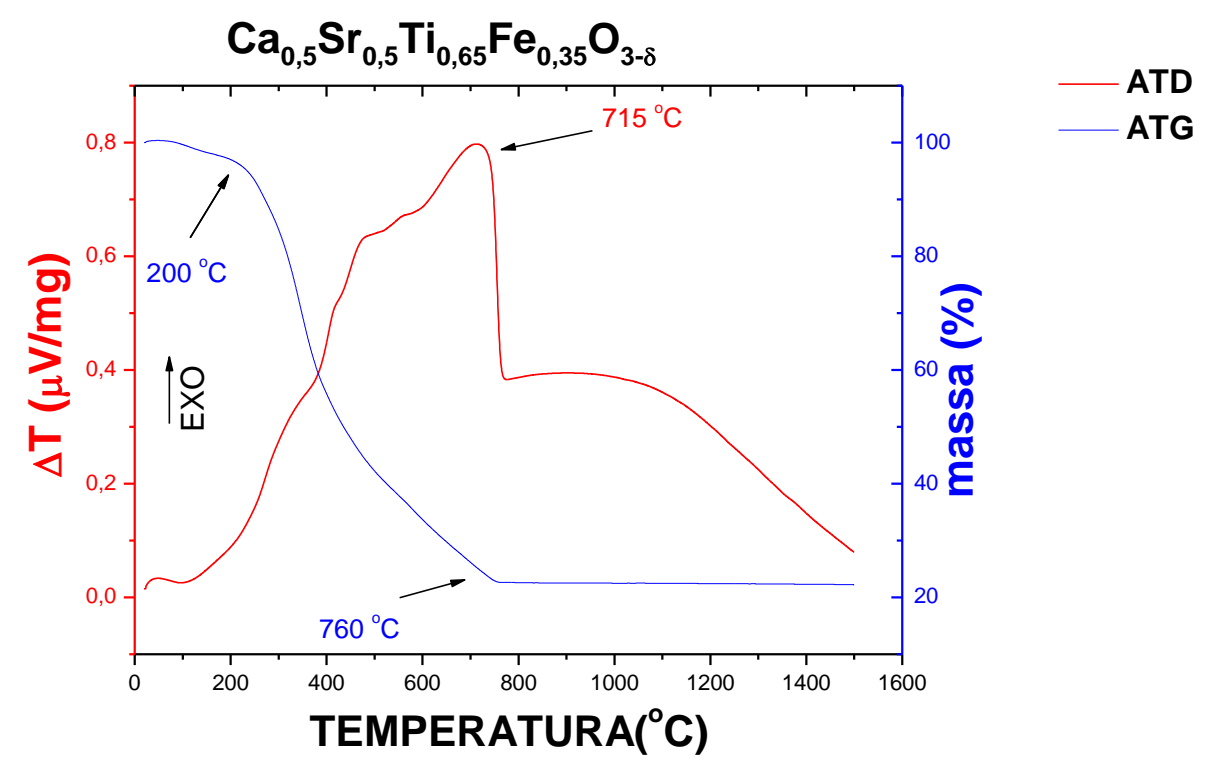

Figura 23 - Curvas de análise termogravimétrica e térmica diferencial da resina precursora de $\mathrm{Ca}_{0,5} \mathrm{Sr}_{0,5} \mathrm{Ti}_{0,65} \mathrm{Fe}_{0,35} \mathrm{O}_{3-\delta}$ - método dos precursores poliméricos; atmosfera: ar sintético.

A perda de massa total é de $78,1 \%$, Figura 23. Valem aqui os mesmos comentários feitos sobre os resultados da Figura 22.

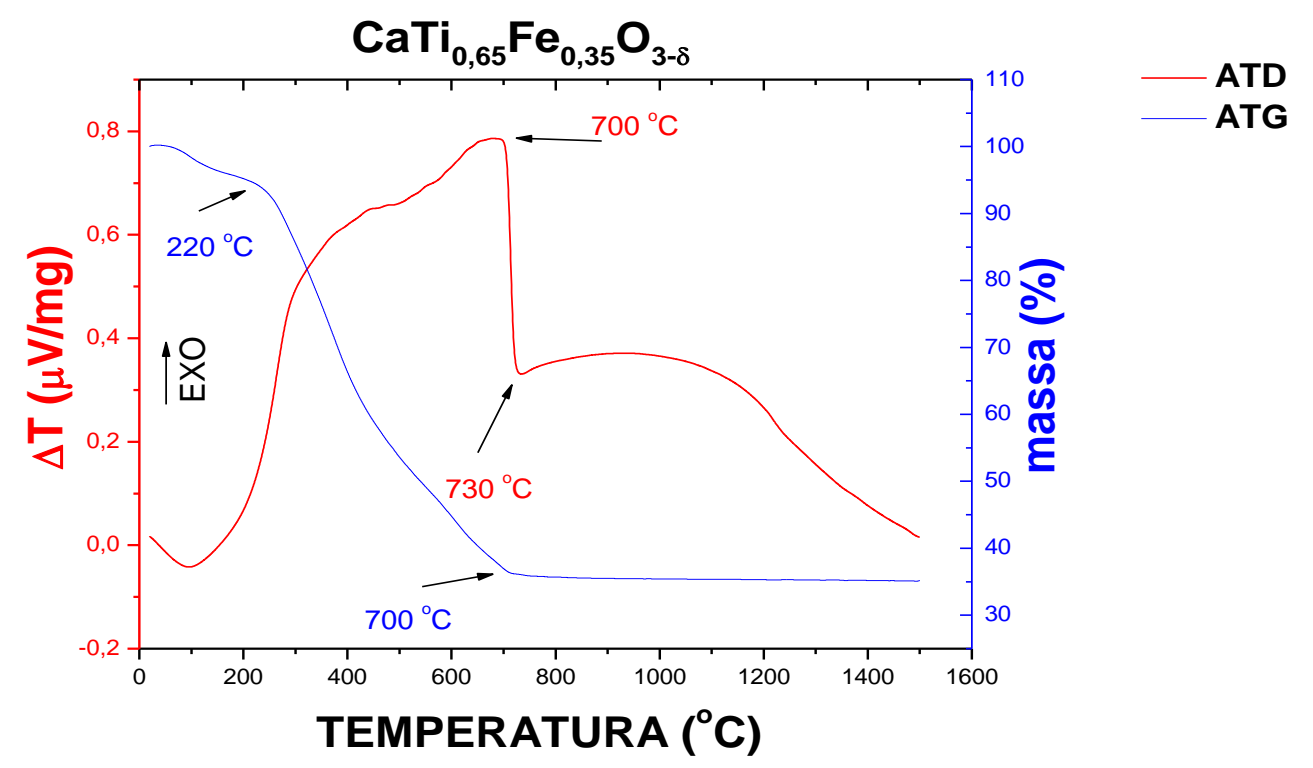

Figura 24 - Curvas de análise termogravimétrica e térmica diferencial da resina precursora de $\mathrm{CaTi}_{0,65} \mathrm{Fe}_{0,35} \mathrm{O}_{3-\delta}$ - método dos precursores poliméricos; atmosfera: ar sintético. 
É mostrada na Figura 24 que a perda de massa é de $65 \%$, na faixa de temperatura 220 a $700{ }^{\circ} \mathrm{C}$. O pico exotérmico em $700{ }^{\circ} \mathrm{C}$ é associado à cristalização do material ${ }^{[12]}$.

Para fins de comparação são mostrado na Figura 25, em uma única figura, os resultados de análise térmica diferencial apresentados nas Figuras 22, 23 e 24.
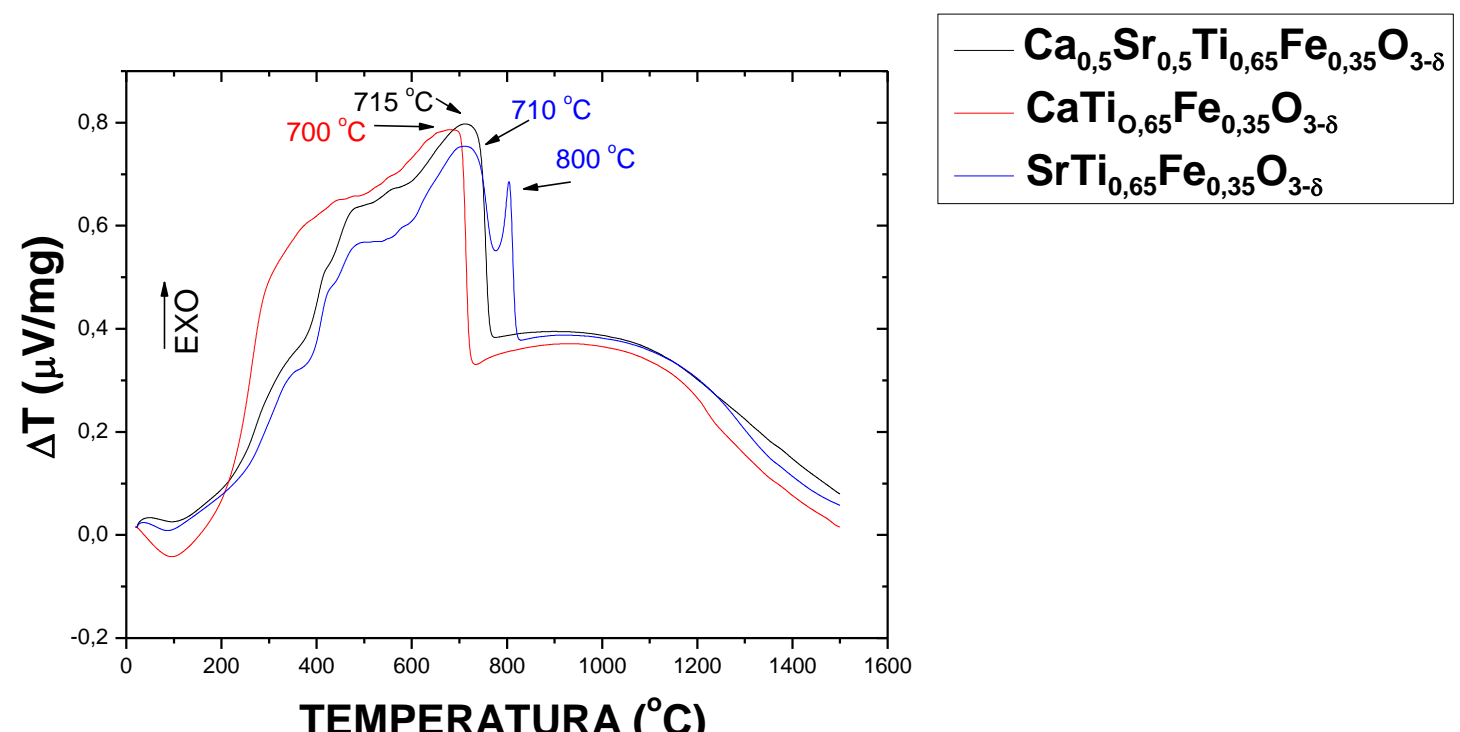

Figura 25 - Curvas de análise térmica diferencial das resinas precursoras de $\mathrm{SrTi}_{0,65} \mathrm{Fe}_{0,35} \mathrm{O}_{3-\delta}$, $\mathrm{Ca}_{0,5} \mathrm{Sr}_{0,5} \mathrm{Ti}_{0,65} \mathrm{Fe}_{0,35} \mathrm{O}_{3-\delta}$ e $\mathrm{CaTi}_{0,65} \mathrm{Fe}_{0,35} \mathrm{O}_{3-\delta}$ - método dos precursores poliméricos; atmosfera: ar sintético.

As curvas possuem um formato característico, conforme Figura 25, com exceção da curva da mistura dos precursores de $\mathrm{SrTi0}_{, 65} \mathrm{Fe}_{0,35} \mathrm{O}_{3-\delta}$, que possui 2 picos exotérmicos, localizados em 710 e $800{ }^{\circ} \mathrm{C}$. Também pode ser observado que a formação de fase cristalina dos três compostos ocorre em temperaturas muito próximas, entre 700 e $800{ }^{\circ} \mathrm{C}$. A adição de carbonato de cálcio faz com que seja menor a temperatura para formação de fase do composto, exercendo um papel de catalisador da reação. Um provável mecanismo está ligado à formação de vacâncias de oxigênio pela substituição de $\mathrm{Fe}^{3+}$ por $\mathrm{Ti}^{4+}$ na estrutura perovskita, aumentando a difusão de vacâncias de oxigênio. 
Para fins de comparação são mostrados na Figura 26, em uma única figura, os resultados de análise termogravimétrica apresentados nas Figuras 22, 23 e 24.

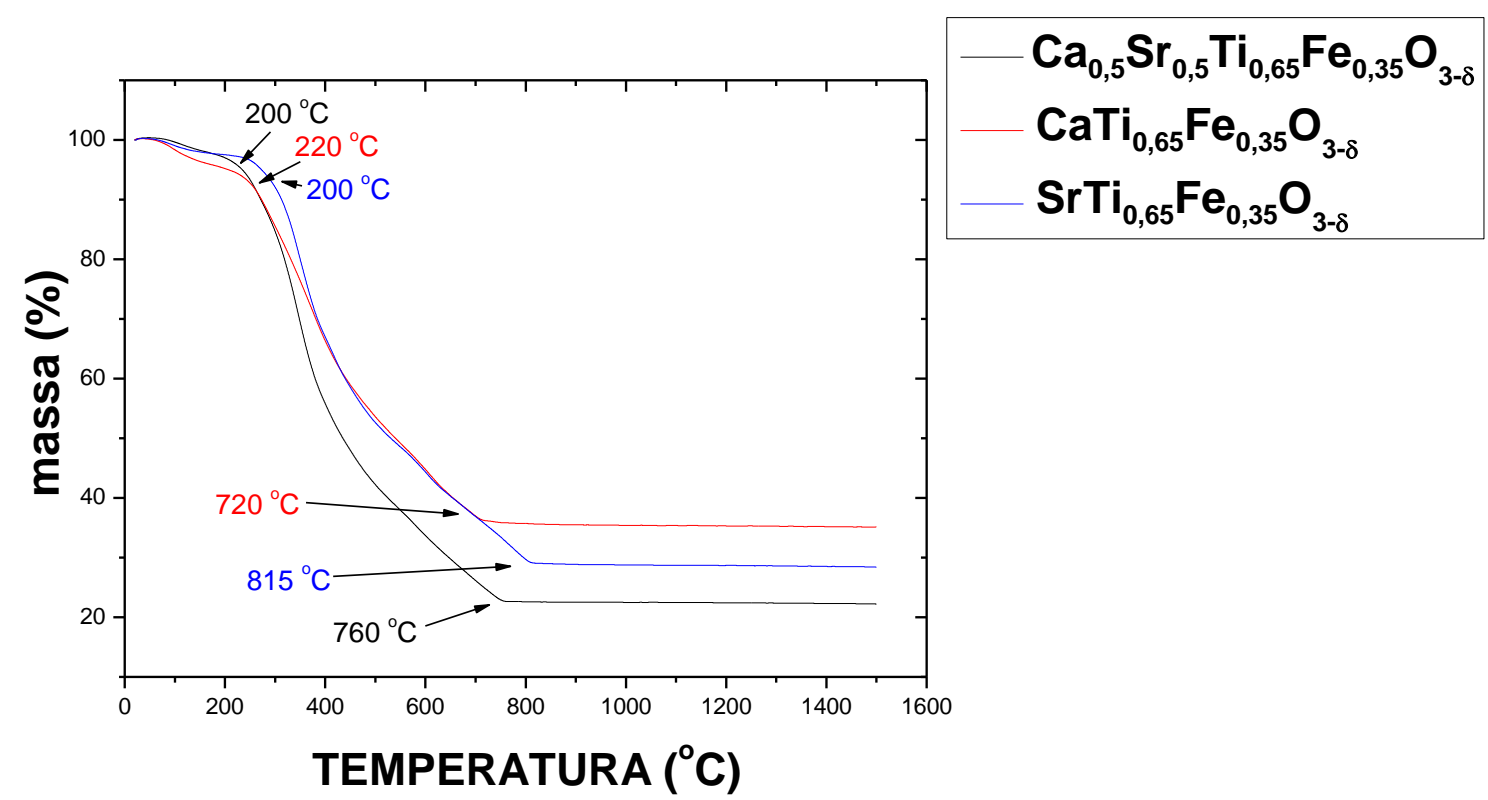

Figura 26 - Curvas de análise termogravimétrica de misturas das resinas poliméricas precursoras de $\mathrm{SrTi}_{0,65} \mathrm{Fe}_{0,35} \mathrm{O}_{3-\delta}, \mathrm{Ca}_{0,5} \mathrm{Sr}_{0,5} \mathrm{Ti}_{0,65} \mathrm{Fe}_{0,35} \mathrm{O}_{3-\delta}$ e $\mathrm{CaTi}_{0,65} \mathrm{Fe}_{0,35} \mathrm{O}_{3-\delta}$; atmosfera: ar sintético.

A decomposição de todas as resinas precursoras ocorre entre 200 e $815^{\circ} \mathrm{C}$, conforme mostrado na Figura 26.

Após as análises dos compostos com a substituição de titânio por ferro $(0,35 \mathrm{~mol})$, foram feitos experimentos dos mesmos compostos sem a formação de solução sólida com ferro.

São mostrados nas Figuras 27, 28 e 29 os resultados obtidos nos experimentos de análise termogravimétrica e análise térmica diferencial das resinas precursoras de $\mathrm{Ca}_{x} \mathrm{Sr}_{1-\mathrm{x}} \mathrm{TiO}_{3-\delta}, \mathrm{x}=0,0,5$ e 1, respectivamente. 
Resultados e discussão

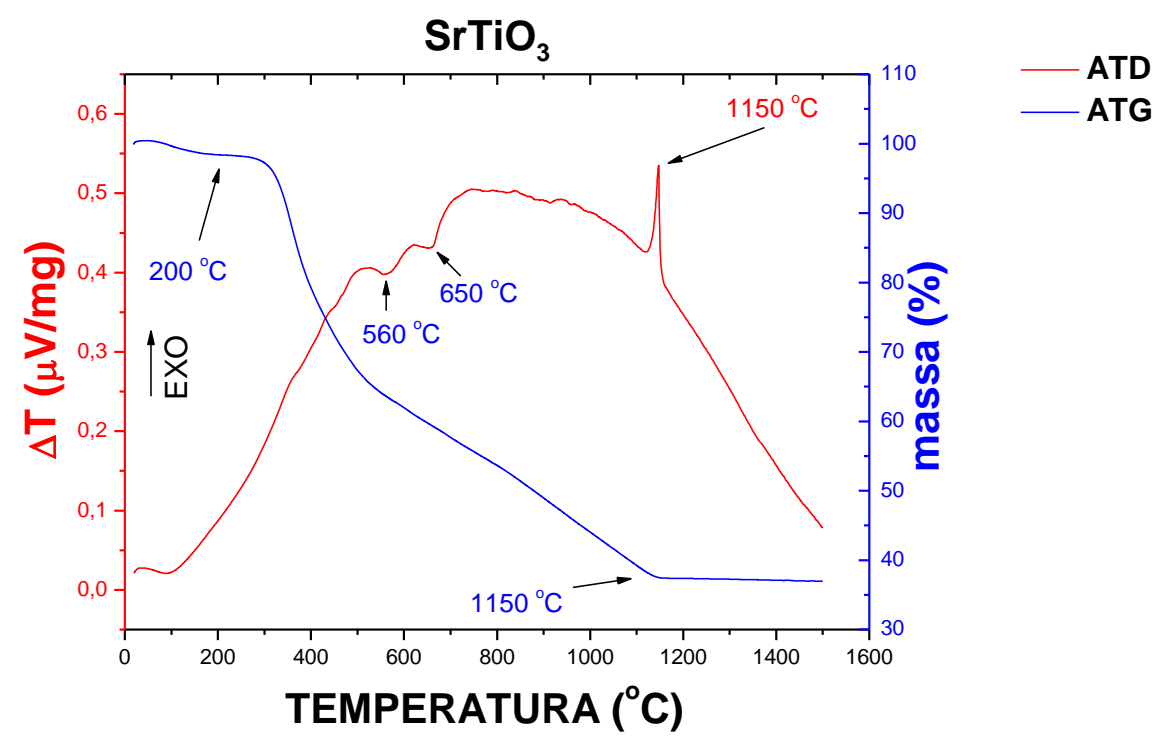

Figura 27 - Curvas de análise termogravimétrica e térmica diferencial da resina precursora de $\mathrm{SrTiO}_{3}$ - método dos precursores poliméricos; atmosfera: nitrogênio.

A perda de massa de $\sim 63 \%$ ocorre entre 200 e $1150^{\circ} \mathrm{C}$, Figura 27 . Há 2 eventos endotérmicos, em 560 e em $650{ }^{\circ} \mathrm{C}$, associados a essa perda de massa. O pico exotérmico em $1150^{\circ} \mathrm{C}$ é provavelmente devido à formação da fase cristalina do $\mathrm{SrTiO}_{3}$.

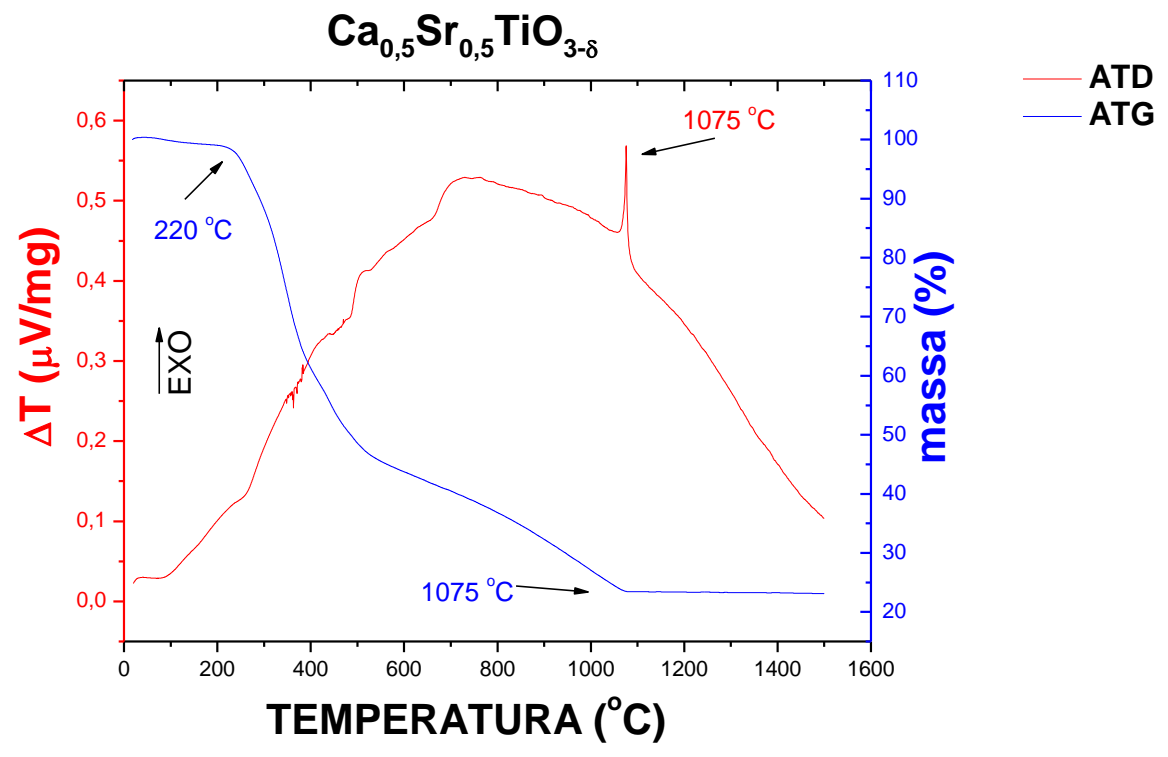

Figura 28 - Curvas de análise termogravimétrica e térmica diferencial da resina precursora de $\mathrm{Ca}_{0,5} \mathrm{Sr}_{0,5} \mathrm{TiO}_{3}$ - método dos precursores poliméricos; atmosfera: nitrogênio. 
É mostrada na Figura 28 que a perda de massa de $\sim 77 \%$ ocorre entre 220 e $1075^{\circ} \mathrm{C}$. Há vários eventos endotérmicos, na faixa de temperaturas entre 500 e $750^{\circ} \mathrm{C}$, associados a essa perda de massa. O pico exotérmico em 1075 ${ }^{\circ} \mathrm{C}$ é provavelmente devido à formação da fase cristalina do $\mathrm{Ca}_{0,5} \mathrm{Sr}_{0,5} \mathrm{TiO}_{3}$.

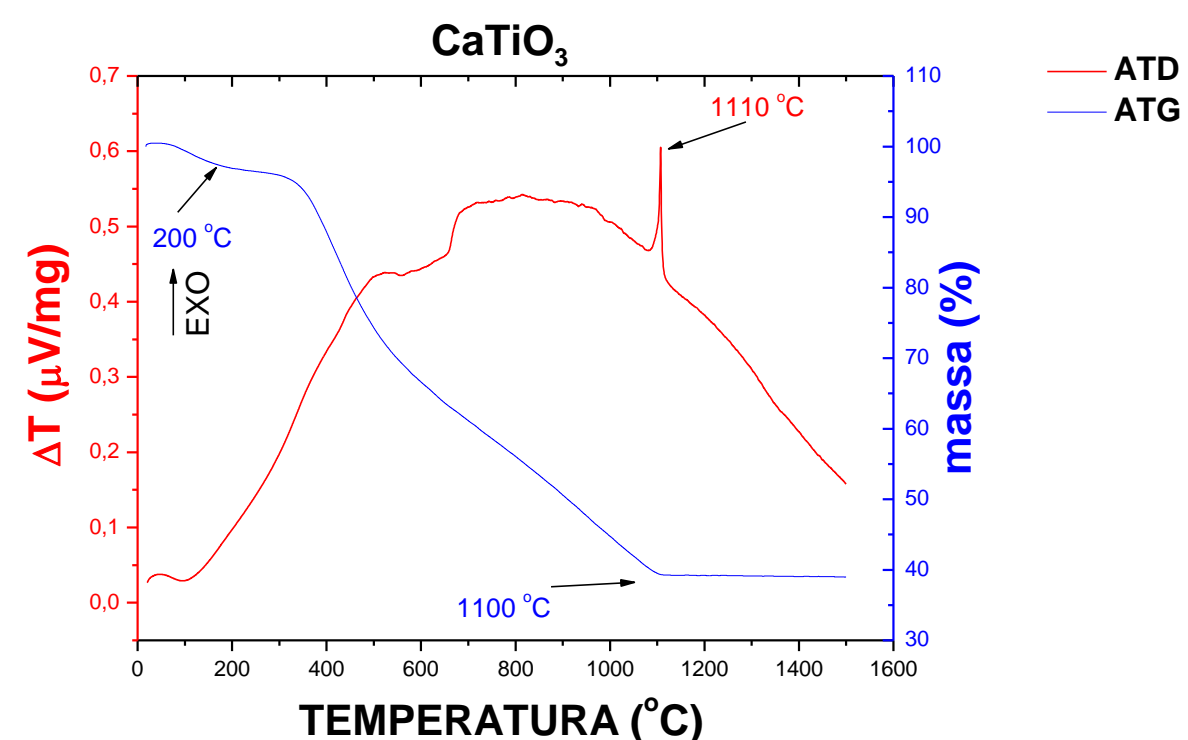

Figura 29 - Curvas de análise termogravimétrica e térmica diferencial da resina precursora de $\mathrm{CaTiO}_{3}$ - método dos precursores poliméricos; atmosfera: nitrogênio.

Tem-se na Figura 29 que a perda de massa de $61 \%$ ocorre entre 200 e $1110^{\circ} \mathrm{C}$. Há vários eventos endotérmicos, na faixa de temperaturas entre $500 \mathrm{e}$ $700{ }^{\circ} \mathrm{C}$, associados a essa perda de massa. O pico exotérmico em $1110^{\circ} \mathrm{C}$ é provavelmente devido à formação da fase cristalina do $\mathrm{CaTiO}_{3}$.

Para fins de comparação são mostrados na Figura 30, em uma única figura, os resultados de análise térmica diferencial apresentados nas Figuras 27, 28 e 29. 

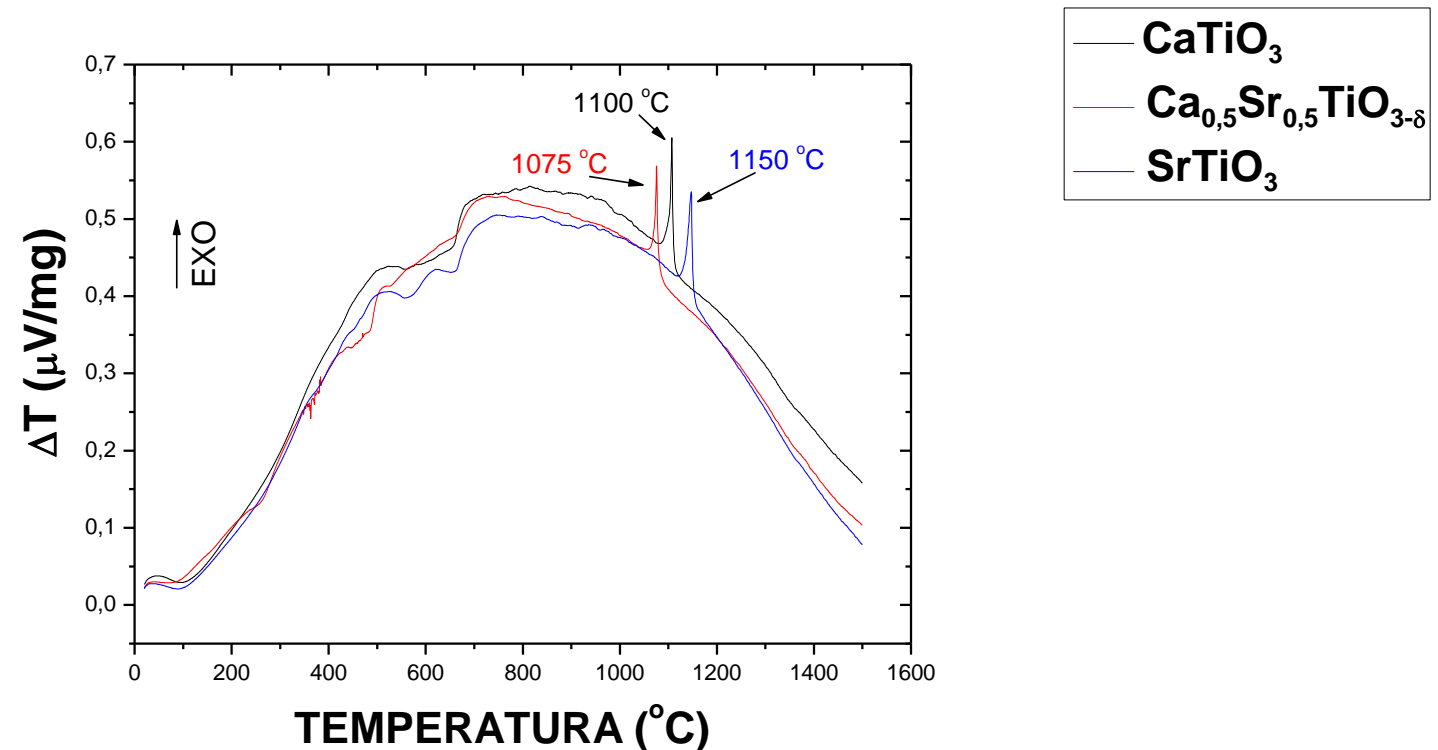

Figura 30 - Curvas de análise térmica diferencial das resinas precursoras de $\mathrm{SrTiO}_{3}$, $\mathrm{Ca}_{0,5} \mathrm{Sr}_{0,5} \mathrm{TiO}_{3}$ e $\mathrm{CaTiO}_{3}$ - método dos precursores poliméricos; atmosfera: nitrogênio.

As curvas de análise térmica diferencial dos três compostos sintetizados pela técnica dos precursores poliméricos e mostrada na Figura 30, apresentando formatos similares, cada composto com um valor de temperatura do pico exotérmico: 1150, 1075 e $1110^{\circ} \mathrm{C}$. Essas são as temperaturas prováveis de cristalização dos compostos $\mathrm{SrTiO}_{3}, \mathrm{Ca}_{0,5} \mathrm{Sr}_{0,5} \mathrm{TiO}_{3}$ e $\mathrm{CaTiO}_{3}$, respectivamente.

Tem-se na Figura 31, para fins de comparação em uma única figura, os resultados de análise termogravimétrica apresentados nas Figuras 27, 28 e 29. 


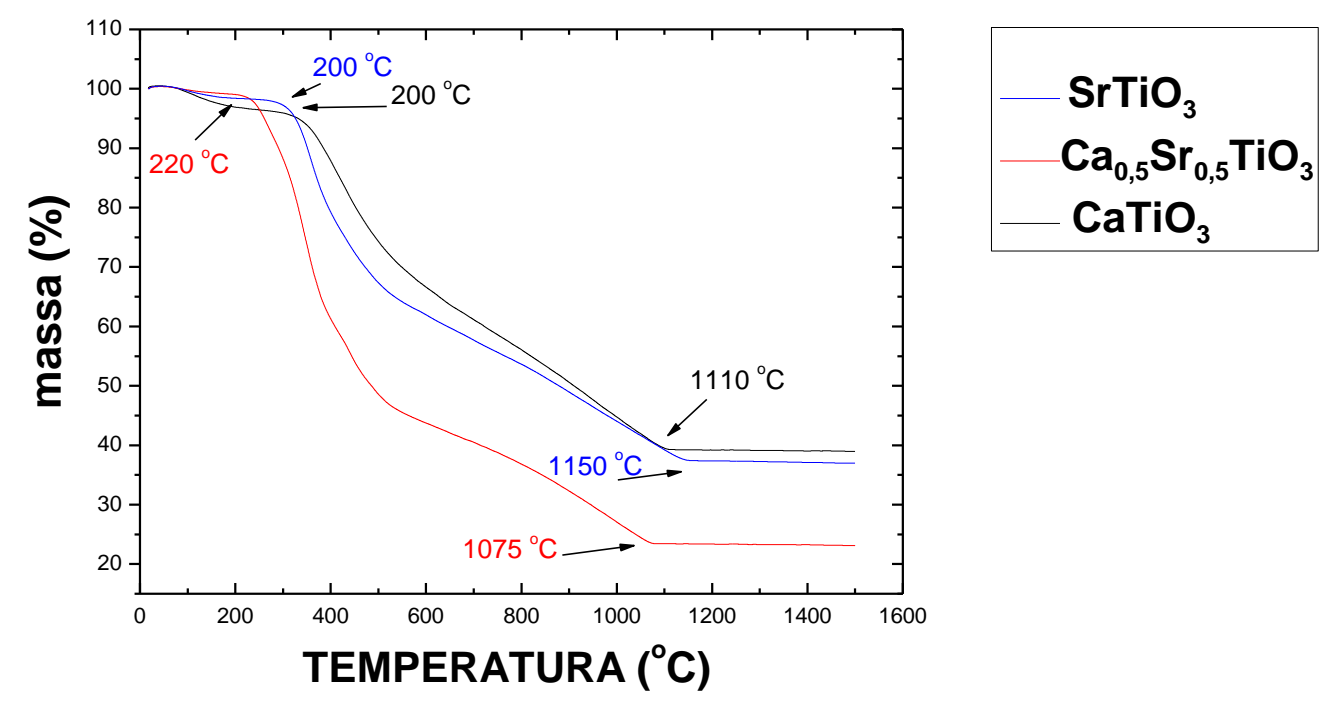

Figura 31 - Curvas de análise termogravimétrica das resinas precursoras de $\mathrm{SrTiO}_{3}$, $\mathrm{Ca}_{0,5} \mathrm{Sr}_{0,5} \mathrm{TiO}_{3}$ e $\mathrm{CaTiO}_{3}$ - método dos precursores poliméricos; atmosfera: nitrogênio.

A perda de massa é significativa entre 200 e $1150{ }^{\circ} \mathrm{C}$, conforme mostrado na Figura 31.

Levando-se em consideração as possíveis reações químicas que ocorrem durante os processos de queima, foram calculados os valores de perda de massa, que são expostos na Tabela 3 juntamente com os determinados na análise dos dados de análise termogravimétrica. 
Tabela 3 - Valores de perda de massa das composições $\operatorname{SrTi0}_{, 65} \mathrm{Fe}_{0,35} \mathrm{O}_{3-\delta}$, $\mathrm{Ca}_{0,5} \mathrm{Sr}_{0,5} \mathrm{TiO}_{, 65} \mathrm{Fe}_{0,35} \mathrm{O}_{3-\delta}, \quad \mathrm{CaTiO}_{, 65} \mathrm{Fe}_{0,35} \mathrm{O}_{3-\delta}, \quad \mathrm{SrTiO}_{3}, \mathrm{Ca}_{0,5} \mathrm{Sr}_{0,5} \mathrm{TiO}_{3}$ e CaTiO $\mathrm{C}_{3}$, durante 0 aquecimento a $10^{\circ} \mathrm{C} / \mathrm{min}$ até a $1550^{\circ} \mathrm{C}$ ao ar.

Perda de massa

Composição

$\Delta \%_{\text {Medido }} \quad \Delta \%_{\text {Calculado }}$

$\Delta \%_{\text {Calc }}-\Delta \%_{\text {Med }}$

\begin{tabular}{|c|c|c|c|c|}
\hline \multirow{6}{*}{ 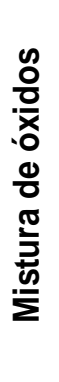 } & $\mathrm{SrTi}_{0,65} \mathrm{Fe}_{0,35} \mathrm{O}_{3-\delta}$ & 17,4 & 19,3 & 1,9 \\
\hline & $\mathrm{Ca}_{0,5} \mathrm{Sr}_{0,5} \mathrm{Ti}_{0,65} \mathrm{Fe}_{0,35} \mathrm{O}_{3-\delta}$ & 18,9 & 21,6 & 2,7 \\
\hline & $\mathrm{CaTi}_{0,65} \mathrm{Fe}_{0,35} \mathrm{O}_{3-\delta}$ & 23,2 & 24,4 & 1,2 \\
\hline & $\mathrm{SrTiO}_{3}$ & 16,5 & 19,3 & 2,8 \\
\hline & $\mathrm{Ca}_{0,5} \mathrm{Sr}_{0,5} \mathrm{TiO}_{3}$ & 21,2 & 21,6 & 0,4 \\
\hline & $\mathrm{CaTiO}_{3}$ & 23,2 & 24,4 & 1,2 \\
\hline \multirow{6}{*}{ 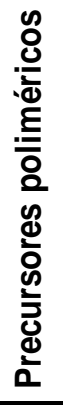 } & $\mathrm{SrTi}_{0,65} \mathrm{Fe}_{0,35} \mathrm{O}_{3-\delta}$ & 71,8 & 55,3 & $-16,5$ \\
\hline & $\mathrm{Ca}_{0,5} \mathrm{Sr}_{0,5} \mathrm{Ti}_{0,65} \mathrm{Fe}_{0,35} \mathrm{O}_{3-\delta}$ & 78,1 & 58,3 & $-19,8$ \\
\hline & $\mathrm{CaTi}_{0,65} \mathrm{Fe}_{0,35} \mathrm{O}_{3-\delta}$ & 65,0 & 61,5 & $-3,5$ \\
\hline & $\mathrm{SrTiO}_{3}$ & 63,4 & 57,5 & $-5,9$ \\
\hline & $\mathrm{Ca}_{0,5} \mathrm{Sr}_{0,5} \mathrm{TiO}_{3}$ & 77,2 & 60,8 & $-16,4$ \\
\hline & $\mathrm{CaTiO}_{3}$ & 61,4 & 64,6 & 3,2 \\
\hline
\end{tabular}

Os valores de perda de massa calculados são maiores que os experimentais para os compostos preparados por síntese de estado sólido, enquanto que são menores para os compostos preparados pelo método dos precursores poliméricos, conforme mostrado na Tabela 3.

Para compostos provenientes da síntese de estado sólido os valores de perda de massa experimental estão próximos dos valores calculados. As diferenças podem ser devidas aos teores de pureza dos materiais de partida, não levados em conta nos cálculos a partir das reações químicas. Já para os compostos provenientes da técnica dos precursores poliméricos, os valores experimentais diferem dos valores calculados, provavelmente por conterem resíduos de água, ácido cítrico e etilenoglicol, não completamente eliminados no primeiro tratamento térmico de calcinação.

Foram determinadas as temperaturas de decomposição térmica dos pós cerâmicos de titanato de estrôncio com óxido de ferro $\left(\mathrm{SrTi}_{0,65} \mathrm{Fe}_{0,35} \mathrm{O}_{3-\delta}\right)$, titanato de cálcio com óxido de ferro $\left(\mathrm{CaTi}_{0,65} \mathrm{Fe}_{0,35} \mathrm{O}_{3-\delta}\right)$ e titanato de cálcio e estrôncio com óxido de ferro $\left(\mathrm{Ca}_{0,5} \mathrm{Sr}_{0,5} \mathrm{Ti}_{0,65} \mathrm{Fe}_{0,35} \mathrm{O}_{3-\delta}\right)$ obtidos por síntese de 
estado sólido e das resinas poliméricas correspondentes obtidas pela técnica dos precursores poliméricos.

\subsubsection{DENSIDADES}

A Tabela 4 mostra os valores das densidades cristalográfica $\left(\rho_{t}\right)$, calculada a partir do método de Rietveld, densidade aparente $\left(\rho_{\mathrm{a}}\right)$, calculada a partir das dimensões e da massa do corpo de prova, densidade hidrostática $\left(\rho_{h}\right)$, calculada pelo método de Arquimedes, e a relação \%DT, que expressa a porcentagem da densidade medida em relação à cristalográfica, para as composições $\mathrm{Ca}_{\mathrm{x}} \mathrm{Sr}_{1-\mathrm{x}} \mathrm{Ti}_{0,65} \mathrm{Fe}_{0,35} \mathrm{O}_{3-\delta}, \mathrm{x}=0$, 0,5 e 1, obtidos pelo método de reação de estado sólido.

Tabela 4 - Comparativo das densidades alcançadas em relação à densidade total para as composições $\mathrm{Ca}_{x} \mathrm{Sr}_{1-\mathrm{x}} \mathrm{Ti}_{0,65} \mathrm{Fe}_{0,35} \mathrm{O}_{3-\delta}, \mathrm{x}=0,0,5$ e 1 .

\begin{tabular}{|c|c|c|c|}
\hline \multirow[b]{2}{*}{ Composição } & \multicolumn{2}{|c|}{ Densidade $\left(\mathrm{g} / \mathrm{cm}^{3}\right)$} & \multirow[b]{2}{*}{$\begin{array}{c}\rho_{\mathrm{h}} \\
(\% \mathrm{DT}) \\
\end{array}$} \\
\hline & $\rho_{\mathrm{t}}$ & $\begin{array}{c}\rho_{\mathrm{a}} \\
(\% \mathrm{DT})\end{array}$ & \\
\hline \multirow[t]{2}{*}{$\mathrm{SrTi}_{0,65} \mathrm{Fe}_{0,35} \mathrm{O}_{3-\delta}$} & 5,05 & 3,39 & 3,40 \\
\hline & & 67,0 & 67,4 \\
\hline \multirow[t]{2}{*}{$\mathrm{Sr}_{0,5} \mathrm{Ca}_{0,5} \mathrm{Ti}_{0,65} \mathrm{Fe}_{0,35} \mathrm{O}_{3-\delta}$} & 4,29 & 3,17 & 3,21 \\
\hline & & 73,9 & 74,8 \\
\hline \multirow{2}{*}{$\mathrm{CaTi}_{0,65} \mathrm{Fe}_{0,35} \mathrm{O}_{3-\delta}$} & 3,85 & 2,89 & 2,93 \\
\hline & & 75,1 & 76,0 \\
\hline
\end{tabular}

O material atinge entre 67 e $76 \%$ da densidade cristalográfica, conforme mostrado na Tabela 4, porém quando observado com microscópio páginas 66 - 69, verifica-se que os compostos são densos, apresentando aglomerados fortes e poucos ou quase nenhum poro.

\subsubsection{DILATOMETRIA}

A técnica de dilatometria foi utilizada para determinação do perfil de sinterização dos compostos $\mathrm{Ca}_{x} \mathrm{Sr}_{1-\mathrm{x}} \mathrm{Ti}_{0,65} \mathrm{Fe}_{0,35} \mathrm{O}_{3-\delta}, \mathrm{x}=0$, 0,5 e 1, obtidos pela técnica de reação de estado sólido. 
A variação longitudinal dos corpos de prova em função da temperatura é mostrada nas Figuras 32, 33 e 34; e na Figura 35 tem-se o resultado das três composições.

Para o ensaio dilatométrico foram conformados corpos de prova cilíndricos com 7,2 mm de diâmetro e $\sim 14 \mathrm{~mm}$ de comprimento; o material na forma de pó foi compactado uniaxialmente a $\sim 100 \mathrm{MPa} / 15 \mathrm{~s}$ e isostaticamente $\sim 207 \mathrm{MPa} / 5 \mathrm{~min}$.

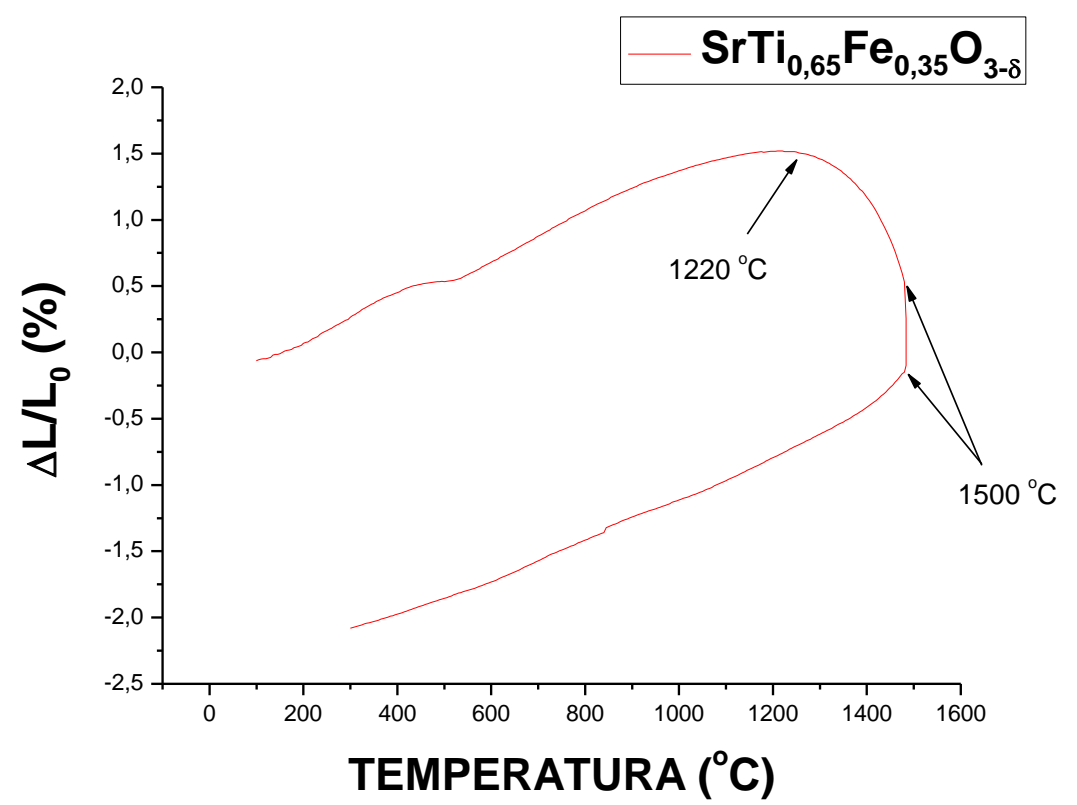

Figura 32 - Curva de retração linear do composto $\mathrm{SrTi}_{0,65} \mathrm{Fe}_{0,35} \mathrm{O}_{3-\delta}$, material obtido pela técnica de reação de estado sólido.

O composto $\mathrm{SrTi}_{0,65} \mathrm{Fe}_{0,35} \mathrm{O}_{3-\delta}$ apresenta expansão linear de 1,5\% durante aquecimento da temperatura ambiente até $1220{ }^{\circ} \mathrm{C}$; durante a isoterma de $1500{ }^{\circ} \mathrm{C} / 15 \mathrm{~min}$. apresentou retração linear de 0,4\%; e resfriado até $300{ }^{\circ} \mathrm{C}$ apresentou uma retração total de $2,1 \%$, conforme mostrado na Figura 32. 


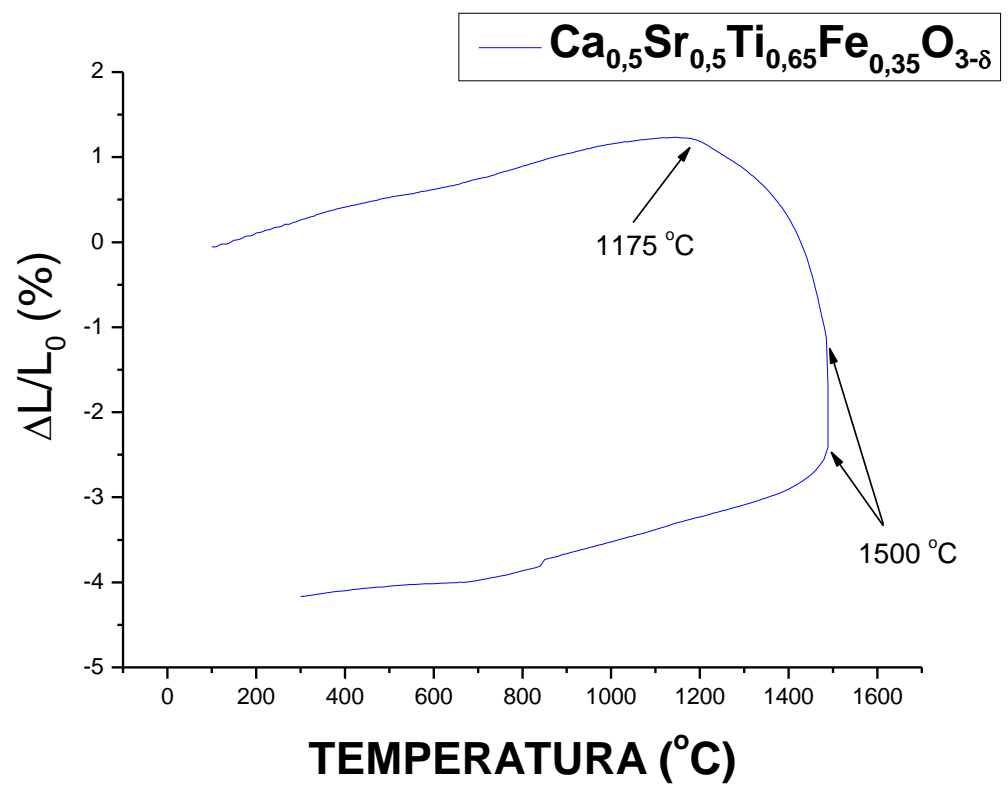

Figura 33 - Curva de retração linear do composto $\mathrm{Ca}_{0,5} \mathrm{Sr}_{0,5} \mathrm{Ti}_{0,65} \mathrm{Fe}_{0,35} \mathrm{O}_{3-\delta}$, material obtido pela técnica de reação de estado sólido.

É mostrada na Figura 33 que a composição $\mathrm{Ca}_{0,5} \mathrm{Sr}_{0,5} \mathrm{Ti}_{0,65} \mathrm{Fe}_{0,35} \mathrm{O}_{3-\delta}$ apresenta expansão de $1,2 \%$ quando aquecida da temperatura ambiente até $1175{ }^{\circ} \mathrm{C}$, apresentando retração a partir desta temperatura, retraindo $0,7 \%$ durante a isoterma de $1500{ }^{\circ} \mathrm{C} / 15 \mathrm{~min}$ e, resfriado a $300{ }^{\circ} \mathrm{C}$, apresenta uma retração total de $4,2 \%$. 


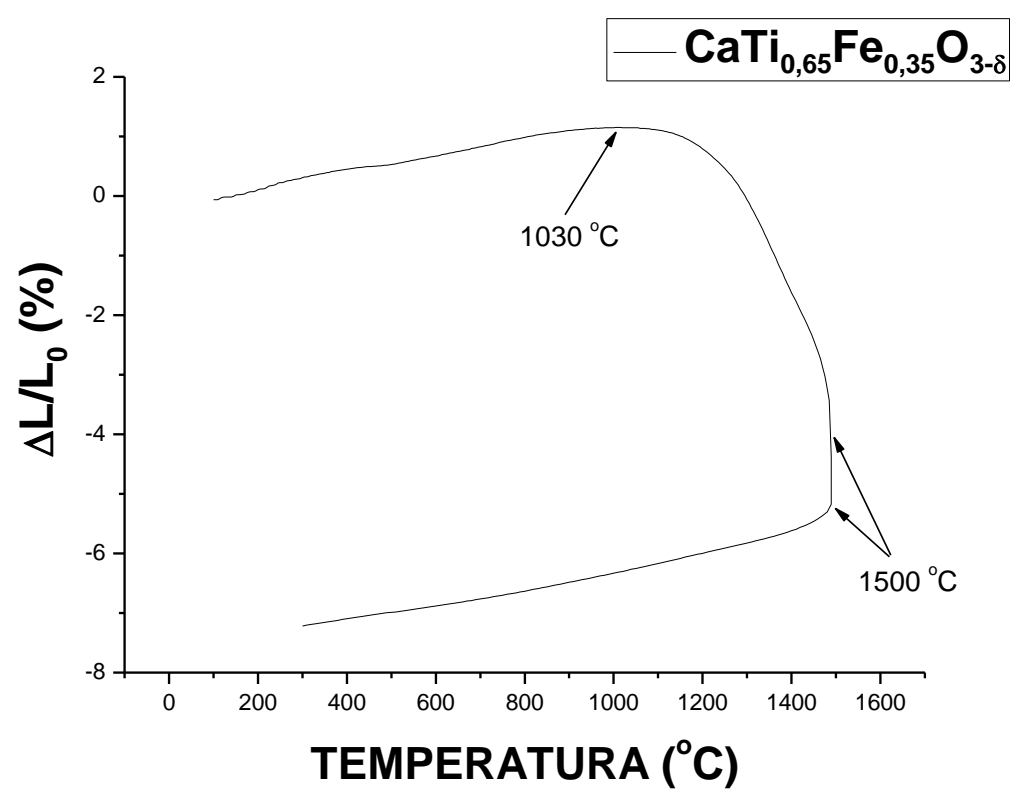

Figura 34 - Curva de retração linear do composto $\mathrm{CaTi}_{0,65} \mathrm{Fe}_{0,35} \mathrm{O}_{3-\delta}$, material obtido pela técnica de reação de estado sólido.

É mostrado na Figura 34 que o corpo de prova do composto $\mathrm{CaTi}_{0,65} \mathrm{Fe}_{0,35} \mathrm{O}_{3-\delta}$, aquecido de temperatura ambiente até $1030{ }^{\circ} \mathrm{C}$, apresenta expansão linear de $1,1 \%$, retraindo a partir desta temperatura, apresentando retração de $0,8 \%$ durante a isoterma de $1500{ }^{\circ} \mathrm{C} / 15 \mathrm{~min}$; retraindo um total de $7,2 \%$ após resfriado até $300{ }^{\circ} \mathrm{C}$. 


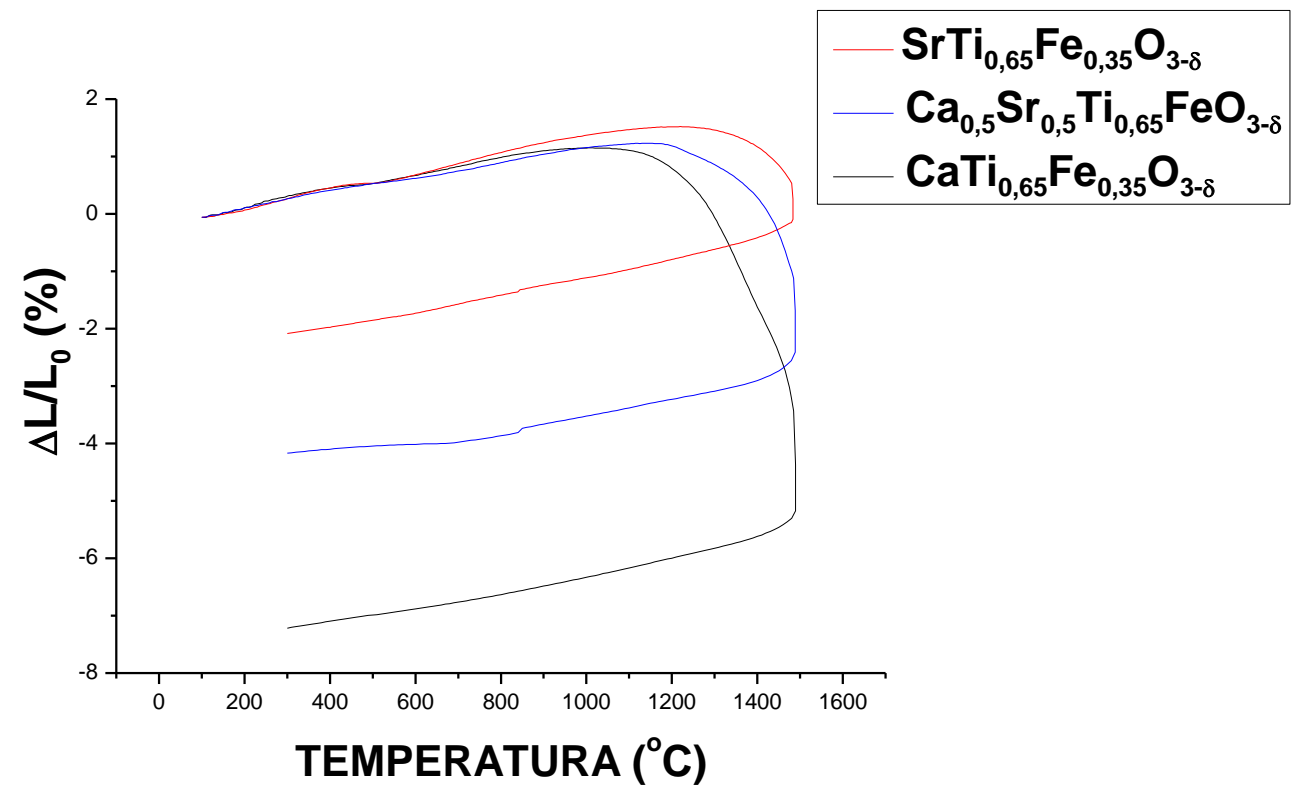

Figura 35 - Curvas de retração linear dos compostos $\mathrm{Ca}_{x} \mathrm{Sr}_{1-x} \mathrm{Ti}_{0,65} \mathrm{Fe}_{0,35} \mathrm{O}_{3-\delta}, x=0,0,5$ e 1, material obtido pela técnica de reação de estado sólido.

Os dados da Figura 35 estão compilados na Tabela 5, mostrando uma retração linear pequena quando comparada a outras cerâmicas sensíveis ao oxigênio, como as à base de zircônia $(\sim 16 \%)^{[58]}$.

Tabela 5 - Valores de expansão e retração máxima para $\mathrm{Ca}_{\mathrm{x}} \mathrm{Sr}_{1-\mathrm{x}} \mathrm{Ti}_{0,65} \mathrm{Fe}_{0,35} \mathrm{O}_{3-\delta} \mathrm{x}=0$, 0,5 e 1, material obtido pela técnica de reação de estado sólido.

\begin{tabular}{|c|c|c|c|c|}
\hline Composição & $\begin{array}{c}\text { Expansão (\%) } \\
\mathrm{T}_{\mathrm{me}}\left({ }^{\circ} \mathrm{C}\right)\end{array}$ & $\begin{array}{c}\text { Retração (\%) } \\
\mathrm{T}_{\text {is }}\left({ }^{\circ} \mathrm{C}\right)\end{array}$ & $\begin{array}{c}\text { Retração } \\
\text { máxima (\%) }\end{array}$ & $\begin{array}{l}\text { Retração } \\
\mathrm{T}_{\max }\left({ }^{\circ} \mathrm{C}\right)\end{array}$ \\
\hline $\mathrm{SrTi}_{0,65} \mathrm{Fe}_{0,35} \mathrm{O}_{3-\delta}$ & $\begin{array}{c}1,5 \\
1220\end{array}$ & $\begin{array}{c}0,4 \\
1500\end{array}$ & 2,1 & 1470 \\
\hline $\mathrm{Ca}_{0,5} \mathrm{Sr}_{0,5} \mathrm{Ti}_{0,65} \mathrm{Fe}_{0,35} \mathrm{O}_{3-\delta}$ & $\begin{array}{c}1,2 \\
1175\end{array}$ & $\begin{array}{c}0,7 \\
1500\end{array}$ & 4,2 & 1470 \\
\hline $\mathrm{CaTi}_{0,65} \mathrm{Fe}_{0,35} \mathrm{O}_{3-\delta}$ & $\begin{array}{c}1,1 \\
1030\end{array}$ & $\begin{array}{c}1,0 \\
1500\end{array}$ & 7,2 & 1460 \\
\hline
\end{tabular}

Considerando-se os dados da Tabela 5 e as micrografias que serão apresentadas nas Figuras 54 - 57, páginas 66 - 69, e os dados da Tabela 7, página 63, as composições $\mathrm{Ca}_{x} \mathrm{Sr}_{1-x} \mathrm{Ti}_{0,65} \mathrm{Fe}_{0,35} \mathrm{O}_{3-\delta}, \mathrm{x}=0$, 0,5 e 1, sinterizam, porém não densificam. 


\subsubsection{DifRAçÃo DE RAIOS $X$ CONVENCIONAL E COM FONTE} SÍNCROTRON

\subsubsection{Difração de raios $X$ convencional}

Para os compostos $\mathrm{SrTi}_{0,65} \mathrm{Fe}_{0,35} \mathrm{O}_{3-\delta}, \quad \mathrm{Ca}_{0,5} \mathrm{Sr}_{0,5} \mathrm{Ti}_{0,65} \mathrm{Fe}_{0,35} \mathrm{O}_{3-\delta} \quad$ e $\mathrm{CaTi}_{0,65} \mathrm{Fe}_{0,35} \mathrm{O}_{3-\delta}$, na forma de pó, obtidos pela técnica de reação de estado sólido foram feitas medidas de difração de raios $X$ convencional e com fonte Síncrotron, e para os compostos obtidos pela técnica dos precursores poliméricos foram feitas medidas de difração de raios $X$ convencional.

São mostrados na Figura 36 os difratogramas de $\mathrm{SrTi}_{0,65} \mathrm{Fe}_{0,35} \mathrm{O}_{3-\delta}$, $\mathrm{Ca}_{0,5} \mathrm{Sr}_{0,5} \mathrm{Ti}_{0,65} \mathrm{Fe}_{0,35} \quad \mathrm{O}_{3-\delta}$ e $\mathrm{CaTi}_{0,65} \mathrm{Fe}_{0,35} \quad \mathrm{O}_{3-\delta}$, normalizados para fins de comparação para as amostras obtidas pela técnica de reação de estado sólido e a Figura 40 mostra os difratogramas dos mesmos materiais obtidos pela técnica dos precursores poliméricos. O procedimento seguido foi:

1) Identificação das fases cristalinas por comparação com o banco de dados Powder Diffraction Data - PDF ${ }^{[59]}$;

2) A partir da estrutura identificada no passo 1, procurou-se a estrutura cristalina no banco de dados Inorganic Crystal structure database ICSD, e

3) Refinamento de Rietveld para confirmação do grupo espacial e determinação dos parâmetros da estrutura cristalina e posição dos átomos na estrutura.

Esse procedimento permite a confirmação do grupo espacial, dos parâmetros de rede e da localização dos átomos na estrutura.

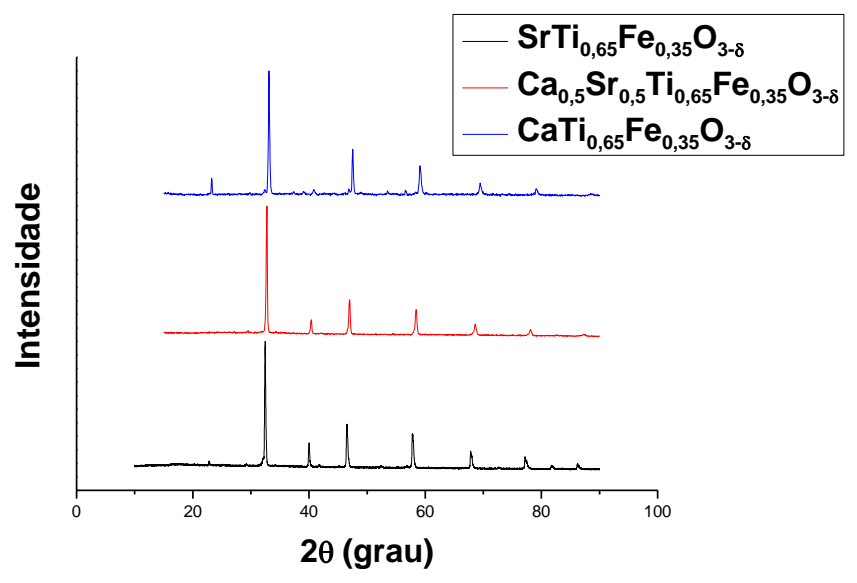

Figura 36 - Difratogramas de raios $X$ de pós de $\mathrm{SrTi}_{0,65} \mathrm{Fe}_{0,35} \mathrm{O}_{3-\delta}, \mathrm{Ca}_{0,5} \mathrm{Sr}_{0,5} \mathrm{Ti}_{0,65} \mathrm{Fe}_{0,35} \mathrm{O}_{3-\delta}$ e $\mathrm{CaTi}_{0,65} \mathrm{Fe}_{0,35} \mathrm{O}_{3-\delta}$, normalizados, obtidos pela técnica de reação de estado sólido $1250{ }^{\circ} \mathrm{C} / 15 \mathrm{~h}$. 
Os ajustes pelo método de Rietveld para os difratogramas das composições $\mathrm{SrTi}_{0,65} \mathrm{Fe}_{0,35} \mathrm{O}_{3-\delta}, \mathrm{Ca}_{0,5} \mathrm{Sr}_{0,5} \mathrm{Ti}_{0,65} \mathrm{Fe}_{0,35} \mathrm{O}_{3-\delta}$ e $\mathrm{CaTi}_{0,65} \mathrm{Fe}_{0,35} \mathrm{O}_{3-\delta}$ são mostrados nas Figuras 37, 38 e 39. A simetria, o grupo espacial, e os parâmetros de rede ${ }^{[49,51,60]}$ são mostrados na Tabela 6.

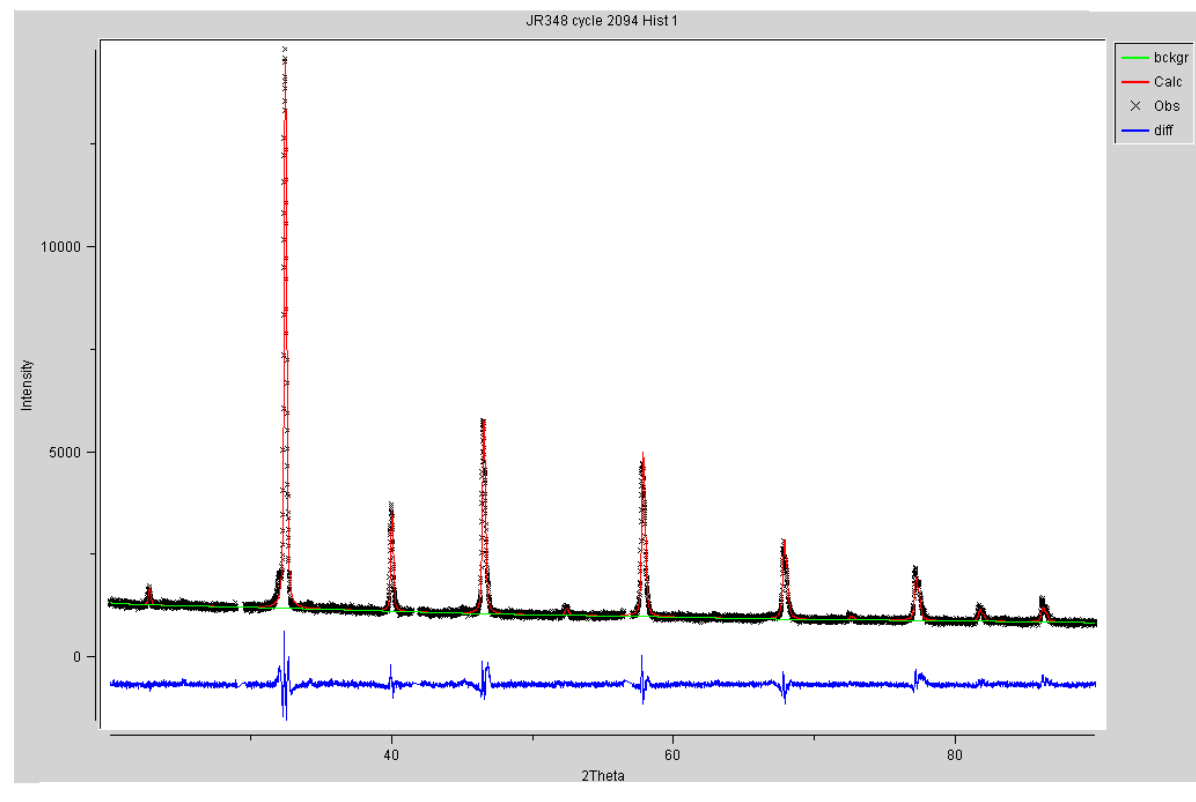

Figura 37 - Gráfico do ajuste de Rietveld para a amostra de composição $\operatorname{SrTi}_{0,65} \mathrm{Fe}_{0,35} \mathrm{O}_{3-\delta}$, com base numa simetria cúbica, $\mathrm{P} \mathrm{m}-3 \mathrm{~m}$.

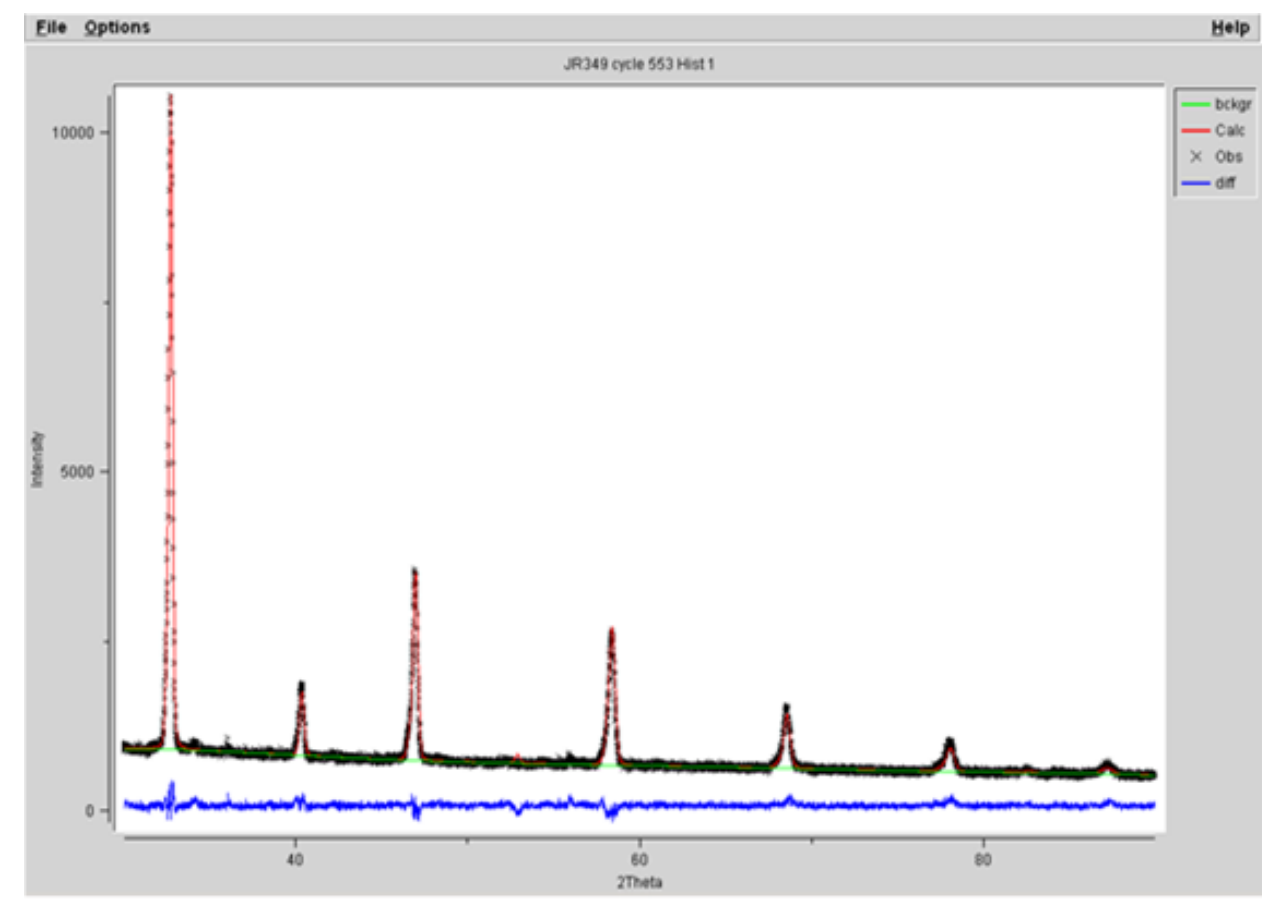

Figura 38 - Gráfico do ajuste de Rietveld para a amostra de composição $\mathrm{Ca}_{0,5} \mathrm{Sr}_{0,5} \mathrm{Ti}_{0,65} \mathrm{Fe}_{0,35} \mathrm{O}_{3-\delta}$, com base numa simetria cúbica, $\mathrm{P} \mathrm{m}-3 \mathrm{~m}$. 


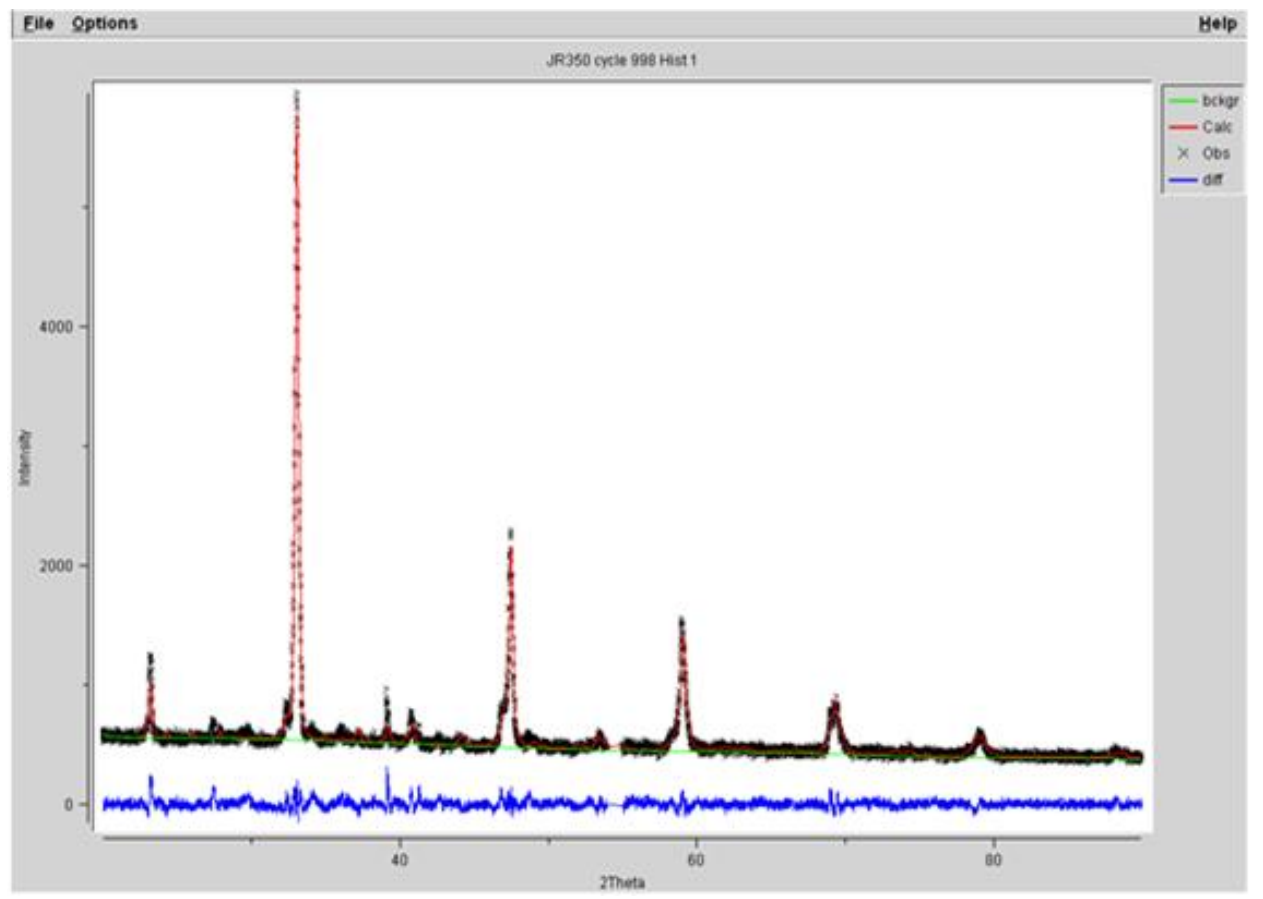

Figura 39 - Gráfico do ajuste de Rietveld para a amostra de composição $\mathrm{CaTi}_{0,65} \mathrm{Fe}_{0,35} \mathrm{O}_{3-\delta}$, com base numa simetria ortorrômbica, $\mathrm{P}$ c $\mathrm{m} \mathrm{n}$.

Os valores obtidos pelo ajuste de Rietveld são mostrados na Tabela 6 e repetidos propositalmente na Tabela 7 a fim de facilitar a comparação entre os resultados obtidos pelos ajustes provenientes de equipamento convencional e com fonte Síncrotron.

Tabela 6 - Resultados do ajuste de Rietveld, parâmetros de rede e simetria para as composições $\mathrm{SrTi}_{0,65} \mathrm{Fe}_{0,35} \mathrm{O}_{3-\delta}, \mathrm{Ca}_{0,5} \mathrm{Sr}_{0,5} \mathrm{Ti}_{0,65} \mathrm{Fe}_{0,35} \mathrm{O}_{3-\delta}$ e $\mathrm{CaTi}_{0,65} \mathrm{Fe}_{0,35} \mathrm{O}_{3-\delta}$, obtidos pela técnica de reação de estado sólido medidos em equipamento convencional.

\begin{tabular}{llll}
\multicolumn{1}{c}{ Composição } & Simetria & $\begin{array}{c}\text { Grupo } \\
\text { espacial }\end{array}$ & $\begin{array}{c}\text { Parâmetro de } \\
\text { rede }\end{array}$ \\
\hline $\operatorname{SrTi}_{0,65} \mathrm{Fe}_{0,35} \mathrm{O}_{3-\delta}$ & cúbico & $\mathrm{P} \mathrm{m} \mathrm{-3} \mathrm{m}$ & $\mathrm{a}=3,90054(3)$ \\
$\mathrm{Ca}_{0,5} \mathrm{Sr}_{0,5} \mathrm{Ti}_{0,65} \mathrm{Fe}_{0,35} \mathrm{O}_{3-\delta}$ & cúbico & $\mathrm{P} \mathrm{m} \mathrm{-3} \mathrm{m}$ & $\mathrm{a}=3,86838(3)$ \\
$\mathrm{CaTi}_{0,65} \mathrm{Fe}_{0,35} \mathrm{O}_{3-\delta}$ & ortorrômbico & $\mathrm{P} \mathrm{c} \mathrm{m} \mathrm{n}$ & $\begin{array}{l}\mathrm{a}=5,4068(2) \\
\mathrm{b}=5,4173(2) \\
\end{array}$ \\
& & & $\mathrm{c}=7,6682(5)$ \\
\hline
\end{tabular}


São mostrados na Figura 40 os difratogramas de $\mathrm{SrTi}_{0,65} \mathrm{Fe}_{0,35} \mathrm{O}_{3-\delta}$, $\mathrm{Ca}_{0,5} \mathrm{Sr}_{0,5} \mathrm{Ti}_{0,65} \mathrm{Fe}_{0,35} \mathrm{O}_{3-\delta}$ e $\mathrm{CaTi}_{0,65} \mathrm{Fe}_{0,35} \mathrm{O}_{3-\delta}$, obtidos pela técnica dos precursores poliméricos, normalizados para fins de comparação.

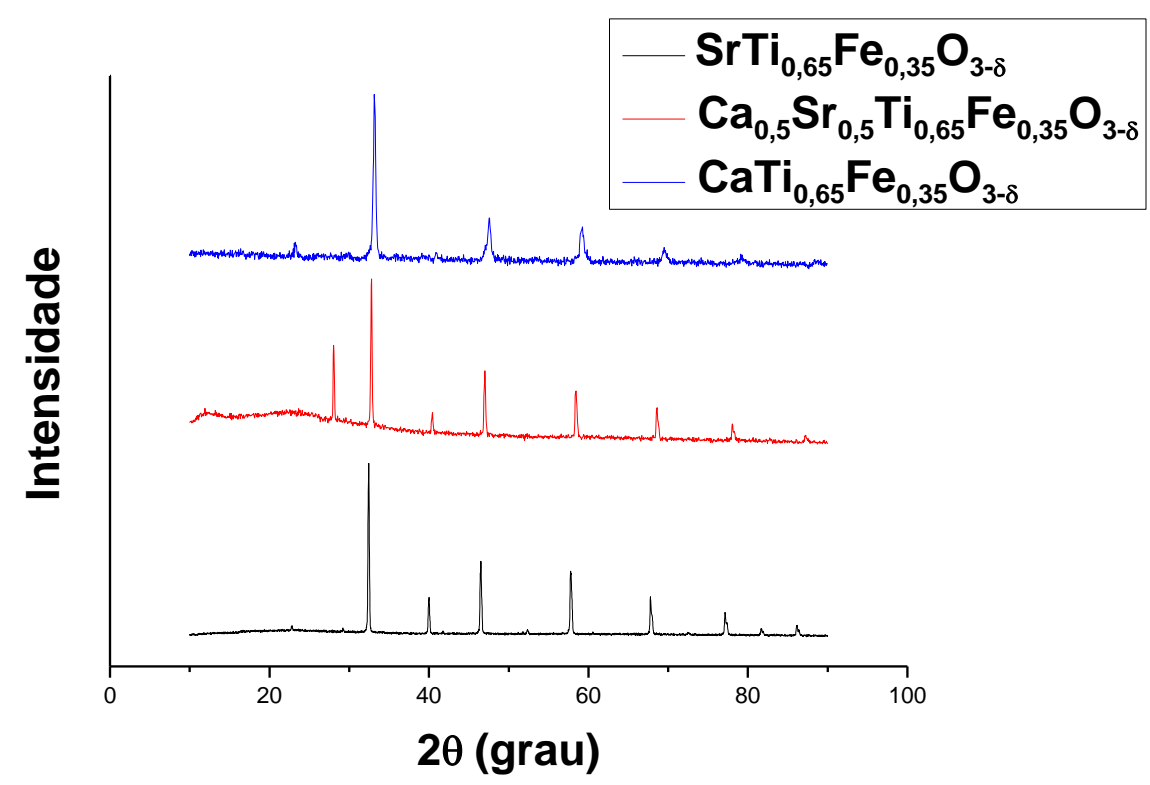

Figura 40 - Difratogramas de raios $X$ de pós de $\mathrm{SrTi}_{, 65} \mathrm{Fe}_{0,35} \mathrm{O}_{3-\delta} \quad \mathrm{Ca}_{0,5} \mathrm{Sr}_{0,5} \mathrm{Ti}_{0,65} \mathrm{Fe}_{0,35} \mathrm{O}_{3-\delta} \mathrm{e}$ $\mathrm{CaTi}_{0,65} \mathrm{Fe}_{0,35} \mathrm{O}_{3-\delta}$, normalizados, preparados pela técnica dos precursores poliméricos.

Não foi feito ajuste pelo método de Rietveld para as medidas dos pós de $\mathrm{SrTi}_{0,65} \mathrm{Fe}_{0,35} \mathrm{O}_{3-\delta}, \mathrm{Ca}_{0,5} \mathrm{Sr}_{0,5} \mathrm{Ti}_{0,65} \mathrm{Fe}_{0,35} \mathrm{O}_{3-\delta}$ e $\mathrm{CaTi}_{0,65} \mathrm{Fe}_{0,35} \mathrm{O}_{3-\delta}$, preparados pela técnica dos precursores poliméricos.

\subsubsection{Difração com fonte Síncrotron}

Tem-se na Figura 41 os difratogramas obtidos com fonte Síncrotron das composições $\mathrm{SrTi}_{0,65} \mathrm{Fe}_{0,35} \mathrm{O}_{3-\delta}, \mathrm{Ca}_{0,5} \mathrm{Sr}_{0,5} \mathrm{Ti}_{0,65} \mathrm{Fe}_{0,35} \mathrm{O}_{3-\delta}$ e $\mathrm{CaTi}_{0,65} \mathrm{Fe}_{0,35} \mathrm{O}_{3-\delta}$, obtidos pela técnica de reação de estado sólido, normalizados para fins de comparação, sendo reapresentados isoladamente nas Figuras 42, 45 e 48 para análises.

Foi utilizado o banco de dados ICDD-PDF ${ }^{[59]}$ para identificação das estruturas cristalinas, conforme Figuras 43,46 e 49. São mostrados nas Figuras 44, 47 e 50 os gráficos dos ajustes de Rietveld. 


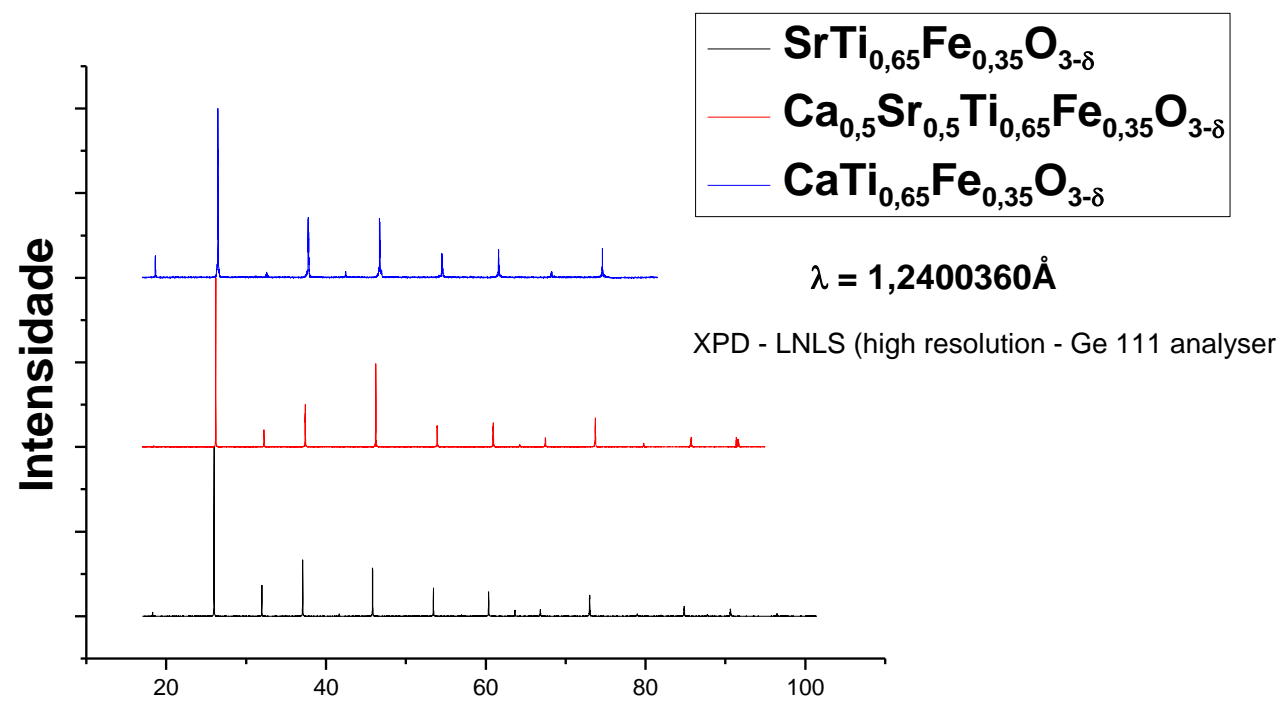

$2 \theta$ (grau)

Figura 41 - Difratograma de raios $X$ com fonte Síncrotron de $\operatorname{SrTi}_{0,65} \mathrm{Fe}_{0,35} \mathrm{O}_{3-\delta}$, $\mathrm{Ca}_{0,5} \mathrm{Sr}_{0,5} \mathrm{Ti}_{0,65} \mathrm{Fe}_{0,35} \mathrm{O}_{3-\delta}$ e $\mathrm{CaTi}_{0,65} \mathrm{Fe}_{0,35} \mathrm{O}_{3-\delta}$, material obtido por reação de estado sólido; dois tratamentos térmicos: $1250{ }^{\circ} \mathrm{C} / 15 \mathrm{~h}+1400^{\circ} \mathrm{C} / 60 \mathrm{~h}$.

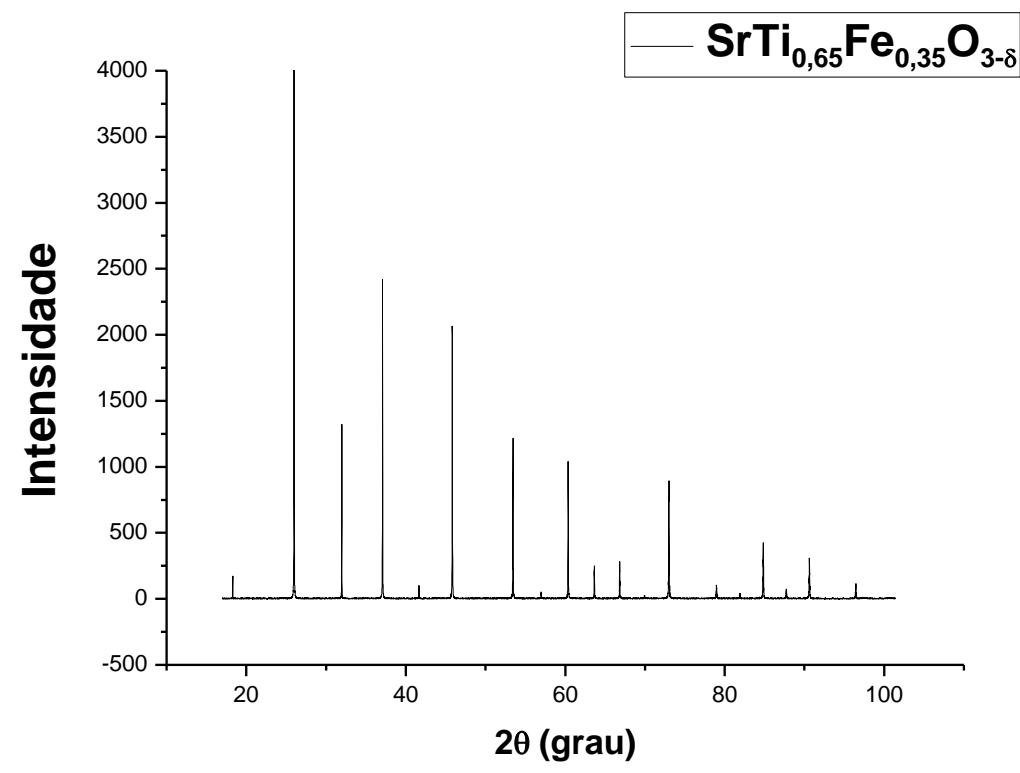

Figura 42 - Difratograma de raios $X$ com fonte Síncrotron de $\mathrm{SrTi}_{0,65} \mathrm{Fe}_{0,35} \mathrm{O}_{3-\delta}$, material obtido por reação de estado sólido; dois tratamentos térmicos: $1250^{\circ} \mathrm{C} / 15 \mathrm{~h}+1400{ }^{\circ} \mathrm{C} / 60 \mathrm{~h}$. 


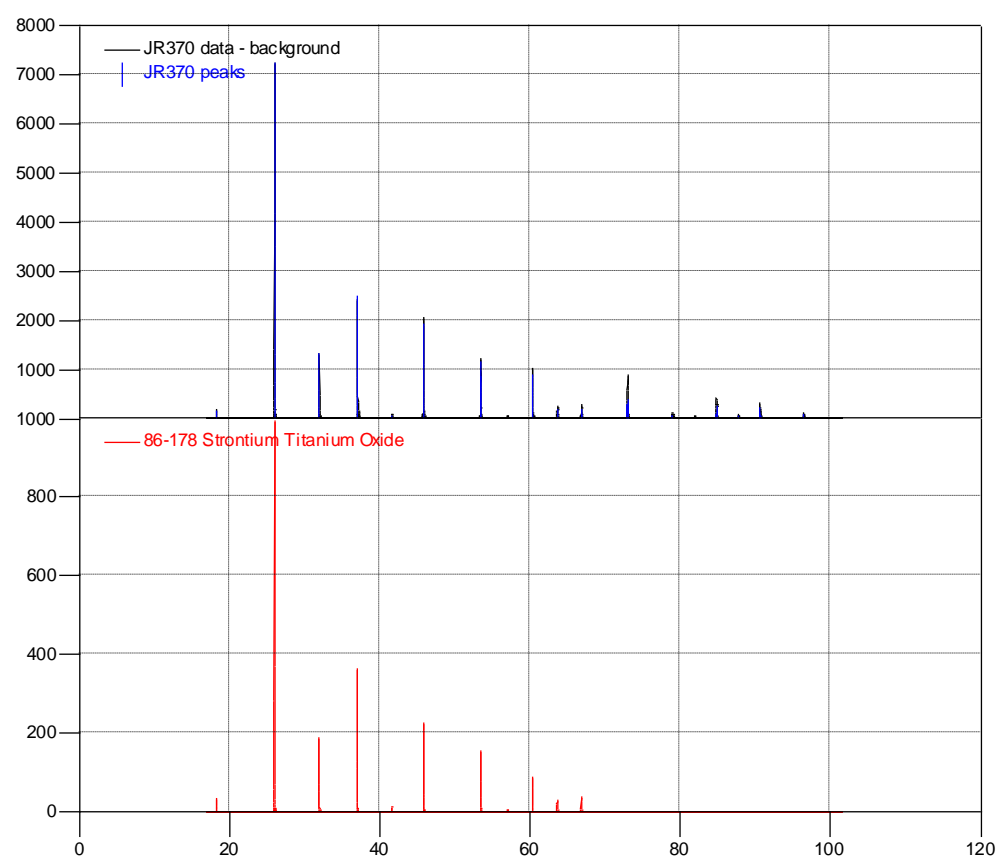

Figura 43 - Identificação da fase cristalina da amostra de $\mathrm{SrTi}_{0,65} \mathrm{Fe}_{0,35} \mathrm{O}_{3-\delta}$, com o programa Search Math ${ }^{[61]}$ e do banco de dados de difração ICDD-PDF ${ }^{[59]}$. Em azul o difratograma medido, em vermelho a simulação do difratograma da fase SrTiO.

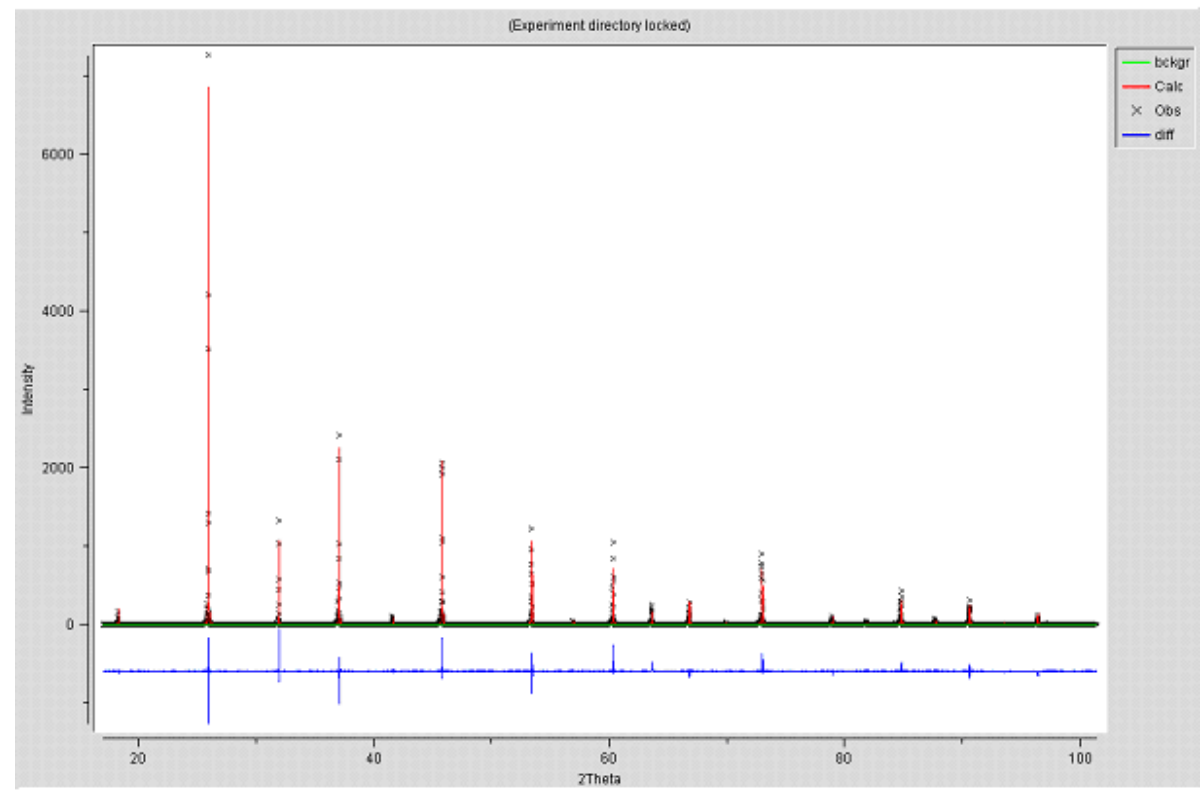

Figura 44 - Gráfico do ajuste de Rietveld para a amostra de composição $\mathrm{SrTi}_{0,65} \mathrm{Fe}_{0,35} \mathrm{O}_{3-\delta,}$ com base numa simetria cúbica, $\mathrm{P} \mathrm{m}-3 \mathrm{~m}$. 


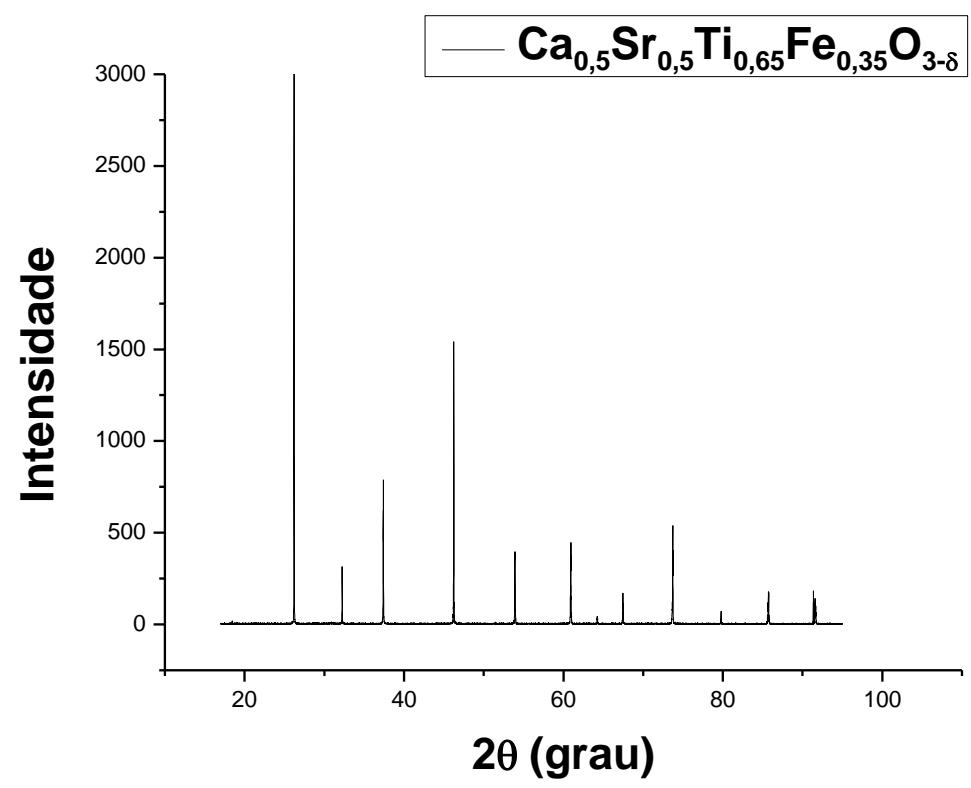

Figura 45 - Difratograma de raios $X$ com fonte Síncrotron de $\mathrm{Ca}_{0,5} \mathrm{Sr}_{0,5} \mathrm{Ti}_{0,65} \mathrm{Fe}_{0,35} \mathrm{O}_{3-\delta}$, material obtido por reação de estado sólido; dois tratamentos térmicos: $1250^{\circ} \mathrm{C} / 15 \mathrm{~h}+1400^{\circ} \mathrm{C} / 60 \mathrm{~h}$.

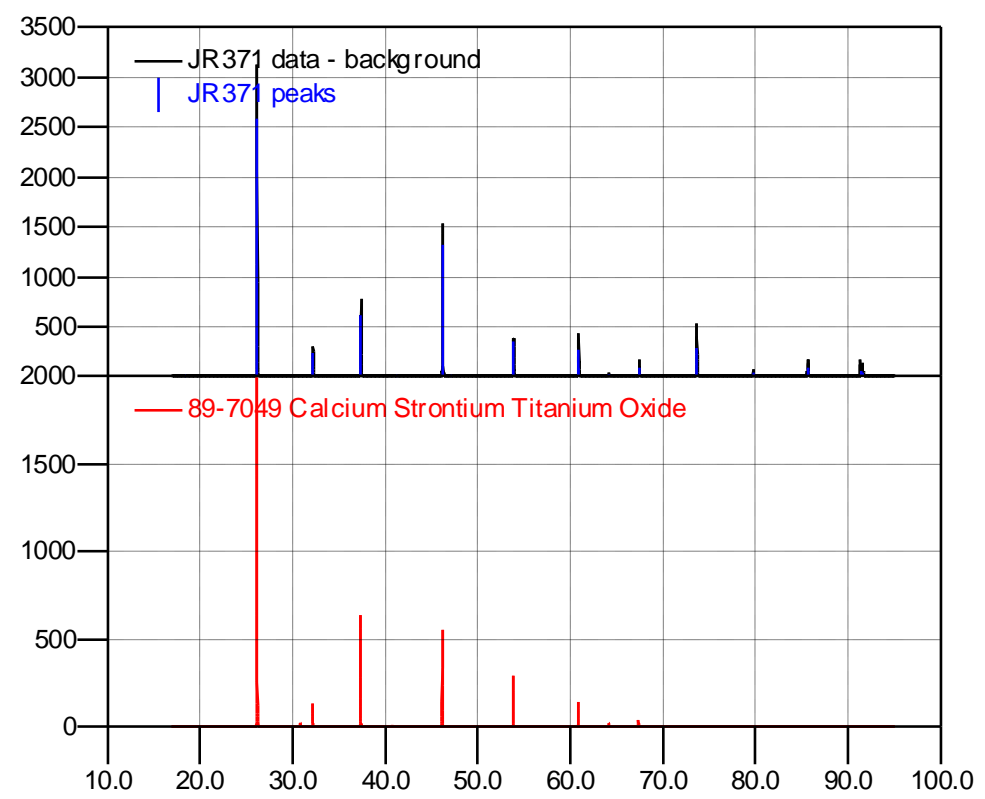

Figura 46 - Identificacão da fase cristalina da amostra de $\mathrm{Ca}_{0,5} \mathrm{Sr}_{0,5} \mathrm{Ti}_{0,65} \mathrm{Fe}_{0,35} \mathrm{O}_{3-\delta}$, pelo programa Search Math ${ }^{[61]}$ e do banco de dados de difração PDF ${ }^{[59]}$. Em azul o difratograma medido, em vermelho a simulação do difratograma da fase CaSrTiO. 


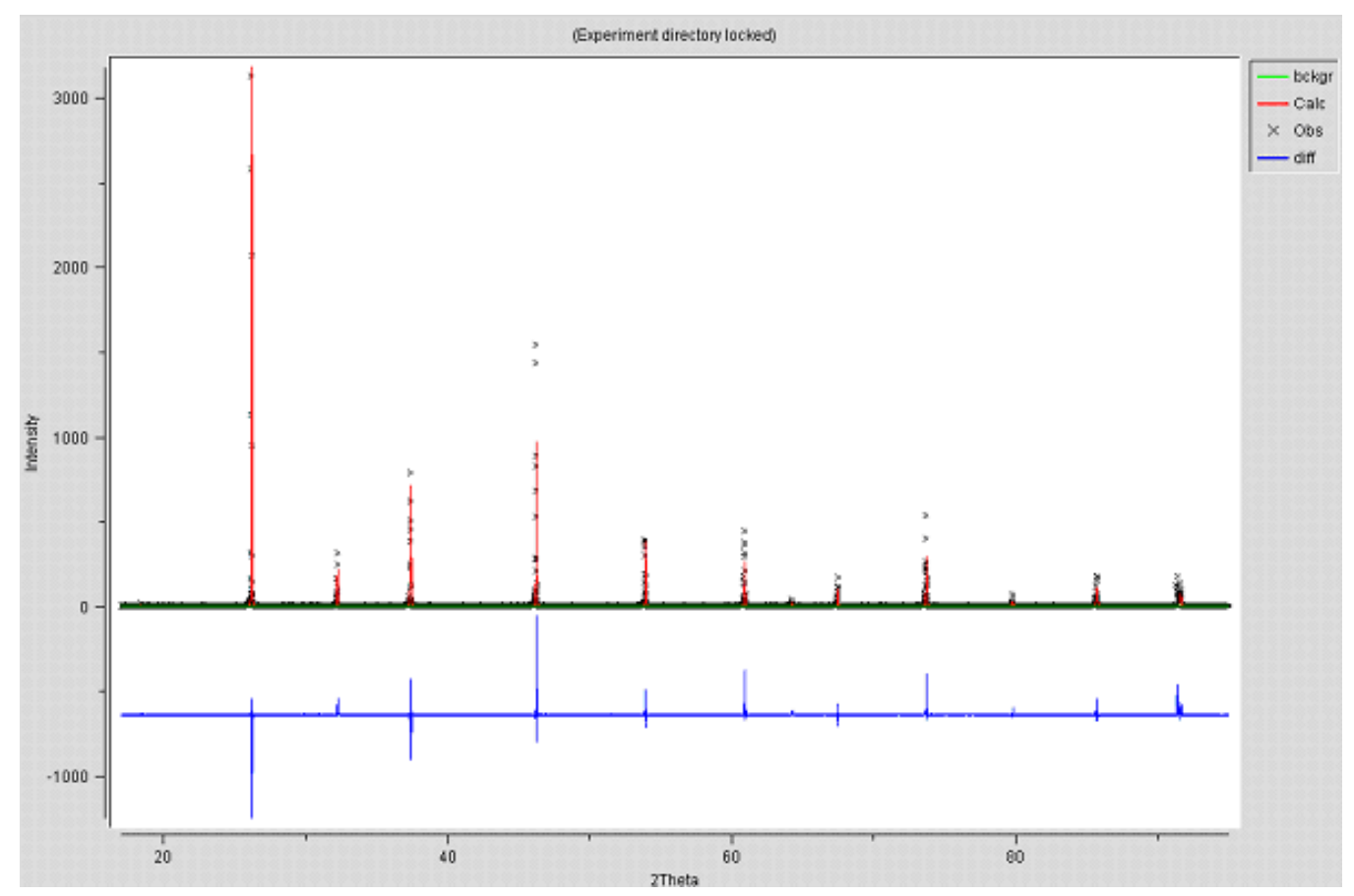

Figura 47 - Gráfico do ajuste de Rietveld para a amostra de composição $\mathrm{Ca}_{0,5} \mathrm{Sr}_{0,5} \mathrm{Ti}_{0,65} \mathrm{Fe}_{0,35} \mathrm{O}_{3-\delta}$, com base numa simetria ortorrômbica, $\mathrm{B} \mathrm{m} \mathrm{m} \mathrm{b.}$

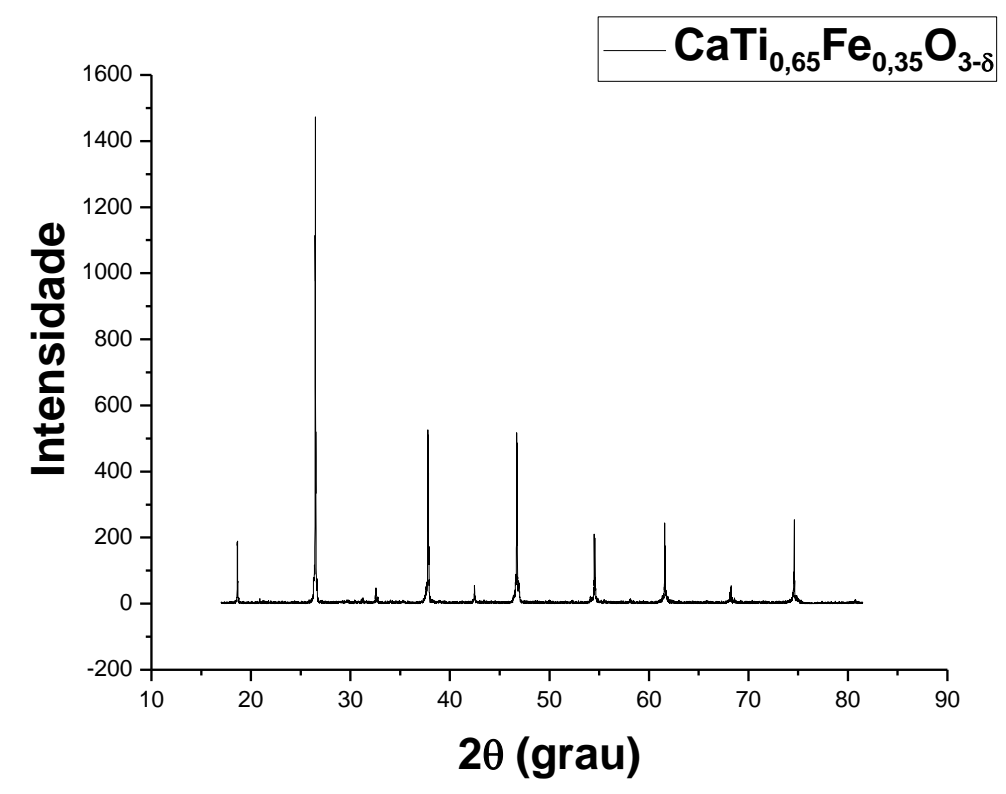

Figura 48 - Difratograma de raio $X$ com fonte Síncrotron de $\mathrm{CaTi}_{0,65} \mathrm{Fe}_{0,35} \mathrm{O}_{3-\delta}$, material obtido por reação de estado sólido; dois tratamentos térmicos: $1250{ }^{\circ} \mathrm{C} / 15 \mathrm{~h}+1400^{\circ} \mathrm{C} / 60 \mathrm{~h}$. 


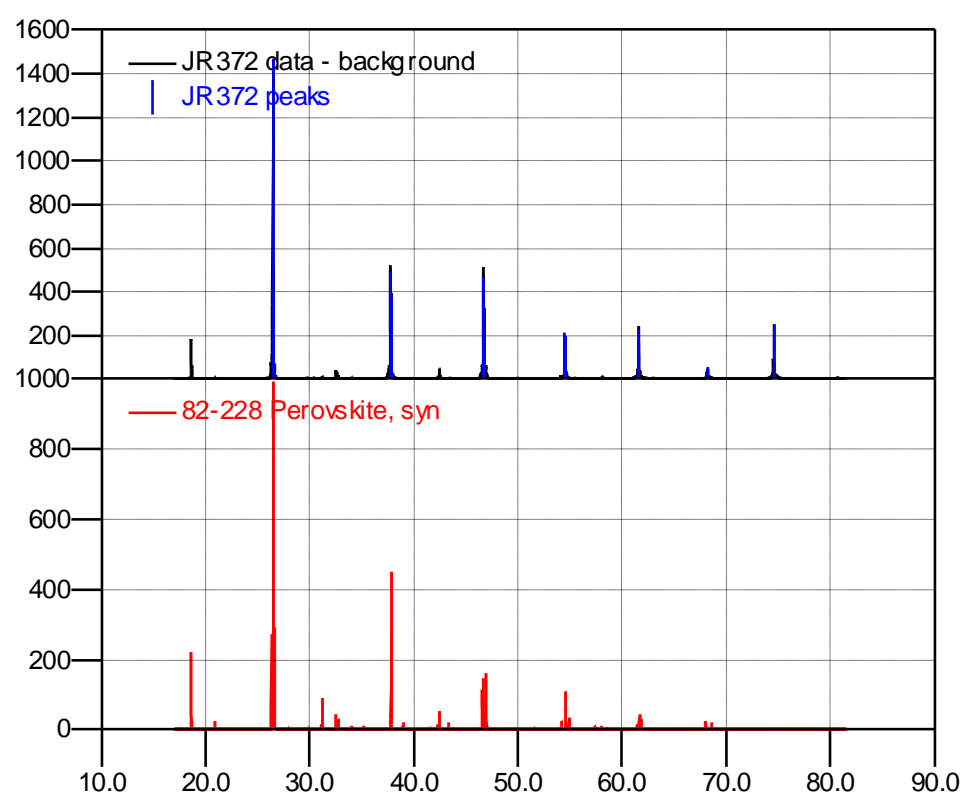

Figura 49 - Identificação da fase cristalina da amostra de $\mathrm{CaTi}_{0,65} \mathrm{Fe}_{0,35} \mathrm{O}_{3-\delta}$, pelo programa Search Math ${ }^{[61]}$ e do banco de dados de difração PDF ${ }^{[59]}$. Em azul o difratograma medido, em vermelho a simulação do difratograma da fase CaSrTiO.

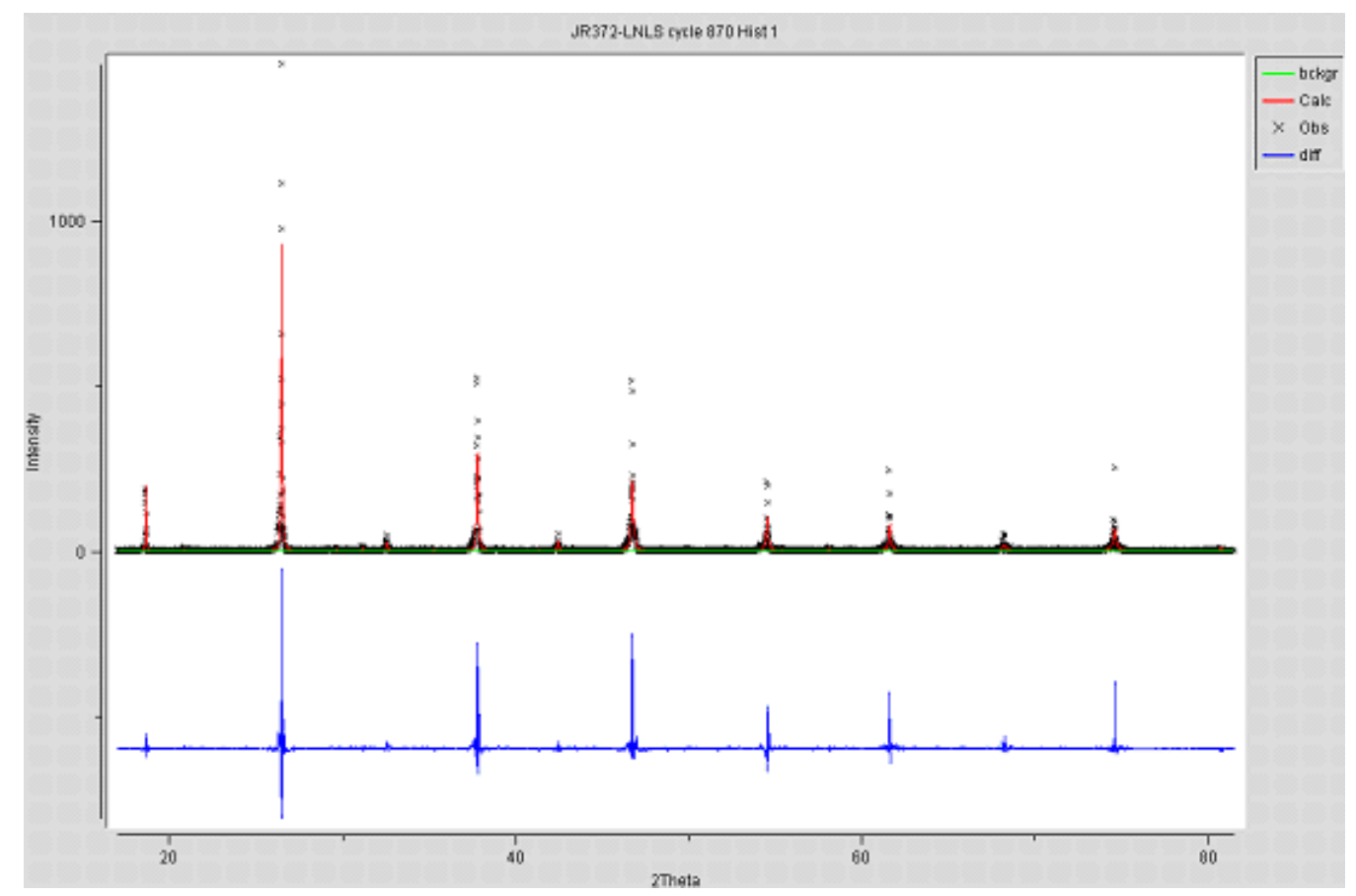

Figura 50 - Gráfico do ajuste de Rietveld para a amostra de composição $\mathrm{CaTi}_{0,65} \mathrm{Fe}_{0,35} \mathrm{O}_{3-\delta}$, com base numa simetria ortorrômbica, $\mathrm{P}$ b n $\mathrm{m}$. 
Tabela 7 - Principais resultados obtidos pela técnica de refinamento Rietveld para as composições $\mathrm{SrTi}_{0,65} \mathrm{Fe}_{0,35} \mathrm{O}_{3-\delta}, \mathrm{Ca}_{0,5} \mathrm{Sr}_{0,5} \mathrm{Ti}_{0,65} \mathrm{Fe}_{0,35} \mathrm{O}_{3-\delta}, \mathrm{CaTi}_{0,65} \mathrm{Fe}_{0,35} \mathrm{O}_{3-\delta} ;$ dois tratamentos térmicos: $1250^{\circ} \mathrm{C} / 15 \mathrm{~h}+1400^{\circ} \mathrm{C} / 60 \mathrm{~h}$.

\begin{tabular}{|c|c|c|c|}
\hline \multirow[b]{2}{*}{ Composição } & \multirow[b]{2}{*}{$\begin{array}{l}\text { Valores } \\
\text { estruturais }\end{array}$} & \multicolumn{2}{|c|}{ DRX } \\
\hline & & $\begin{array}{l}\text { Convencional } \\
\lambda=1,5418(\AA)\end{array}$ & $\begin{array}{l}\text { Síncrotron } \\
\lambda=1,2400360(\AA)\end{array}$ \\
\hline 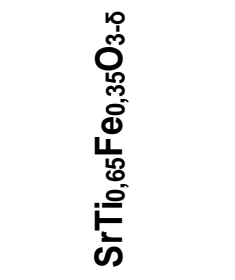 & $\begin{array}{l}\text { Grupo espacial } \\
\text { Simetria } \\
\text { Parâmetros da cela }(\AA ̊)\end{array}$ & $\begin{array}{l}P \text { m }-3 \text { m } \\
\text { cúbico } \\
a=3,90054(3)\end{array}$ & $\begin{array}{l}\text { P m -3 m } \\
\text { cúbico } \\
\text { 3,90006(1) }\end{array}$ \\
\hline 品 & $\begin{array}{l}\text { Grupo espacial } \\
\text { Simetria }\end{array}$ & $\begin{array}{l}\mathrm{P} \text { m -3 m } \\
\text { cúbico }\end{array}$ & $\begin{array}{l}\text { B m m b } \\
\text { ortorrômbico } \\
a=7,74010(8)\end{array}$ \\
\hline 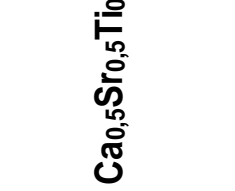 & Parâmetros da cela $(\AA ̊)$ & $a=3,86838(3)$ & $\begin{array}{l}b=7,73177(8) \\
c=7,73528(6)\end{array}$ \\
\hline 品 & $\begin{array}{l}\text { Grupo espacial } \\
\text { Simetria } \\
\text { Parâmetros da cela }(\AA)\end{array}$ & $\begin{array}{l}P \text { c m n } \\
\text { ortorrômbico } \\
a=5,4068(2) \\
b=5,4173(2) \\
c=7,6682(5)\end{array}$ & $\begin{array}{l}\mathrm{P} \text { b n m } \\
\text { ortorrômbico } \\
a=5,4085(2) \\
b=5,41533(7) \\
c=7,6619(2)\end{array}$ \\
\hline
\end{tabular}

São mostrados nas Figuras 51, 52 e 53 o posicionamento dos átomos na estrutura cristalina de $\mathrm{SrTi}_{0,65} \mathrm{Fe}_{0,35} \mathrm{O}_{3-\delta}, \quad \mathrm{Ca}_{0,5} \mathrm{Sr}_{0,5} \mathrm{Ti}_{0,65} \mathrm{Fe}_{0,35} \mathrm{O}_{3-\delta} \quad$ e $\mathrm{CaTi}_{0,65} \mathrm{Fe}_{0,35} \mathrm{O}_{3-\delta}$, respectivamente. Os raios iônicos de $\mathrm{Ca}^{2+}, \mathrm{Sr}^{2+}, \mathrm{Ti}^{4+}, \mathrm{Fe}^{3+} \mathrm{e}$ $\mathrm{O}^{2-}$ são 0,$99 ; 1,13 ; 0,68 ; 0,64$ e 1,40 Å respectivamente. 


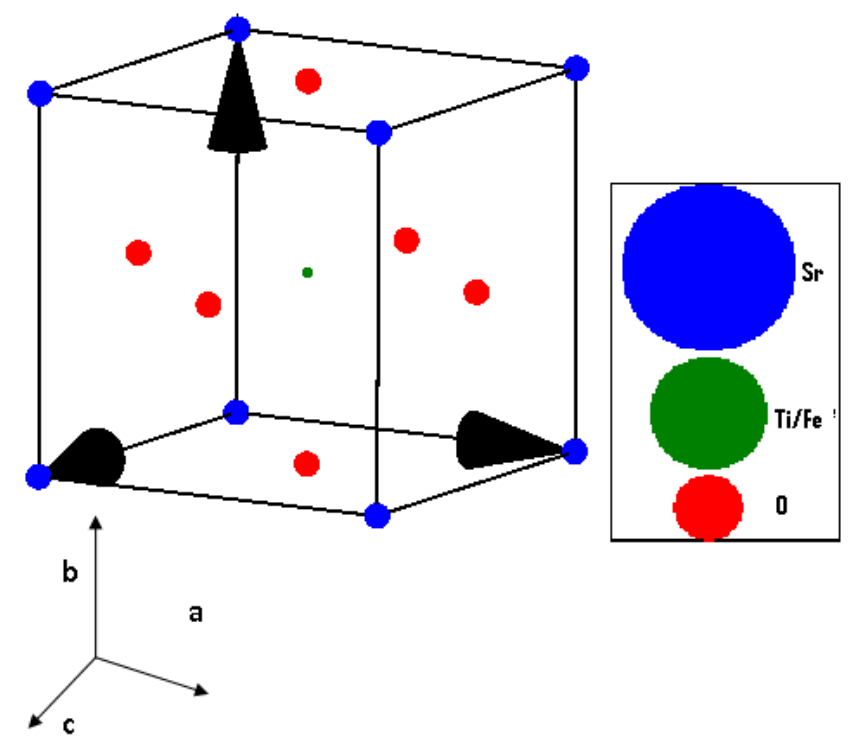

Figura 51 - Cela unitária refinada da amostra de $\mathrm{SrTi}_{0,65} \mathrm{Fe}_{0,35} \mathrm{O}_{3-\delta,}$, estrutura cúbica, simetria P m -3 m, conforme Tabela 7, dados do Síncrotron. Detalhe: átomos não em escala.

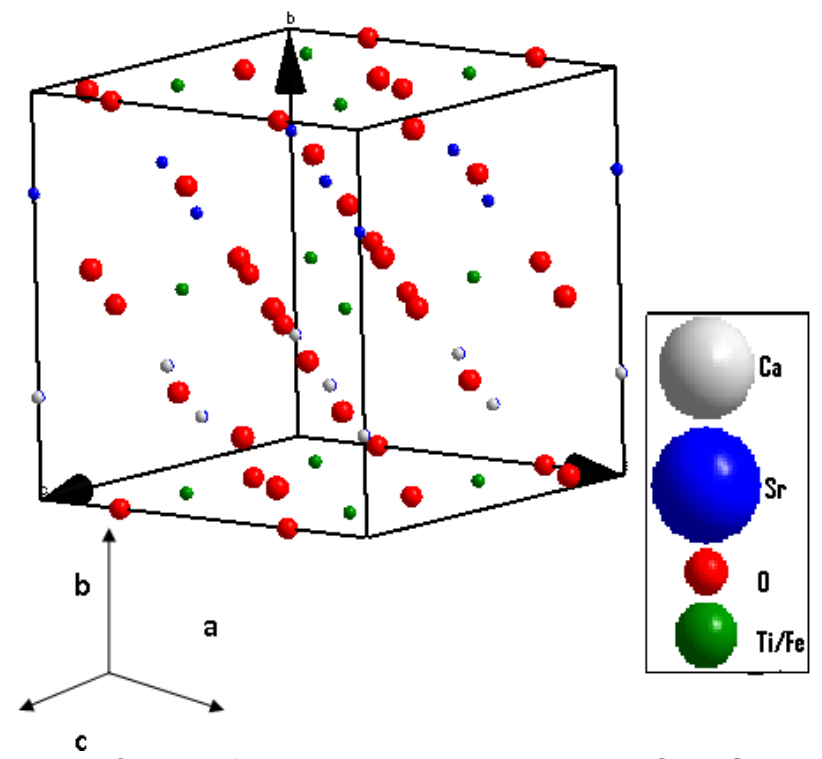

Figura 52 - Cela unitária refinada da amostra de $\mathrm{Ca}_{0,5} \mathrm{Sr}_{0,5} \mathrm{Ti}_{0,65} \mathrm{Fe}_{0,35} \mathrm{O}_{3-\delta}$, estrutura ortorrômbica, simetria B m m b, conforme Tabela 7, dados do Síncrotron. Detalhe: átomos não em escala. 


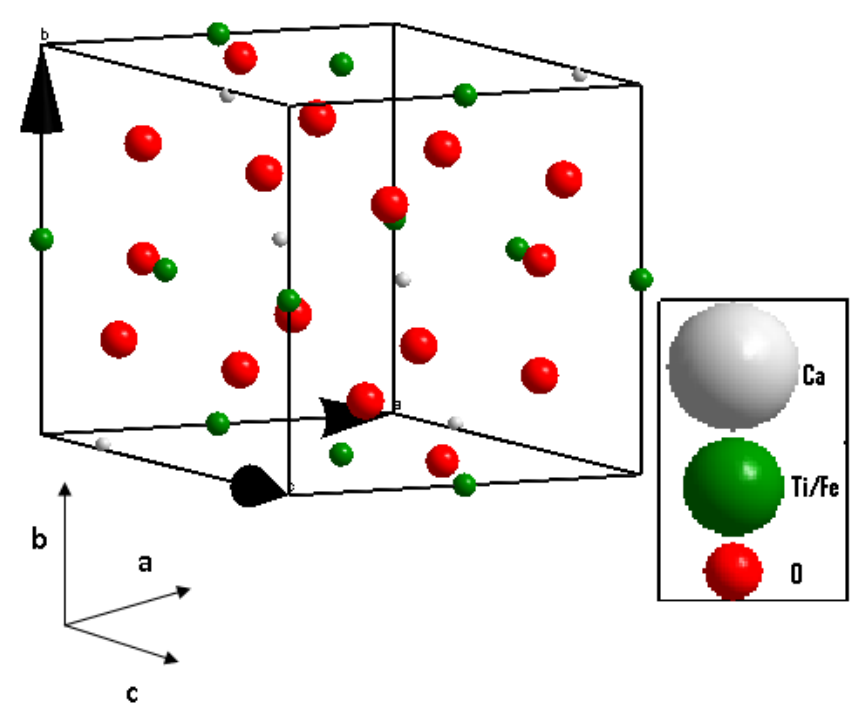

Figura 53 - Cela unitária refinada da amostra de $\mathrm{CaTi}_{0,65} \mathrm{Fe}_{0,35} \mathrm{O}_{3-\delta}$, estrutura ortorrômbica, simetria P b n m, conforme Tabela 7, dados do Síncrotron. Detalhe: átomos não em escala.

Para o desenho das celas unitárias das Figuras 51, 52 e 53 foi usado o ajuste de Rietveld proveniente dos difratogramas do Síncrotron, por serem de alta resolução comparativamente aos obtidos com 0 equipamento convencional, mostrando detalhes que não são vistos na análise de difração de raios $\mathrm{X}$ convencional.

Compostos de titanato de estrôncio com ferro $\left(\mathrm{SrTi}_{0,65} \mathrm{Fe}_{0,35} \mathrm{O}_{3-\delta}\right)$ apresentaram predominantemente fase perovskita cúbica, enquanto que titanato de cálcio com ferro $\left(\mathrm{CaTi}_{0,65} \mathrm{Fe}_{0,35} \mathrm{O}_{3-\delta}\right)$ e titanato de cálcio e estrôncio com ferro $\left(\mathrm{Ca}_{0,5} \mathrm{Sr}_{0,5} \mathrm{Ti}_{0,65} \mathrm{Fe}_{0,35} \mathrm{O}_{3-\delta}\right)$ apresentaram fase ortorrômbica, fases minoritárias com estrutura ortorrômbica são também observadas.

\subsubsection{MICROSCOPIA ELETRÔNICA}

4.1.5.1 Microscopia eletrônica de varredura dos compostos obtidos por reação de estado sólido

São mostradas na Figura 54 micrografias de $\mathrm{SrTi}_{0,65} \mathrm{Fe}_{0,35} \mathrm{O}_{3-\delta}(a, b)$ $\mathrm{Ca}_{0,5} \mathrm{Sr}_{0,5} \mathrm{Ti}_{0,65} \mathrm{Fe}_{0,35} \mathrm{O}_{3-\delta}$ (c,d) e $\mathrm{CaTi}_{0,65} \mathrm{Fe}_{0,35} \mathrm{O}_{3-\delta}$ (e,f) obtidas em microscópio eletrônico de varredura. 


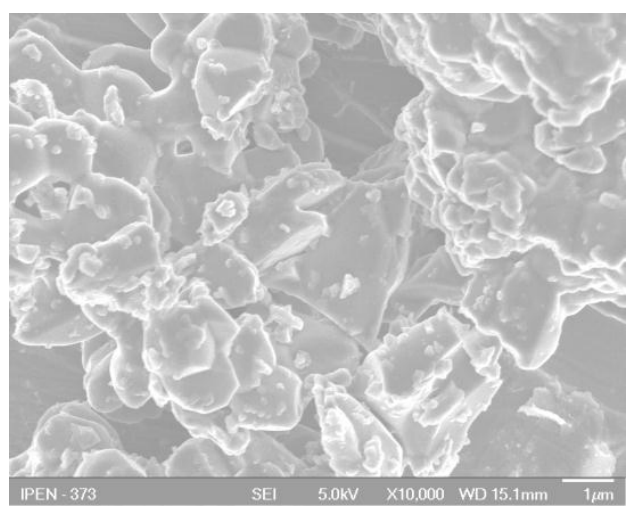

a

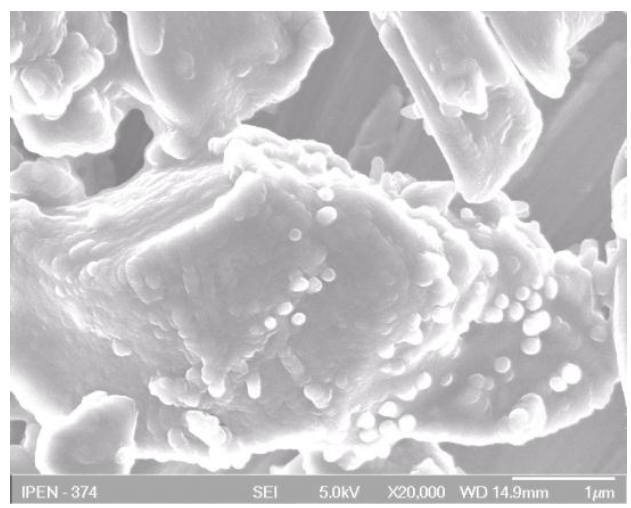

C

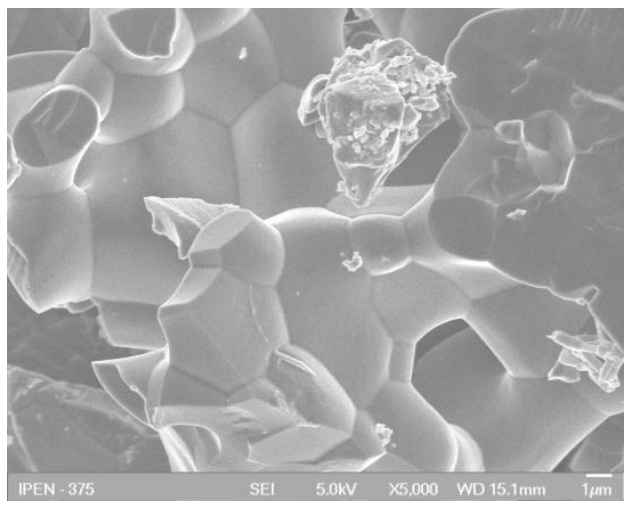

e

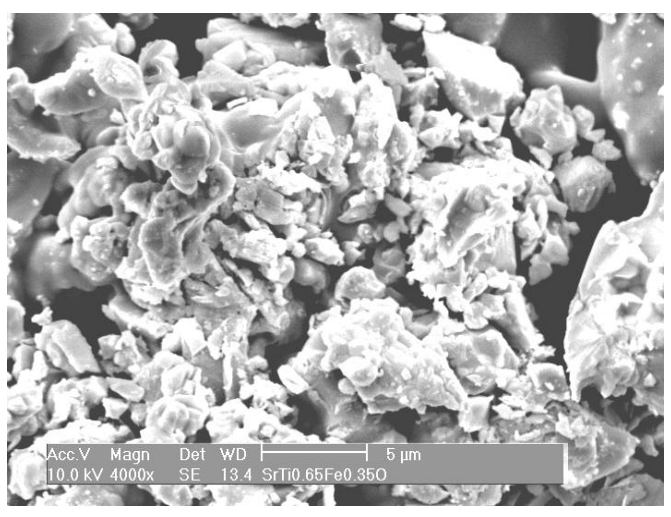

b

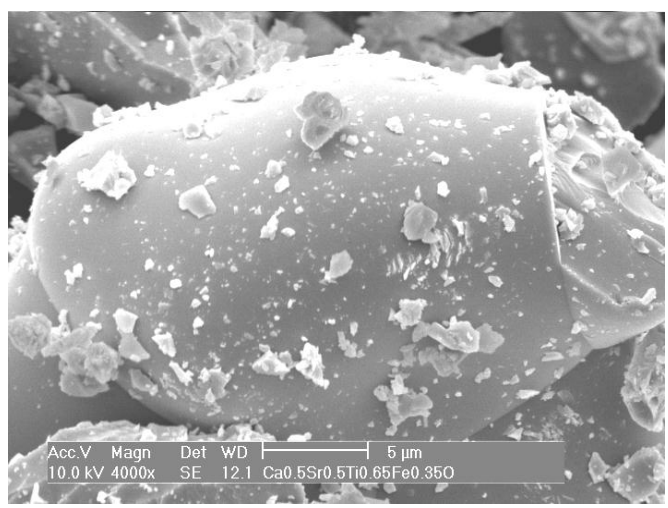

d

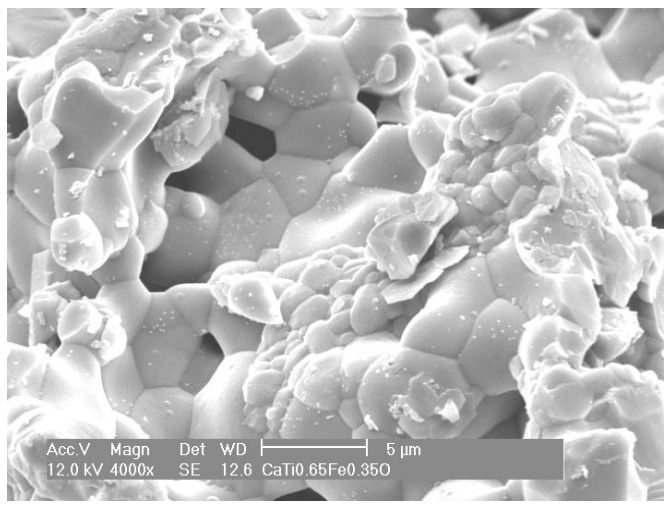

f

Figura 54 - Micrografias obtidas por microscopia eletrônica de varredura de pós de $\mathrm{SrTi}_{0,65} \mathrm{Fe}_{0,35} \mathrm{O}_{3-\delta}(\mathrm{a}, \mathrm{b}), \mathrm{Ca}_{0,5} \mathrm{Sr}_{0,5} \mathrm{Ti}_{0,65} \mathrm{Fe}_{0,35} \mathrm{O}_{3-\delta}$ (c,d) e $\mathrm{CaTi}_{0,65} \mathrm{Fe}_{0,35} \mathrm{O}_{3-\delta}$ (e,f). Esquerda: FEGMEV; Direita: MEV.

Todos os pós são compostos por aglomerados fortes e não homogêneos, o que justifica a dificuldade encontrada para a densificação dos compactos destes pós. As composições com $50 \%$ de $\mathrm{Ca}$ e $50 \%$ de $\mathrm{Sr}$ apresentam formação de pescoço inter-partículas, evidenciando início de sinterização durante a calcinação. 
4.1.5.2 Microscopia eletrônica de transmissão dos pós obtidos pela técnica dos precursores poliméricos

Como pós preparados pela técnica dos precursores poliméricos geralmente apresentam partículas com tamanho médio sub-micrométrico, foram preparadas suspensões para observação em microscópio eletrônico de transmissão. São mostradas na Figura 55 as micrografias dos materiais na forma de pó.

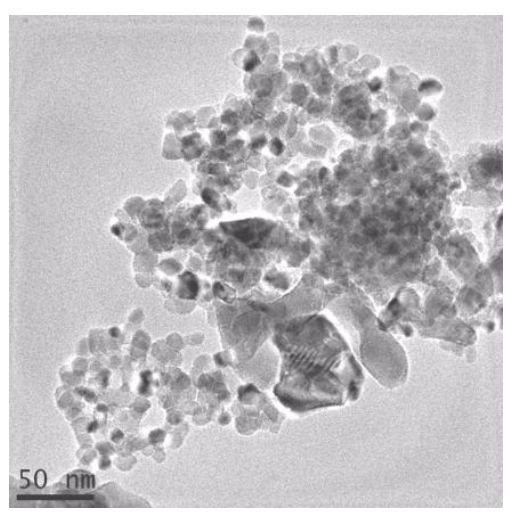

a

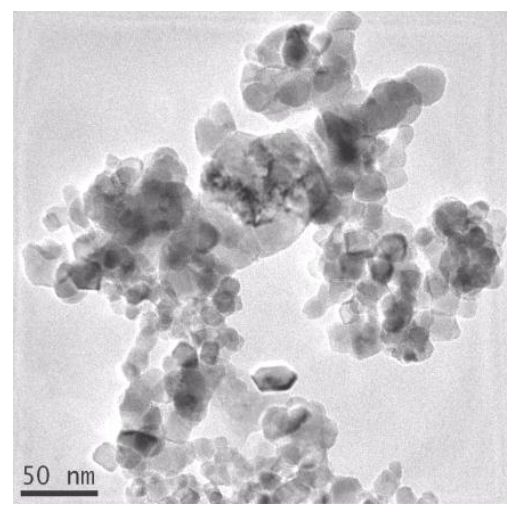

d

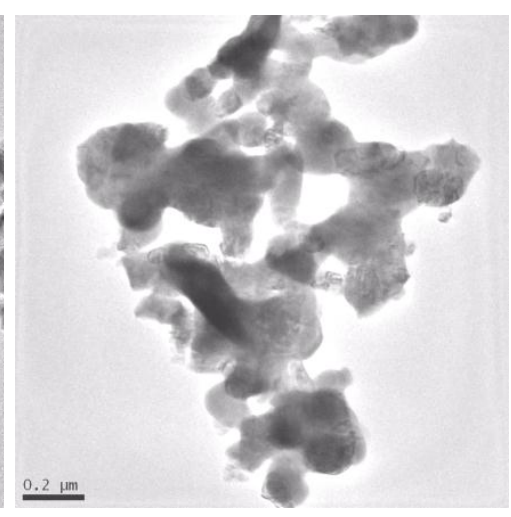

b

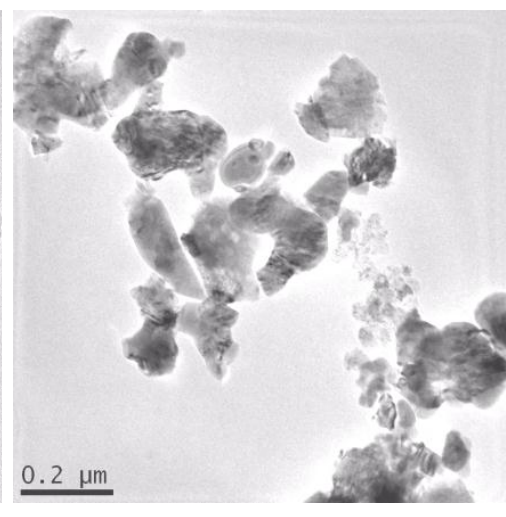

e

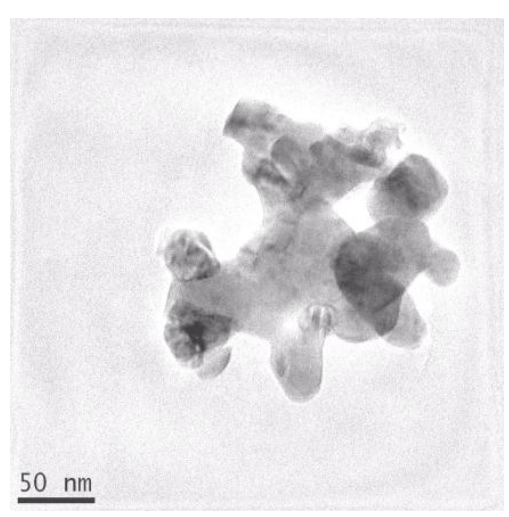

C

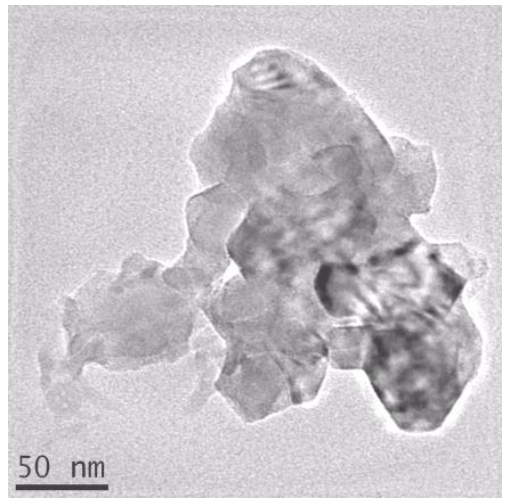

f

Figura 55 - Micrografias obtidas por microscopia eletrônica de transmissão dos pós de $\mathrm{SrTi}_{0,65} \mathrm{Fe}_{0,35} \mathrm{O}_{3-\delta}(\mathrm{a}, \mathrm{d}), \mathrm{Ca}_{0,5} \mathrm{Sr}_{0,5} \mathrm{Ti}_{0,65} \mathrm{Fe}_{0,35} \mathrm{O}_{3-\delta}(\mathrm{b}, \mathrm{e})$ e $\mathrm{CaTi}_{0,65} \mathrm{Fe}_{0,35} \mathrm{O}_{3-\delta}(\mathrm{c}, \mathrm{f})$.

Todos os pós apresentam tamanho de partículas sub-micrométrico, em estado de aglomeração. 
4.1.5.3 Microscopia eletrônica de varredura por emissão de campo dos pós obtidos pela técnica dos precursores poliméricos

As micrografias dos pós de $\mathrm{SrTi}_{0,65} \mathrm{Fe}_{0,35} \mathrm{O}_{3-\delta}, \mathrm{Ca}_{0,5} \mathrm{Sr}_{0,5} \mathrm{Ti}_{0,65} \mathrm{Fe}_{0,35} \mathrm{O}_{3-\delta} \mathrm{e}$ $\mathrm{CaTi}_{0,65} \mathrm{Fe}_{0,35} \mathrm{O}_{3-\delta}$ são mostradas na Figura 56.

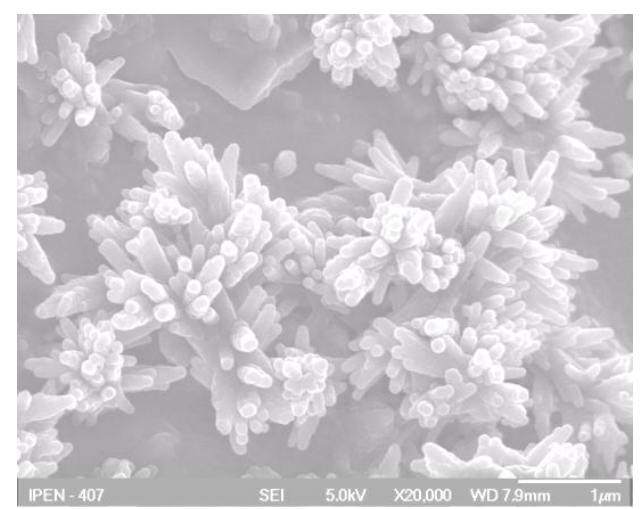

a

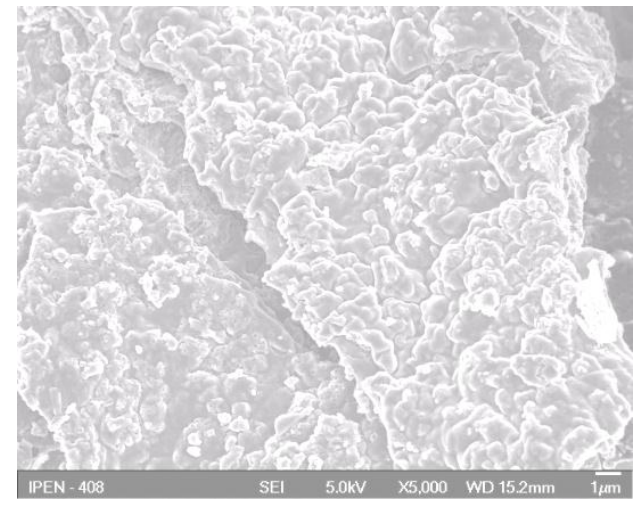

C

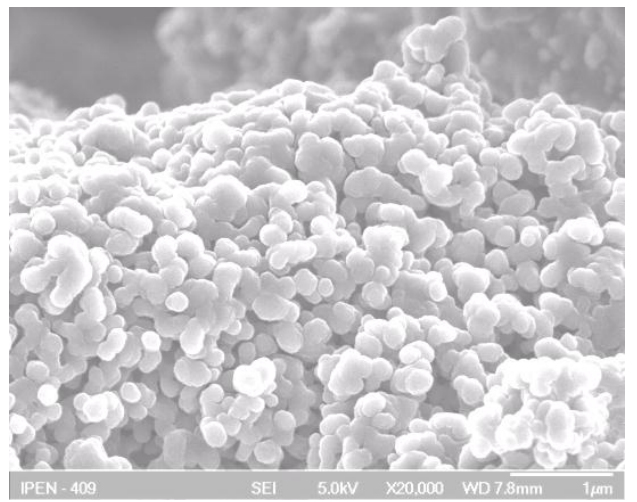

e

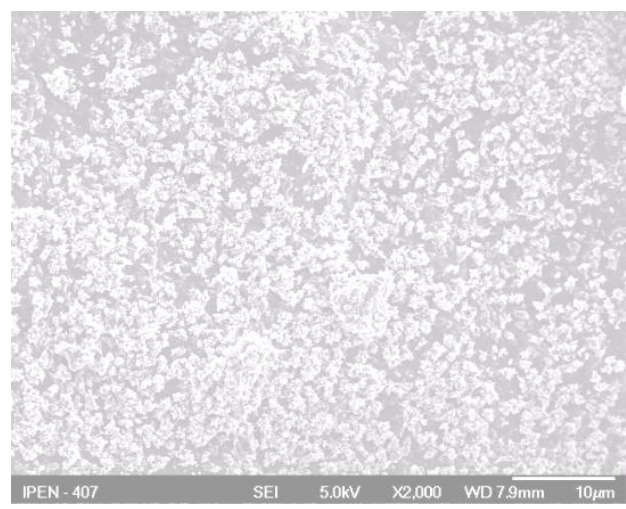

b

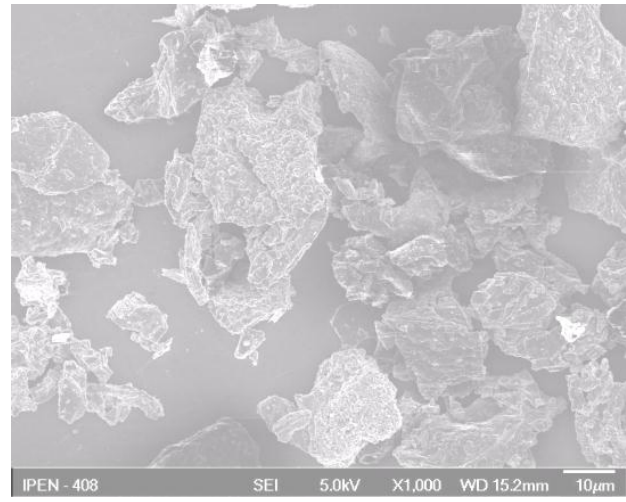

d

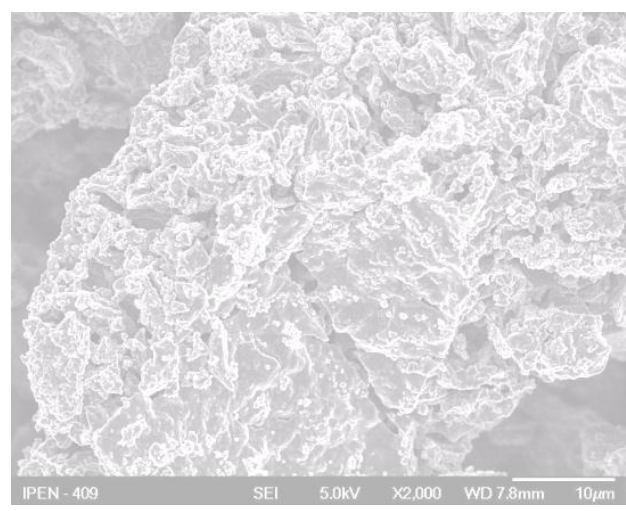

f

Figura 56 - Micrografias obtidas por microscopia eletrônica de varredura (FEG) de pós de $\mathrm{SrTi}_{0,65} \mathrm{Fe}_{0,35} \mathrm{O}_{3-\delta}(\mathrm{a}, \mathrm{b}), \mathrm{Ca}_{0,5} \mathrm{Sr}_{0,5} \mathrm{Ti}_{0,65} \mathrm{Fe}_{0,35} \mathrm{O}_{3-\delta}(\mathrm{c}, \mathrm{d})$ e $\mathrm{CaTi}_{0,65} \mathrm{Fe}_{0,35} \mathrm{O}_{3-\delta}(\mathrm{e}, \mathrm{f})$. 
Essas análises foram feitas como alternativa às análises em microscopia eletrônica de transmissão, que requerem preparação mais elaborada das suspensões para permitir a observação de partículas sub-micrométricas. Podem ser observadas partículas de formas bem definidas nas composições com $\mathrm{Ca}$ e com $\mathrm{Sr}$, enquanto que a composição mista ( $\mathrm{Ca}$ e $\mathrm{Sr}$ ) mostra aglomerados de forma indefinida, conforme Figura 56. Todos mostram início de sinterização das partículas, causados pelos tratamentos térmicos de calcinação.

4.1.5.4 Microscopia eletrônica de varredura por sonda dos corpos de prova

Os corpos de prova compactados e sinterizados foram polidos e atacados termicamente para observação em microscópio eletrônico de varredura por sonda. Algumas das imagens podem ser vistas na Figura 57.

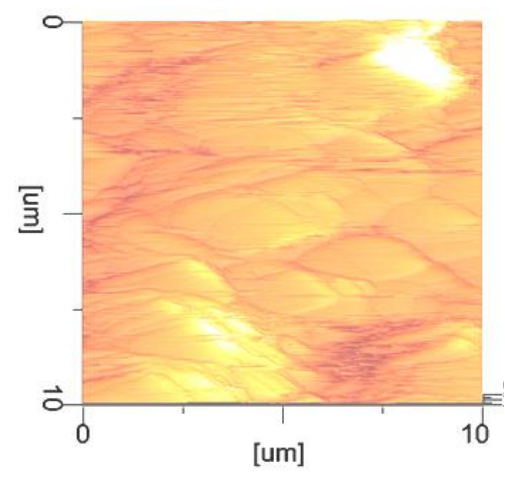

a

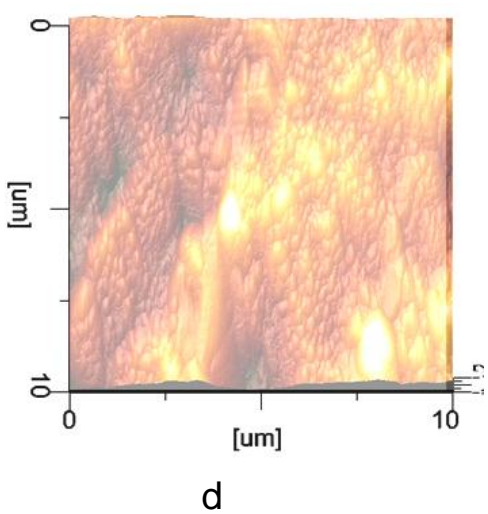

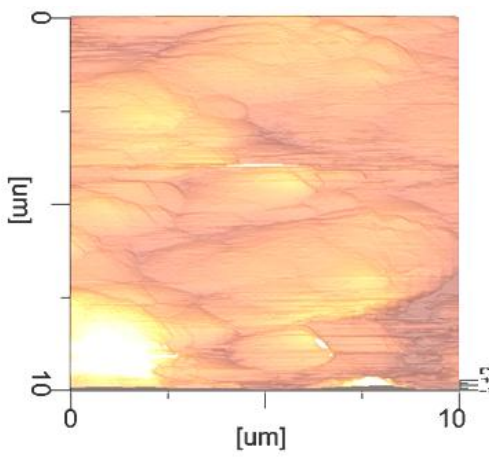

$\mathrm{b}$

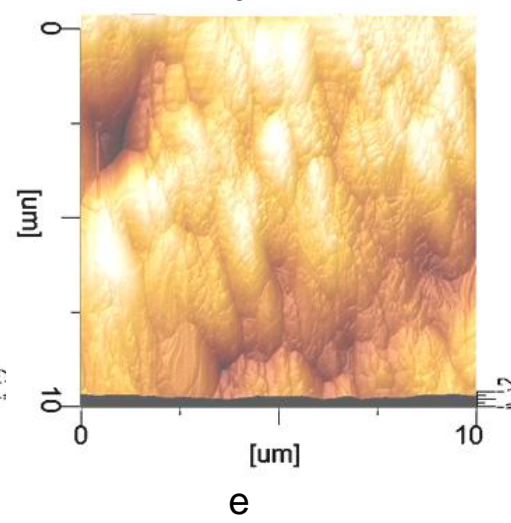

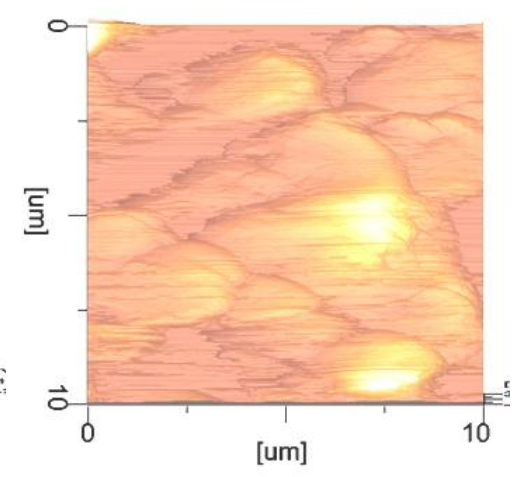

C

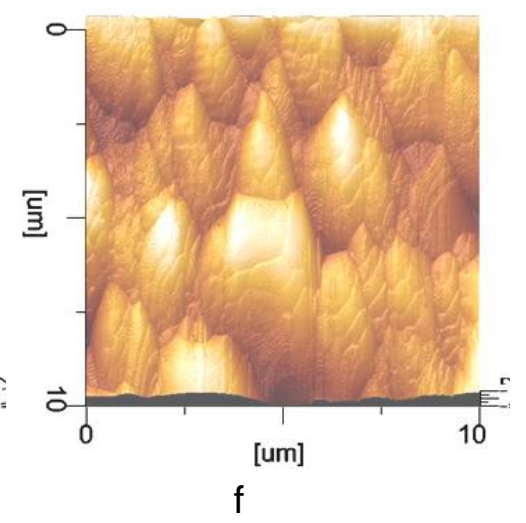

Figura 57 - Micrografias obtidas por microscopia eletrônica de varredura por sonda de superfícies polidas e atacadas termicamente de $\mathrm{SrTi}_{0,65} \mathrm{Fe}_{0,35} \mathrm{O}_{3-\delta}$ (a) $\mathrm{MO}$ e (d) PP, $\mathrm{Ca}_{0,5} \mathrm{Sr}_{0,5} \mathrm{Ti}_{0,65} \mathrm{Fe}_{0,35} \mathrm{O}_{3-\delta}$ (b) MO e (e) PP, e CaTi ${ }_{0,65} \mathrm{Fe}_{0,35} \mathrm{O}_{3-\delta}$ (c) MO e (f) PP. 
As micrografias dos materiais provenientes de reação de estado sólido e dos precursores poliméricos apresentam morfologias distintas. Os compostos preparados pela técnica dos precursores poliméricos, Figura 57 (d), (e) e (f), são homogêneos, densos e com os contornos de grão definidos, mostrando cada grão ser composto por um empacotamento de grãos menores (subgrãos). Por outro lado os compostos preparados pela técnica de reação de estado sólido, Figura 57 (a), (b) e (c), mostram grãos não bem definidos, pouca homogeneidade, formato alongado com uma grande densidade de interfaces. Essas interfaces são interpretadas como responsáveis por bloquear os portadores de carga, resultando em uma resistência de contorno de grão relativamente alta.

\subsection{CARACTERIZAÇÃo ELÉtRICA}

\subsubsection{ESPECTROSCOPIA DE IMPEDÂNCIA}

São mostrados nas Figuras 58 - 63 os diagramas de impedância dos corpos de prova sinterizados de $\mathrm{SrTi}_{0,65} \mathrm{Fe}_{0,35} \mathrm{O}_{3-\delta}, \mathrm{Ca}_{0,5} \mathrm{Sr}_{0,5} \mathrm{Ti}_{0,65} \mathrm{Fe}_{0,35} \mathrm{O}_{3-\delta}$ e $\mathrm{CaTi}_{0,65} \mathrm{Fe}_{0,35} \mathrm{O}_{3-\delta}$, preparados com pós obtidos pela técnica da mistura de óxidos, Figuras 58, 59 e 60 e pela técnica dos precursores poliméricos, Figuras 61, 62 e 63. Os diagramas são compostos por dois semicírculos que, após processo matemático de deconvolução (parametrizado em freqüência) permitem a determinação dos valores de resistência, capacitância e freqüência característica dos grãos e dos contornos de grão. Os valores calculados da capacitância específica para as três composições preparadas com pós obtidos pelas técnicas de mistura de óxidos e dos precursores poliméricos são mostrados na Tabela 8. 
Tabela 8 - Valores de capacitância dos grãos e dos contornos de grão de compostos sinterizados de $\mathrm{SrTi}_{0,65} \mathrm{Fe}_{0,35} \mathrm{O}_{3-\delta}, \mathrm{Ca}_{0,5} \mathrm{Sr}_{0,5} \mathrm{Ti}_{0,65} \mathrm{Fe}_{0,35} \mathrm{O}_{3-\delta}$ e $\mathrm{CaTi}_{0,65} \mathrm{Fe}_{0,35} \mathrm{O}_{3-\delta}$, preparados com pós obtidos pelas técnicas dos precursores poliméricos e síntese de estado sólido.

$$
\text { Composição } \quad \mathrm{C}_{\mathrm{g}}\left(10^{-11} \mathrm{~F} / \mathrm{cm}\right) \quad \mathrm{C}_{\mathrm{cg}}\left(10^{-9} \mathrm{~F} / \mathrm{cm}\right)
$$

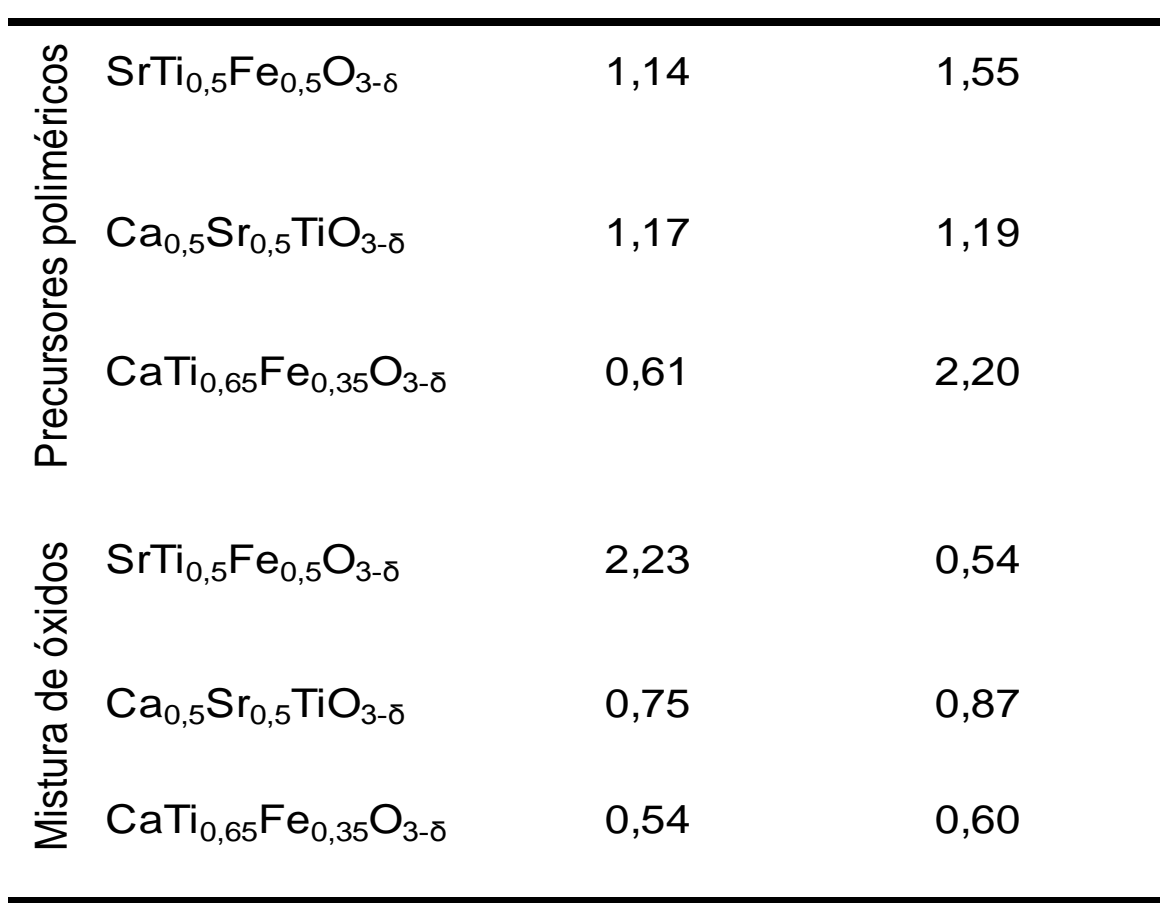

Os valores são típicos de capacitâncias de grãos (região de altas freqüências) e de contornos de grão (região de baixas freqüências) ${ }^{[62]}$.

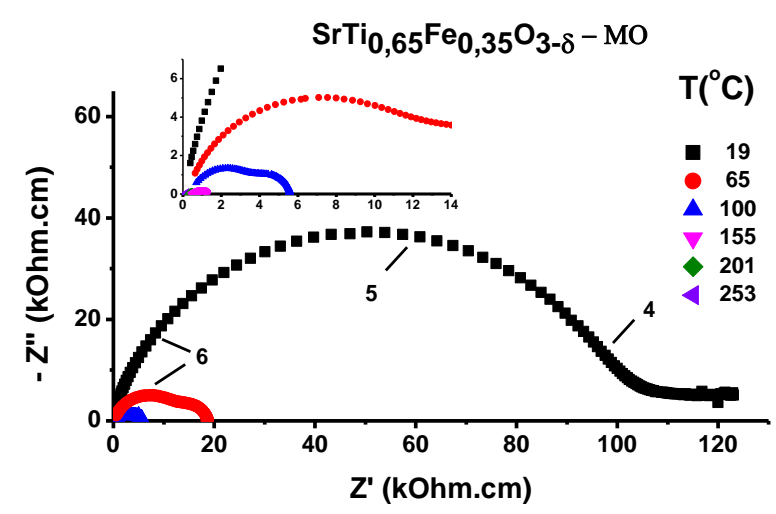

Figura 58 - Diagramas de impedância na faixa de freqüências $5 \mathrm{~Hz}-13 \mathrm{MHz}$ de $\mathrm{SrTi}_{0,65} \mathrm{Fe}_{0,35} \mathrm{O}_{3-\delta}$ (pós obtidos por síntese de estado sólido - MO), a várias temperaturas. Os números são o logaritmo da freqüência $(\mathrm{Hz})$. 


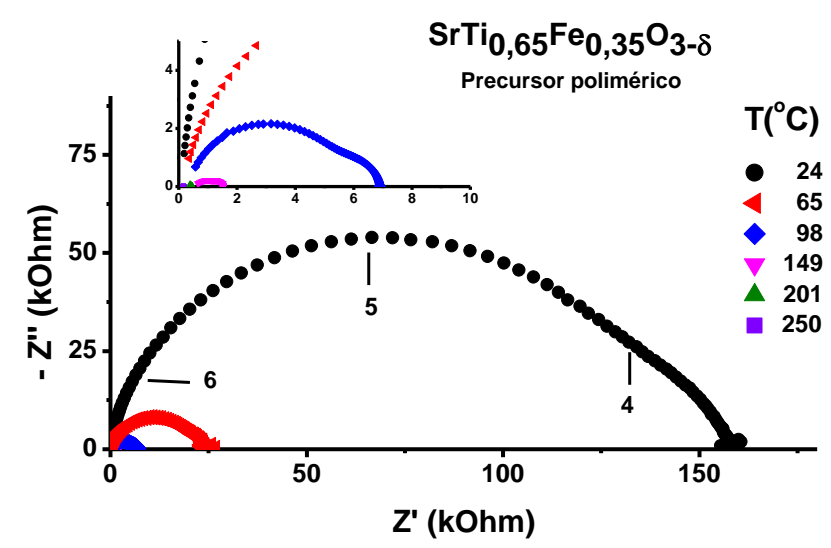

Figura 59 - Diagramas de impedância na faixa de freqüências $5 \mathrm{~Hz}-13 \mathrm{MHz}$ de $\mathrm{SrTi}_{0,65} \mathrm{Fe}_{0,35} \mathrm{O}_{3-\delta}$ (pós obtidos pela técnica dos precursores poliméricos - PP), a várias temperaturas. Os números são o logaritmo da freqüência $(\mathrm{Hz})$.

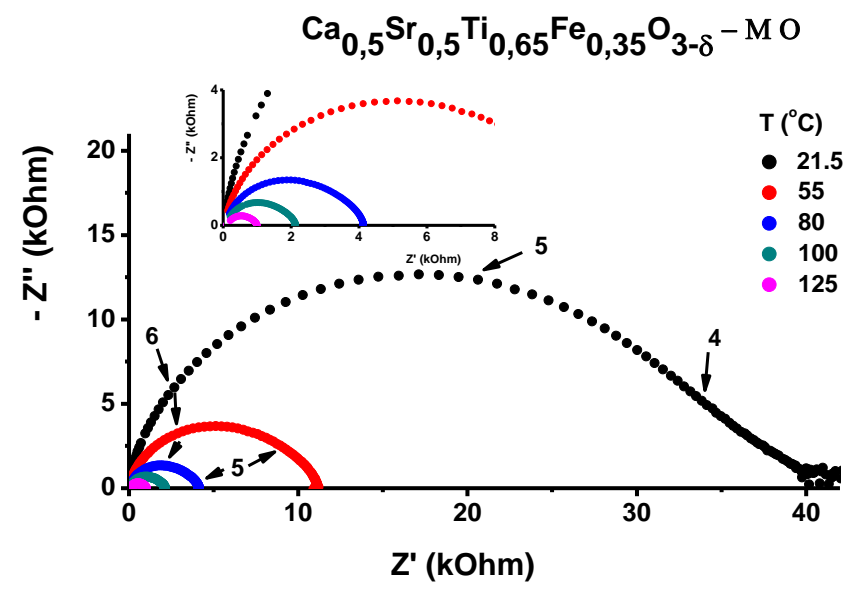

Figura 60 - Diagramas de impedância na faixa de freqüências $5 \mathrm{~Hz}-13 \mathrm{MHz}$ de $\mathrm{Ca}_{0,5} \mathrm{Sr}_{0,5} \mathrm{Ti}_{0,65} \mathrm{Fe}_{0,35} \mathrm{O}_{3-\delta}$ (pós obtidos por síntese de estado sólido - MO), a várias temperaturas. Os números são o logaritmo da freqüência $(\mathrm{Hz})$.

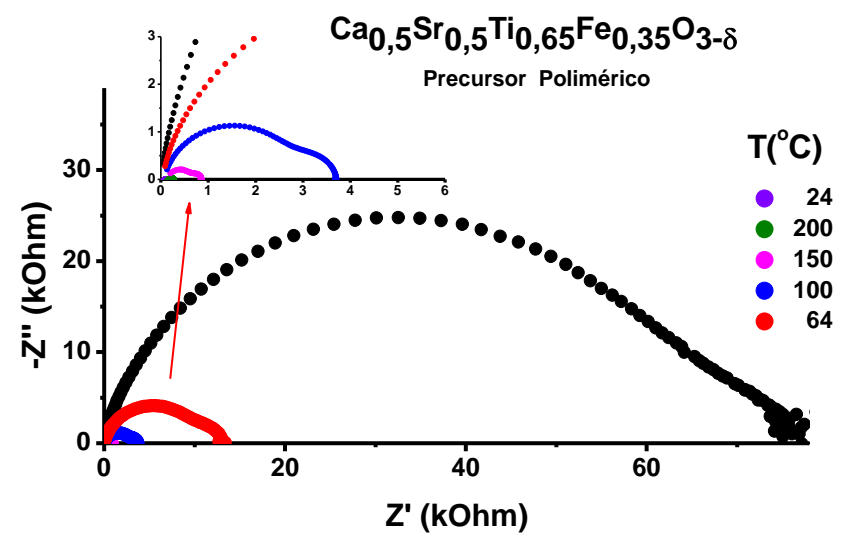

Figura 61 - Diagramas de impedância na faixa de freqüências $5 \mathrm{~Hz}$ - $13 \mathrm{MHz}$ de $\mathrm{Ca}_{0,5} \mathrm{Sr}_{0,5} \mathrm{Ti}_{0,65} \mathrm{Fe}_{0,35} \mathrm{O}_{3-\delta}$ (pós obtidos pela técnica dos precursores poliméricos - $\mathrm{PP}$ ), a várias temperaturas. Os números são o logaritmo da freqüência $(\mathrm{Hz})$. 


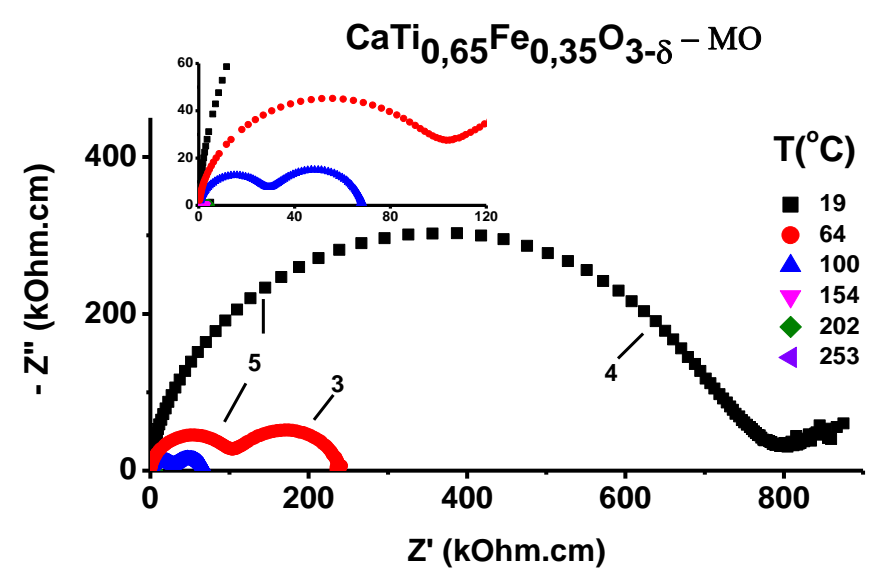

Figura 62 - Diagramas de impedância na faixa de freqüências $5 \mathrm{~Hz}-13 \mathrm{MHz}$ de $\mathrm{CaTi}_{0,65} \mathrm{Fe}_{0,35} \mathrm{O}_{3-\delta}$ (pós obtidos por síntese de estado sólido - $\mathrm{MO}$ ), a várias temperaturas. Os números são o logaritmo da freqüência $(\mathrm{Hz})$.

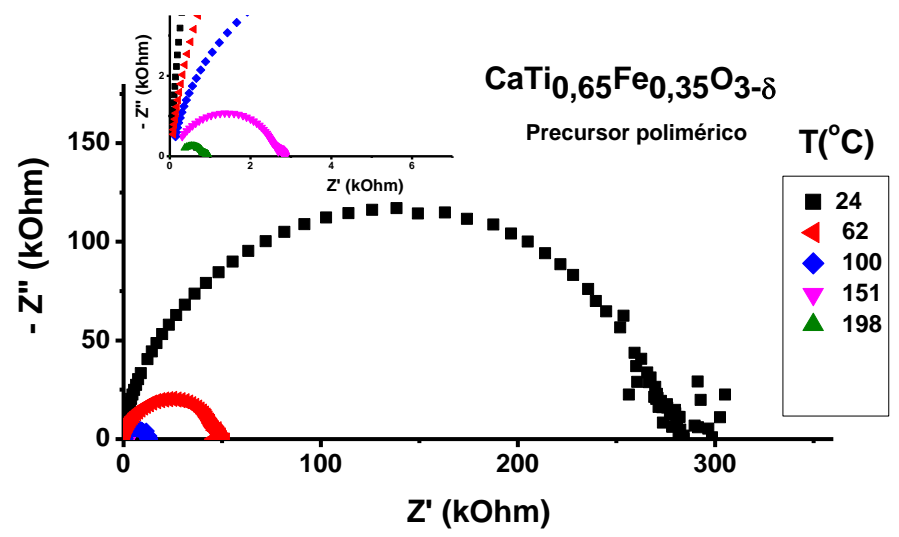

Figura 63 - Diagramas de impedância na faixa de freqüências $5 \mathrm{~Hz}-13 \mathrm{MHz}$ de $\mathrm{CaTi}_{0,65} \mathrm{Fe}_{0,35} \mathrm{O}_{3-\delta}$ (pós obtidos pela técnica dos precursores poliméricos - PP), a várias temperaturas.

Tem-se na Figura 64 a comparação dos diagramas de impedância de $\mathrm{SrTi}_{0,65} \mathrm{Fe}_{0,35} \mathrm{O}_{3-\delta}, \quad \mathrm{Ca}_{0,5} \mathrm{Sr}_{0,5} \mathrm{Ti}_{0,65} \mathrm{Fe}_{0,35} \mathrm{O}_{3-\delta}$ e $\mathrm{CaTi}_{0,65} \mathrm{Fe}_{0,35} \mathrm{O}_{3-\delta}$ medidos em $65{ }^{\circ} \mathrm{C}$. O composto $\mathrm{SrTi}_{0,65} \mathrm{Fe}_{0,35} \mathrm{O}_{3-\delta}$ apresenta resistividade elétrica menor que $\mathrm{Ca}_{0,5} \mathrm{Sr}_{0,5} \mathrm{Ti}_{0,65} \mathrm{Fe}_{0,35} \mathrm{O}_{3-\delta}$. A substituição de íons $\mathrm{Sr}^{2+}$ por $\mathrm{Ca}^{2+}$, transformando o composto de estrutura cúbica em estrutura ortorrômbica, promove aumento na resistividade elétrica, mostrando que a estrutura cúbica é a principal responsável pelo menor valor de resistividade. Na estrutura ortorrômbica, a distância para o salto da vacância de oxigênio (portador de carga responsável 
pela condutividade elétrica no titanato de estrôncio) é maior que no titanato de estrôncio, com conseqüente diminuição na mobilidade elétrica).

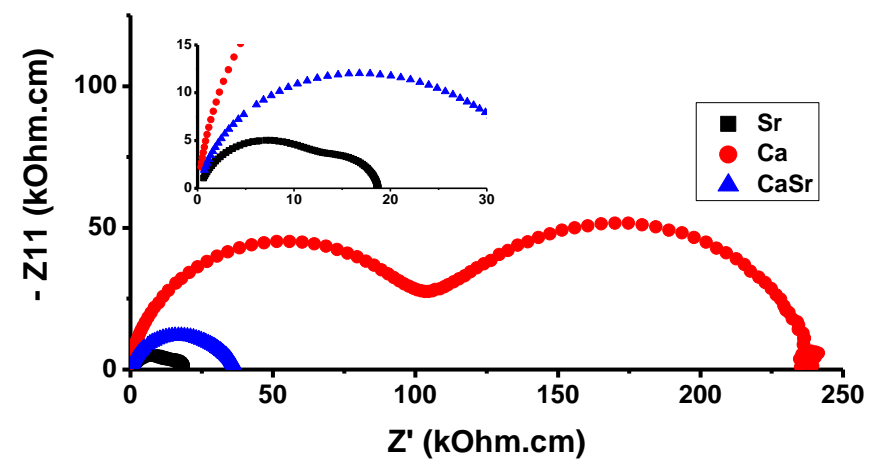

Figura 64 - Diagramas de impedância na faixa de freqüências $5 \mathrm{~Hz}-13 \mathrm{MHz}$ de $\mathrm{SrTi}_{0,65} \mathrm{Fe}_{0,35} \mathrm{O}_{3-\delta}, \mathrm{Ca}_{0,5} \mathrm{Sr}_{0,5} \mathrm{Ti}_{0,65} \mathrm{Fe}_{0,35} \mathrm{O}_{3-\delta}$ e $\mathrm{CaTi}_{0,65} \mathrm{Fe}_{0,35} \mathrm{O}_{3-\delta}$ (pós obtidos por síntese de estado sólido - MO), medidos em $65^{\circ} \mathrm{C}$.

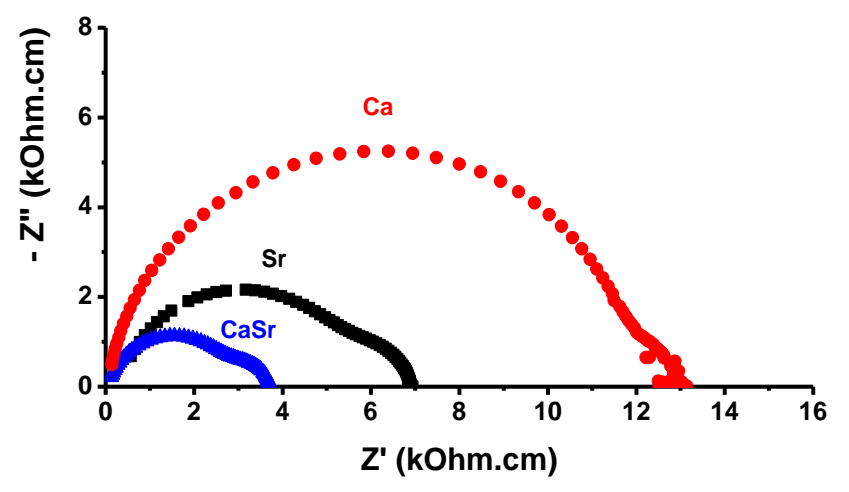

Figura 65 - Diagramas de impedância na faixa de freqüências de $5 \mathrm{~Hz}-13 \mathrm{MHz}$ de $\mathrm{SrTi}_{0,65} \mathrm{Fe}_{0,35} \mathrm{O}_{3-\delta}, \mathrm{Ca}_{0,5} \mathrm{Sr}_{0,5} \mathrm{Ti}_{0,65} \mathrm{Fe}_{0,35} \mathrm{O}_{3-\delta}$ e $\mathrm{CaTi}_{0,65} \mathrm{Fe}_{0,35} \mathrm{O}_{3-\delta}$ (pós obtidos pela técnica dos precursores poliméricos - PP) medidos em $100^{\circ} \mathrm{C}$.

A substituição de $\mathrm{Ti}^{4+}$ por $\mathrm{Fe}^{3+}$ em $\mathrm{SrTiO}_{3}, \mathrm{CaTiO}_{3}$, e $\mathrm{Ca}_{0,5} \mathrm{Sr}_{0,5} \mathrm{TiO}_{3}$ contribui para a condutividade iônica, via vacâncias de oxigênio, com valores similares de energia de ativação para a condutividade intragranular e intergranular $(0,40 \mathrm{eV}$ na faixa $300 \mathrm{~K}$ - $530 \mathrm{~K})$. Maiores valores de condutividade iônica foram medidas em compactos sinterizados preparados com estes pós, que apresentam grãos e sub-grãos homogêneos. Pós preparados pela técnica da síntese de estado sólido, por outro lado, tem estrutura cúbica na composição $\mathrm{SrTi}_{0,65} \mathrm{Fe}_{0,35} \mathrm{O}_{3}$ e ortorrômbica para as composições $\mathrm{Ca}_{0,5} \mathrm{Sr}_{0,5} \mathrm{Ti}_{0,65} \mathrm{Fe}_{0,35} \mathrm{O}_{3}$, e $\mathrm{CaTi}_{0,65} \mathrm{Fe}_{0,35} \mathrm{O}_{3}$, sendo as três composições do tipo perovskita. A distribuição de grãos é não homogênea e os 
compactos sinterizados tem maior valor de resistividade elétrica que os preparados com pós sintetizados pela técnica dos precursores poliméricos.

Compactos sinterizados de titanato de estrôncio com ferro, titanato de cálcio com ferro e titanato de cálcio e estrôncio com ferro preparados com pós sintetizados pela técnica dos precursores poliméricos apresentam menores valores de resistividade elétrica, determinados por espectroscopia de impedância, que compostos similares preparados com pós sintetizados pela técnica de síntese de estado sólido.

\subsubsection{RESISTIVIDADE ELÉTRICA}

A deconvolução dos diagramas de impedância permitiu a determinação das contribuições da resistividade elétrica dos grãos e dos contornos de grão de $\mathrm{SrTi}_{0,65} \mathrm{Fe}_{0,35} \mathrm{O}_{3-\delta}, \mathrm{Ca}_{0,5} \mathrm{Sr}_{0,5} \mathrm{Ti}_{0,65} \mathrm{Fe}_{0,35} \mathrm{O}_{3-\delta}$ e $\mathrm{CaTi}_{0,65} \mathrm{Fe}_{0,35} \mathrm{O}_{3-\delta}$. Os gráficos de Arrhenius são mostrados nas Figuras 66, 67 e 68.

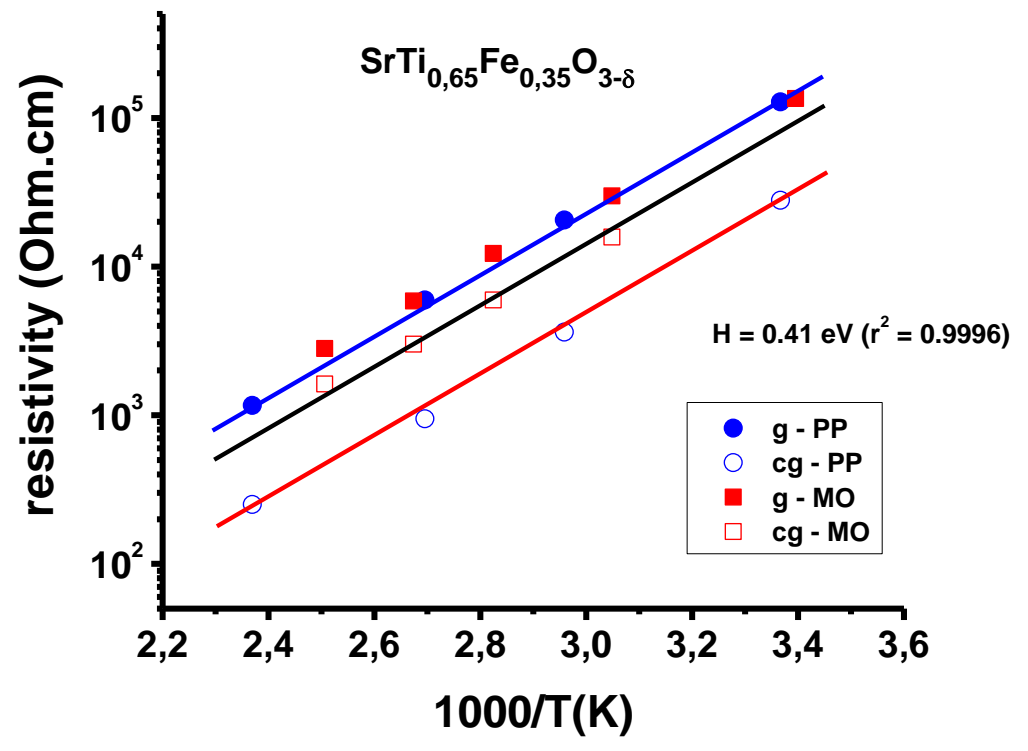

Figura 66 - Gráficos de Arrhenius da resistividade elétrica dos grãos e dos contornos de grão de $\mathrm{SrTi}_{0,65} \mathrm{Fe}_{0,35} \mathrm{O}_{3-\delta}$ (pós obtidos por síntese de estado sólido e técnica dos precursores poliméricos). 


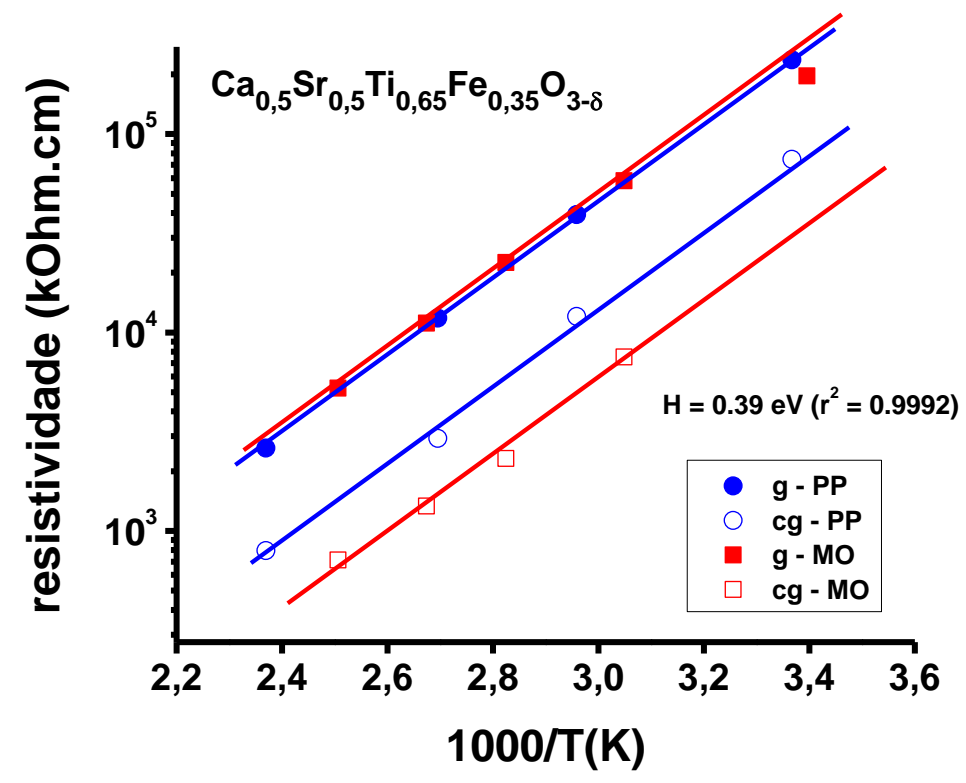

Figura 67 - Gráficos de Arrhenius da resistividade elétrica dos grãos e dos contornos de grão de $\mathrm{Ca}_{0,5} \mathrm{Sr}_{0,5} \mathrm{Ti}_{0,65} \mathrm{Fe}_{0,35} \mathrm{O}_{3-\delta}$ (pós obtidos por síntese de estado sólido e técnica dos precursores poliméricos).

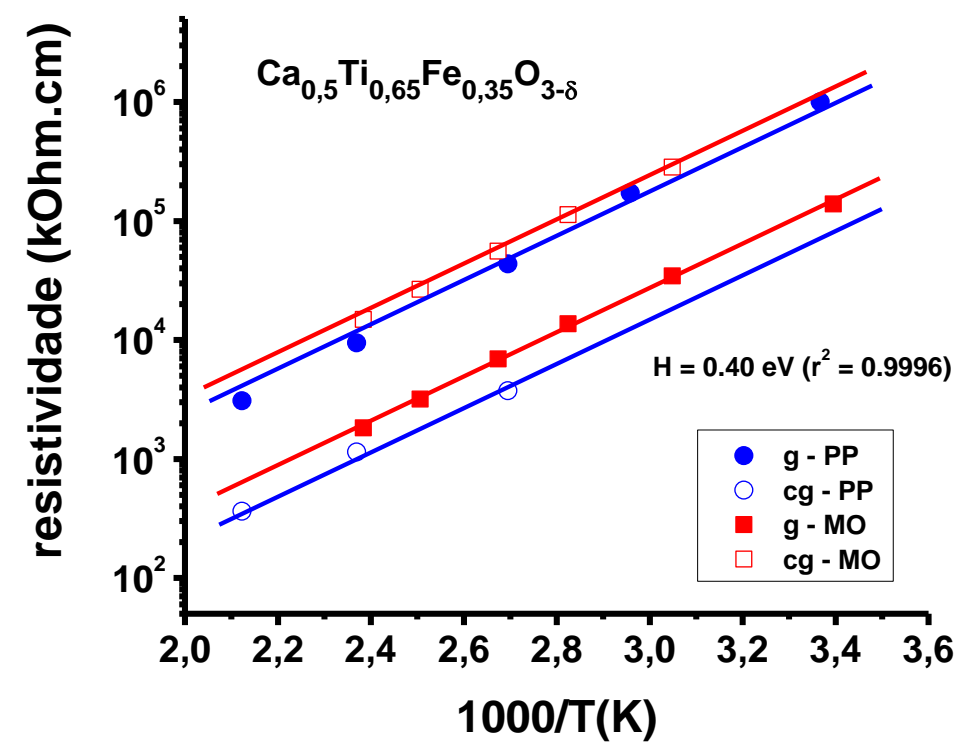

Figura 68 - Gráficos de Arrhenius da resistividade elétrica dos grãos e dos contornos de grão de $\mathrm{CaTi}_{0,65} \mathrm{Fe}_{0,35} \mathrm{O}_{3-\delta}$ (pós obtidos por síntese de estado sólido e técnica dos precursores poliméricos). 
São mostrados na Figura 69 os gráficos de Arrhenius da resistividade elétrica dos grãos e dos contornos de grão das várias composições sinterizadas, obtidas com pós preparados pela técnica de síntese de estado sólido e dos precursores poliméricos.

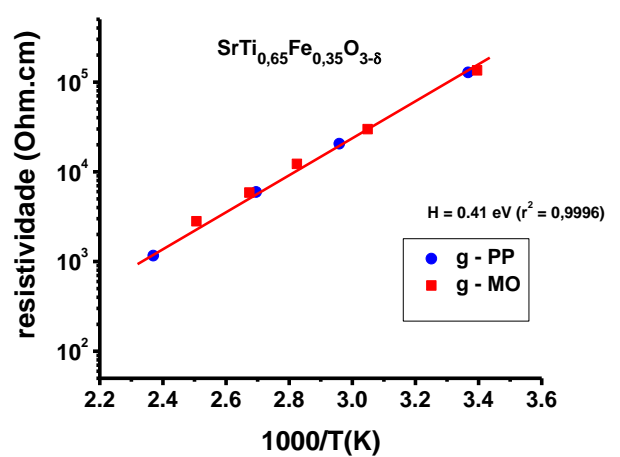

a

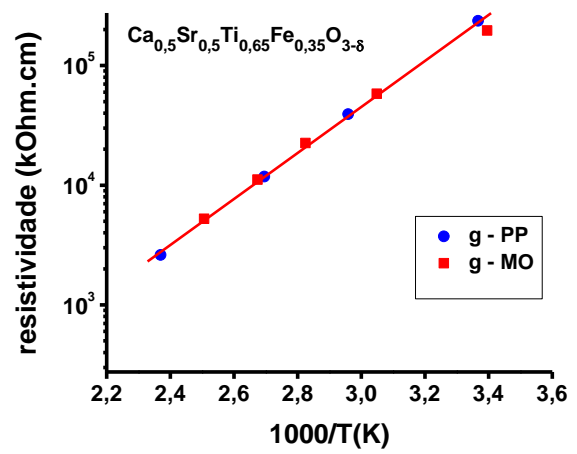

C

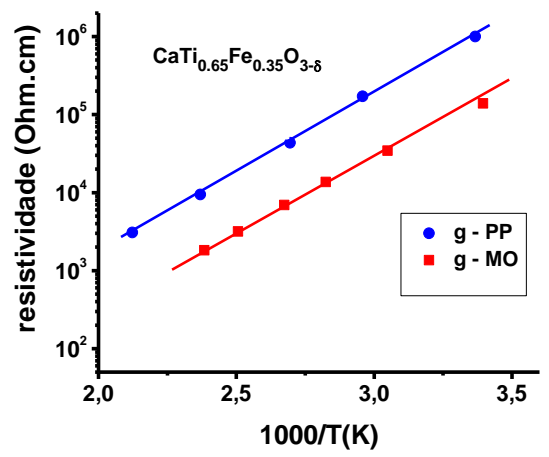

e

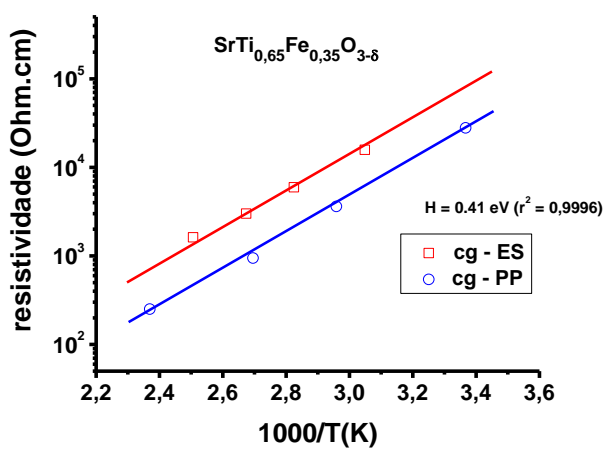

b

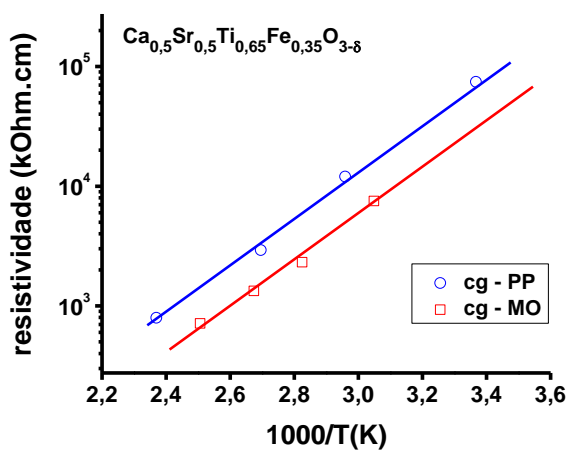

d

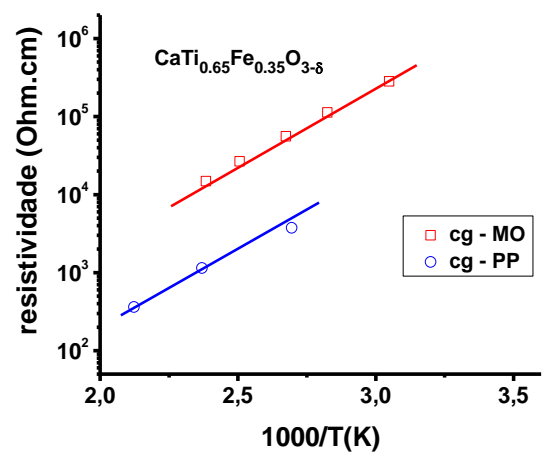

f

Figura 69 - Gráficos de Arrhenius da resistividade elétrica dos grãos (esquerda) e dos contornos de grão (direita) de $\mathrm{SrTi}_{0,65} \mathrm{Fe}_{0,35} \mathrm{O}_{3-\delta}, \mathrm{Ca}_{0,5} \mathrm{Sr}_{0,5} \mathrm{Ti}_{0,65} \mathrm{Fe}_{0,35} \mathrm{O}_{3-\delta}$ e $\mathrm{CaTi}_{0,65} \mathrm{Fe}_{0,35} \mathrm{O}_{3-\delta}$. MO: pós obtidos por síntese de estado sólido e PP; pela técnica dos precursores poliméricos. 
Quanto à origem dos pós, seja pela síntese de estado sólido ou pela técnica dos precursores poliméricos:

- O comportamento da resistividade elétrica intragranular de $\mathrm{SrTi}_{0,65} \mathrm{Fe}_{0,35} \mathrm{O}_{3-\delta}$ e de $\mathrm{Ca}_{0,5} \mathrm{Sr}_{0,5} \mathrm{Ti}_{0,65} \mathrm{Fe}_{0,35} \mathrm{O}_{3-\delta}$ é idêntico, enquanto que no caso de $\mathrm{CaTi}_{0,65} \mathrm{Fe}_{0,35} \mathrm{O}_{3-\delta}$ os materiais obtidos pela técnica dos precursores poliméricos são mais resistivos.

- O comportamento da resistividade elétrica intergranular de $\mathrm{SrTi}_{0,65} \mathrm{Fe}_{0,35} \mathrm{O}_{3-\delta}$ e de $\mathrm{CaTi}_{0,65} \mathrm{Fe}_{0,35} \mathrm{O}_{3-\delta}$ é idêntico, isto é, os pós sintetizados pela rota química produzem compactos sinterizados menos resistivos. O oposto é verificado para as composições de $\mathrm{Ca}_{0,5} \mathrm{Sr}_{0,5} \mathrm{Ti}_{0,65} \mathrm{Fe}_{0,35} \mathrm{O}_{3-\delta}$.

\subsubsection{MEDIDAS DA FORÇA ELETROMOTRIZ X TEOR DE OXIGÊNIO}

É mostrado na Figura 70 o comportamento da força eletromotriz gerada para as composições $\mathrm{SrTi}_{0,65} \mathrm{Fe}_{0,35} \mathrm{O}_{3-\delta}, \quad \mathrm{Ca}_{0,5} \mathrm{Sr}_{0,5} \mathrm{Ti}_{0,65} \mathrm{Fe}_{0,35} \mathrm{O}_{3-\delta} \quad$ e $\mathrm{CaTi}_{0,65} \mathrm{Fe}_{0,35} \mathrm{O}_{3-\delta}$ em função da temperatura para $\sim 50$ ppm de $\mathrm{O}_{2}$.

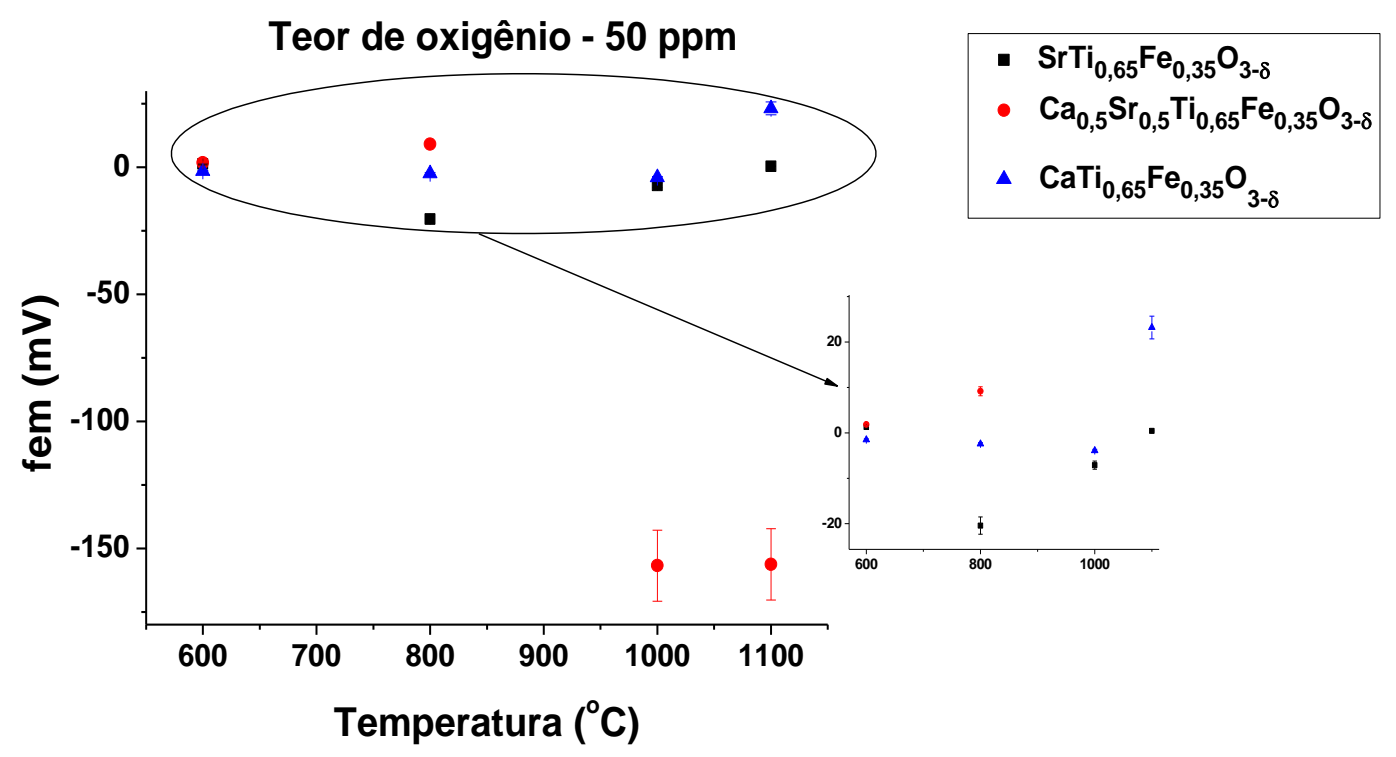

Figura 70 - Gráfico da força eletromotriz gerada para as composições $\operatorname{SrTi}_{0,65} \mathrm{Fe}_{0,35} \mathrm{O}_{3-\delta}$, $\mathrm{Ca}_{0,5} \mathrm{Sr}_{0,5} \mathrm{Ti}_{0,65} \mathrm{Fe}_{0,35} \mathrm{O}_{3-\delta}$ e $\mathrm{CaTi}_{0,65} \mathrm{Fe}_{0,35} \mathrm{O}_{3-\delta}$ em função da temperatura para 50 ppm de $\mathrm{O}_{2}$. Detalhe: ampliação da parte selecionada. 
As composições $\mathrm{SrTi}_{0,65} \mathrm{Fe}_{0,35} \mathrm{O}_{3-\delta}$ e $\mathrm{CaTi}_{0,65} \mathrm{Fe}_{0,35} \mathrm{O}_{3-\delta}$ possuem respostas em função da temperatura para $50 \mathrm{ppm}$ de $\mathrm{O}_{2}$ muito próximas, já para $\mathrm{Ca}_{0,5} \mathrm{Sr}_{0,5} \mathrm{Ti}_{0,65} \mathrm{Fe}_{0,35} \mathrm{O}_{3-\delta}$ há uma variação de tensão considerável, evidenciando ter uma resposta elétrica mais adequada para esta faixa de teor de oxigênio. 


\section{CONCLUSÕES}

Foram sintetizados pela primeira vez compostos de $\mathrm{SrTiO}_{3}$, $\mathrm{Ca}_{0,5} \mathrm{Sr}_{0,5} \mathrm{TiO}_{3}, \quad \mathrm{CaTiO}_{3}, \quad \mathrm{SrTi}_{0,65} \mathrm{Fe}_{0,35} \mathrm{O}_{3-\delta}, \quad \mathrm{Ca}_{0,5} \mathrm{Sr}_{0,5} \mathrm{Ti}_{0,65} \mathrm{Fe}_{0,35} \mathrm{O}_{3-\delta} \quad$ e $\mathrm{CaTi}_{0,65} \mathrm{Fe}_{0,35} \mathrm{O}_{3-\delta}$, pela técnica dos precursores poliméricos.

Foram determinados a simetria, os parâmetros de rede e o grupo espacial dos compostos $\mathrm{Ca}_{x} \mathrm{Sr}_{1-\mathrm{x}} \mathrm{Ti}_{0,65} \mathrm{Fe}_{0,35} \mathrm{O}_{3-\delta}, \mathrm{x}=0$, 0,5 e 1,0, sendo: $\mathrm{SrTi}_{0,65} \mathrm{Fe}_{0,35} \mathrm{O}_{3-\delta}$, simetria: cúbico, parâmetro de rede: $a=3,90006(1)$ e grupo espacial: P m -3 m. $\mathrm{Ca}_{0,5} \mathrm{Sr}_{0,5} \mathrm{Ti}_{0,65} \mathrm{Fe}_{0,35} \mathrm{O}_{3-\delta}$, simetria: ortorrômbico, parâmetros de rede: $\mathrm{a}=7,74010(8), \mathrm{b}=7,73177(8), \mathrm{c}=7,73528(6)$ e grupo espacial: $\mathrm{B} \mathrm{m} \mathrm{m} \mathrm{b.} \mathrm{CaTi}_{0,65} \mathrm{Fe}_{0,35} \mathrm{O}_{3-\delta}$, simetria: ortorrômbico, parâmetros de rede: $\mathrm{a}=5,4085(2), \quad \mathrm{b}=5,41533(7), \quad \mathrm{c}=7,6619(2)$ e grupo espacial: P b n m, sintetizados pela técnica de reação de estado sólido.

Foi determinada a energia de ativação térmica na faixa de temperatura $300-500 \mathrm{~K},(\sim 0,40 \mathrm{eV})$, para a condutividade iônica por meio da técnica de espectroscopia de impedância dos compostos $\mathrm{Ca}_{x} \mathrm{Sr}_{1-\mathrm{x}} \mathrm{Ti}_{0,65} \mathrm{Fe}_{0,35} \mathrm{O}_{3-\delta}, \mathrm{x}=0$, 0,5 e 1,0 .

Foi mostrado que compostos sintetizados pela rota química apresentam condutividade iônica maior que a apresentada pelos compostos sintetizados por reação de estado sólido.

A substituição parcial de $\mathrm{Sr}^{2+}$ por $\mathrm{Ca}^{2+}$ na estrutura cristalina de $\mathrm{SrTi}_{0,65} \mathrm{Fe}_{0,35} \mathrm{O}_{3-\delta}$, melhora a resposta elétrica sob baixa pressão parcial de oxigênio ( $50 \mathrm{ppm})$, mostrando a possibilidade de uso deste material em sensores de oxigênio na faixa de temperatura $600-1100{ }^{\circ} \mathrm{C}$, sendo $\mathrm{O}$ melhor sinal elétrico obtido com o composto $\mathrm{Ca}_{0,5} \mathrm{Sr}_{0,5} \mathrm{Ti}_{0,65} \mathrm{Fe}_{0,35} \mathrm{O}_{3-\delta}$. 


\section{REFERÊNCIAS}

[1] J. Gerblinger, W. Lohwasser, U. Lampe, H. Meixner, High-Temperature Oxygen Sensor-Based on Sputtered Cerium Oxide, Sens. Act. B-Chem., 26 1-3, (1995) 93.

[2] E. Ivers-Tiffee, K. H. Hardtl, W. Menesklou, J. Riegel, Principles of solid state oxygen sensors for lean combustion gas control, Electrochim. Acta, 47 5, (2001) 807.

[3] R. Moos, A brief overview on automotive exhaust gas sensors based on electroceramics, Int. J. Appl. Ceram. Tec., 2 5, (2005) 401.

[4] S. J. Litzelman, A. Rothschild, H. L. Tuller, The electrical properties and stability of $\mathrm{SrTi}_{0.65} \mathrm{Fe}_{0.35} \mathrm{O}_{3-\delta}$ thin films for automotive oxygen sensor applications, Sens. Act. B-Chem., 108 1-2, (2005) 231.

[5] R. Moos, W. Menesklou, H. J. Schreiner, K. H. Hardtl, Materials for temperature independent resistive oxygen sensors for combustion exhaust gas control, Sens. Act. B-Chem., 67 1-2, (2000) 178.

[6] J. J. Sprague, O. Porat, H. L. Tuller, Mixed conducting gas sensors: Atmosphere dependent electrode impedance, Sens. Act. B-Chem., 36 13, (1996) 348.

[7] J. Gerblinger, H. Meixner, Fast Oxygen Sensors Based on Sputtered Strontium-Titanate, Sens. Act. B-Chem.. 4 1-2, (1991) 99.

[8] J. Fouletier, Gas analysis with potentiometric sensors. A review, Sens. Act., $\underline{3}$, (1983) 295.

[9] G. Velasco, J. P. Schnell, M. Croset, Thin Solid-State Electrochemical Gas Sensors, Sens. Act., 2 4, (1982) 371.

[10] J. H. Lee, Review on zirconia air-fuel ratio sensors for automotive applications, J. Mater. Sci., 38 21, (2003) 4247.

[11] J. Luxova, P. Sulcova, M. Trojan, Study of Perovskite compounds, J. Therm. Anal. Calorim., 93 3, (2008) 823.

[12] L. F. da Silva, M. I. B. Bernardi, L. J. Q. Maia, G. J. M. Frigo, V. R. Mastelaro, Synthesis and thermal decomposition of $\mathrm{SrTi}_{1-\mathrm{x}} \mathrm{Fe}_{(\mathrm{x})} \mathrm{O}_{3}(0.0 \mathrm{a}$ parts per thousand currency sign $x$ a parts per thousand currency sign $0.1)$ powders obtained by the polymeric precursor method, J. Therm. Anal. Calorim., 97 1, (2009) 173.

[13] Q. X. Fu, S. B. Mi, E. Wessel, F. Tietz, Influence of sintering conditions on microstructure and electrical conductivity of yttrium-substituted $\mathrm{SrTiO}_{3}$, J. Eur. Ceram. Soc., 28 4, (2008) 811. 
[14] U. Balachandran, N. G. Eror, Electrical-Conductivity in LanthanumDoped Strontium-Titanate, J. Electrochem. Soc., 129 5, (1982) 1021.

[15] J. Karczewski, B. Riegel, M. Gazda, P. Jasinski, B. Kusz, Electrical and structural properties of $\mathrm{Nb}$-doped $\mathrm{SrTiO}_{3}$ ceramics, J. Electroceram., $\underline{24}$ 4, (2010) 326.

[16] B. Odekirk, U. Balachandran, N. G. Eror, Conductivity of strongly reduced and quenched ceramic La-doped $\mathrm{SrTiO}_{3}$, J. Am. Ceram. Soc., $\underline{66},(1983)$.

[17] U. Balachandran, N. G. Eror, Solubility of Lanthanum in StrontiumTitanate, J. Am. Ceram. Soc., $\underline{64}$ 4, (1981) C75.

[18] N. G. Eror, U. Balachandran, Self-Compensation in Lanthanum-Doped Strontium-Titanate, J. Solid State Chem., $\underline{40}$ 1, (1981) 85.

[19] R. Moos, S. Schöllhammer, K. H. Härdtl, Electron mobility of $\mathrm{Sr}_{1-\mathrm{x}} \mathrm{La}_{\mathrm{x}} \mathrm{TiO}_{3}$ ceramics between $600^{\circ} \mathrm{C}$ and $1300^{\circ} \mathrm{C}$, Appl. Phys. A: Mater. Sci. Proc., $\underline{65}$ 3, (1997) 291.

[20] S. Hashimoto, F. W. Poulsen, M. Mogensen, Conductivity of $\mathrm{SMO}_{3}$ based oxides in the reducing atmosphere at high temperature, J. Alloy Compd., $\underline{439}$ 1-2, (2007) 232.

[21] T. Kolodiazhnyi, A. Petric, The applicability of Sr-deficient n-type $\mathrm{SrTiO}_{3}$ for SOFC anodes, J. Electroceram., 15 1, (2005) 5.

[22] P. Blennow, A. Hagen, K. K. Hansen, L. R. Wallenberg, M. Mogensen, Defect and electrical transport properties of $\mathrm{Nb}$-doped $\mathrm{SrTiO}_{3}$, Solid State Ionics, 179 35-36, (2008) 2047.

[23] P. Blennow, K. K. Hansen, L. R. Wallenberg, M. Mogensen, Electrochemical characterization and redox behavior of $\mathrm{Nb}$-doped $\mathrm{SrTiO}_{3}$, Solid State lonics, 180 1, (2009) 63.

[24] B. J. Kennedy, C. J. Howard, B. C. Chakoumakos, High-temperature phase transitions in $\mathrm{SrZrO}_{3}$, Phys. Rev. B, $\underline{59}$ 6, (1999) 4023.

[25] B. J. Kennedy, C. J. Howard, B. C. Chakoumakos, Phase transitions in perovskite at elevated temperatures - a powder neutron diffraction study, J. Phys-Condens. Mat., 11 6, (1999) 1479.

[26] R. F. Gonçalves, N. L. V. Carreño, M. T. Escote, K. P. Lopes, A. Valentini, E. R. Leite, E. Longo, M.A. Machado, Fotoluminescência e adsorção de $\mathrm{CO}_{2}$ em nanopartículas de $\mathrm{CaTiO}_{3}$ dopadas com lantânio, Quim., 27, (2004) 862. 
[27] G. M. Mi, Y. Murakami, D. Shindo, F. Saito, Microstructural investigation of $\mathrm{CaTiO}_{3}$ formed mechanochemically by dry grinding of a $\mathrm{CaO}-\mathrm{TiO}_{2}$ mixture, Powder Technol., 104 1, (1999) 75.

[28] M. G. Rubio. acessado em 11/04/2008. Disponível em: $<$ http://www.lsi.usp.br/ gongora $>$.

[29] T. Takeuchi, Oxygen Sensors, Sens. Act., 14 2, (1988) 109.

[30] J.W. Fergus, Chemical Sensors for Improved Control in the Processing of Molten Metals, JOM-e, $\underline{52}$ 10, (2000).

[31] E. T. Turkdoga, R. J. Fruehan, Review of Oxygen Sensors for Use in Steelmaking and of Deoxidation Equilibria, Can. Metall. Quart., 112 , (1972) 371.

[32] NGK-NTK. acessado em 04/05/2010. Disponível em:

$<$ http://www.ngkntk.com.br/sens ox/caracteristicas.html $>$.

[33] D. Segal, Chemical synthesis of ceramic materials, J. Mater. Chem., $\underline{7}$ 8, (1997) 1297.

[34] C. Marcilly, P. Courty, B. Delmon, Preparation of Highly Dispersed Mixed Oxides and Oxide Solid Solutions by Pyrolysis of Amorphous Organic Precursors, J. Am. Ceram. Soc., 53 1, (1970) 56.

[35] M.P. Pechini, US Patent No. 3330697 (1967).

[36] M. Kakihana, "Sol-Gel" preparation of high temperature superconducting oxides, J. Sol-Gel Sci. Techn., $\underline{6}$ 1, (1996) 7.

[37] M. Kakihana, M. Yoshimura, Synthesis and characteristics of complex multicomponent oxides prepared by polymer complex method, B. Chem. Soc. Jpn., 72 7, (1999) 1427.

[38] A. Rothschild, W. Menesklou, H. L. Tuller, E. Ivers-Tiffee, Electronic structure, defect chemistry, and transport properties of $\mathrm{SrTi}_{1-\mathrm{x}} \mathrm{FexO}_{3-\mathrm{y}}$ solid solutions, Chem. Mater., 18 16, (2006) 3651.

[39] D. R. Lide, CRC Handbook of Chemistry and Physics, 89th ed. CRC Press/Taylor and Francis, Boca Raton, FL., (2009).

[40] All-in-one 2001-02 (Alfa Aesar - A Johnson Mattley company). Ward Hill, (2001-2002).

[41] P. Hansen, D. Hennings, H. Schreinemacher, High-K dielectric ceramics from donor/acceptor-codoped $\left.\left(\mathrm{Ba}_{1-\mathrm{x}} \mathrm{Ca}_{\mathrm{x}}\right) \mathrm{Ti}_{1-\mathrm{y}} \mathrm{Zr}_{\mathrm{y}}\right) \mathrm{O}_{3}(\mathrm{BCTZ})$, J. Am.

Ceram. Soc., 81 5, (1998) 1369. 
[42] D.F.K. Hennings, B.S. Schreinemacher, H. Schreinemacher, Solid-state preparation of $\mathrm{BaTiO}_{3}$-based dielectrics, using ultrafine raw materials, J. Am. Ceram. Soc., 84 12, (2001) 2777.

[43] A. Beauger, J. C. Mutin, J. C. Niepce, Synthesis Reaction of Metatitanate $\mathrm{BaTiO}_{3} .1$. Effect of the Gaseous Atmosphere Upon the Thermal Evolution of the System $\mathrm{BaCO}_{3}-\mathrm{TiO}_{2}$, J. Mater. Sci., 18 10, (1983) 3041.

[44] F. Goutenoire, O. Isnard, R. Retoux, P. Lacorre, Crystal structure of $\mathrm{La}_{2} \mathrm{Mo}_{2} \mathrm{O}_{9}$, a new fast oxide-ion conductor, Chem. Mater., 12 9, (2000) 2575.

[45] A.C. Larson, R.B. Von Dreele, "General Structure Analysis System (GSAS)" Los Alamos National Laboratory Report LAUR (1994).

[46] B. H. Toby, EXPGUI, a graphical user interface for GSAS, J. Appl. Cryst., 34, (2001) 210.

[47] H. M. Rietveld, A Profile Refinement Method for Nuclear and Magnetic Structures, J. Appl. Cryst., 2 , (1969) 65.

[48] R.A. Young, The Rietveld Method, IUCr Monographs on Crystallography - 5, IUCr, Oxford, (1995).

[49] D. B. Wiles, R. A. Young, A New Computer-Program for Rietveld Analysis of X-Ray-Powder Diffraction Patterns, J. Appl. Cryst., 14, (1981) 149.

[50] R.A. Young, A.C. Larson, C.O. Paiva-Santos, User's guide to program dbws-9807a for Rietveld analysis of X-Ray and Neutron powder diffraction patterns with a PC and various other computers, School of Physics, , Georgia Institute of Thechnology. Atlanta, (2000).

[51] N. Masciocchi, The contribution of powder diffraction methods to structural crystallography: Rietveld and Ab-initio techniques, Rigaku J., $14,(1997) 2$.

[52] C.O. Paiva-Santos. Aplicações do Método de Rietveld., acessado em 15/03/2011. Disponível em: < http://labcacc.iq.unesp.br >.

[53] Proteus Thermal Analysis - Netzsch Proteus thermal Analysis - Versão 4.8.5 (14.08.2008) - Copyright @ 1999-2008 Garaetebau GmbH.

[54] M. Kleitz, J. H. Kennedy. In, P. Vashishta, J. N. Mundy and G. K. Shenoy, Editors, Fast ion transport in solids, (1979) 185.

[55] M.C. Steil, F.C. Fonseca, Y.V. França, J.F.Q. Rey, E.N.S. Muccillo, R. Muccillo, Montagem, calibração e testes de um sistema de medidas elétricas em função da temperatura e da pressão parcial de oxigênio, Cerâmica, $\underline{48}$ 307, (2002) 3. 
[56] B. V. L'vov, Mechanism and kinetics of thermal decomposition of carbonates, Thermochim. Acta, $\underline{386}$ 1, (2002) 1.

[57] B.V. L'vov, Mechanism of thermal decomposition of alkaline-earth carbonates, Thermochim Acta, $\underline{303}$ 2, (1997) 161.

[58] H. Ikawa, A. Iwai, K. Hiruta, H. Shimojima, K. Urabe, S. Udagawa, Phase transformation and thermal expansion of zirconium and hafnium titanates and their solid solutions, J. Am. Ceram. Soc., 71 2, (1988) 120.

[59] Internacional Centre for Diffraction Data, Powder Diffraction File, PDF2ICDD, USA, edição 2003., (2003).

[60] R.A. Young, "The Rietveld Method, 298 p. International Union of Crystallography", (Oxford University Press, New York, 1995).

[61] Crystallographica Search-Match - versão 2, 1, 1, 1 - Copyright (C 19962004 Oxford Cryosystems (2011).

[62] J. G. Fletcher, A. R. West, J. T. S. Irvine, The Ac-Impedance Response of the Physical Interface between Yttria-Stabilized Zirconia and $\mathrm{YBa}_{2} \mathrm{Cu}_{3} \mathrm{O}_{7-\delta}$, J. Electrochem. Soc., 142 8, (1995) 2650. 


\section{APÊNDICES}

\subsection{APÊNDICE A}

\subsubsection{ANÁLISES COM O SOFTWARE PROTEUS}

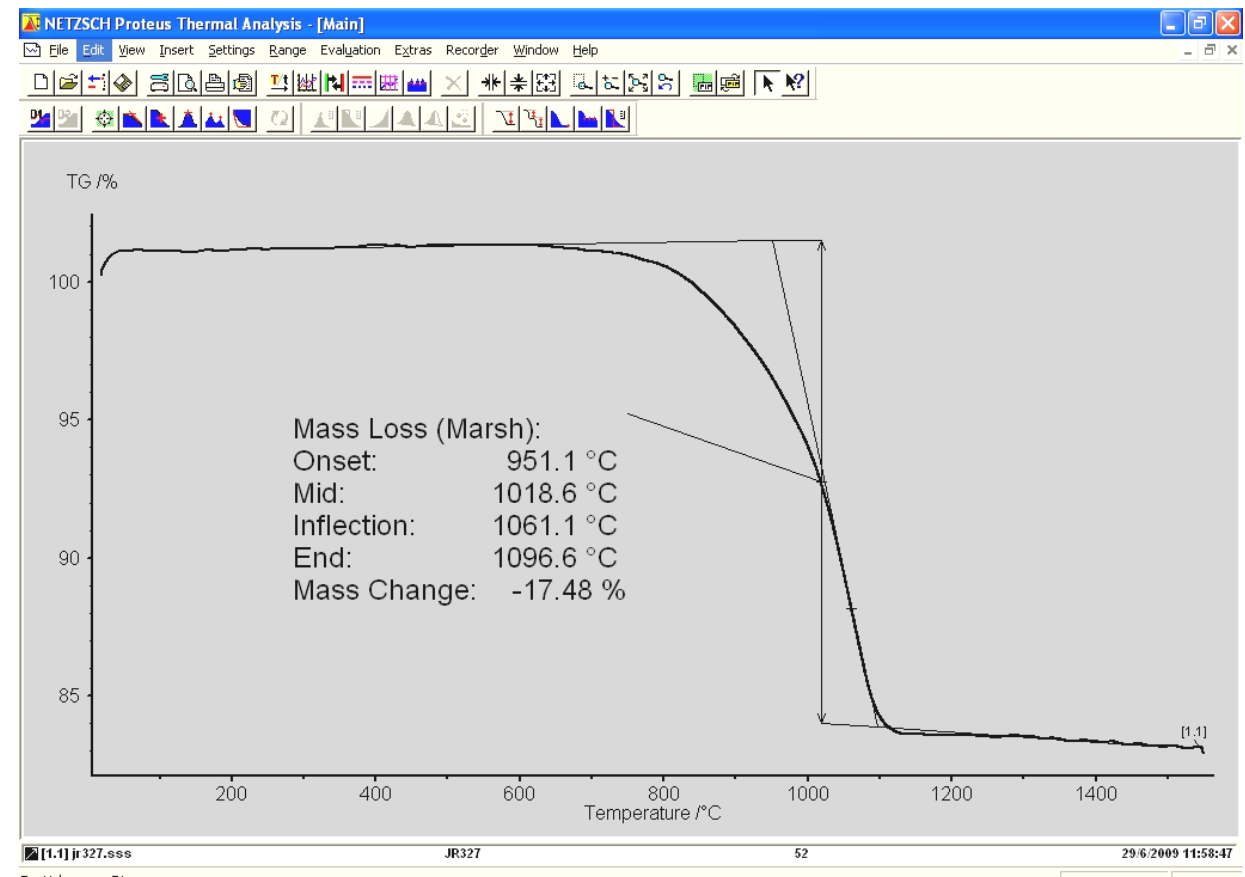

Figura 71 - Curva de análise termogravimétrica de mistura de $\mathrm{SrCO}_{3}, \mathrm{TiO}_{2}$ e $\mathrm{Fe}_{2} \mathrm{O}_{3}$ na proporção molar 1,0:0,65:0,35; análise feita com o software Proteus ${ }^{[53]}$.

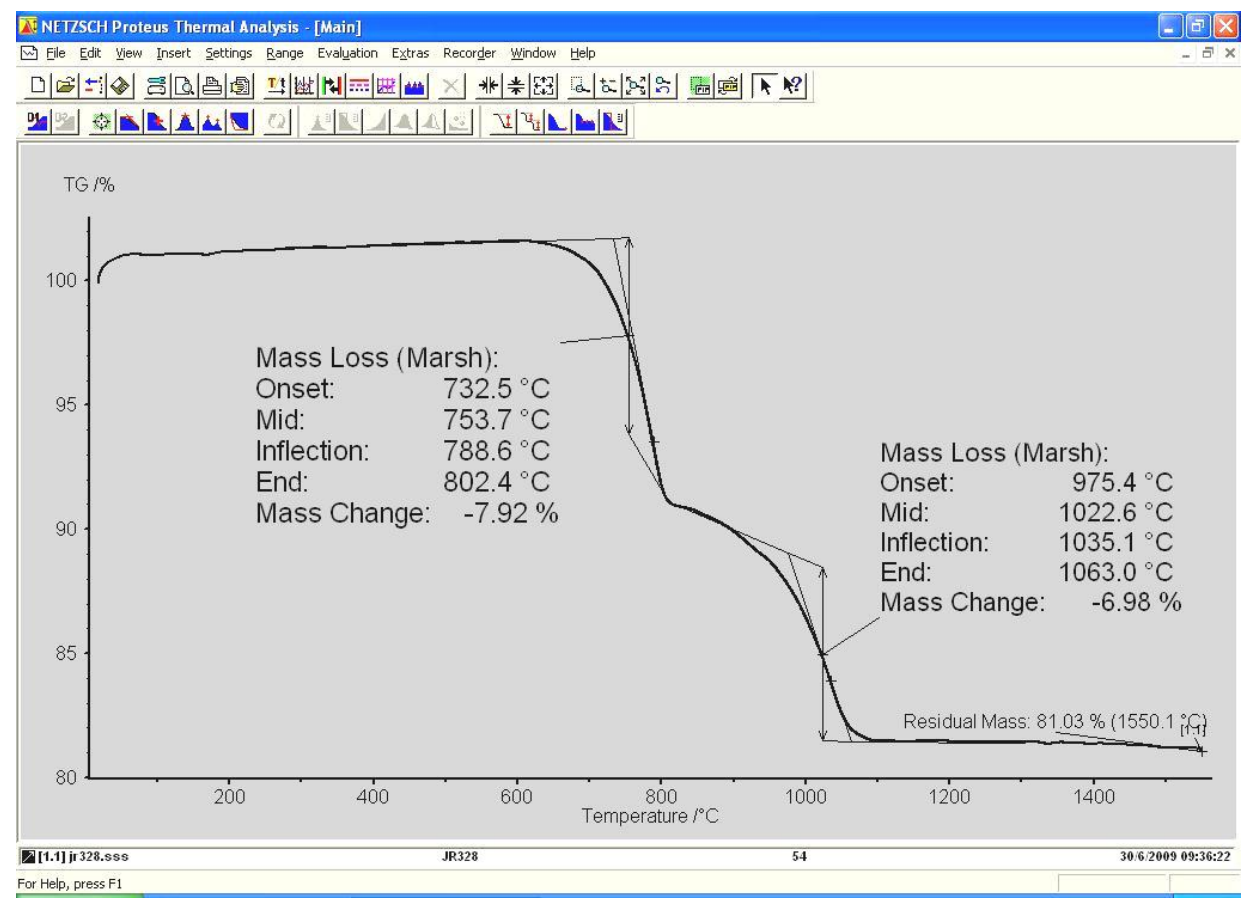

Figura 72 - Curva de análise termogravimétrica de mistura de $\mathrm{CaCO}_{3}, \mathrm{SrCO}_{3}, \mathrm{TiO}_{2}$ e $\mathrm{Fe}_{2} \mathrm{O}_{3}$ na proporção molar 0,5:0,5:0,65:0,35; análise feita com o software Proteus ${ }^{[53]}$. 


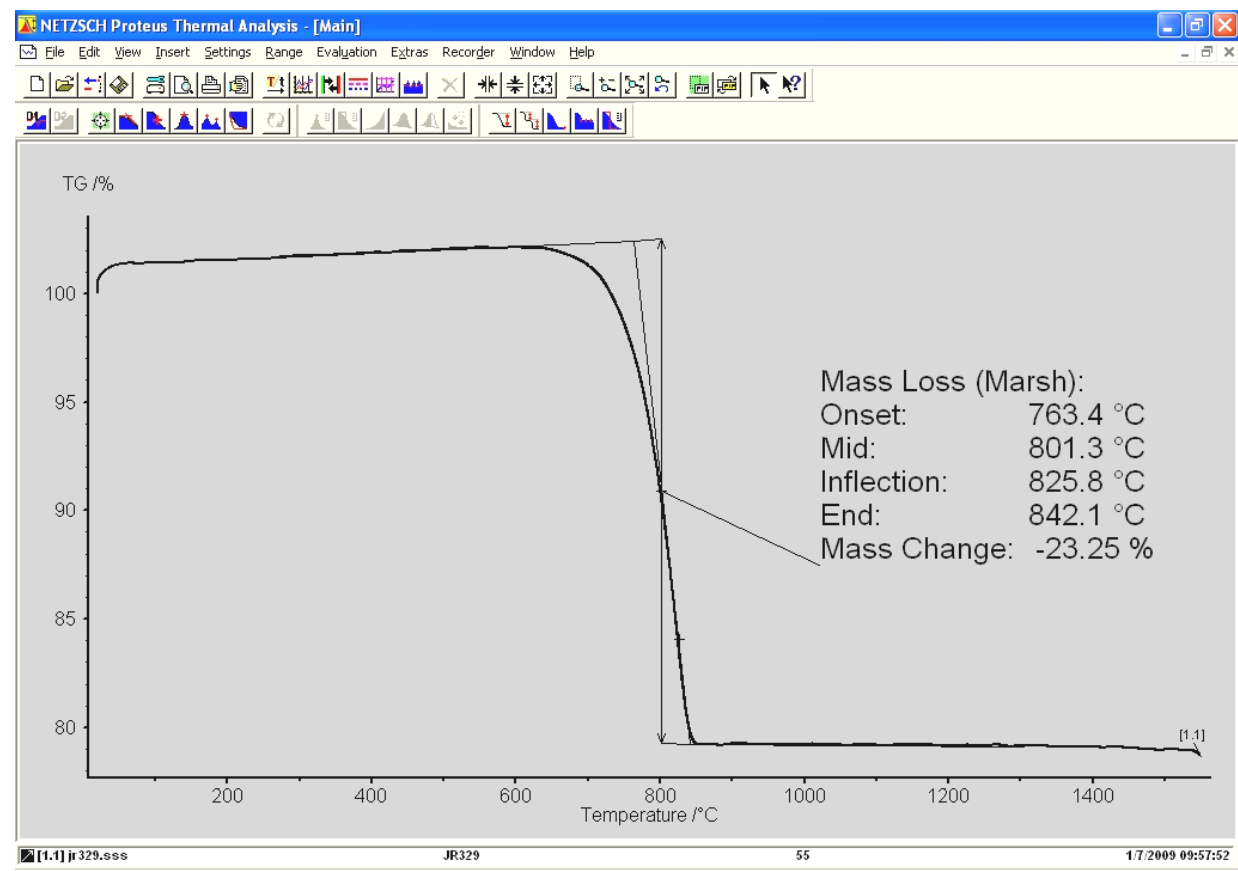

$\nabla[1.1] \mathrm{j}$ i329.s

JP329

Figura 73 - Curva de análise termogravimétrica de mistura de $\mathrm{CaCO}_{3}, \mathrm{TiO}_{2}$ e $\mathrm{Fe}_{2} \mathrm{O}_{3}$ na proporção molar 1,0:0,65:0,35; análise feita com o software Proteus ${ }^{[53]}$.

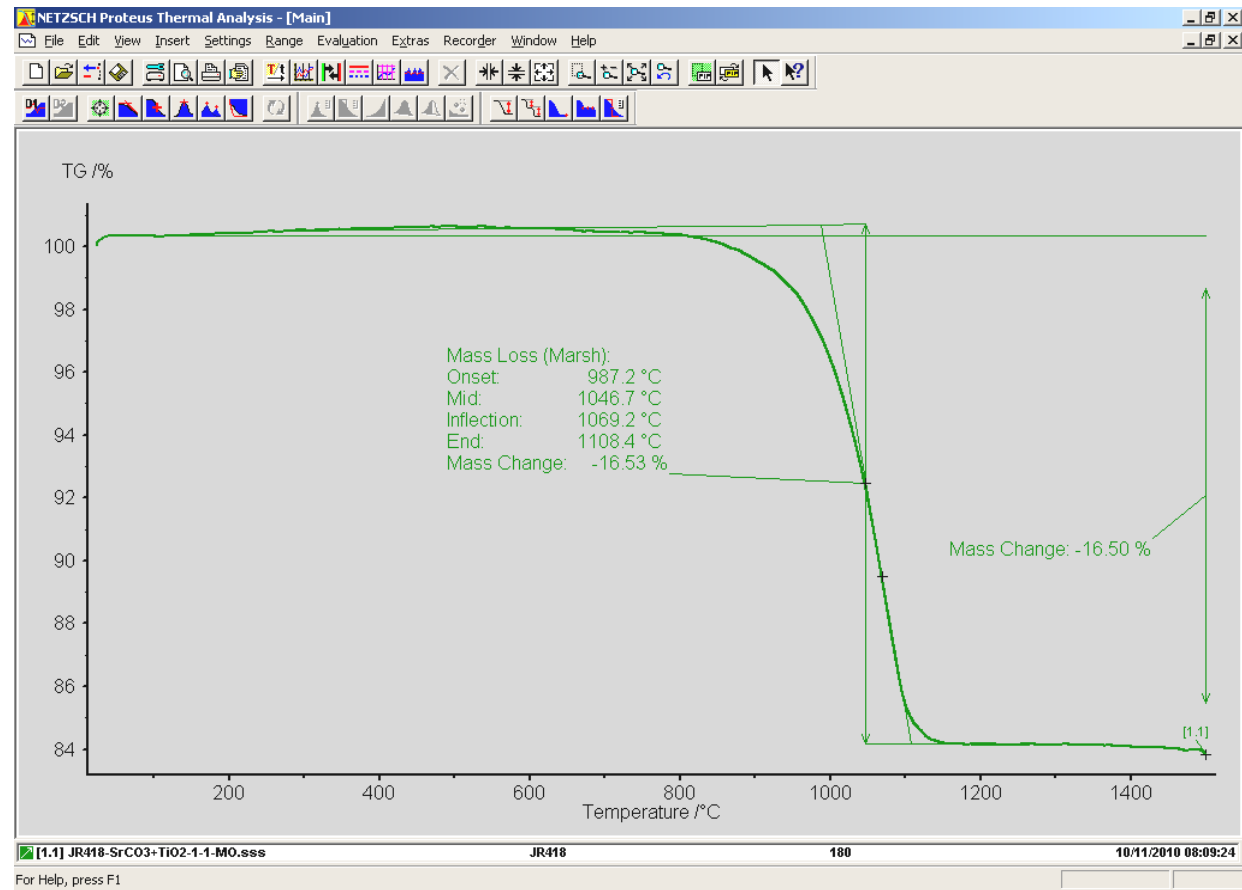

Figura 74 - Curva de análise termogravimétrica de mistura de $\mathrm{SrCO}_{3}$ e $\mathrm{TiO}_{2}$ na proporção molar 1,0:1,0; análise feita com o software Proteus ${ }^{[53]}$. 


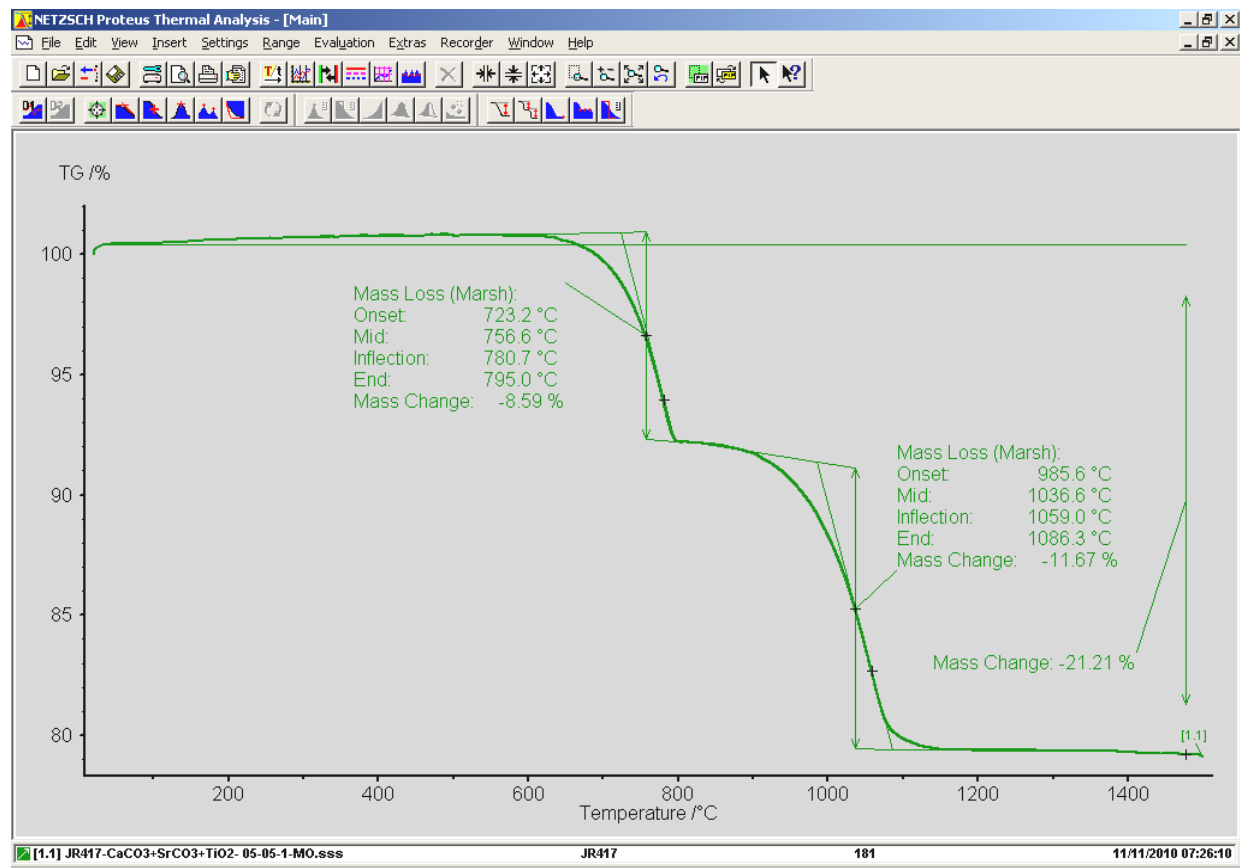

T[1.1] JR417-CaCO3+SrCO3+TiO2-05051M0.5s

11/11/2010 07:26:10

For Help, press F1

Figura 75 - Curva de análise termogravimétrica de mistura de $\mathrm{CaCO}_{3}, \mathrm{SrCO}_{3}$ e $\mathrm{TiO}_{2}$ na proporção molar 0,5:0,5:1,0; análise feita o software Proteus ${ }^{[53]}$.

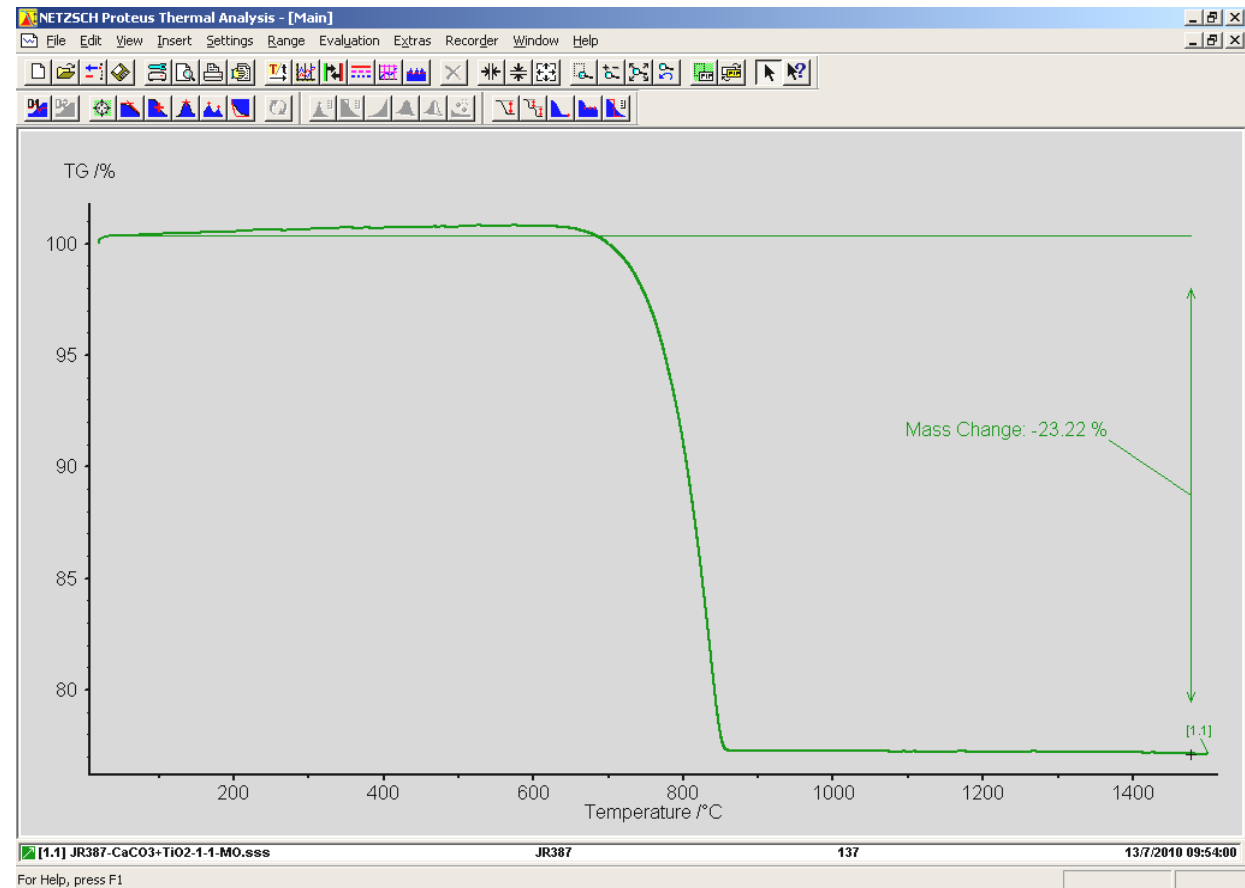

Figura 76 - Curva de análise termogravimétrica de mistura de $\mathrm{CaCO}_{3}$ e $\mathrm{TiO}_{2}$ na proporção molar 1,0:1,0; análise feita com o software Proteus ${ }^{[53]}$. 


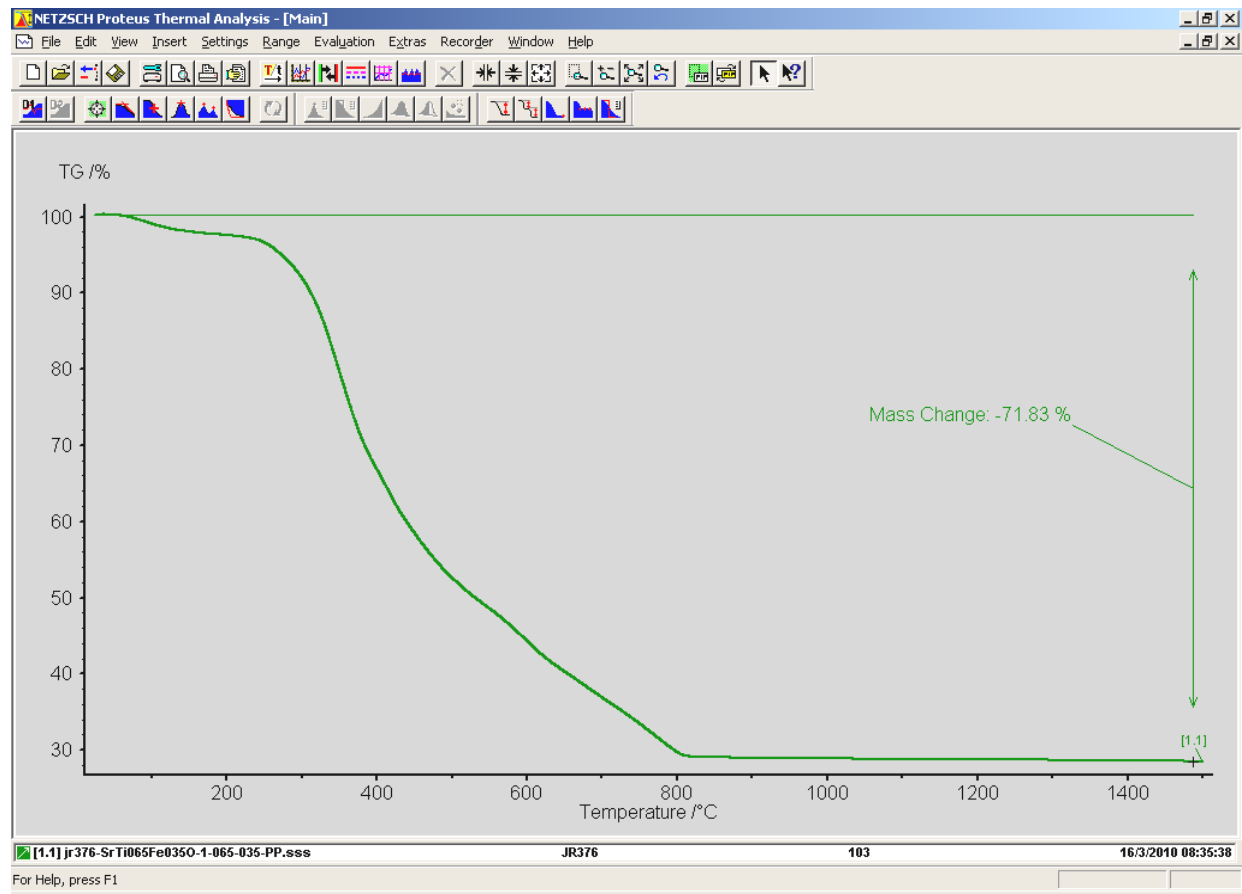

Figura 77 - Curva de análise termogravimétrica da resina precursora de $\mathrm{SrTi}_{0,65} \mathrm{Fe}_{0,35} \mathrm{O}_{3-\delta}-$ método dos precursores poliméricos; análise feita com o software Proteus ${ }^{[53]}$.

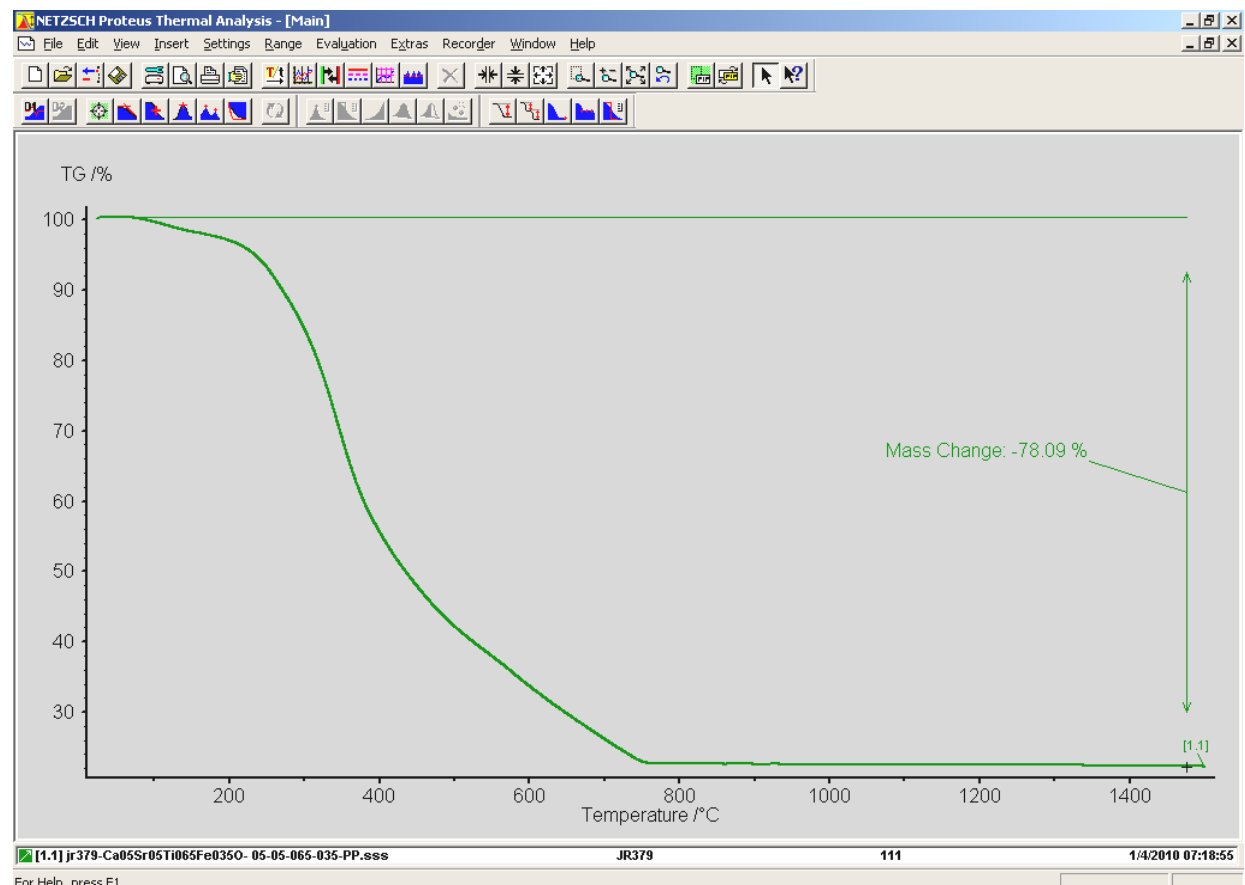

Figura 78 - Curvas de análise termogravimétrica da resina precursora de $\mathrm{Ca}_{0,5} \mathrm{Sr}_{0,5} \mathrm{TiO}_{65} \mathrm{Fe}_{0,35} \mathrm{O}_{3-\delta}$ - método dos precursores poliméricos, análise feita com o software Proteus ${ }^{[53]}$ 


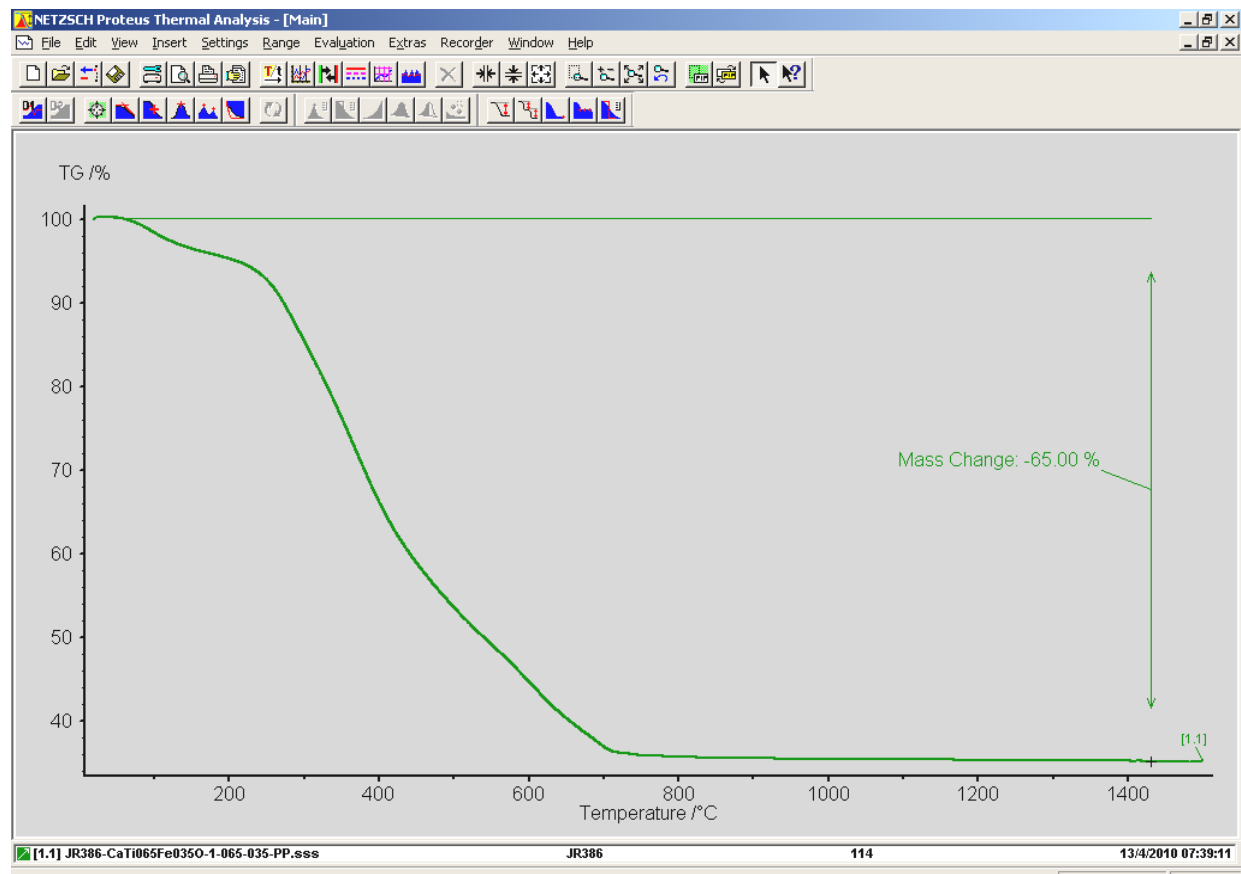

Q11.1] 3/4:2010 07:39:11

Figura 79 - Curva de análise termogravimétrica da resina precursora de $\mathrm{CaTi}{ }_{65} \mathrm{Fe}_{0,35} \mathrm{O}_{3-\delta}-$ método dos precursores poliméricos, análise feita com o software Proteus ${ }^{[53]}$.

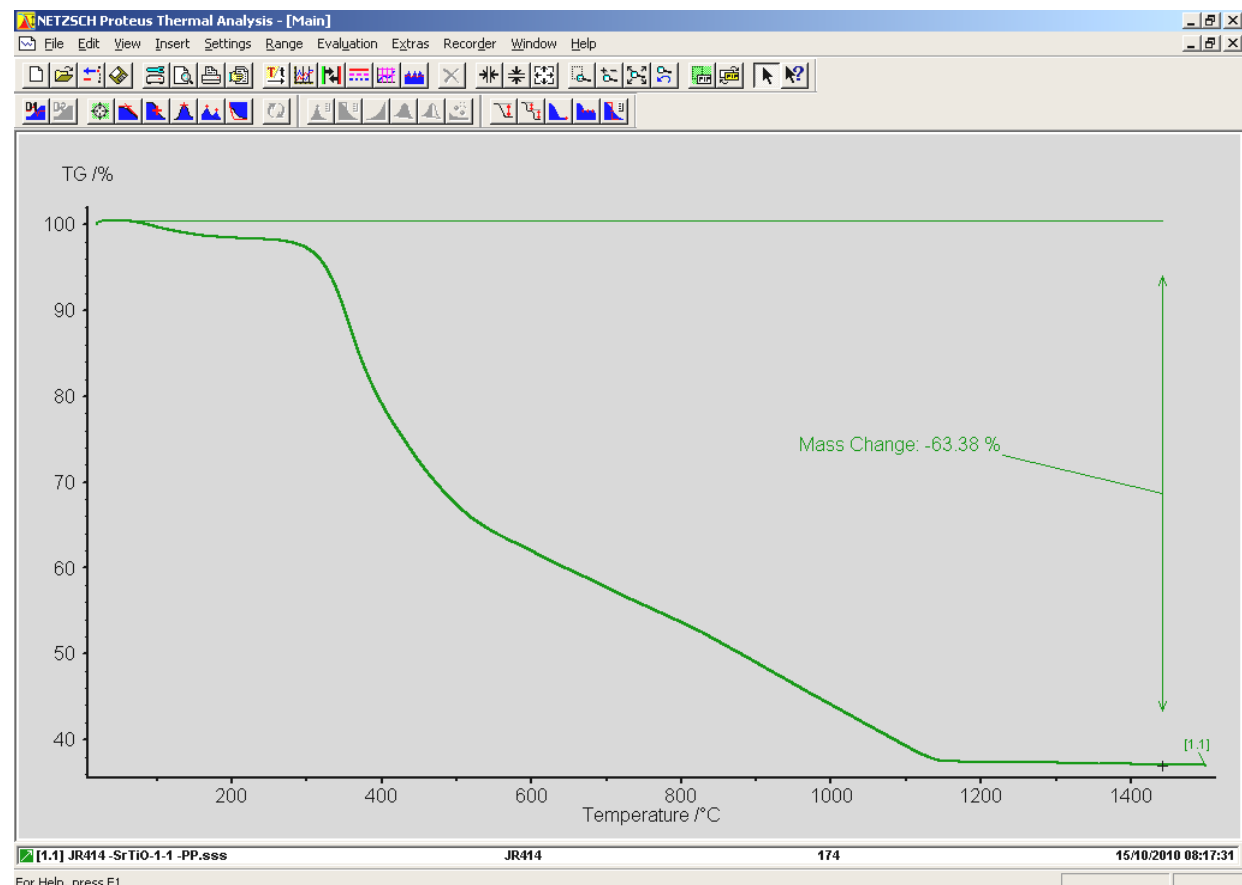

Figura 80 - Curvas de análise térmica diferencial da resina precursora de $\mathrm{SrTiO}_{3}$ - método dos precursores poliméricos; atmosfera: nitrogênio, análise feita com o software Proteus ${ }^{[53]}$. 


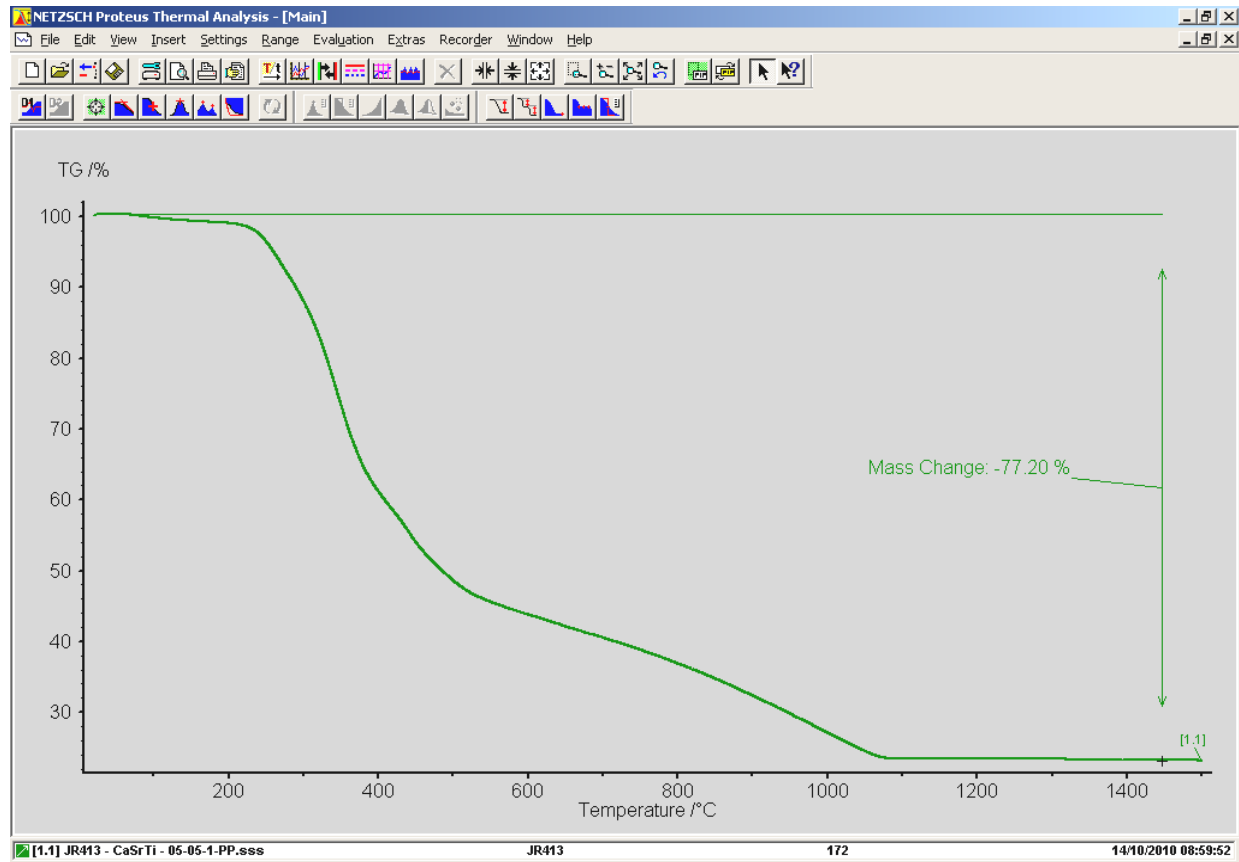

\begin{tabular}{llll}
\hline 2[1.1] JR413 - CaSrTi - 05-05-1.PP.sss & JR413 & 172 & $14 / 10: 2010$ 08:59:52 \\
\hline For Help, press F1 & &
\end{tabular}

Figura 81 - Curvas de análise térmica diferencial da resina precursora de $\mathrm{Ca}_{0,5} \mathrm{Sr}_{0,5} \mathrm{TiO}_{3-\delta}$ método dos precursores poliméricos; atmosfera: nitrogênio, análise feita com o software Proteus ${ }^{[53]}$.

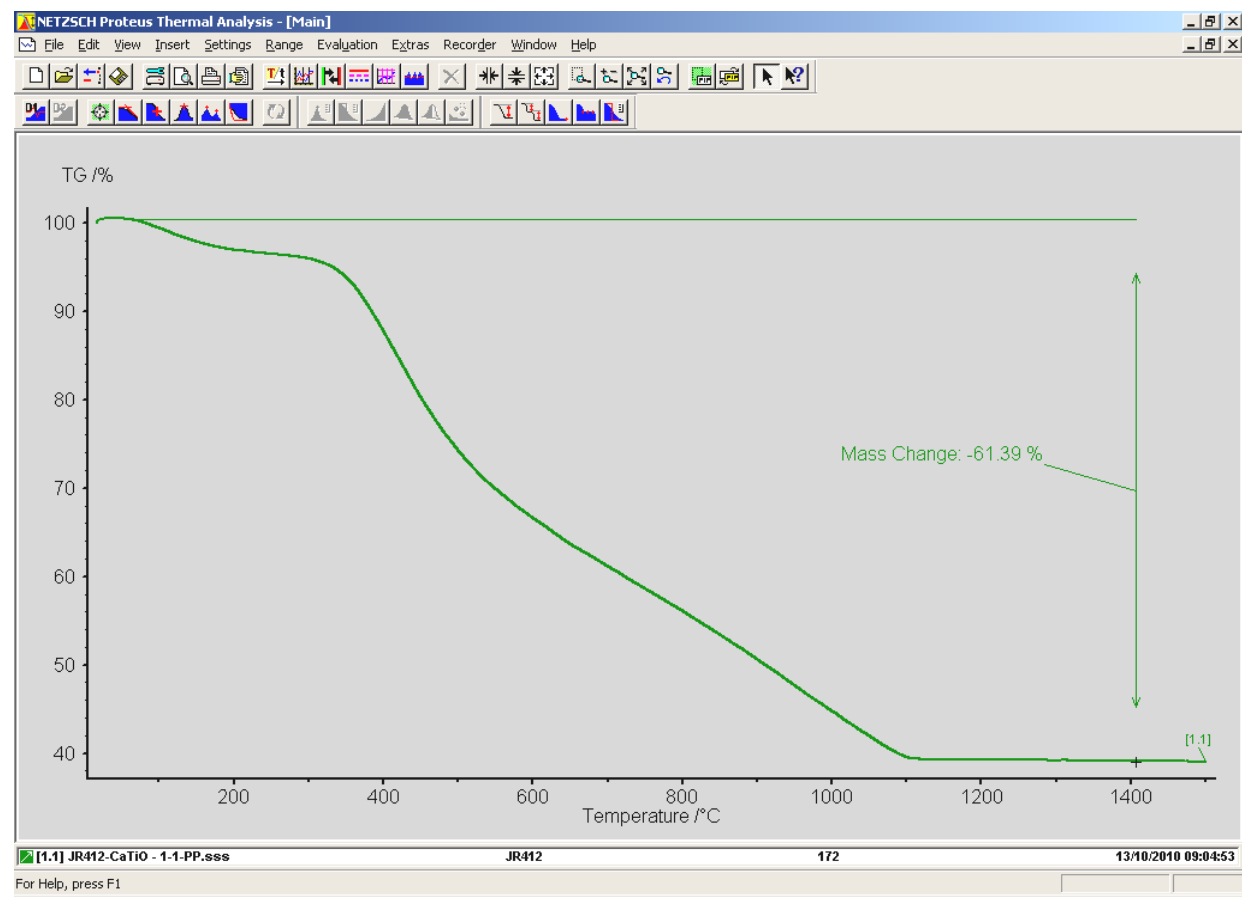

Figura 82 - Curvas de análise térmica diferencial da resina precursora de $\mathrm{CaTiO}_{3}$ - método dos precursores poliméricos; atmosfera: nitrogênio, análise feita com o software Proteus ${ }^{[53]}$. 
7.1.2 CuRVAS BASE DE CALIBRAÇÃO DO EQUIPAMENTO DE ANÁLISE TÉRMICA

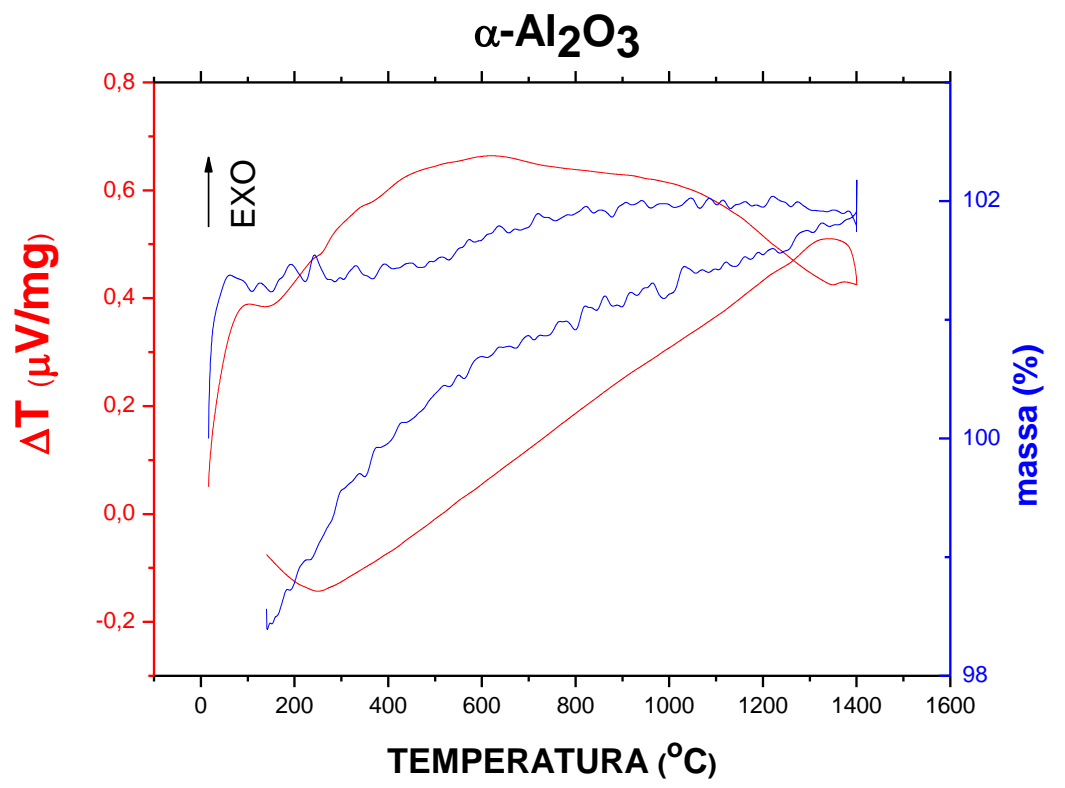

Figura 83 - Curva de calibração usada nas análises termogravimétricas e térmica diferencial.

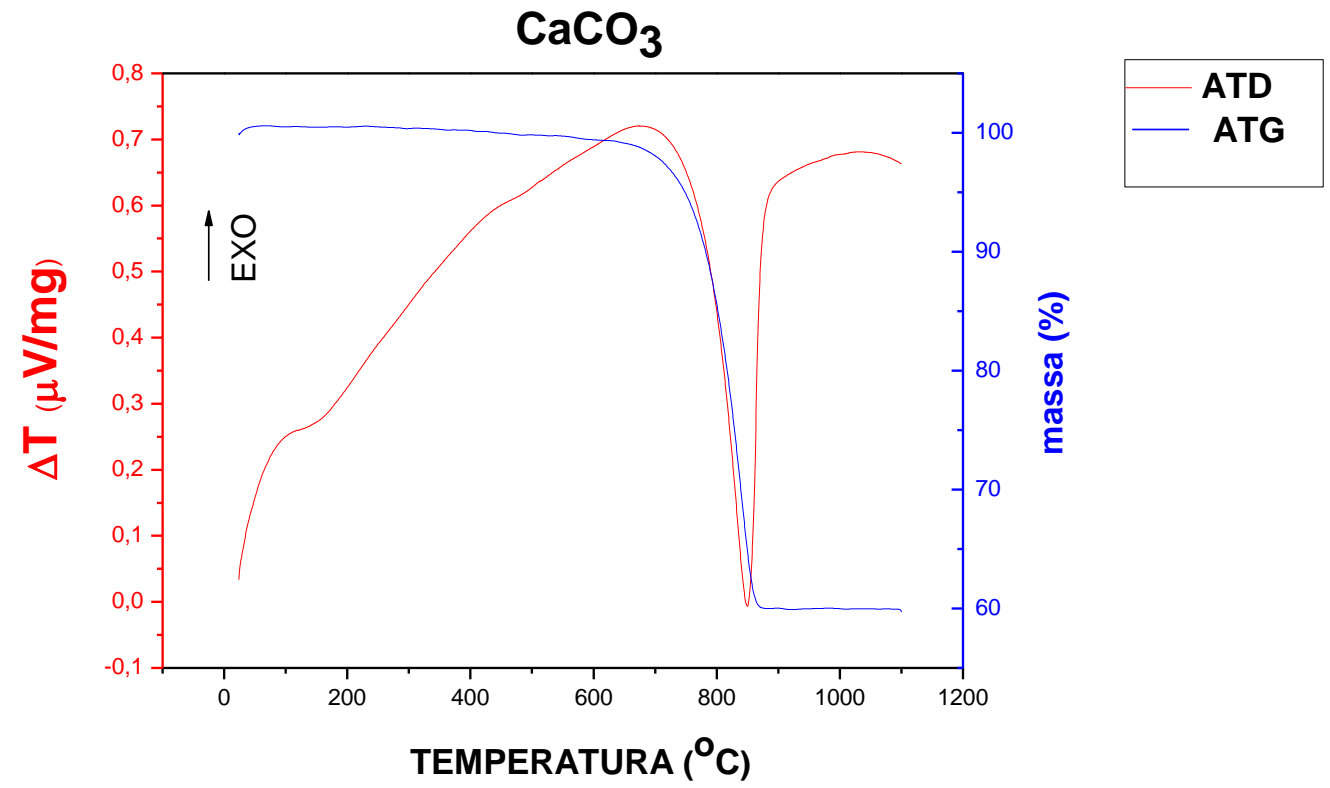

Figura 84 - Curva termogravimétrica e térmica diferencial de $\mathrm{CaCO}_{3}$ 


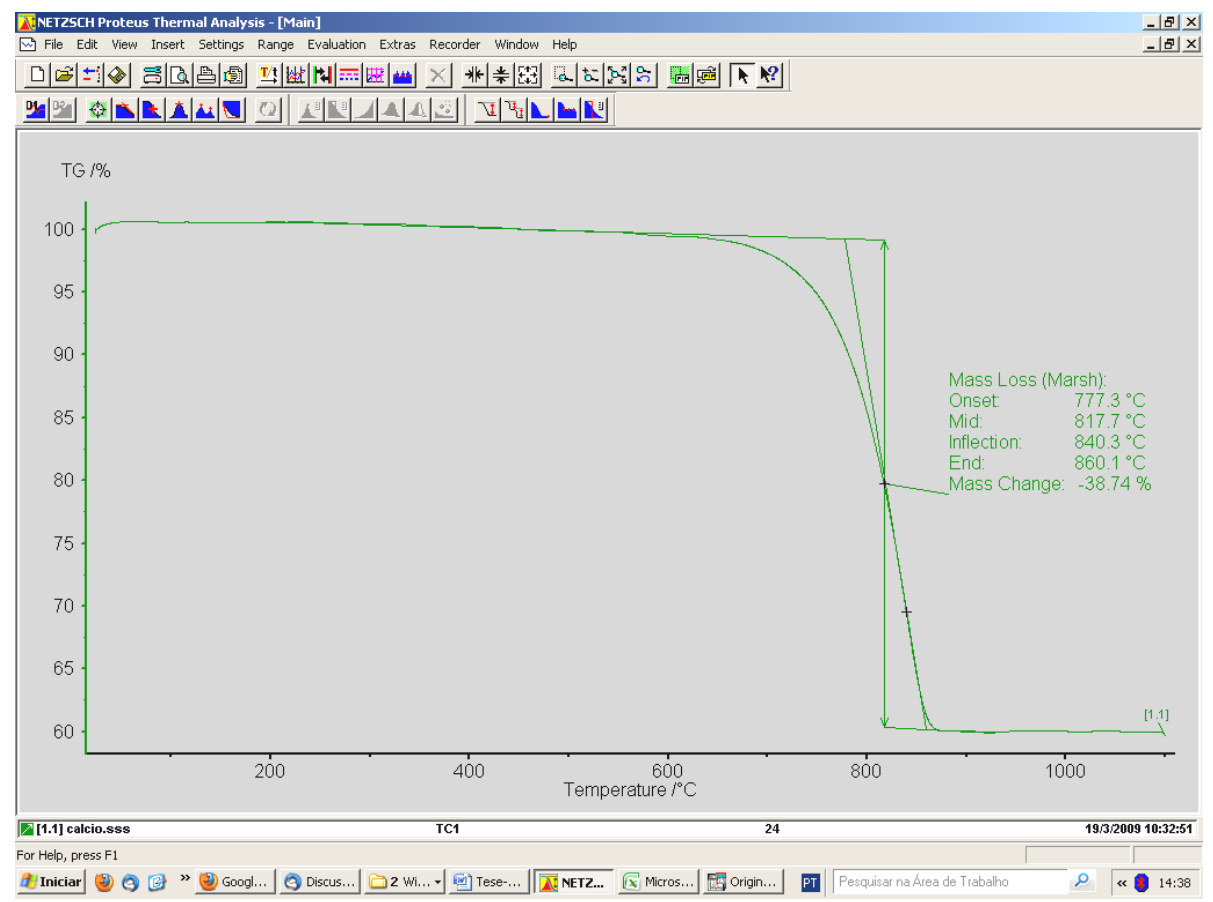

Figura 85 - Curva de análise termogravimétrica de $\mathrm{CaCO}_{3}$, análise feita com o software Proteus ${ }^{[53]}$.

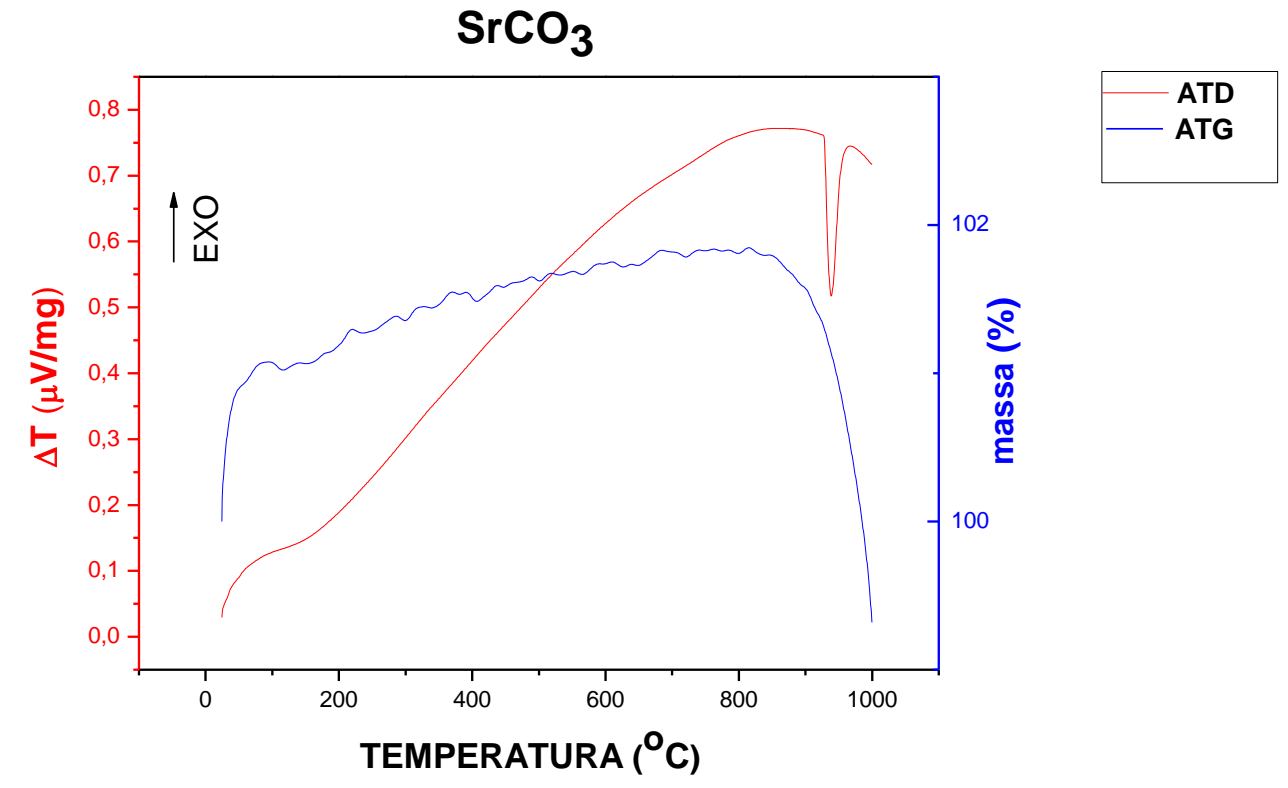

Figura 86 - Curva termogravimétrica e térmica diferencial de $\mathrm{SrCO}_{3}$ 
Apêndices

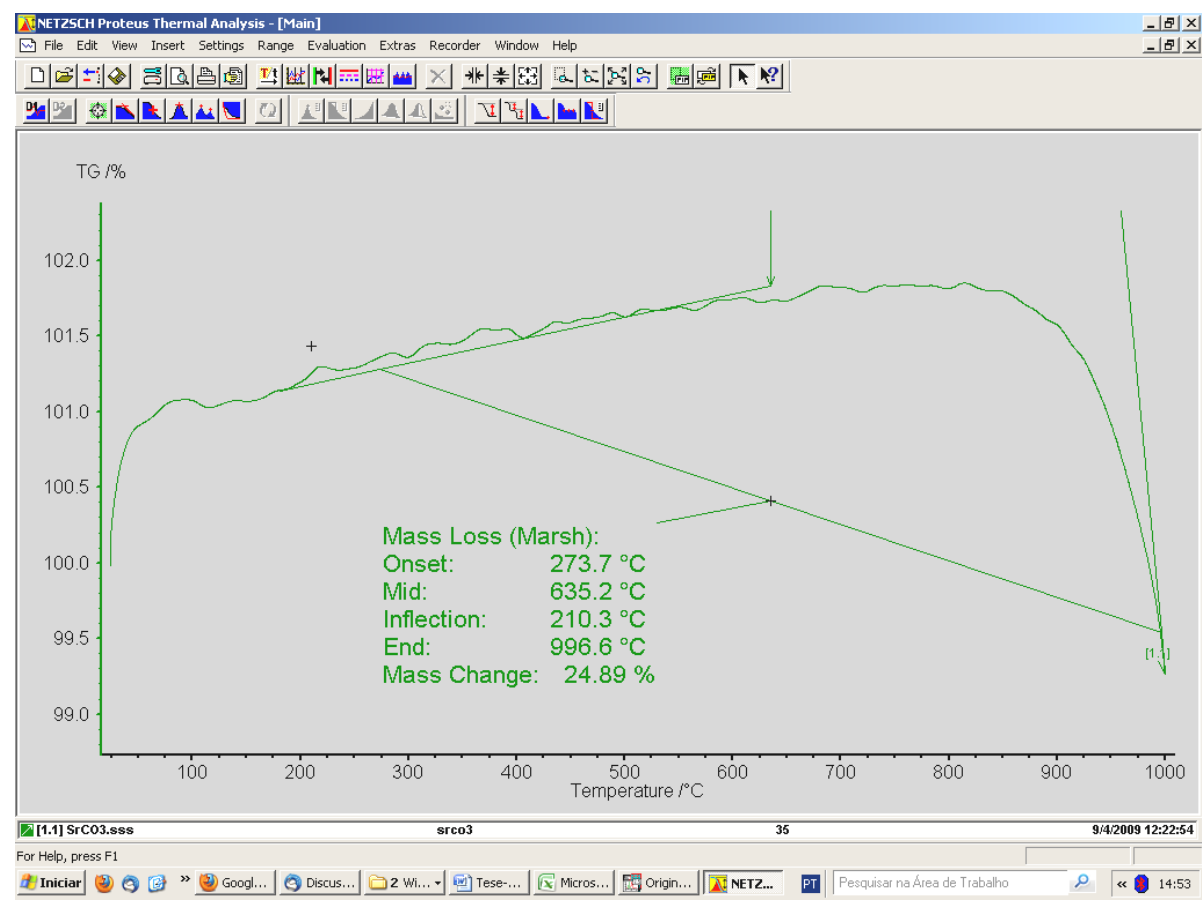

Figura 87 - Curva de análise termogravimétrica de $\mathrm{SrCO}_{3}$, análise feita com o software Proteus ${ }^{[53]}$. 
Apêndices

\subsection{APENDICE B}

\subsubsection{DESCRIÇÃO MATEMÁTICA DA CURVA DE ARCO DE CIRCUNFERÊNCIA DE IMPEDÂNCIA COMPLEXA}

Uma tensão alternada é uma freqüência que muda de sinal ciclicamente com o tempo, representada pela Equação (7).

$v_{t}=v_{\max } \cdot \cos (\omega \cdot t)$

$v_{\max }=$ valor máximo, ou de pico da tensão alternada, $\omega$ é a velocidade angular, expressa pela freqüência pela Equação (8)

$\omega=2 . \Pi . f$

Uma grandeza alternada pode ser representada no plano cartesiano complexo, Figura 88, em função de suas componentes real e imaginária, Equação (9).

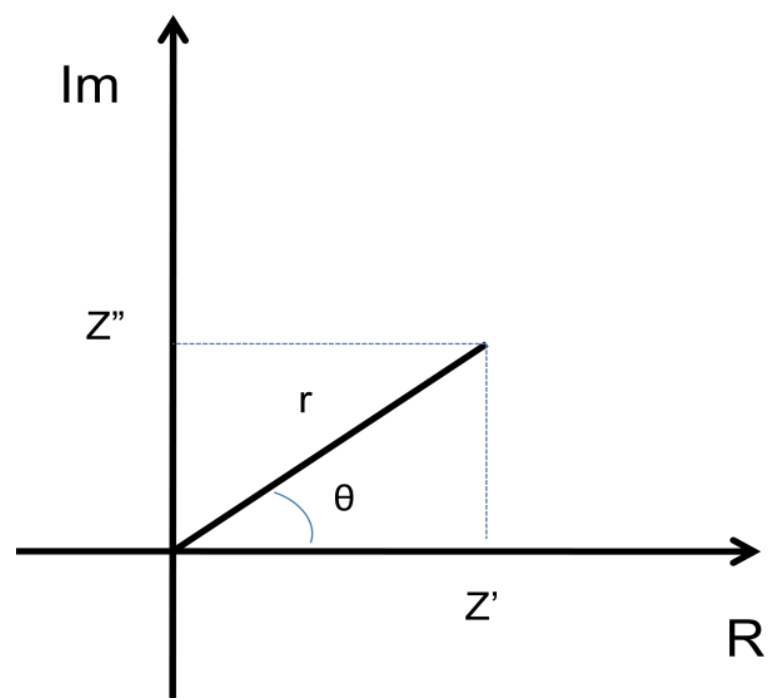

Figura 88 - Plano cartesiano complexo

$v=v_{\max } \cdot \cos (\omega \cdot t)+j v_{\max } \cdot \operatorname{sen}(\omega \cdot t)=x+j y$

Sendo:

$v=$ tensão complexa

$j=$ Unidade imaginária $(j=\sqrt{-1})$. 
Uma grandeza complexa pode ser escrita na forma trigonométrica, Equação (9), ou nas formas: polar e exponencial, Equações (10) e (11) respectivamente.

$\hat{V}=v_{e f} \angle \Theta$

onde:

$v_{e f}=\sqrt{x^{2}+y^{2}}$

$\Theta=\operatorname{tg}^{-1} \frac{y}{x}$

$V e f=v_{\max } \cdot \cos \Theta+j \cdot v_{\max } \cdot \operatorname{sen} \Theta=v_{\max } \cdot e^{j \cdot \omega \cdot t}$

$e$

Vef $=$ valor eficaz datensão

Igualmente uma corrente elétrica senoidal pode ser representada utilizando-se a notação complexa, Equação (12).

Ief $=\mathrm{I}_{\max } \cdot \cos \Theta+j_{\cdot \operatorname{Im} a x} \cdot \operatorname{sen} \Theta=i_{\max } \cdot e^{j(\omega . t+\phi)}$

sendo:

Ief $=$ Corrente eficaz

$\phi=$ diferença de fase entre $v_{\max } e i_{\max }$

Utilizando-se a primeira lei de Ohm para calcular a impedância de um circuito elétrico, tem-se que:

$\hat{Z}=\frac{v e f}{i e f}$

$\hat{Z}=\frac{v_{\max } \cdot e^{j(\omega . t)}}{i_{\max } \cdot e^{j(\omega . t+\phi)}}$

$\hat{Z}=\frac{V_{\text {max }}}{\mathrm{I}_{\text {max }}} \angle-\phi=Z \angle-\phi$

Escrevendo-se a Equação (15) na forma trigonométrica, como na Equação (9), tem-se que:

$Z=Z \cdot \cos (\omega . t)+j Z \cdot \operatorname{sen}(\omega . t)$ 
que pode ser representado no plano cartesiano complexo como:

$\hat{Z}=\underbrace{Z \cdot \cos (\omega \cdot t)}_{R}+j \underbrace{Z \cdot \operatorname{sen}(\omega \cdot t)}_{\mathrm{Im}}$

ou

$\hat{Z}=\underbrace{Z \cdot \cos (\omega \cdot t)}_{Z}+j \underbrace{Z . \operatorname{sen}(\omega \cdot t)}_{Z^{\prime}}$

Desta forma:

$Z^{\prime}=Z \cdot \cos (\omega \cdot t)$

$Z^{\prime \prime}=Z \cdot \operatorname{sen}(\omega . t)$

Observa-se experimentalmente que os gráficos de impedância são semicírculos ou arcos de circunferência; esta observação pode ser descrita matematicamente, considerando-se um circuito elétrico característico composto por uma carga RC em paralelo, Figura 89.

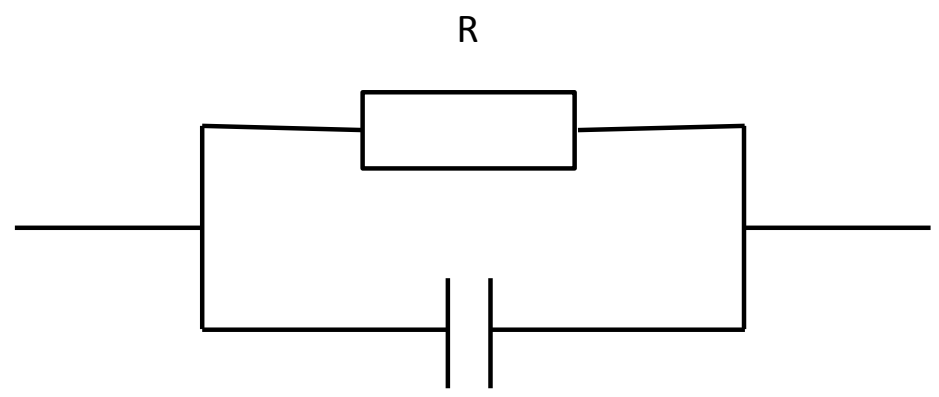

C

Figura 89 - Circuito RC paralelo no domínio do tempo 
Este circuito pode ser escrito no domínio da freqüência como mostrado na Figura 90.

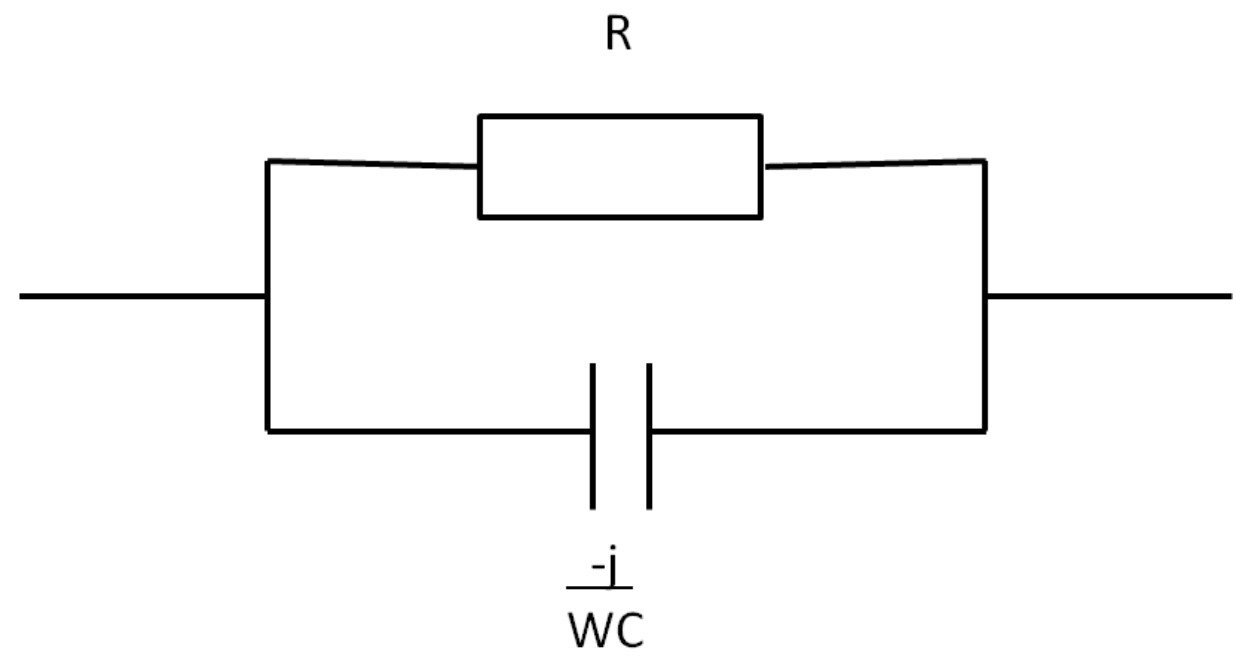

Figura 90 - Circuito RC paralelo no domínio da freqüência.

A impedância $Z$ equivalente do circuito paralelo $R C$ em função da freqüência é determinada por:

$$
Z=\frac{R \cdot \frac{-j}{\omega \cdot C}}{R+\frac{-j}{\omega \cdot C}}
$$

Desenvolvendo-se a Equação (19) tem-se:

$$
Z=\frac{-j R}{\omega \cdot R \cdot C-j}
$$

Multiplicando-se o numerador e o denominador da Equação (20) pelo conjugado de seu denominador $\left(\omega^{2} \cdot R \cdot C^{2}+j\right)$ tem-se que:

$Z=\frac{-j R}{\omega \cdot R \cdot C-j} \cdot \frac{\omega \cdot R \cdot C+j}{\omega \cdot R \cdot C+j}$

resultando em:

$$
Z=\frac{-j \omega \cdot R^{2} \cdot C+R}{\omega^{2} \cdot R^{2} \cdot C^{2}+1}
$$


Separando-se a componente real da componente imaginária resulta em:

$Z=\underbrace{\frac{R}{\omega^{2} \cdot R^{2} \cdot C^{2}+1}}_{\operatorname{Re} a l}-j \underbrace{\frac{\omega \cdot R^{2} \cdot C}{\omega^{2} \cdot R^{2} \cdot C^{2}+1}}_{\text {Im aginária }}$

Reescrevendo a Equação (23), chegamos à:

$Z=\underbrace{\frac{R}{(\omega \cdot R \cdot C)^{2}+1}}_{\operatorname{Re}}-j \underbrace{\frac{R}{(\omega \cdot R \cdot C)^{2}+1} \cdot \omega \cdot R \cdot C}_{\mathrm{Im}}$

Fazendo $\omega \cdot R \cdot C=K$, escrevemos a Equação (24) como:

$Z=\underbrace{\frac{R}{K^{2}+1}}_{\operatorname{Re}(Z)}-j \underbrace{\frac{R}{K^{2}+1} \cdot K}_{\operatorname{Im}(Z)}$

Para condição de ressonância $|\operatorname{Im}(Z)|=|\operatorname{Re}(Z)|$, o que permite escrever que, $|\operatorname{Im}(Z)|=|\operatorname{Re}(Z)| . K, \log$ :

$K=\frac{|\operatorname{Im}(Z)|}{|\operatorname{Re}(Z)|}$

Substituindo a Equação (26) na parte real da Equação (24), tem-se:

$\underbrace{\frac{R}{(\omega \cdot R \cdot C)^{2}+1}}_{\operatorname{Re}(Z)}$

ou

$\operatorname{Re}(Z)=\frac{R}{(\omega \cdot R \cdot C)^{2}+1}$

$\operatorname{Re}(Z)=\frac{R}{\left(\frac{|\operatorname{Im}(Z)|}{|\operatorname{Re}(Z)|}\right)^{2}+1}$ 
Desenvolvendo-se a Equação (27),

$\operatorname{Im}(Z)^{2}+\operatorname{Re}(Z)^{2}=R \cdot \operatorname{Re}(Z)$

Reescrevendo-se a Equação (28) e somando-se $\frac{R^{2}}{4}$ em ambos os lados da igualdade, tem-se:

$\operatorname{Im}(Z)^{2}+\operatorname{Re}(Z)^{2}-R \cdot \operatorname{Re}(Z)+\frac{R^{2}}{4}=\frac{R^{2}}{4}$

que pode ser escrito como:

$\operatorname{Im}(Z)^{2}+\left(\operatorname{Re}(Z)-\frac{R}{2}\right)^{2}=\left(\frac{R}{2}\right)^{2}$

Reescrevendo-se a Equação (30), chega-se a:

$$
\begin{aligned}
\underbrace{\left(\operatorname{Re}(Z)-\frac{R}{2}\right)^{2}}_{\downarrow}+\underbrace{\operatorname{Im}(Z)^{2}}_{\downarrow} & =\left(\frac{R}{2}\right)^{2} \\
\downarrow & \\
(x-a)^{2}+(y-b)^{2} & =r^{2}
\end{aligned}
$$

Por comparação pode-se afirmar que a Equação (30) é uma equação de uma circunferência de raio $\frac{R}{2}$ e centro em $\frac{R}{2}$, como mostrado na Equação(6), página 26.

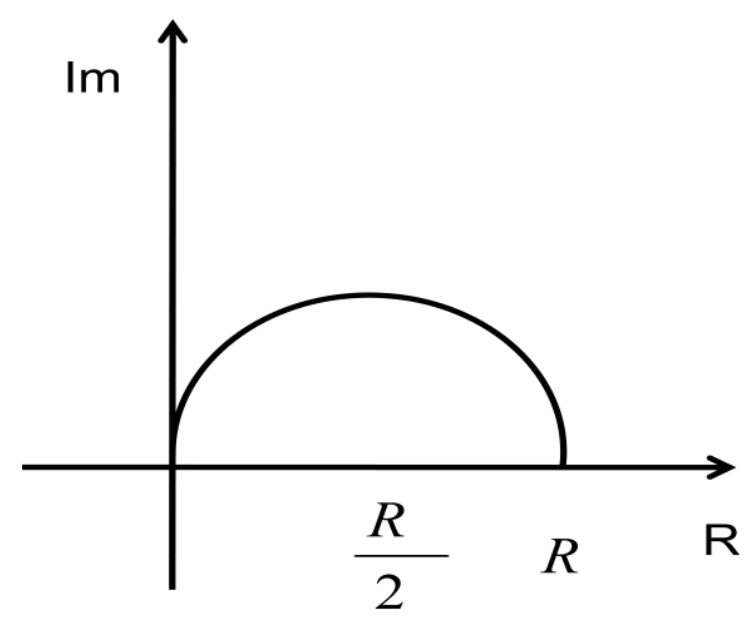

Figura 91 - Semicírculo de raio $\frac{R}{2}$, centrado em $\frac{R}{2}$, gerado pelo circuito elétrico da Figura 89 